\title{
Poverty and Climate Change
}

Most, if not all of the global biogeochemical cycles on the earth have been broken or are at dangerous tipping points. These broken cycles have expressed themselves in various forms as soil degradation and depletion, ocean acidification, global warming, and climate change. The best proposal for an organic solution to fixing the myriad broken cycles is a deliberate investment in solutions that first acknowledge the historic roles played by both the subjugated peoples and the economic beneficiaries of the environmental exploitations of the past.

Ever since Europeans made contact with the West, a series of global circumstances including the genocide of the indigenous people of the Americas, the enslavement and global subjugation of Africans, and the emergence of Western concepts of trade dominance and capitalism, have led to deleterious impacts on the global biogeochemical cycles. Addressing the broken biogeochemical cycles should be done with a clear understanding that it was not only human subjects which were subjugated, but also land, water, and air. These three global stores must be replenished from the ideological position that poverty is not simply the absence of money, but is also the lack of access to non-polluting energy sources, to clean air devoid of runaway greenhouse gasses, and to local conditions devoid of climate change instabilities. With this in mind, the global power brokers can enter into a new deal with developing nations, shifting the paradigm toward a new ecological approach that rewards good behavior and sets new standards of worldwide relations based on ecologic inclusivity rather than the exclusive economic arrangements currently in order.

Harnessing a forward thinking approach to analyzing the current global environmental crisis, this book will be of great interest to students and scholars of sustainable development, political ecology, sustainable agriculture, climate change, and environmental justice.

Fitzroy B. Beckford is an agricultural scientist who holds a $\mathrm{PhD}$ in Sustainability Education with a research emphasis on integrated food-energy systems (IFES). Integral areas of his work include concepts in nutrient biogeochemical cycling and restorative anthropedogenesis. 


\section{Routledge Studies in Sustainable Development}

This series uniquely brings together original and cutting-edge research on sustainable development. The books in this series tackle difficult and important issues in sustainable development including: values and ethics; sustainability in higher education; climate compatible development; resilience; capitalism and de-growth; sustainable urban development; gender and participation; and well-being.

Drawing on a wide range of disciplines, the series promotes interdisciplinary research for an international readership. The series was recommended in the Guardian's suggested reads on development and the environment.

Engineering Education for Sustainable Development

A capabilities approach

Mikateko Mathebula

Sustainable Pathways for our Cities and Regions

Planning within planetary boundaries

Barbara Norman

Land Rights, Biodiversity Conservation and Justice

Rethinking parks and people

Edited by Sharlene Mollett and Thembela Kepe

Metagovernance for Sustainability

A framework for implementing the Sustainable Development Goals

Louis Meuleman

Survival: One Health, One Planet, One Future

George R. Lueddeke

Poverty and Climate Change

Restoring a Global Biogeochemical Equilibrium

Fitzroy B. Beckford

For more information about this series, please visit: www.routledge.com 


\section{Poverty and Climate Change Restoring a Global Biogeochemical Equilibrium}

Fitzroy B. Beckford 
First published 2019

by Routledge

2 Park Square, Milton Park, Abingdon, Oxon OX14 4RN

and by Routledge

711 Third Avenue, New York, NY 10017

Routledge is an imprint of the Taylor $\mathcal{B}$ Francis Group, an informa business

(C) 2019 Fitzroy B. Beckford

The right of Fitzroy B. Beckford to be identified as author of this work has been asserted by him in accordance with sections 77 and 78 of the Copyright, Designs and Patents Act 1988.

The Open Access version of this book, available at www.taylorfrancis.com, has been made available under a Creative Commons Attribution-Non Commercial-No Derivatives 4.0 license.

Trademark notice: Product or corporate names may be trademarks or registered trademarks, and are used only for identification and explanation without intent to infringe.

British Library Cataloguing-in-Publication Data

A catalogue record for this book is available from the British Library

Library of Congress Cataloging-in-Publication Data

A catalog record for this book has been requested

ISBN: 978-1-138-34541-6 (hbk)

ISBN: 978-0-429-43789-2 (ebk)

Typeset in Goudy

by Apex CoVantage, LLC 


\section{Contents}

List of tables vii

List of figures viii

\section{PART I}

How global environmental democracy died 1

1 The American native and the European invader - the nexus 5

2 Facets and consequences of environmental slavery 16

3 It's the ecology, stupid 26

4 The biogeochemical cycles in the era of anthropogenic climate change 41

5 A review of the biogeochemical cycling of the elements of life $\quad 50$

6 Addressing the biogeochemical cycles with Transformative Anthropocentrism

PART II

Applying practical solutions: reconnecting Earth and sky

7 Feeding the future: farming in a post-carbon economy

8 Transitioning to low-carbon farming: an assessment of the process

9 The kinetic role of biochar in climate change mitigation 
vi Contents

10 Biochar in the age of renewable energy policy

11 How alleviating energy-poverty will also improve the climate

12 Envisioning a transformative age

Index 


\section{Tables}

4.1 Gleick's estimate of the quantity of water in the systems of the hydrosphere

5.1 Annual fluxes of atmospheric oxygen (units of $10^{10} \mathrm{~kg} \mathrm{O}_{2}$ per year)

8.1 Estimated GHG emissions and carbon sequestration: U.S. agricultural and forestry activities, 2003-2007 (million metric tons $\mathrm{CO}_{2}$ equivalent - $\mathrm{MMTCO}_{2} \mathrm{e}$ )

8.2 Decision-making factors for transition to low-carbon farm economy

9.1 Net primary productivity by ecological area 


\section{Figures}

3.1 Market effects on natural resources 30

4.1 The structure of the atmosphere 44

5.1 Reactive nitrogen on Earth by human activity 63

7.1 The modern farming superstructure: energy and
economic networks

9.1 The resilient systems carbon cycle 116

10.1 Degraded soils - world 129 


\section{Part I}

\section{How global environmental democracy died}

\section{The neo-pollution phenomenon: a problem statement}

On a quiet Sunday morning in the summer of 1969, a fire erupted on the Cuyahoga River in Cleveland, Ohio. In contemporary times, the people who were within easy distance from the burning river would have been aghast at the sight, but on this quiet Sunday morning there was hardly a reaction. The sad reality of the times was that the people of Cleveland, through which the Cuyahoga cuts its sinuous, oil slick-covered path toward Lake Erie, had seen similar fires before, so this one was hardly a novelty. In fact, no one even took pictures of the river fire that morning, not even Time Magazine which reported the story using a 17-yearold picture taken in 1952 of an even more serious river fire on the Cuyahoga. The Time magazine story, however, caused the world to take notice of the industrialized pollution plaguing the city of Cleveland and other places around the United States (U.S.), where rivers and coastal waters were considered the ideal places in which to pour the billions of gallons of chemical and toxic wastes generated from industry.

The August 1, 1969 Time Magazine report on the burning Cuyahoga, however, was well timed. Only a few years before in September 1962, Rachel Carson had published her blockbuster report - 'Silent Spring' - on the effects of pesticides on the environment. The message in Carson's book delivered a world-changing viewpoint on agro-industrial pollution's deleterious effects on birds and other animal species, leading to a wave of positive reactions which ended in the restriction of certain pesticides considered too hazardous. By 1972, in response to growing awareness and concern for water pollution, the U.S. Federal Government radically amended the Federal Water Pollution Act of 1948, naming the revised law the Clean Water Act (CWA). The amendments in the CWA were very bold at the time, providing specific rules for cleaning up and protecting water resources. The amendments included the following specific provisions:

- Establishment of the basic structures for regulating pollutant discharges into the waters of the United States.

- Providing the EPA with the authority to implement pollution control programs such as setting wastewater standards for industry. 
2 How global environmental democracy died

- Maintaining existing requirements to set water quality standards for all contaminants in surface waters.

- Making it unlawful for any person to discharge any pollutant from a point source into navigable waters, unless a permit was obtained under its provisions.

- Making funds available for the construction of sewage treatment plants under the construction grants program.

- Recognizing the need for planning to address the critical problems posed by nonpoint source pollution.

(EPA, 2017)

In 1982, yet another environmental domain - beyond those reported on by Time and by Rachel Carson - was observably in a state of demise, and this time it threatened to affect the entire world. Scientists had discovered a massive hole in the Ozone Layer of the atmosphere, the damage caused by the accumulation of chlorofluorocarbon gasses (CFCs). Driven into action by a near global cancer scare, environmentalists banded their efforts through the Montreal Protocol which was ratified by 196 countries as well as the European Union, the goal being to reduce the production and use of ozone depleting substances, in order to reduce their abundance in the atmosphere, and thereby protect the earth's fragile ozone Layer (UNDP Ozone Secretariat). The Montreal Protocol, the first universally ratified treaty in the history of the United Nations, was unprecedented in its scope, in the level of collaboration, and in its global impact.

The fear that galvanized collective global action was not unsubstantiated. Acting as a protective shield that blocks high-frequency ultraviolet rays from the sun, the ozone layer screens against skin cancers and cataracts in humans, and mitigates against reproductive problems in aquatic life including amphibians, reptiles, and phytoplankton. The worldwide reaction to the hole in the ozone was so swift and so effective that by the end of the year 2000, more than 98 percent of CFCs - about 2.5 million metric tons as estimated by the United Nations Environment Program had been phased out globally, the ozone hole over the Antarctic had significantly reduced in size and was expected to return to pre-1980 levels by the year 2050 .

Despite the gravity of each situation, the three scenarios shared here (the burning Cuyahoga, the petrochemical problems unearthed by Carson, and the hole in the ozone layer) were the good stories because they each ended with positive response to the shared problem of pollution. However, an examination of current trends determines that the bad behavior of indiscriminate waste disposal and overuse of nutrients has continued, and may even be worse than the situations previously discovered and solved. Three significant contemporary problems elucidate this argument, and are italicized below to show stark comparison to problems which are purported to have been previously solved. When elucidated in this way, it brings into question whether lessons have been learned, or whether progress has been made.

- The petrochemical loads that damaged natural environments and systems, and described by Rachel Carson in 1962 (Nutrient runoff from agricultural and residential sources continue to upset the natural balance of aquatic systems, 
polluting major water bodies across the U.S., and destabilizing biogeochemical cycles. The EPA (April 2012) reports that 15,000 major water bodies, 101,000 miles of rivers and streams, and 3,500,000 acres of lakes and reservoirs in the U.S. are impaired by nutrients).

(b) The issues which caused the Cuyahoga River Fires as elucidated by Time Magazine in 1969 (Islands of floating trash have appeared on all of Earth's oceans. The National Geographic Magazine reported in 2015 that an estimated 5.25 trillion pieces of plastic debris are in the oceans, and of that mass of trash, 269,000 tons float on the water's surface. An additional 4 billion microfibers per square kilometer litter the Earth's seas).

(c) The releases of gasses which resulted in the ozone hole, as discovered by British Antarctic survey scientists in 1982 (Greenhouses gasses have pushed the atmosphere to its highest post-Carboniferous warming limits. Since the start of the new millennium, and despite the forewarnings of the ozone layer crisis, anthropogenic greenhouse gas emissions to the atmosphere has increased annually, totaling an enormous 3.8 gigatons of $\mathrm{CO}_{2}$ in 2016. One gigaton [unit of mass] is equal to a billion metric tons).

The neo-pollution issues described in the preceding statements are well known; their causes widely defined and fully understood to be mainly first world vices with third world consequences. For clarity, many of the people who live in third world conditions do not necessarily live in developing countries, but they are subjects of deprived wealth even in developed states, the lack of access to resources denying them upward social and economic mobility. Too often, social injustice dictates the environmental conditions in their communities.

It is becoming increasingly more understood in the context of development that an egalitarian global system can only be built when there is recognition that the global poor are not only landless, but are distant from those pivotal ecosystems services provided through proximity to land, and to environmental resources essential to their livelihoods. At the same time, the global poor continue to be too closely connected to the wastes and polluting discharges created when raw natural resources are used up and then dumped - often where they live. Sadly, with respects to the impact of global pollution on the un-owned spheres of the Earth, particularly the atmosphere, the hydrosphere and lithosphere not owned by countries or corporations, we have moved to the tipping point at which the impact of human actions are about to plummet mankind into the abyss of irreparable damage. Hallucinations about an escape to Mars where a few elite Earth survivors will rebuild humanity inside glass greenhouses is simply laughable, mainly because it is so much easier and so much more rational to fix the Earth's environments rather than to engineer livable habitats on a planet that's already dead.

\section{The Noah's Flood Inertia Syndrome}

Unlike the reaction to the hole in the ozone, many corporations as well as governments have been operating under the illogical premise (or deliberate denial) that if you can't see global warming then it's probably not there. As a result they 


\section{How global environmental democracy died}

do little or nothing in the face of growing concerns and amidst the resounding denial of scientific data, choosing to continue along established paths toward certain calamity. Yet they hope, paradoxically, that as a last resort, the science of geo-engineering will save humanity if both apathy and ignorance prove consequential. In light of the apathetic response to rising greenhouse gas emissions and to global warming, it is difficult to understand how humans have banded together in the recent past, how they heeded the warnings provided by the science of the day, and how they stemmed or even reversed those critical problems encountered in 1962, 1969, and 1982.

So how did we get to this point of political apathy where ignorance, intolerance, and even extremism seem to abound? How did we get to the point where polarized politics has dominated the debate, where right-wing climate-deniers shout disagreements at left wing vaccination-skeptics, while the poor get further marginalized as their children die of preventable childhood diseases, and their young people become environmental refugees as their coastal lands flood from rising seas? All of this while primary tropical forests get increasingly farmed out after carbon sequestrating trees are harvested to make room for methane belching cattle, this while the climate gets warmer and the northern tundra burns. Using the biblical story of Noah's Flood as analogy (with no acknowledgment of the veracity of the event), it becomes easier to comprehend how people shrugged off the warnings of danger amidst swelling rainclouds, even while Noah's Ark loomed ready to save humanity from certain apocalypse. The harsh reality of global climate change is that it is having a 'Noah's Flood Inertia Syndrome' upon modern humans, where despite the scientific evidence for an apocalypse, the human response is paltry.

The gravest challenge of twenty-first-century humanity in the face of these growing complexities is how to accommodate a paradigm shift in attitudes, in behaviors, and in those actions that engage poor and marginalized peoples as equal contributors to the global public good? How do we band together collectively to save the Earth again, this time from runaway greenhouse gas emissions? These questions require a review of the past and present, but must also proffer simple and useful ideas about how to reconfigure human relationships with nature through the neo-economics of environmental democracy. The basic quest of this book is therefore to render an understanding of past actions along with their crippling consequences, discuss the means by which changes in present attitudes can be influenced, thus elucidating a clearer trajectory toward practical solutions through the experiential engagement of the global native. 


\section{The American native and the European invader - the nexus}

European exploration beyond the borders of the continent began long before the 1400s, but the latter part of that century ushered in a period of events spearheaded by Christopher Columbus. Columbus's inadvertent discoveries led to the occupation of the lands of the 'Americas', and the overexploitation of the vast resources of this 'New World' began in earnest after 1492. While largely seen as a period of success from the vantage point of the old world (Europe), the natural resources of the Americas, as well as Oceana (Australia, New Zealand and surrounding islands) and the human resources of Africa, experienced a period of human and environmental exploitation that was unprecedented in human history. This clash of worldviews between the old world and the newly subjugated land and peoples thus heralded the uncomfortable juxtaposition of the 'Native' versus the 'Invasive'.

Perhaps the best way this unfortunate meeting between the old and new worlds can be described from the viewpoint of the Indian (a name which while now stuck to the natives of the entire Americas, owes its origins in Columbus's error in believing he had actually reached the eastern-most regions of India) is summarized in the poem 'There was an Indian' by the British author and satirist John Squire.

\section{There was an Indian}

There was an Indian, who had known no change,

Who strayed content along a sunlit beach

Gathering shells. He heard a sudden strange

Commingled noise: looked up; and gasped for speech.

For in the bay, where nothing was before, Moved on the sea, by magic, huge canoes

With bellying cloths on poles, and not one oar, And fluttering colored signs and clambering crews.

And he, in fear, this naked man alone, His fallen hands forgetting all their shells, His lips gone pale, knelt low behind a stone, 
And stared, and saw, and did not understand,

Columbus's doom-burdened caravels

Slant to the shore, and all their seaman land.

- By Sir John Squire (Stabroek News, 2016)

\section{How the western world was won}

It is not difficult to imagine that Native Americans did not like the new type of mankind that they encountered disembarking from the ships of Christopher Columbus. Historian David Abulafia (2008) offers an account from Bartolme Las Casas who despaired about what the conquest of America revealed about the true character of his Spanish compatriots. Las Casas tells the story of Hatuey, a cacique (Chief) from Hispaniola who fled to Cuba in the aftermath of the desperation experienced on the island of Hispaniola after Columbus established the first Spanish settlement there. After being captured by European conquistadores, Hatuey was tied to the stake and told that if he did not convert to Christianity he would go to Hell and eternal torment. Hatuey enquired where the Spanish went after death. When he learned that the Spanish went to a place called heaven, Hatuey replied he would gladly prefer to go to Hell, and so, according to Las Casas, he was burnt, un-baptized, unrepentant, and bound for an afterlife in Hell.

Las Casas may have "exaggerated the peacefulness of pre-Columbian Hispaniola" to give greater effect to his stories about Spanish cruelty in the Americas, but his intention was to use Hatuey's story to inform his countrymen and perhaps all Europe about the true nature of the "rogues and villains who ruled Indians" in the new world. This inspired several writers in the mid-eighteenth century to argue, as Abulafia (2008) noted, that it would have "been best for humanity if the Indies had never been discovered by Europeans". One such writer, Abbé Guillaume Thomas Raynal, thought European discovery of the Americas was terrible, not just because Spanish rule was disastrous for native populations, but also because Spanish conquest of American Natives revealed a certain kind of heartlessness at the center of European culture (Abulafia, 2008).

Hostile Spanish rule of the Americas developed despite Columbus' initial words to the Queen of Spain about the docility of the people of the new world with whom he had come in contact. Columbus informed her:

These people in the Caribbean have no creed and they are not idolaters, but they are very gentle and do not know what it is to be wicked, or to kill others, or to steal ... they brought us parrots and balls of cotton and spears and many other things, which they exchanged for our glass beads and hawks' bells. They willingly traded everything they owned. They do not bear arms, and do not know them, for I showed them a sword, they took it by the edge and cut themselves out of ignorance. With fifty men we could subjugate them all and make them do whatever we want.

(Digital History, 2016) 
The natives' well understood and important practice of reciprocity (exchanging gifts) was lost on Columbus when his worldview readily recognized the relative 'value' of the 'things exchanged', while failing to recognize the 'act' of exchanging those gifts. He went on to explain to the Queen, after taking time to describe the docility of the Indians, that with only 50 armed men, the entire community of Hispaniola could be captured and subjected to any duty desired. Columbus's worldview underscored the divide between contemporary European 'value systems' and the Native Americans 'acts of symbolism'.

Columbus, and indeed the European conquistadors that followed him, had a greater interest in the possessions of the natives and what could be had from their land, and the humble inhabitants were just mere obstacles in their way. Much less, these conquerors of the west didn't care about the relationship that these 'ignorant' people had with nature or the natural materials within it. Across the new world, wherever native groups were not completely eliminated through the consequence of human and material acquisition, it would be centuries before the relationship between nature and the native would even begin to be recognized as an important resiliency attribute of those once considered both ignorant and disposable (Gomez, 2008).

\section{Nature as 'knowledge' domain}

For as long as they have existed, small-scale native societies have been involved in the practices of extracting, producing, processing, and trading a diversity of products from a broad spectrum of natural environments. Brosius et al. (2000) explains that scholars working in Southern Asia, Africa, Latin America, and the South Pacific have provided documentation of both the cultural modification of nature and the development of complex commodity chains which imply the global circulation of natural products into and out of these regions. Native communities have not been ignorant to the existence of their neighbors even across wide divides of land and water, in many cases being very familiar with distant communities with whom they interacted through exploration for trade in natural products and other social exchanges. Through these meetings and visits, commodity chains helped to link relatively remote communities with the material, cultural, economic, and ideological flows emanating from and flowing to global centers for centuries, and, in some cases, millennia.

While the evidence suggests that many ancient cultures had figured out how to live sustainably within nature in order to survive, there have been several cases where tragic mistakes were made. Many of these cases may have escaped modern observation perhaps due to the absence of written information, and indeed it should be noted that many well-developed ancient cultures around the world, including pre-Columbian American cultures, did not have written languages. Evidence exists, however, which indicates that environmental mistakes were made by native peoples and cultures that resulted in their own genocide, or at best the tragic splintering of native society. The collapse of Easter Island, for example, is a rather telling story. 


\section{How global environmental democracy died}

\section{The Easter Island 'ecocide'}

Modern Easter Island is an outpost nearly 2,300 miles west of South America and 1,100 miles from the nearest Pacific island. Historical assessments reveal that early occupiers of the island chiseled away at the naturally occurring volcanic stone, carving giant statues to honor their ancestors. Each block of stone measuring an average of 13 feet tall and weighing 14 tons was moved to different ceremonial structures around the island, a feat that obviously required significant manpower, coordination, and time. To conduct this kind of work, the dwellers (the Rapanui) depended on giant palms that grew abundantly on the island. Many of these palms trees were cut down to make room for agriculture, others were burned for fire, and some were used to transport the giant statues across the island. Eventually the palms dwindled in numbers until treeless terrain eroded nutrient-rich soil, leaving poor conditions for agriculture. Finally, perhaps out of desperation, with little wood to use for daily activities, the people turned to burning grass. By the time Dutch explorers arrived on Easter day in 1722 (hence the name Easter Island), the land was barren.

Perhaps an additional factor might have played a significant role in the 'ecocide' of Easter Island. Recent findings by archaeologist Terry Hunt of the University of Hawai'i indicate the presence of large numbers of rats on Easter Island. The deforestation, it appears, might have been accelerated by Polynesian rats which accompanied the Rapanui to Easter Island at the time of first settlement. The rats found an unlimited food supply in the lush palm trees on the island and flourished in number on the palm seeds, becoming invasive and progressively pervasive, adding to the negative human impact on the environment which declined quickly and immediately (Dangerfield, 2007).

\section{Indigenous people and nature - positive user traits}

Catastrophic ecological mistakes such as evidenced on Easter Island were definitely made by native cultures, solidifying the fact that overexploitation of natural resources by any group can lead to disasters and even native groups are not immune from such occurrences. However, in the majority of cases, native societies devoid of external resources and influences have learned how to adjust their behavior toward nature and the environment in order to sustain their communities in perpetuity. The manner in which many indigenous peoples go about their lives today is a reflection of the wisdom, knowledge, and understanding gained from their interaction with nature over time. Understandably, the organic holistic operational wisdom (HOW) and traditional ecological knowledge (TEK) many Native groups now possess have been passed down through the ages to descendants currently existing outside modern capitalist mechanisms. Therefore, any attempt to disregard indigenous knowledge is an unwise dismissal of proven information which has been tried, applied, and adapted over time, although often existing beyond the comprehension or acceptance of modern scientific knowledge (MSK) systems. 
The following examples depict some of the positive user traits of the HOW and TEK exhibited by indigenous peoples around the world.

\section{Potlatching in the NWC indigenous culture}

Salmon represents a very important part of the diet of the indigenous people of the Northwest Coast (NWC) of the Pacific. So uniquely intertwined was the relationship with this fish that the indigenous tribes of this region have been defined as existing within the salmon culture that developed out of the ancient institutional arrangement known as the potlatch - an Indian term meaning "to give with the expectation of a return gift" (Barnett, 1938, in Johnsen, 2009, p. 2). With the inability to catch considerable amounts of salmon in the open sea or perhaps having learned through experience to make their catch in a different way, tribe fishers practiced harvesting them in "terminal, river-based fisheries" within a system that was subject to exclusive tribal property rights (ETRs). This system was generally enforced through long-term reciprocity relations, brokered at potlatch ceremonies (Johnsen, 2009).

A potlatch ceremony was usually done in winter and was arranged by a tribal chief who hosted a visiting tribe. The host chief would provide an extravagant feast for his guests during which he would assert various privileges and justify his claims to certain productive salmon streams. Gifts would be presented at the end of the ceremony, upon acceptance of which the guests would be essentially contracting to respect the host chief's claims on the salmon resources he identified during the contractual ceremony. Essentially, the practice of potlatching created a certain 'local' ownership of salmon streams, where the host tribe or the chief responsible for certain streams would ensure the protection and survival of the fish and the streams, using tribal resources and rules to prevent overharvesting. In this way, everyone within the tribe learned to respect the 'potlatch agreement'. However, should another tribe ever become hungry and needed food, the host tribe would make accommodations to share resources, but this would be done in a manner in which salmon were protected from being harvested out of the stream. As Johnsen (2009) remarked, the significant benefit of this arrangement was that salmon would be 'protected' in the streams where they bred, ensuring their survival and productivity.

When Europeans made contact with the NWC, almost all the rivers and even many smaller streams in the region supported one or more species of Pacific salmon. Recognizing the abundance of salmon, the Europeans quickly established modern fisheries and canneries for processing salmon for markets around the world. In due course, the area declined significantly in abundance of fish, prompting Johnsen (2009) to conclude that in order to halt the tragedy now unfolding in the Pacific salmon fishery, it may be essential to learn from the behavioral evolution of the institutional arrangements of the potlatch arrangements which were obviously much more superior to modern behavior. 


\section{Age and wisdom of old muskox - the Inuit}

When the Canadian government passed a law allowing the recreational hunting of Arctic muskox that had aged beyond their reproductive years, Inuit hunters strongly objected. The Inuit natives knew that herd elders (older muskox) were critical to the survival of the herd when it was under certain stresses, for example, keeping younger muskox calm during sieges by wolves. The Inuit tribesmen also knew that the larger, heavier older muskox were essential for breaking through thick ice encrusted snow, allowing the younger, smaller animals to access the browse beneath the snow. The knowledge of the Inuit went unheeded and in short course, muskox herds began to decline and then to crash. Martinez (2010) noted that it wasn't until the herd numbers began to collapse that modern scientists recommended stopping the shooting of 'over the hill' muskox. It had taken near catastrophe to heed the knowledge and wisdom of the native peoples.

\section{Fire as a restorer of life - American Indians}

In "The value of indigenous ways of knowing to western science and environmental sustainability", Dennis Martinez (2010) gives an account of the fire suppression policies of the past century in several parts of North America. The combination of wide-scale industrial logging and the replanting of monoculture lumber plantations of pine species have necessitated fire suppression policies throughout many parts of North America. Fire suppression became widespread, allowing biomass fuels to build up to levels that are totally outside the natural or historical range in natural as well as human-established forests. In many natural areas such as seasonal marshes which support a myriad of birds, herbaceous wildflowers, and terrestrial animal species, fire suppression results in the process known as ecological succession which is the germination, growth, and spread of hardwood species including invasive trees that eventually change the original marsh habitat to forested environments. New forest trees eventually shade out shrubs and medicinal plants, in some instances causing their loss and extinction.

Martinez (2010) explained that when the fires came as they inevitably do from lightning strikes, or from human error or ill will, the resulting high severity fires over the built-up dry biomass cause important cultural plants to be burnt out. Contrastingly, when Native Americans used to burn regularly wherever their tribes existed in North America, the frequent low intensity fires (from the absence of massive amounts of biomass) rejuvenated forests and permitted the culturally rich herbaceous understory species to flourish. By mimicking nature, North American tribes learned to sustain their ecological landscapes which in turn supported the conditions on which food, fuel, fiber, and medicine were available for sustainable harvest over time. It has taken decades of observation, but modern scientists have now come to understand that the long-practiced cultural strategy employed by the natives was far superior to modern notions of fire suppression as a forest management tool. 


\section{Nature as 'shopping' mall - the Aboriginal way of predicting nature}

Indigenous peoples have developed seasonal knowledge, knowledge of the weather, and seasonal cycles of plants and animals in their quest to find sources of foods, medicines, and other resources. Australian Aborigines in southeast Queensland can predict the clustering of breeding mullet in the waterways by the presence of string-like processions of hairy caterpillars. In the Canadian Province of British Columbia, the call of Swainsons' thrush indicates to native tribes that salmonberries would soon be ripe and ready to harvest (Prober et al., 2011).

This type of information, when collated over an annual cycle or longer, forms the basis of indigenous calendars, also known as seasonal calendars. It is also the precise observational information which has led to the development of the modern scientific field of 'Phenology' which is gaining increasing interest in many western universities today (National Phenology Network, 2011). The development of phenology as a scientific tool indicates an acknowledgment of the value of observation used by indigenous peoples as aforementioned.

\section{The resiliency trait - the Subaks}

The irrigated rice terraces of the Indonesian island of Bali consist of intricate latticelike structures of canals, tunnels, and aqueducts which are managed by organized farmers groups called Subaks. These structures have been built over generations and the Subaks have become a self-governing assembly which holds regular meetings in water temples and among other regulatory acts, they assess fines on members who do not abide by group decisions. Fines are however infrequently imposed as members are encouraged to focus on their shared dependence on nature's bounty, and recognize that their synchronized role in maintaining their portion of the system affects their neighbor's production and harvest, just as theirs is also dependent on the work of others. There is therefore a mutual interest in making sure the river system works collectively for the common good of all Subaks.

Lansing (1987) explains that a test of the merits of this system occurred in the 1970s through a World Bank project which promised increased rice yields over the traditional approach. Lacking the inherent resilience of the water temple approach to rice production, the modern system failed, leading the World Bank to conclude that the lack of appreciation for the merits of the traditional arrangement was a costly mistake. Capitalist goals and objectives which values individualism above communal approaches, it appears, are not always superior in every cultural setting, and thus should be necessarily relegated below tried and true arrangements that have survived the test of time as the case of the Subaks showed.

\section{Haida ethics and values}

Perhaps all the positive attributes described in the previous narratives can be summarized in the six Haida ethics and values as determined by their Council in a document published in 2007. The Haida is an indigenous nation of British 


\section{How global environmental democracy died}

Columbia, Canada. Jones et al. (2010) outline these ethics and values as follows. The italicized sentences further clarify each value.

- Respect - taking only what is needed from nature.

- The world is as sharp as the edge of a knife - use nature sustainably, as we can easily reach a point of no return.

- Everything depends on everything else - implementing a systems approach is paramount.

- Giving and receiving - 'reciprocity' is an important practice in relationships. Because it is a living community, we must learn to give back to nature. Just as we are prepared to give back to people from whom we borrow.

- Seeking wise council - The elders are wise because they have lived before us. They must be consulted because they possess Operational Wisdom.

- Responsibility - we accept the responsibility passed on to us from our ancestors. We should ensure that this is passed on.

\section{When indigenous people rule, nature has rights}

Around the world and in every instance where European adventurers have met indigenous peoples, the natives have been confounded by the apparent irrationality with which the Europeans have sought individual ownership of earthly possessions. This relentless pursuit of natural resources resulted in the following egregious offenses against human and natural democracy.

- The genocide of new world natives (For example, Jamaica's Taino population was exterminated by the time the British captured the island from Spain in 1655. Spain had occupied the island for a period of 161 years prior to the British invasion).

- The mass movement of Africans to establish and perpetuate the longest and most barbaric period of human chattel slavery ever recorded in history.

- The birth of monoculture agriculture during which commercial crops such as cotton, sugarcane, and tobacco displaced native trees and disrupted delicate habitats, resulting in an exhaustive drain on soils and water resources that changed the ecological character of entire islands for generations.

The genocide of indigenous citizens, African chattel slavery, and monoculture agriculture altogether shaped the capitalist system that drives the modern world, and the lasting effect of these triple causations now threatens to choke out nature's bounty both in the terrestrial and atmospheric realms. All of the consequences of harvest for individual wealth and nation building have collectively relegated the ecological landscape to a kind of environmental abuse from which there is hardly any course for rebound. There however is reason for hope in many societies, beginning with those dominated by native priorities and ways of thinking. In the fall of 2010 the Bolivian government began to plan the passage of a law called 
"The Law of Mother Earth" which promised to decree that nature has several rights similar to those enjoyed by human beings. The Law of Mother Earth had the full support of Bolivian president Evo Morales - Bolivia's first indigenous president who is from native Aymara descent. The Aymaran people subscribe to the Andean worldview that all living things, including nature itself, have equal rights, and humans have no greater claim to existence than the animals and plants in nature. This marked the first time in recent history that a politician acknowledged so unequivocally that nature deserves to be respected not only for human benefit but for its own sake.

Reproduced from the web posting of the articles by World Future Fund (2017), the Bolivian law, revised and passed in October 2012, states that Mother Earth is endowed with the following rights:

To life: The right to maintain the integrity of living systems and natural processes that sustain her, and the capacities and conditions for her regeneration.

To the diversity of life: The right to preservation of the diversity of beings that make up Mother Earth, without being genetically altered or structurally modified so that their natural existence, functioning or future potential would be threatened.

To water: The right to preserve the functionality of the water cycle, its existence in the quantity and quality needed to sustain living systems, and its protection from pollution for the reproduction of the life of Mother Earth and all her components.

To clean air: The right to preserve the quality and composition of air for sustaining living systems and its protection from pollution, for the reproduction of the life of Mother Earth and all its components.

To equilibrium: The right to maintenance or restoration of the interrelationship, interdependence, complementarity, and functionality of the components of Mother Earth in a balanced way for the continuation of her cycles and reproduction of vital processes.

To restoration: The right to timely and effective restoration of living systems affected by human activities directly or indirectly.

To pollution-free living: The right to the preservation of any of Mother Earth's components from contamination, as well as toxic and radioactive waste generated by human activities.

There is a lesson that capitalists, corporations, environmentalists and world leaders can take from this story, and it lies in the respect for nature long bestowed upon the conscience of indigenous peoples. Ideas such as The Law of Mother Earth lay the foundation for a reformed approach to managing the world around us, including the people that live in it. This is not a call for the worship of nature, but the development of newfound regard for her sustenance based entirely on a newfound respect of nature and its natural balances.

The poem below, 'Ode of the Lost Indian Nation' is an appropriate sequel to 'There was an Indian' by John Squire that is provided at the beginning of this chapter. It tells the story of the American native long after Columbus's ships came 


\section{How global environmental democracy died}

ashore. Moreover, it tells the story of the plight of the indigenous Americans, and in many more ways, the beginning of the plight of the Earth, and the point where both global environmental democracy and social justice began gasping for breath in synchronous unity. Equally significant, the anonymity of the poem's author is a telling reminder of the lost identity of the American native.

\section{Ode of the lost Indian nation}

You came to our land of milk and honey fair, and trampled through our woods, as if we were not there.

You ignored all our pleas for peace, and marched us to and fro, and now we are scattered here and there with no place else to go.

You beat us like dogs, and expect us to bow down, you made us hungry and weak, till we fall to the ground. You took our daughters for wives, and made our nation weak, you made cowards out of most, and now we are afraid to speak.

So now I humbly ask you, was it worth the fight, to scourge our village, and raid us through the night? You thinned out our bloodlines; you thought you were smart, you may take the Indian from our blood, but never from our heart. - Anonymous (Becca's Corner, 2013)

\section{References}

Abulafia, D. (2008). The discovery of mankind: Atlantic encounters in the age of Columbus. New Haven, CT: Yale University Press.

Barnett, H.G. (1938). The nature of the potlatch. American Anthropologist. (Vol. 40, pp. 349-358).

Becca's corner. (2013). Ode of the lost Indian nation. Retrieved from http://beccas-corner. tripod.com/id22.html

Brosius, J.P., Anna Lowenhaupt-Tsing, A., and Zerner, C. (Eds.). (2000). Communities and conservation: Histories and politics of community-based natural resources. Lanham, MD: AltaMira Press.

Dangerfield, W. (2007). The Mystery of Easter Island: New findings rekindle old debates about when the first people arrived and why their civilization collapsed. The Smithsonian. March 31, 2007. Retrieved from https://www.smithsonianmag.com/travel/ the-mystery-of-easter-island-151285298/

Digital History, ID 3788. (2016). European discovery of the new world. Retrieved from www. digitalhistory.uh.edu/disp_textbook.cfm?smtID=11\&psid=3788

EPA. (2017). Laws and regulations: History of the clean water act. Retrieved from www.epa. gov/laws-regulations/history-clean-water-act

Gomez, N. (2008). The tropics of empire: Why Columbus sailed South to the Indies. Cambridge, MA: MIT Press.

Johnsen, D.B. (2009). Salmon, science, and reciprocity on the northwest coast. Ecology and Society. (Vol. 14, Issue 2, Art. 43). Retrieved from www.law.gmu.edu/assets/files/ publications/working_papers/1014SalmonScience.pdf 
Jones, R., Rigg, C., and Lee, L. (2010). Haida marine planning: First Nations as a partner in marine conservation. Ecology and Society. (Vol. 15, Issue 1, p. 12). Retrieved from www.ecologyandsociety.org/vol15/iss1/art12/

Lansing, J.S. (1987). Balinese "water temples" and the management of irrigation. American Anthropologist. New Series. (Vol. 89, Issue 2, June, pp. 326-341).

Martinez, D. (2010). The value of indigenous ways of knowing to western science and environmental sustainability. The Journal of Sustainability Education. Retrieved from www.jsedimensions.org/wordpress/content/the-value-of-indigenous-ways-ofknowing-to-western-science-and-environmental-sustainability_2010_05/

National Phenology Network. (2011). Retrieved from www.usanpn.org/

Prober, S.M., O'Connor, M.H., and Walsh, F.J. (2011). Australian Aboriginal peoples' seasonal knowledge: A potential basis for shared understanding in environmental management. Ecology and Society. (Vol. 16, Issue 2, p. 12). Retrieved from www.ecologyand society.org/vol16/iss2/art/12/

Stabroek News. (2016). Two approaches to the Columbus-Indigenous encounter. September 11. Retrieved from www.stabroeknews.com/2016/features/09/11/two-approachescolumbus-indigenous-encounter/

World Future Fund. (2017). Law of the rights of mother Earth. Retrieved from www.world futurefund.org/Projects/Indicators/motherearthbolivia.html 


\section{Facets and consequences of environmental slavery}

Many of the social and environmental problems being encountered in the modern world are the consequences of the prevailing domineering attitudes and activities of a capitalist worldview toward the earth's welfare, these behaviors being relics carried over from the era of New World Slavery. African slavery was lucrative for Europeans in that it exploited the labor of slaves in order to accrue capital without the payment of wages. As a whole, this unjustified institution forced men and women to labor on inhospitable landscapes until plantations brimming with both food and non-food crops emerged under sweaty bloodstained backs. The institution of New World Slavery is the tortuous path through which modern capitalism emerged, and there are many similarities between the moral injustices which were practiced against slaves and indigenous tribes, and the manner in which the earth's environment has since been mistreated by those corporations and institutions upon whom global power has been conferred. The stark truth of the matter is that environmental slavery has been sustained beyond the defunct institution of human slavery, and it has contributed disproportionately to the wealth of capitalist economies while creating a disproportionately negative impact upon the biogeochemical cycles within those environments upon which the descendants of both slaves and native peoples are left to salvage their livelihoods.

The emergence of environmental and social justice movements over the last four to five decades is a direct result of the recognition of the failures of neocapitalism, these two new notional concepts clearly arguing for the adoption of eco-psychology as a moral means to re-educating Earth's citizens on the matter of applying a whole systems approach to planning and redesigning human habitats and production systems. This worldview advocated by environmental justice adherents redefines the ways in which humans impact nature through the development of cognitive values adjustments which purport that the intrinsic rights of nature must be as equally respected as the rights of human beings. This moral framework however appears to have an intractable application when contemplated in the midst of economic adherence, as the latter imposes a code of ethics that puts profit ahead of morality, and the interests of corporate stakeholders ahead of ecological futures. 


\section{Slavery and economics - incompatibilities}

In accounting for the rise of New World Slavery, historians, economic theorists, and social philosophers have invariably drawn attention to the important role played by market forces. Due to the circumstances prevailing in the Americas where labor was scarce, resources plentiful, and the European market for goods being very elastic, the attractions of slavery were perhaps too good to be ignored by the world powers of that time and age. Despite being recognized as being socially and morally repressive, the slavery institution provided exceptionally cheap goods and high profits to European and eventually American societies, and these economic factors triggered and reinforced a general disregard of moral conscience (Temperley, 1977).

In the early 1800 s it was becoming increasingly clear to those involved in the European mercantile economic system that workers (slaves) who did not earn money and were not free to direct their own lives could not participate in the economic marketplace. With this scenario existing in slave societies, the world economy, increasingly moving toward private enterprising, was destined to remain underdeveloped if the practice of slavery continued. Thus slavery as an economic institution was seen as no longer being able to aid the accumulation of private capital, instead only holding it back (Swetnam, 2010).

The decline of chattel slavery heralded the Industrial Revolution which ushered in a prolonged period of economic growth. The Industrial Revolution, consequently, was maintained through reiterations of the following characteristics.

- Driven by machinery and technological advancement

- Fueled by coal and petroleum

- Sustained by the natural resources in the earth's biosphere (considered limitless)

- Financed by profits gained through the action of market forces

- Maintained by the privatization of property which heralded the loss of the commons

- Reinforced and legitimized by modern democratic governments

- Enlarged by corporations inspired by wealth and accumulation of capital.

These listed factors all have impacts and consequences which affected every living and nonliving entity on the face of the earth during the roaring years of the industrial age. In fact, many have argued that we have emerged into the Anthropocene age largely due to the unrestrained manner in which capitalist structures have been allowed to operate without restrictions. Without moral boundaries, capitalist actors increasingly control and jeopardize larger parts of the lithosphere, biosphere, and atmosphere through private ownership and private profit accumulation, while releasing contaminants and dumping polluting wastes into the public domain, therefore ensuring that the poor and powerless occupants participate only in the shared losses. The net effect of this exploitation and almost total domination over the environment has been the creation of entropic influences on the earth's ecological processes, the enormity of which now threatens the entire web of life including the future of human civilization (Foster, 2009). 
Learning little from the moral depravity of human subjugation during slavery, the exploitation and consumption of limited resources has been driven by market forces through a value system that justifies harvest and conquest as the intrinsic right of modern corporations. Despite its achievements and the boasts of industrialized countries, the Industrial Revolution has also ushered in a new era of exploitation that will be viewed in this discourse as the practice of environmental slavery, a situation which mimics human slavery in the absence of moral conscience and the disregard of justice toward nature and its most powerless inhabitants.

\section{Understanding ecology}

Any attempt to understand the way nature works within the sphere of living things on the earth (the biosphere) must begin with an understanding of the science of ecology. Ecology is the scientific study of the relations that living organisms have with each other as well as their natural environment, their collective relationship with nonliving variables and other factors including the composition, distribution, amount, number, and changing states of organisms within and among ecosystems (Odum, 1994). Thus, the arrangements of complex interrelationships into an organized whole is referred to as an ecosystem. Ecosystems are sustained by the biodiversity of living organisms and the existence of nonliving variables within them. Biodiversity is defined as the full-scale of life and its physical and chemical processes, including genes, species, and ecosystems forming lineages that integrate into a complex and regenerative spatial arrangement of types, forms, and interactions. At the global level, ecosystems are fundamental to life in that they create biophysical feedback mechanisms between the living and nonliving components of the planet, and these feedback loops regulate and sustain local communities, continental climate systems, and global biogeochemical cycles (Foster, 2009).

Biogeochemical cycles, also referred to as substance turnover or cycling of substances, are the pathways by which a chemical element or molecule moves through both biotic (biosphere) and abiotic (lithosphere, atmosphere, and hydrosphere) compartments of the Earth. The cycle then is the series of change which comes back to the starting point and which can be repeated over and over again (McGuire and Lukina, 2006). These cycles are fundamental to life and livelihoods, specific examples being the Nitrogen, Carbon, Hydrologic, and Oxygen Cycles, all of which, by their cyclical changes, render a life-sustaining impact on ecosystems.

\section{Understanding systems ecology}

In its attempts to understand phenomena, modern science takes the approach of isolating parts of the whole and making examinations and observations which hopefully provide an understanding of the manner in which the whole works. In the study of ecological systems, the traditional procedure - a practice which has been hard to break - is to draw a diagram of the system of interest, indicating 
the system's boundaries by a solid line. Within these boundaries, a series of components are isolated which have been chosen to represent that portion of the ecosystem in which the analyst is interested. If there are no perceived connections across the systems' boundaries with the surrounding systems environments, the systems are described as closed, or having no effect on neighboring systems. Systems ecology takes a departure from this habit, in that this type of ecological work deals almost exclusively with open systems, seeing everything as being connected beyond perceived boundaries (Odum, 1994).

The current thinking among systems ecologists is that the function of any ecosystem can be influenced by human economics in fundamental ways, the negative impacts all stemming from the traditional approach which plans economic development by assuming it will only impact those relationships within the boundary in which it is established. Systems ecologists have therefore taken an additional transdisciplinary step by including economics in the consideration of ecological systems, focusing on interactions and transactions within and between defined biological and ecological boundaries, and are especially concerned with the way the functioning of ecosystems can be influenced by human interventions (Nash, 1989).

\section{Habitat fragmentation - divide, conquer, and profit}

The concerns of systems ecologists are founded out of the manner in which landscapes have been radically disrupted and converted to the exclusive use of humans. In nearly every case examined, what drove the design were purely selfish desires, but these actions have nearly always resulted in the enslavement of the environment for profit accumulation. An airplane flight over the U.S. will reveal a mosaic of rectangular grids on the ground, within which boundaries are found a variety of human-made constructs. These constructs include towns, cities, farms, forestry projects, industrial scale factories, mining operations, and power plants. The solid lines depicted on paper to denote boundaries as determined by planners and engineers are in reality roads, highway systems, fences, walls, railroads, and power lines. Because these built systems are too often arbitrarily etched into the landscape, it is not difficult to understand how certain ecological flows and processes are permanently disrupted or diverted. These disruptions and disturbances are varied, and include factors such as the permanent loss of water flow from one area to another when a road is cut through the landscape, creating scenarios where wildlife animals are cut off from traditional routes or from mating ranges - thus risking becoming road kill - or cut off from sources of water or food.

The widely practiced human habit of breaking up the landscape into smaller disconnected parcels (often sold to investors, builders, and financial prospectors) has become known as habitat fragmentation, and is responsible for the following eventualities as noted by Fahrig (2003):

- Isolation of species resulting in reduced gene flows in plants and animals

- Loss of species of importance (such as keystone species)

- Loss of habitat over time as lands are further divided and 'developed' 
- Disruptions of physical and chemical cycles

- Reduction in the productive capacity of nature

- Absolute loss of habitats (as is the case when cities are built and suburbs encroach on, erode, and eventually absorb natural habitat)

- Complete loss of habitat or ecosystem biodiversity.

\section{Roads - tools of fragmentation and social disturbance}

One can expound on several of the problems associated with the types of architecture and other human constructs which impact negatively on biodiversity, roads being one example of habitat fragmentation and social disturbance. The tropics, particularly in rapidly developing economics such as Brazil, cannot be matched for the sheer scale and pace of road expansion and the degree of environmental change roads bring to the rain forests. Road building has a range of direct impacts on rainforest ecology, ranging from the cut-and-fill operations associated with road construction impeding streams in wet tropical environments, causing increased flooding, and increased soil erosion. Laurance (2012) noted that roads that cut through rain forests also create barriers for sensitive wildlife, many of which are ecological specialists; unpaved roads drastically reduce or halt local movements for scores of forest bird species, and also discharge chemical and nutrient pollutants into local waterways providing avenues of invasion for many disturbance-loving exotic species.

For many animal species, especially those with low reproductive rates and low group numbers to begin with, highways and roads are becoming death zones that propel the species toward local extinction. By bringing naïve rainforest wildlife into close proximity with fast-moving vehicles, roads not only promote heavy animal mortality, but the death of humans also. Over the years, several tragic incidences of the deaths of indigenous children and women have been recorded in the rain forests of Brazil as they crossed newly cut highways in search of food, water, firewood, or on other social promenading. The deaths of members of seminomadic tribes have also been reported as they walked along highways with which they are largely unaccustomed.

Other problems associated with roads is the access it provides to land grabbers, loggers, gold miners, ranchers, and soybean farmers looking to expand their farming enterprises and causing human conflicts with indigenous groups. In many parts of South America, Africa, Indonesia, and India, these profit-seeking groups pay little attention to the plight of local peoples, oftentimes forcibly evicting them from their lands and subjecting them to a miserable new existence in a money economy to which they are ill suited to survive (Hecht and Cockburn, 1990).

\section{Disruptions of the biogeochemical cycles}

The living and nonliving matter that Earth contained from the time of its birth is limited in proportion, but is being transformed and circulated geographically in continuing cycles. This constant change of states through cycling and recycling 
of matter is explained by the Law of Conservation of Mass which states that "the total mass of a closed system always remains constant. Energy cannot be created or destroyed, but only transferred from one system to another" (Crowell, 2005, p. 15). In simple terms, this means that the original proportion of carbon dioxide or oxygen contained on Earth is constant, but chemical and physical reactions change these elements from one state to another, for example carbon dioxide to carbonate rocks, or water to water vapor and so on.

Biogeochemical cycles are often referred to as nutrient cycles, because they involve the transfer of compounds that provide nutritional support to living organisms within ecosystems, but the concept is also broadly expanded to explain those pathways for the transport and transformation of matter within the four categorical zonal spheres that make up planet Earth, that is, the biosphere, hydrosphere, lithosphere, and the atmosphere (Fahrig, 2003). What this suggests is that there is constant and intimate connections between these four categorical realms, and any action within one will trigger reaction in the others in very important ways.

Managing and understanding environmental problems caused by climate change requires an understanding of the biogeochemical cycles. This is because life on earth is inextricably linked to climate through a variety of interacting cycles and feedback loops. There is growing awareness of the degree to which human action and activities such as deforestation and the combustion of fossil fuels have directly or indirectly modified the biogeochemical cycling of elements and physical processes involved in determining the earth's climate equilibrium. In addition to helping to maintain relative climate stability, ecosystem services protect living organisms on earth from the sun's harmful ultraviolet rays, mediate runoff and evapotranspiration, and regulate nutrient cycling (Moses, 2010).

Consequently, changes in atmospheric processes disturb a variety of ecosystem services that humans and every other living species depend upon, but as noted earlier, those who gain the most financially from the actions that result in ecological disturbances have been slow or reluctant to address the fact that the losses from ecosystems services are borne more acutely by the poorest and most vulnerable people. Biogeochemical cycles always involve equilibrium states, that is, a balance in the cycling of the elements between the four interacting spheres (Moses, 2010). Importantly, overall balance often involves elements distributed on a global scale, thus a disruption in one cycle within an important ecological habitat such as the South American rain forests causes a disruption in all other cycles, and this is why the issue of biogeochemical cycling is important in the conversation on climate change, social justice, and biodiversity. Once again, these assumedly diverse factors are all connected and therefore necessary subject matters upon which the re-education of neo-economists must bear some focus.

\section{Addressing the marginalization of TEK}

As previously defined, Indigenous Knowledge or Native Science, also referred to as Traditional Ecological Knowledge (TEK), is the body of knowledge acquired by local and indigenous peoples over hundreds or thousands of years through 


\section{How global environmental democracy died}

direct contact with their natural environment. The knowledge acquired by TEK is specific to a place or location and includes the relationships between plants, animals, seasons, natural phenomena, and other processes that are used to inform critical life habits such as hunting, fishing, farming, and the preparation of medicines, among others. TEK is regarded as a body of knowledge comprised of a set of practices and beliefs evolving by adaptive processes and handed down from one generation to another through cultural transmission (Rinkevich et al., 2011). In almost every regard, TEK is shown to be of more value than many modern approaches in the use of and preservation of nature through its expression of benevolence to both the living and nonliving things within the environment. In many cultures, TEK essentially views the environment as a living entity, thus demanding a certain level of respect, care, and temperance in one's dealings upon it. It is this basic principle of respect and temperance that modern scientific approaches disregard, and in so doing have done perhaps irreparable damage to earth systems. The damage, however, has forced native cultures and their ways of doing things into less resourceful corners of existence, reducing them to mere peons of the dominant modern society who caused the damage in the first place (Wilson, 2012). This has been most evident in South American societies in recent years, but also historically significant in many parts of the U.S., Canada, Australia, New Zealand, and Africa.

When the environment loses its best stewards to bulldozers and powerful mechanical tools, it is left at the mercy of capitalism which cares only for the raw materials from which it derives profits. This argument is painfully true even for capitalists who believe in land restoration. However, the loss of the voice and language of indigenous peoples is not a matter on which the conscience of modern science, technology, and capitalism dwells for long. One can argue that the conscience of science and technology has been eroded by the success of capitalism, sustaining a behavior through which it becomes evident that the full conquest of Earth's environment has already occurred. Earth has been beaten into subjection by powerful corporate entities intent on exploiting every last limited resource, and they are betting that the domination will continue for quite a lot longer.

\section{Eco-psychology - revolution of the subjective worldview}

In his essay 'Viable Human', Thomas Berry (1993) argues that a major philosophical or religious paradigm shift is required in modern society. This, Berry argues, is essential to navigate humanity living within or governed by modern capitalist ideology toward a bio-centric sense of value, and away from prevailing anthropocentric value systems which have resulted in the environmental crises being experienced today. Berry believes that the ownership of the media and control of education by industrialists is among the most devastating forces threatening the viability of humanity, with the education system, demonstrably, being manipulatively designed for a transmissive delivery of information suited solely for the preparation of society's youth for jobs in the destructive industrial society. What Berry's words imply is that there is a need for finding the conscience of 
science and technology and discovering new methods and approaches for ecological literacy, or identifying better codes for reading nature to be applied at all levels of society affecting education, economics, spirituality, politics, and human psychology.

The concept of eco-psychology, as Fox (1983) states, is the expression of a newer conception of the world which lends itself far more readily to organismic rather than mechanical metaphors. This approach suggests that the education of children and other learners in eco-psychology will minimize the language associated with industrialization (abandoning the word 'growth' in economics, for example), while increasing the language associated with nature (adopting the word 'biodiversity', for example). Note here that both words - growth and biodiversity - imply the concept of 'increase' in very different ways.

Fox (1983) also suggests the development of pan-psychic rather than deadmatter conceptions of the non-human world through eco-psychology. This implies that objects in nature such as mountains, lakes, and rock formations will be viewed as matter containing inherent sacredness, thus eliciting forethought from humans when resources are harvested from these stores of natural materials. Eco-psychology advances the idea that upon adopting these educational and psychological approaches to nature, humans would have become more environmentally and socially literate, thus being able to treat nature and its inhabitants with respect, rather than as a storage area from which objects are harvested solely for the gratification of the powerful, and for the satisfaction of greedy industrialists.

\section{Facets of environmental literacy}

In the proposition of a model for enabling the development of environmental literacy, Golley (1998) distinguishes between the natural (ecosystems) and built environment (human technology) and notes the dominance of the latter over the former. This dominance has resulted in most of the current man-made problems observed in natural ecological systems. In the pursuit of mechanistic approaches to problem solving, designers and decision-makers define problems narrowly, often without identifying their causes or identifying the connections with other parts of the system they intend to change. Because contemporary planning, designing, building, and extracting are not based on holistic approaches that consider the whole ecosystem, the important biogeochemical connections between the lithosphere, the biosphere, the hydrosphere, and the atmosphere (the global environmental ecosystem) are ignored. It is this flaw or 'environmental illiteracy' that led to the increase in the parts per million of carbon dioxide in the atmosphere, the increase in the parts per billion of plastic particles in the oceans, the disturbance in rainfall patterns, and the associated social despair observed in many parts of the world. The loss of biodiversity and the marginalization of, and sometimes unfortunate full assimilation of indigenous peoples into western value systems, are the inevitable factors responsible for the loss of indigenous knowledge and sensibility toward nature. 


\section{How global environmental democracy died}

Whole-systems approaches counter the status quo development strategies in revealing longer-lasting and cheaper solutions with 'benefits' accruing beyond mere 'profits'. It also takes ingenuity, intuition, and teamwork into consideration, positing that relationships impacting the system must be considered simultaneously and teased apart to reveal mutually helpful methods of process (Golley, 1998). Teamwork implies the use of alternative methods of knowing - the concept of resiliency, which means consulting with local peoples where necessary and employing the use of TEK to better ensure the social justice of people and the living and nonliving things in nature with whom they share mutual relationships. This approach avoids past errors and ensures a more equitable use of resources and materials in a manner which may return the cycles to more sustainable norms. Given the existing conditions of economic hegemony in which we now exist, this romanticized idea for fixing the global ecosystems may be overly simplistic and will require more heavy lifting to be recognized as a meaningful strategy.

\section{The intrinsic rights of ecosystems}

An article in the Earth Island Journal titled 'Natural Law' (Mark, 2012) discussed a growing movement in the U.S. which promoted the idea that ecosystems have intrinsic rights. The article spoke to the work of Cathy Miorelli who ran for office in a small Pennsylvania town (Tamaqua Borough) in 2004 and began opposing plans for an outside company to dump sewage sludge and coal fly ash into abandoned mining pits on the edge of the town. Miorelli spearheaded the passage of an anti-sewage sludge ordinance which importantly included a provision recognizing the rights of 'natural communities' to flourish. According to Mark (2012), "this was the first law of its kind in the world, and it flies in the face of ... years of Western legal precedent that treats nature strictly as property". The rights of nature, according to the journal article, provides a path for transforming the existing culture in the so-called West into one that coalesces sustainably in a world where it becomes natural to think "What would the forest say about this?"

Although the sustainable approach to nature has long been successfully practiced by indigenous peoples through TEK, modern education perceives this type of relationship of humans to nature as being extraordinary irrational, often even as idolatrous. Theodore Roszak (2001) provides clarity on this in stating that the kind of sanity that connects people to each other in society is not the same kind of sanity that establishes the compassionate bonds between us and the creatures and objects with whom we share the earth. Ironically, many of those who often accuse social justice proponents of insanity for their cause in 'humanizing nature' have been deeply involved in advocating for the creation of laws that convey personhood or 'human-ness' upon corporations.

Roszak (2001) makes the case that the greater implications of the ordered and evolving complexity of the universe - including those which humans have contributed - will have to be confronted sooner or later, and it will likely be that the deep systems of nature from which the psyche of humanity has arisen over thousands of years - our cultures, our natural instincts, our medicines, and our 
science and technology - will once more become the language through which the Earth finds its voice again. This is the new point from which humanity reorients its relationship with the environment, and in transforming it from a dominator/ dominated arrangement, abolishes the stranglehold of subjugation over Earth's threatened biodiversity.

\section{References}

Berry, T. (1993). The viable human. Retrieved from www.questia.com/PM.qst?a=o\&d= 95141193

Crowell, B. (2005). Conservation laws. Fullerton, CA: Light and Matter.

Fahrig, L. (2003). Effects of habitat fragmentation on biodiversity. Annual Review of Ecology, Evolution and Systematics. doi: 10.1146/annurev.ecolsys.34.011802.132419

Foster, J.B. (2009). Envisioning ecological revolutions: Making peace with the planet. New York, NY: Monthly Review Press.

Fox, W. (1983). Deep ecology: A new philosophy of our time? In Light, A. (Ed.). (2003). Environmental ethics: An anthology. MA: Blackwell Publishing.

Golley, F.B. (1998). A primer for environmental literacy. New Haven, CT: Yale University Press.

Hecht, S., and Cockburn, A. (1990). The fate of the forest: Developers, destroyers, and defenders of the Amazon. New York, NY: Harper Collins Publishers.

Laurance, W. (2012). As roads spread in rainforests, the environmental toll grows. Environment 360, January 19. Retrieved from http://e360.yale.edu/feature/as_roads_spread_ in_tropical_rain_forests_environmental_toll_grows/2485/

Mark, J. (2012). Natural law: From rural Pennsylvania to South America, a global alliance is promoting the idea that ecosystems have intrinsic rights. Retrieved from www.earthisland.org/ journal/index.php/eij/article/natural_law/

McGuire, M.D., and Lukina, N.V. (2006). Biogeochemical cycles. In Northern Eurasia Earth Science Partnership Initiative (NEESPI) Science Plan Overview. Retrieved from http://neespi.org/science/NEESPI_SP_chapters/SP_Chapter_3.2.pdf

Moses, M. (2010). Biogeochemical cycles. The Encyclopedia of Earth. Retrieved from www. eoearth.org/article/Biogeochemical_cycles?topic $=49553$

Nash, R.F. (1989). The rights of nature: A history of environmental ethics. Madison, WI: University of Wisconsin Press.

Odum, H.T. (1994). Ecological and general systems: An introduction to systems ecology. Niwot, CO: University Press of Colorado.

Odum, H.T., and Odum, C.E. (1976). Energy basis of man and nature. NY: McGraw Hill Book Company.

Rinkevich, S., Greenwood, K., and Leonetti, C. (2011). Traditional ecological knowledge: For application by service scientists. US Fish and Wildlife Service. Retrieved from www. fws.gov/nativeamerican/graphics/TEK_Fact_Sheet.pdf

Roszak, T. (2001). The voice of the Earth: An exploration of eco-psychology. MI: Phanes Press.

Swetnam, J. (2010). Slavery and the early development of modern capitalism. Free Liberal. July 22. Retrieved from http://freeliberal.com/articles/12135/slavery-and-the-earlydevelopment-of-modern-capitalism

Temperley, H. (1977). Capitalism, slavery and ideology. Past and Present. (Issue 75, May, pp. 94-118). Oxford University Press. Retrieved from www.jstor.org/stable/650442

Wilson, E.O. (2012). The social conquest of Earth. New York, NY: Liveright Publishing Corporation. 


\section{It's the ecology, stupid}

\section{The Anthropocene problem complex}

It is supremely logical to deduce that the rampant environmental, social, and economic imbalances being observed on Earth have resulted from the overexploitation of people and of resources - both biological and natural. The massive species depletion across the expanse of the biosphere with resulting weakened ecosystems has given rise to extreme rural poverty in many places, causing mass urban migration and urban overpopulation in others. Spin-off effects include increasing public health pressures from infectious diseases, and unavailability of, or lack of access to food has resulted in weakened economic sectors even in industrialized countries.

At the same time, global climatic change resulting from greenhouse gas emissions to the atmosphere has contributed to warming of the earth beyond normal pre-industrial levels. Author and scientist Bill McKibben (2010) in his book Eaarth, noted that the level of atmospheric carbon dioxide which kept the Earth's temperature and weather stable for 10,000 years stood at roughly 275 parts per million until the dawn of the Industrial Revolution when fossil fuel usage began in earnest. From that point onwards, there has been an annual increase in the parts per million of greenhouse gasses into the atmosphere. Should the trend continue and there is no sign that fossil fuel usage will decline significantly - by the year 2100 there will be more than 725 parts per million of carbon dioxide in the atmosphere. This amount of carbon dioxide will almost certainly trigger such dangerous levels of warming it will cause violent extremes of weather and complete changes in climatic patterns everywhere on the earth. Those changes will not wait until the year 2100. As the levels of carbon dioxide and other greenhouses gasses rise, the predicted extremes of weather will begin to occur more often with increasing and prolonged levels of intensity.

With global warming already a stark reality, many overt changes are currently occurring in the Earth's weather events, but the irony is that poorer countries which have so far contributed significantly less to greenhouse emissions from fossil fuel combustion have less economic resources and thus the inability to adapt to starkly changing environments. Ironically, it will be the wealthier countries with overwhelmingly higher greenhouse gas emissions (due to greater use of fossil fuels) 
that will have the necessary financial resources to adapt to and save themselves from the havoc caused by their own actions, even as they enact restrictive laws to keep environmental refugees away from their national borders.

The need for food, fiber, and fuel amidst rapid population increases in developing and poor countries creates more complexities. Energy availability and costs are tied to food production costs and prices, which will continue to cause food prices to rise as real energy production costs grow even higher. In 2009 the United Nations (UN) estimated that the global population will increase from 6.8 billion to 8.3 billion people by the year 2030. To satisfy the demand for food for this many people, assuming that equitable distribution is possible, world food production will have to increase by $50 \%$, the availability of potable water will have to improve to $30 \%$ higher, and global energy demand will rise by 50\% on 2009 levels (Scherr and Sthapit, 2009).

Much of this global rise in population predicted for 2030 will however be observed in developing countries, particularly on the Asian and African continents, where in order to sustain unprecedented demand for basic needs, these countries will have to increase their livestock numbers among other agricultural commodities. Furthermore, primary forests will have to be cleared to make room for people, crops, and animals, and fuel consumption of all types will also have to be increased. Every single need outlined here includes production of goods and provision of services that will generate greenhouse gas emissions, adding to and escalating the rate and pace at which threshold levels of atmospheric carbon dioxide will be reached and surpassed.

A 2012 UNESCO report showed that a language disappears on average every two weeks as capitalist power and demands infringe upon the rights and properties of native peoples across the world. When a language disappears, it carries with it an entire cultural and intellectual heritage. The disappearance of human language is yet only a symptom of an equally grave demise in the biodiversity of Earth's ecosystems. The tragedy which often causes the forced migration of people and languages also causes the loss of species which contain their own inherent unspoken languages and information - assets which are often impossible to retrieve.

The threat of climate change as caused by the action of humanity in the Anthropocene age is therefore not simply an issue of socio-economic discomfort to be experienced by the world's unfortunate poor, but encompasses a complex eco-anthropological spectrum that will have a lasting destabilizing impact on the way humanity continues to live on the earth.

\section{A diagnosis of causes - an examination of markets, the economy, education, and the concept of growth}

\section{The market}

Author Vandana Shiva (2005) indicates that there are two general types of markets in existence in the global marketplace. The first type of markets are those embedded in nature and society which place emphases on the meeting of people, exchanges between them, and a sharing of culture. This market type may be 
referred to as the Natural/Traditional Market System. Secondly, there are markets which are shaped by capital and exclude people as producers, and may be referred to as the Free Capitalist Market System. Shiva notes that markets shaped by Capital replaces the cultural space with invisible processes such as stock exchanges, and supplants physical and emotional needs with profit and consumerism. This supplanting of humanity has resulted in the disembodied, inhuman and often inhumane marketplace that has been the greatest cause of the environmental destruction of nature and of peoples' ways of life.

While both weaknesses and strengths are observed in each market type, the Free Capitalist Market system has come to dominate the global marketplace in such a manner that the Natural/Traditional Market system has ceased to exact any level of importance in the neo-classical monetary space. This marginalization of the inherent ecological relationships of the Natural/Traditional Market system has eroded its value to such an extent that there has been a complete assimilation of natural assets by the Free Capitalist Market system.

\section{The economy}

With the rise in importance of the Free Capitalist Market system, lands once referred to as the 'commons' became increasingly enclosed as the power of privateers and corporations rose correspondingly with the rate of profits accrued from resources contained within property boundaries. As a direct result, the local commons - those natural environments from which resources were traditionally gathered by everyone - became too limiting upon profits as private interests grew, thus their boundaries were expanded and privatized far beyond the original enclosures. In time, Free Marketers increasingly claimed resources from outside the scope of community, country, and continent, as private interests broadened under the guise of growth and development. Shiva (2005) suggests that the worldview which dictated this global capitalization of resources facilitated the movement from commons to commodities and the birth and development of corporate globalization. The co-opting of the global environment into the capitalist marketplace ensured the relative rise in importance of the economy over the environment despite the economy being clearly dependent upon the environment for its existence, survival, and growth.

\section{Education}

The market economy and its related corporate power structures have become such a dominant force in the world that the lives of everyone on Earth depend upon, and are impacted by it. Since the beginning of the Industrial Revolution, a major benchmark for success has been the ability of people to get ahead in the economic stream dominated by corporate power brokers and governments whose members are usually drawn from this corporate pool, and who inevitably become a part of the for-profit agenda. The education system which in many countries of the world are managed by governments, has been carefully structured to turn out 
students at all levels that are readied for the corporate world of work. David Orr (2002) writes that whatever they once might have been, higher education institutions over time have become a massive corporate conveyor belt where students are prepared for entry into the corporate system in such an inflexible manner that they are incapable of adapting to a coherent, ecologically solvent worldview.

Orr (2002), in his book 'The nature of design', further laments the consequences of modern education in the manner by which promising young people are launched into academic careers that literally "eviscerate their idealism and energy" (p. 155), largely through the burdensome financial demands placed upon them to receive the kind of education that dictates buying into a worldview agreeable only to professionalized, disciplinary knowledge and institutionalized science. Orr's argument shows how capitalist perspectives have coopted institutions and systems of education into a profit-making worldview that ensures its own survival by reinforcing a mechanistic educational design suited to its own ends.

To further illuminate the points raised earlier, Stephen Sterling (2001) constructs the term 'extreme instrumentalism' to explain the transmission of knowledge (learning) that occurs in today's classroom environment. He reasons that contemporary schooling in the industrial world has been re-structured and repackaged to conform to the philosophy and needs of the Free Capitalist Market. Sterling believes that this approach has failed to achieve the goals and functions of education, causing the distortions between education policy, theory, and practice being encountered in the twenty-first century world. To lend coherence to this argument, Sterling suggests that the four functions of education are:

- The socialization function - to replicate society and culture and promote citizenship

- The vocational function - to train people for employment

- The liberal function - to develop the individual and his or her potential

- The transformative function - to encourage change toward a fairer society.

Sterling (2001) explains that the obvious failure of modern education to achieve the liberal and transformative functions is directly the result of an exclusion of the concepts of sustainability from the curricula, which has had the effect of almost total ignorance of systems-thinking, or at best, the ignoring of the rise of the kind of ecological thinking which seeks to foster a more integrative awareness of people and their essential connections to the environment. These grave omissions of the modern education system have had a numbing effect on the minds of citizens in the name of development, thus allowing the corporate world to ensure a continuation of its quest to reduce the natural environment to a mere storage area from which it amasses its fortunes, thereby achieving its greatest victory yet.

\section{Growth}

Herman Daly (2007) notes that growth as a capitalist concept is widely considered to be the modern day solution to all economic ills, including the debt crisis observed from 2008 in western economies which itself grew out of a growth in 


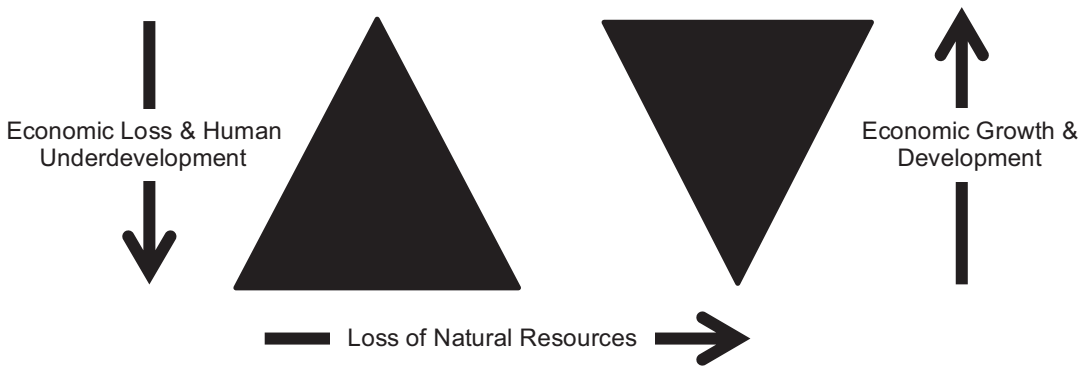

Figure 3.1 Market effects on natural resources

'stocks' of debt, particularly in the U.S. housing 'debt market' which collapsed in 2007. Because Free Capitalist markets are invisible, it is nearly impossible to see their boundaries. Since prices and values of invisible stocks and other trading instruments continue to increase, enriching investors beyond conceivable limits, the economy has grown beyond the physical boundaries of the real and visible environment, well removed from the domain of rational society. Shiva (2005) illustrates this concept very well, and leaning on her idea, Figure 3.1 shows the way in which capital accumulation leads to financial growth for corporate entities while simultaneously eroding the natural resource base upon which wider society directly depends.

Current capitalist structures depend on growth so exclusively and have amassed such enormous riches from economic 'growth' strategies that there is little impetus or incentive to change behavior or fully contemplate - beyond lip service - the ecological implications of the growth strategy upon the natural ecology (Smith, 2010). This partly explains the reason why, in the face of failing stock markets, many on Wall Street continued to disregard clear warnings about climate change and environmental pollution caused by disasters such as the 2010 Gulf of Mexico oil spill. Rather, they almost immediately advocated for more oil drilling in similarly delicate environments, including, believe it or not, the Gulf of Mexico itself. Corporations have therefore managed, with time and profits, to grow to the point at which they now own and control the world, possessing the dangerous capacity to exploit the earth without an army to stop them from doing so. And they are able to do this largely because they control money, education, and politics, and therefore wield enormous bargaining power over every aspect of society from cradle to grave.

\section{Is change possible?}

It would be so nice if something would make sense for a change.

- From Alice in Wonderland 
In his groundbreaking work 'The Tragedy of the Commons', ecologist Garrett Hardin (1968) makes the bold statement that in order to solve the destructive behavior of mankind, there is a requirement for the development of personal moral boundaries. The pursuit and achievement of morality is partly contained in the component parts of the precepts of Education for Sustainability, which include the following principles advocated by the Brundtland Commission of 1987 ;

- Consciousness transformation leading to a new relationship between humanity and nature

- Lifetime learning, experiential learning, and an emphasis on personal responsibility

- Community-based learning, the development of social partnerships, and cultural exchange between peoples.

Over the last few decades there has been a movement toward stronger advocacy for changes in the educational system, and even more fundamentally, for education to focus on sustainability, and for sustainability education as a singular message to become an inherent part of modern educational strategies. The Cloud Institute for Sustainability Education derives some of its current thinking from the 1987 Brundtland Commission, and thus defines Education for Sustainability as

a transformative learning process that equips students, teachers, and school systems with the new knowledge and ways of thinking we need to achieve economic prosperity and responsible citizenship while restoring the health of the living systems upon which our lives depend.

(Cloud Institute for Sustainability Education, 2018)

These principles provide the pathways toward awareness and action, and because they are interactive and systems derived, permeate personal decisionmaking, community action, and national and global policy. These levels of awareness and action encapsulate the fundamental change which must occur first in individuals, then in grassroots movements in communities, and must permeate society before becoming expressed in policies that stimulate and provide moral incentives to the corporate politic.

\section{Transforming education}

The current educational system built largely around transmissive (assembly line) approaches to learning has been responsible for much of the resistance (or inability to respond adequately) to change observed in modern society. The necessity to evolve to a new learning paradigm has never been greater, so whereas education is concerned with dealing with the problems and challenges of the modern world, the need exists for the development of an engaged, responsible citizenry 
capable of critical thought and equipped with the adaptive strategy to solve modern problems. This implies that societies must evolve toward educational models that can achieve this transformation by applying civic engagement in learning environments to bring about sociopolitical change through civically transformative partnerships (Taylor, 1998). This is a task that is near impossible unless methods can be found to break the institutionalized stranglehold of corporate power created out of the addiction to profits.

It has been argued by many, including Taylor (1998), that a major reason for the apparent lack of action in addressing many of the problems being experienced in the Anthropocene age is an education system developed before the emergence of modern Anthropocene challenges. Unable to adapt to change, the education model continues to prepare learners to contribute to the causes of modern problems with little capacity to proffer solutions. People educated under this paradigm are in no position to lead an effective strategy against the failures caused by factories and market economics, as they are educated to perpetuate the thinking that developed the very factories and economic machinery that caused them in the first place.

As a change strategy developed to influence the trajectory of modern education, Education as Sustainability (EaS) as a learning paradigm must therefore seek to adopt an evolving framework which embraces civically engaged people in a cross-cultural, practice-to-action, team-oriented, and experiential model of learning to help learners utilize knowledge and awareness as they move to act in a manner which contributes to the greater good of society. When society increasingly understands the connectedness between its collective actions, the economy, and the environment, and that withdrawal of finite resources from an environment with quantifiable boundaries produces a logical shortage over time, it is forced to take steps to address those actions by rationing entitlements, or by seeking alternative ways to collectively survive (Shiva, 2005). Collective action therefore becomes a natural behavior of the ecological system which begins to revalue relationships across the invisible boundaries through which nature and humanity symbiotically interact.

\section{Sustainable development as a change dynamic}

Sustainable development theory is advocated as a newer paradigm upon which to educate researchers, university faculty, and policymakers in the social and natural science disciplines that underpin those basic issues originally defined by the Brundtland Commission of 1987. The Commission sees sustainable development as "development that meets the needs of the present without compromising the ability of future generations to meet their own needs" (Brundtland Commission Report, 1987, p. 24). This definition has however been criticized as an oxymoron as many pro-environment people see 'development' as a concept aligned only to 'growth', and therefore as the main culprit of environmental exploitation and degradation which render the ability to feed future generations impossible. Even then, the definition proposed mainly by environmentalists - "sustainability is 
living within one's own ecological means" (Liu, 2009, p. 1412) - has itself been criticized for conveying the idea of sustainability having quantifiable biological limits without regard to the tendency of species toward adaptability and diversity.

Regardless of the debate and the varying degrees of perception, society has reached the critical point at which policymakers, natural and social scientists, environmentalists, and those held culpable for the most egregious acts against nature must find collective agreement in order to reach the common goal of sustainability, however the concept is defined. Education for sustainability must therefore critically advance an understanding of the importance of relationships between disciplines, in order to create a systems-thinking worldview where it is understood that nothing exists in isolation in the real world (Taylor, 1998). Sustainability education therefore becomes the driving catalyst providing new ideas and approaches for understanding and reinforcing the relationships between the intertwined components of environment, economy, and society. With this achievement, the concept of sustainability education will reflect a call to action from the current position of non-action. Equally, sustainability education as a change paradigm must become a political journey toward a more effective use of technology in order to birth a society "founded on respect for nature, universal human rights, economic justice and a culture of peace" (The Earth Charter Initiative, 2012, p. 1). How this gets done in developed societies remains an essential component part of the ultimate challenge, but perhaps this kind of educational reset may be brokered as a change experiment in places where transmissive educational systems have failed to lift people out of abject poverty, and where perhaps, grassroots organizations see the need to force the establishment of a bold new model.

\section{Natural capitalism as environmental reform}

Native, small-scale societies have been involved in the practices of extracting, producing, processing, and trading a diversity of products from a broad spectrum of natural environments for a long time, so commodity trade has not been the design of modern capitalist economies. Scholars working on all continents have documented the cultural modification of nature by every group of indigenous people. As mentioned in Chapter 1, native communities have not been ignorant of their neighbors, and have traded local products with groups located at considerable distances away. Even before the reintroduction of the horse to the American continent, Native American groups have traded and re-traded goods - almost like passing a baton in a relay race - all the way up and down the continent.

The wealth and development of humankind, especially those in western societies, have been largely aided and abetted by the Industrial Revolution that gave rise to the modern capitalist ideology which dominates the world economy today, albeit at a severe cost to the Earth's natural resource materials, to environmental quality, and to bio-cultural diversity. Over the last century in particular, a significant amount of nature on all of Earth's continents has been destroyed in search of material wealth and profit. Profit, wealth, and power have propelled industrial 
systems to pinnacles of economic success by honing the human capacity to accumulate capital at the decline, pollution, and death of the natural capital on which human civilizations depended for thousands of years (Hawkin et al., 2011).

Natural capital includes those materials in nature commonly referred to as 'resources' largely because they are used by people: things such as water, minerals, trees, fish, soil, air, rocks, animals, and more recently, fossil oils. An ecological refocus would offer a re-definition of 'resources' to indicate those natural 'materials' derived from natural or living systems (ecological habitats) such as oceans, coral reefs, estuaries, wetlands, grasslands, savannas, riparian corridors, tundras, and rain forests. The requirement for a new look at the way resources are defined is important because every ecological system listed here is in various states of demise across the entire world, their conditions deteriorating at unprecedented rates. This interconnecting and burgeoning state of ecological destabilization has reached epic proportions in the twenty-first century, thereby ushering in what Crutzen (2006) referred to as the Anthropocene age - the age of global environmental decline.

Santone (2010) explains that in the context of modern economics, 'natural resources' imply that the environment contains sets of materials available solely for the purpose of human extraction and use. This assumption disregards the biological reality that all known species, including humans, are part of the biospheric environment and in varying degrees depend upon natural resources in their unharvested forms. Thus, many sustainability-minded educators prefer the term 'natural materials' as an alternative to 'resources' to more accurately reflect the fact that the environment supports all life forms, not just human, and any materials in the natural landscape should be made available for communal use and not just for human extraction and processing.

Within wetland ecological communities there are living organisms such as algae from which, for example, humans derive essential omega-3 fatty acids upward through the food web. The provision of omega-3 is an ecosystem service that is invaluable but often disregarded in the quest to collect unsustainably large amounts of intermediate materials from these habitats, even though the materials may be integral to the mobility of omega-3 (Peet and Stokes, 2005). Other organisms providing important ecosystem services include fungi, mammals, humus, amphibians, bacteria, trees, flagellates, insects, and flowers that make life possible and worth living on Earth. The decline in these natural resources has been proportionally supplanted by the growth in human populations, but the tragedy of the decline has prompted many to call for a New Industrial Revolution that responds to the changing patterns of scarcity. This new Industrial Revolution will embrace a worldview that considers natural resource materials as natural capital, operating within a market framework that restores capital value to both the living and nonliving elements within ecosystems. This approach is enshrined in the concept of Natural Capitalism, which is a business model seeking to overturn twentieth-century approaches to business and education.

In the blueprint they developed for envisioning a new resource sustainable economy, Hawkin et al. (2011) describe a world in which there is a promise to transform existing ideas about commerce and the fundamental role it plays in 
shaping future action. The blueprint proffers the concept of Natural Capitalism as a future in which business and environmental interests increasingly overlap, and in which businesses can better satisfy their customers' needs, increase profits, and help solve environmental problems all at the same time. The authors further reason that natural capitalism offers alternative solutions to the modern economic paradigm through some specific approaches:

Buy time by using resources dramatically more productively.

This approach proposes that humanity should continue to use the 'resources' to which we are accustomed, but by applying the virtues of natural capitalism we would reduce our needs through using less to begin with, re-using materials as many times as possible, and recycling materials after each use-cycle. An issue that compounds this proposal is the reality that world population continues to increase, creating a need for additional 'raw materials' to satisfy growing demand. With respects to food demands, for example, farm productivity has been declining over the last decades, having reached what appears to be its productivity plateau at which point technology simply may not be able to do more. As reported in the October 22-28, 2011 issue of the Economist, a matter further impacting the global agriculture sector is the increasing loss of farmlands across the world. No new farmlands are coming available and chronic shortages of water for irrigation are already a stark reality in many parts of the world.

Hawkin et al. (2011) suggest a second natural capitalism approach.

Redesign all industrial processes and the delivery of products and services to do business as nature does, described in such approaches as bio-mimicry and cradle to cradle.

Biomimicry, as the name implies, is an examination of nature, a study of its models, systems, processes, and elements in order to emulate or take inspiration from it to solve human problems. Cradle to cradle, a biomimetic approach, applies the understanding that design of products and manufacturing systems growing out of the Industrial Revolution reflected the spirit of the time and yielded a host of unintended yet tragic consequences. To correct this flaw, designers employ the intelligence of natural systems such as the effectiveness of nutrient cycling or the abundance of the sun's energy to create products, technologies, industrial systems, buildings, even regional plans that allow nature and commerce to fruitfully coexist (McDonough and Braungart, 2002).

The third approach suggested by Hawkin et al. (2011) is as follows.

\section{Manage all institutions to be restorative of natural and human capital.}

In the context of modern capitalist approaches, the common reaction to the problem of near depleted resources is that after richer storage of ores are exhausted, skilled mining companies level and pulverize whole mountaintops of 
poorer-quality ores to extract the metals or other materials desired. The problem with this approach is that while technology keeps just ahead of depletion, providing what appear to be ever-cheaper materials as time passes, the materials only appear cheap because the stripped rain forests and the toxic wastes spilling into rivers, into groundwater, into impoverished villages, and the erosion of indigenous cultures in 'third world' countries are never factored into the costs of production.

As more demands are placed on living systems, limits to prosperity are coming to be determined by the ready availability of natural materials rather than by industrial prowess. This means, inevitably, that management responses will have to change to meet this new reality because it simply will be unable to do anything else (McDonough and Braungart, 2002). Although conventional engineering has not given a high level of interest to biomimetic approaches in the realm of environmental applications, the approach is broadly recognized and supported by a scientific community that has become aware that the measures hold the ability to arrest and reverse many of the effects of environmental decline. Furthermore, there has been a determination by many scientific and environmental groups that biomimicry has the potential for reversing climate change over the next 40-100 years, and even more, there are practical choices which can be implemented immediately (Scherr and Sthapit, 2009). Indeed, taking steps through the inherent concepts of natural capitalism to stabilize or reverse many of the effects of global environmental decline is possible in the Anthropocene age, so all that needs to happen is for an increasingly cognizant society to demand an immediate start.

\section{Revisiting system theory - wholeness as a new paradigm}

Human lives are fully embedded in systems such as families, communities, industries, economies, and ecosystems. Essentially, because system thinking is involved with understanding how things influence each other, both naturally and socially, there has been the observation that the incorporation of this philosophy into a business operation increases its effectiveness, resulting in a decrease in costs and creating strong competitive advantage (Gharajedaghi, 2007). It is becoming increasingly clear that the mistakes of the past have been made in part due to a flaw in how projects were implemented. This flaw is rooted in the error of omission, which pays little or no attention to the myriad of externalities that impacts the life cycle of projects, so that when problems are exerted beyond the defined boundaries of the project, the necessary responses are almost completely absent. Particularly because of the impact to the global biogeochemical cycles, system thinking becomes a valuable component in the conceptualization of natural and social system projects, especially with respect to the production and consumption of energy.

\section{Energy is power: it should reside with people}

In 'Feeding the Fire', Mark Eberhart (2007) asks how America will respond as the plentiful and abundant energy to which it has become accustomed becomes 
scarce. His answer to the question puts into context the level of dependency that the average citizen has upon fossil fuels, and shows how difficult it will be to wean modern American expectations away from a commodity which is taken for granted the way breathable air is taken for granted. Eberhart answers his own question by stating;

Whereas two hundred years ago a summer evening's activities might have brought the family together to share poetry by the light of a whale-oil lamp, today's kids grab burgers at drive-thru windows before zipping across town to the multiplex. Mom and Dad take the SUV to the gym, work out, take a steam, and then head home to watch a movie on pay-per-view. The pastimes of two hundred, fifty, even twenty years ago are now boring, because our imaginations have grown accustomed to a higher-energy diet, one that may not be sustainable [for much longer].

(Eberhart, 2007, p. 3)

Today, more than 1 billion fossil fuel vehicles populate the earth, and like miniature volcanoes, they are constantly pumping hundreds of millions of metric tons of pollutants into the atmosphere while draining conventional petroleum supplies. Sperling and Gordon (2009) recognize the sheer difficulty in which cars, like cigarettes, could ever be legislated away from daily use because they bestow so much personal benefits upon their owners. Additionally, cars and other motor vehicles are often a means of financial asset that gives the working poor a sense of pride and ownership, and this makes them exceptionally relevant to people's wellness and livelihood. The answer to the dilemma is therefore to change vehicles to use less fossil energy, and adapt them increasingly to run on alternative fuels that offer zero pollution.

More than any other single resource material exploited for human use, fossil fuels and their by-products have created the most damaging human-induced problem the world has ever seen. The increase in the use of fossil fuels as a source of energy across the world also correlates with the increase in the greenhouse gas carbon dioxide in the atmosphere from 275 parts per million determined at preindustrial levels, to more than 400 parts per million observed by 2017. As the atmosphere heats up, it triggers a process that scientists refer to as positive feedback (Koch, 2012). An example of positive feedback is the arctic tundra melting due to warming, which then releases trapped methane gas held in the ice for thousands of years. With the warming potential of methane gas being several times greater than carbon dioxide, this eventually results in even greater degrees of trapped heat in the atmosphere.

The effects of feedback loops from excessive warming should not be shrugged away, and the human factor in climate change must be accounted for politically, as it has been scientifically. The practical ideas being explored to combat climate change include a range of engineering applications and techniques which require large investments of money and a commitment to repeated 'treatments' over 
hundreds of years. These technological fixes focus on the group of strategies called 'carbon capture and storage' (CCS) which are aimed at removing carbon dioxide from emissions point sources such as factories or power plants; sequestering carbon dioxide from the atmosphere, and storing the gas in geologic formations deep in the earth's lithosphere or in the deep cold waters of the oceans. The financial tolls which these technological fixes offer will be huge, and their implementation can result in failures such as massive gas leaks which could exacerbate global warming and reverse any gains made in the reduction of atmospheric carbon dioxide in the first place. As noted by The Economist (2012), CCS methodologies are not likely to be commercially viable until around 2025, and they promise to reinforce universal capitalist profit structures while disregarding all other aspects of ecological failure.

\section{Sustainability economics}

Modern economics has created very successful business ventures that have collectively helped to raise the standard of living for millions of people, but in several ways the system has now become a problem itself. It is evident that transition to a new economy is essential, specifically one requiring better accounting of the inherent biological and physical limits of the global ecosystem. Herman Daly (2007) warns that if we do not make these transitions away from status quo approaches, we will not just experience real economic decline, but also an ecological catastrophe that is bound to significantly and sharply lower living standards for everyone, particularly those who are already poor and marginalized.

The Industrial Revolution triggered the development of a vibrant capitalist system which has derived wealth from the Earth's ecological stores, so it should not be difficult to determine that the problems being experienced today are as a result of anthropogenic collateral damage related to those capitalist activities. It is now evident that modern economic problems are not purely economic, and therefore do not require economists to overly focus on 'growth' initiatives in order to solve the resulting problems (Costanza et al., 2008).

Advocates for sustainability are careful to point out that it's not merely the market that must be corrected in order to address the gravest human problems on the Earth, but rather, it is the beleaguered ecology that requires swiftest attention. We must therefore move quickly to gain a fuller understanding of the intricate connections between resource availability and material limitations, and between markets and ecological boundaries. This should be deeply contemplated while employing an adaptive education model that reorients economic thinking, stimulates action in the face of anthropogenic failures, and solidifies the concepts of sustainable development as a path toward a superior worldview. After spending many years almost exclusively focused on the economy, the time has come to refocus attention on the part of the planet that has suffered most. To save our world, to sustain our biogeochemical cycles, and to cool down our planet to preindustrial levels, our mindsets and our collective action must recognize that the global ecology needs the full attention of the global native. To put it bluntly, it's 
not the economy that must continue to grab our full and immediate attention, necessitating massive financial rescue packages and multi-billion dollar bailouts. It is the ecology, stupid.

\section{References}

Cloud Institute for Sustainability Education. (2018). Brief history. Retrieved from https:// cloudinstitute.org/brief-history/

Costanza, R., Cumberland, J., Daly, H., Goodland, R., and Norgaard, R. (2008). An introduction to ecological economics: Chapter 3. Encyclopedia of Earth. Retrieved from www. eoearth.org/article/An_Introduction_to_Ecological_Economics:_Chapter_3\#gen0

Crutzen, P.J. (2006). The "Anthropocene". In Ehlers, E., and Krafft, T. (Eds.). Earth system science in the Anthropocene. Heidelberg, Berlin: Springer.

Daly, H. (2007). Ecological economics and sustainable development: Selected essays of Herman Daly. Northampton, MA: Edward Elgar.

The Earth Charter Initiative. (2012). The earth charter. Retrieved from http://earthcharter. org/invent/images/uploads/echarter_english.pdf

Eberhart, M.E. (2007). Feeding the fire: The lost history and uncertain future of mankind's energy addiction. New York, NY: Harmony Books.

Economist (2012). Regulating carbon emissions: A blow to coal. Economist, March 31April 6, pp. 38-40.

Gharajedaghi, J. (2007). Systems thinking: A case for second-order-learning. The Learning Organization. (Vol. 14, Issue 6, pp. 473-479). doi: 10.1108/09696470710825088

Hardin, G. (1968). The tragedy of the commons. Science. (Vol. 162, Issue 3859, pp. 1243 1248). doi:10.1126/science.162.3859.1243

Hawkin, P., Lovins, A., and Lovins, L.H. (2011). Natural capitalism: Creating the next industrial revolution. Snowmass, CO: Rocky Mountain Institute.

Koch, W. (2012). NASA: Global warming caused mainly by humans. USA Today, January 31. Retrieved from http://news.cincinnati.com/usatoday/article/617228

Liu, L. (2009). Sustainability: Living within one's own ecological means. Sustainability. (Vol. 2009, Issue 1, pp. 1412-1430). doi:10.3390/su1041412

McDonough, W., and Braungart, M. (2002). Cradle to cradle: Remaking the way we make things. New York: North Point Press.

McKibben, B. (2010). Eaarth: Making a life on a tough new planet. New York, NY: St. Martin's Griffin.

Orr, D.W. (2002). The nature of design: Ecology, culture and the human intention. New York, NY: Oxford University Press.

Peet, M., and Stokes, C. (2005). Omega-3 Fatty Acids in the Treatment of Psychiatric Disorders. Swallownest Court Hospital, Doncaster and South Humber Healthcare NHS Trust, Sheffield, UK. Retrieved from http://uppitysciencechick.homestead.com/peet_omega3 review.pdf

Santone, S. (2010). Sustainability and economics 101: A primer for elementary educators. Retrieved from www.jsedimensions.org/wordpress/?s=sustainability+and+economics +1 $01 \% 3 \mathrm{~A}+\mathrm{a}+$ primer

Scherr, S.J., and Sthapit, S. (2009). Mitigating climate change through food and land use. Worldwatch Report 179. Washington, DC: Ecoagriculture Partners and Worldwatch Institute.

Shiva, V. (2005). Earth democracy: Justice, sustainability and peace. Brooklyn, NY: South End Press. 


\section{How global environmental democracy died}

Smith, R. (2010). Beyond growth or beyond capitalism. Real-World Economics Review. (Issue 53). Retrieved from www.paecon.net/PAEReview/issue53/Smith53.pdf

Sperling, D., and Gordon, D. (2009). Two billion cars: Driving towards sustainability. New York, NY: Oxford University Press.

Sterling, S. (2001). Sustainable education: Revisioning learning and change. Dartington, UK: Green Books.

Taylor, E.W. (1998). The theory and practice of transformative learning: A critical review. Columbus, OH: Center on Education and Training for Employment. ERIC Document Reproduction Service. No. ED423422. Retrieved from http://eric.ed.gov/PDFS/ ED423422.pdf

The Brundtland Commission Report. (1987). Commission report. Retrieved from http:// www.un-documents.net/our-common-future.pdf

UNESCO. (2012). Biocultural diversity: Education for sustainable development: Preserving linguistic and cultural diversity. Retrieved April 12, 2012 from www.unesco.org/new/en/ education/themes/ 


\section{The biogeochemical cycles in the era of anthropogenic climate change}

Life on earth is inextricably linked by the biogeochemical processing and recycling of materials that occur in and through the terrestrial biosphere. The biosphere, where most living organisms reside, is connected to the other zonal spheres (lithosphere, hydrosphere, atmosphere) through a variety of material fluxes, energy flows, interacting cycles, and feedback loops. Within the biosphere, living organisms relate with each other to varying degrees. The relationships between organisms depend on the natural ecological landscapes, physical designs, and chemical processes such as rain, fire, water, and lightning, that determine the survival of individuals as well as the survival of the various species over time.

There is growing awareness that human action and activities such as deforestation, nutrient pollution, and the combustion of fossil fuels have modified the biogeochemical and physical processes involved in determining the earth's climate and ecological states. The result of these actions is that pressure is exerted on the collapsing ecological services to maintain climate stability, mediate runoff and evapotranspiration, and regulate core functions such as nutrient cycling. Biogeochemical cycles always involve equilibrium states, that is, a balance in the cycling of the components between the biosphere, atmosphere, hydrosphere, and lithosphere that are in varying but constant motion. The present reality is that these global cycles are at risk from anthropogenic forces that have disrupted the normal fluxes and feedback patterns, thus making the issue of biogeochemical cycling important in the conversations on global climate change, on ecological sustainability, and on Earth ethics pertaining to environmental preservation.

The global cycles of matter and energy exchanges that occur within and between the Earth's notional spheres are the sum product of localized ecological recycling regulated by geological, physical, and chemical processes. A pivotal role in the global cycles of matter and energy is carried out by the action of food webs moving particulate matter from one living generation onto the next, and between the varieties of living organisms interacting with each other within ecosystems. Bridge and Demicco (2008) note that the ecosystems contained within Earth's biosphere have recycled mineral nutrients sustainably for billions of years, resulting in the multiplicity of localized cycles that aggregate to contribute to the global biogeochemical cycles that sustain the existence of life forces. 


\section{How global environmental democracy died}

The movement and exchange of organic and inorganic elements back and forth for the production of living matter explains ecological recycling as a whole, while the cycling of individual elements and compounds directly between living organisms is referred to as nutrient cycling. Ecosystems recycle matter locally within relational boundaries, converting available mineral nutrients into the production of biomass or organic matter, but on a larger scale ecosystems also participate in a global arrangement of inputs and outputs where matter is exchanged and transported through a larger system of biogeochemical cycles (Schlesinger, 1997). Biogeochemical cycles are the natural movement and exchange of every kind of particulate matter through the living and nonliving components of the Earth. Energy from the sun flows through the atmosphere and into terrestrial and ocean ecosystems along unidirectional and non-cyclic pathways, providing the energy essential for powering photosynthesis among other essential processes (Anderson, 2005). However, the movement of mineral nutrients is cyclic in nature, undergoing relatively fast-paced localized cycling and exchanges at the local ecological level, along with relatively slower-paced global biogeochemical cycling between the biosphere, atmosphere, hydrosphere, and the lithosphere.

The anthropogenic releases of large amounts of gasses such as carbon dioxide and methane into the atmosphere, the increases in the malpractice of deforestation, and those agricultural practices requiring large amounts of synthetic nutrient applications, have disrupted natural ecological cycles, leading to the destabilization of natural processes around the globe. Considering the implication of these giant disturbances, the main objectives of this chapter are to:

- Examine the global biogeochemical cycles in the context of the anthropogenic activities which are negatively impacting global systems

- Offer a general discourse on the direct impacts of anthropogenic forces upon ecosystems

- Discuss some social and ethical approaches that may help to mitigate runaway anthropogenic change.

\section{Earth and its planetary neighbors - a brief comparison}

Within the solar system, planet Earth is positioned in a narrow zone where life as we know it is not only possible, but actually exists. However, in its current orbit, the planet would be too cold for life to have developed (Clegg, 2009) were it not for several factors working together to create conditions conducive to the evolutionary adaptation and maintenance of living organisms. Three main factors or differences from its neighbors appear to be responsible for Earth's success at supporting life as we know it. These factors are the presence of water, free oxygen, and a climate-regulating atmosphere (Gribbin, 2012). The climate-regulating factor is crucial, and the two other life-sustaining components are keenly dependent upon it for equilibrium purposes.

Earth is positioned between the planets Venus and Mars. Venus, closer to the sun than Earth, is too hot for liquid water to exist, while Mars is much too cold 
to have oceans. Water, being one of the materials necessary for life, is found on Earth in abundant quantities. The atmosphere of Earth presents an important regulating mechanism in the greenhouse effect of several gasses and particulates. Without these gasses, life would be difficult, as the absence of the greenhouse effect would result in an average temperature of minus 18 degrees Celsius $(\mathrm{C})$ or minus 0.4 degrees Fahrenheit (F) (Gribbin, 2012).

Venus, an extremely slow rotating planet (it rotates once every 243 earth days) retains its original atmosphere of carbon dioxide gas at a pressure 90 times that of the Earth's atmosphere (Gribbin, 2012). The atmosphere of Venus is composed of $97 \%$ carbon dioxide $\left(\mathrm{CO}_{2}\right), 2 \%$ nitrogen $\left(\mathrm{N}_{2}\right)$, and less than a $1 \%$ combination of oxygen $\left(\mathrm{O}_{2}\right)$, water $\left(\mathrm{H}_{2} \mathrm{O}\right)$, and methane $\left(\mathrm{CH}_{4}\right)$. Since $\mathrm{CO}_{2}$ is a major greenhouse gas, the radiation from the sun is trapped in the atmosphere of Venus producing an extremely high surface temperature of around 890 degrees F, a runaway greenhouse effect causing Venus to have the hottest average temperature in the solar system (Prinn and Fegley, 1987).

By comparison, the atmosphere of Mars is shallow, thin, and less than $1 \%$ as dense as Earth's atmosphere. Much of Mars's oxygen is locked into surface rocks, while the remainder is combined as $\mathrm{CO}_{2}$. While $\mathrm{CO}_{2}$ makes up 95\% of the Martian atmosphere, the low atmospheric pressure means insufficient concentrations to support Earth-like vegetation. Mars does however rotate on its axes in a manner similar to earth, a condition that creates seasons (Gribbin, 2012). While Martian temperatures may reach $20^{\circ} \mathrm{C}\left(68^{\circ} \mathrm{F}\right)$ in the Martian summer, temperatures can be as low as $-140^{\circ} \mathrm{C}\left(-220^{\circ} \mathrm{F}\right)$ during the winters (Prinn and Fegley, 1987). The thin, shallow atmosphere of Mars is highly inefficient at heat transfer, a factor that renders the planet unable to support the type of life existing on Earth. As a result of these conditions, human life on Mars would require such extremes of artificial manipulation that the cost would be prohibitively high, and the dangers exponentially significant.

\section{Down to Earth: the zonal spheres}

The region of space and land that forms the outer surface of the Earth can be divided into four interconnected spheres, the names derived from Greek - atmosphere $($ atmo $=$ air $)$, lithosphere (litho = stone $)$, hydrosphere (hydro = water $)$, and biosphere $($ bio $=$ life). The living and nonliving matter near and on the Earth's surface can be classified scientifically to be in any of these four zonal spheres.

\section{The atmosphere}

The atmosphere, roughly defined as the body of air surrounding the earth, is divided into four notional layers that are described in terms of the way the temperature changes with altitude. Moving upwards from the Earth's surface, these layers are the troposphere, stratosphere, mesosphere, and thermosphere. The composition of air in the atmosphere is approximately $78 \%$ nitrogen, $21 \%$ 


\section{How global environmental democracy died}

oxygen, $0.9 \%$ argon, $0.04 \%$ carbon dioxide, and the $0.06 \%$ remaining, composed of other gasses and particles (Schlesinger, 1997).

Most of the atmosphere is located close to the Earth's surface where the air is most dense. The air in this region is warmed by the energy of sunlight that passes through the upper atmosphere without being absorbed. This sunlight energy warms the surface of the Earth, and the surface in turn warms the air above it both by heat conduction and radiation. Through the process of convection, warm air is carried upwards from the Earth's surface where it eventually cools and falls back downwards. It is this stirring and mixing of the atmosphere by the process of convection that creates the weather systems on the Earth (Gribbin, 2012). Specifically, the thermal mixing of the air in the troposphere is responsible to a large degree for the global circulation of the atmosphere as well as local weather patterns (Schlesinger, 1997). Figure 4.1 illustrates the structure of the atmosphere and shows the temperature of each layer relative to its altitude.

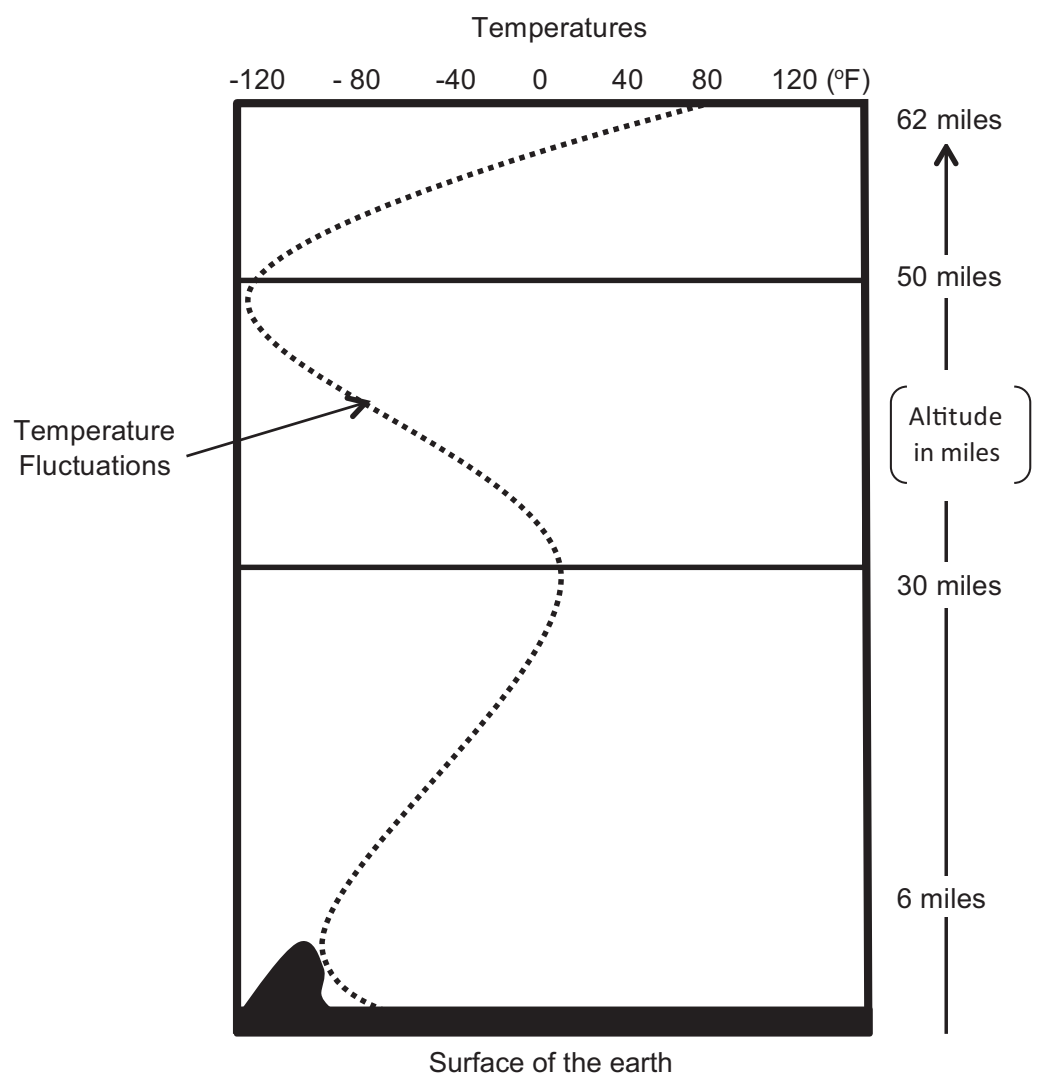

Figure 4.1 The structure of the atmosphere 


\section{The hydrosphere}

All of the water near and on the Earth including the major and minor aquatic systems on the surface comprises the notional sphere known as the hydrosphere. The hydrosphere therefore comprises the moisture in the air, water in oceans, rivers, and lakes. Gleick (1996) estimates that $96.5 \%$ of the hydrosphere exists as water in the oceans, seas, and bays, all saline in content. The next largest quantity of Earth's water, $1.74 \%$, is fresh water that is solid and contained in ice caps, glaciers, and permanent snow. The remaining $1.76 \%$ of the hydrosphere is water found in lakes, rivers, and as underground water. Table 4.1 provides a summary of the various states of the hydrosphere.

Table 4.1 Gleick's estimate of the quantity of water in the systems of the hydrosphere

\begin{tabular}{lc}
\hline Aquatic system & \% of total water \\
\hline Oceans & 96.5219 \\
Ice caps, Glaciers, and Permanent Snow & 1.74 \\
Groundwater & 1.70 \\
Soil Moisture & 0.001 \\
Ground Ice and Permafrost & 0.022 \\
Lakes & 0.013 \\
Atmosphere & 0.001 \\
Swamps & 0.0008 \\
Rivers & 0.0002 \\
Biological Water & 0.0001 \\
Total & $100 \%$ \\
\hline
\end{tabular}

Source: Gleick (1996)

\section{The lithosphere}

The zone described as the lithosphere is the solid, rocky crust and the upper mantle covering the entire surface of the Earth from the top of Mount Everest that stands 9 kilometers (5.6 miles) above sea level, to the bottom of the Mariana Trench in the Western Pacific Ocean that lies 11 kilometers (6.8 miles) below sea level. The crust is relatively thin compared to the entire solid mass of the Earth. It is inorganic, composed of minerals, and is broken into tectonic plates that move laterally at rates ranging from 0 to 100 millimeters annually (Gribbin, 2012). At the boundaries where tectonic plates meet, their relative movement results in geologic activity such as earthquakes and volcanic eruptions. Throughout millennia of movement and tectonic collisions on the Earth, these processes have resulted in formations such as mountains and ocean trenches. 


\section{The biosphere}

The uppermost part of the lithosphere chemically reacts to the atmosphere and hydrosphere through processes accommodated by the transfer of abiotic materials (gasses and minerals) to biotic forces (living and nonliving organic matter). Most of the living organisms are found from 3 meters below the ground to 30 meters above it and in the top 200 meters of the oceans and seas. This relatively thin zone that hosts the living organisms on Earth is called the biosphere and it comprises plants, animals, and single-celled organisms on dry land, in air, water, and in the polar ice caps. Areas where broadly similar animal and plant life as well as certain kinds of abiotic factors inhabit the biosphere are called biomes. Biomes within the terrestrial biosphere (terrestrial biomes) lying within the Arctic and Antarctic Circles are relatively barren of plant and animal life, while the more populous biomes exist near the equator (Campbell et al., 2006). Thus, on land, biomes are separated primarily by latitude and are often identified with particular patterns of ecological succession and climax vegetation.

\section{Interconnectedness of the zonal spheres}

The atmosphere, hydrosphere, biosphere, and lithosphere are in constant motion. Fluid motion in the outer core of the Earth produces its magnetic field, while creeping motions in the mantle becomes apparent at the surface as earthquakes and volcanoes. The Earth's atmosphere and hydrosphere are also fluid. Solar heating of the fluids contained in these spheres ultimately produces fluid motions that range from a few millimeters up to tens of thousands of kilometers in scale. The large-scale circulation of the atmosphere and the oceans (the largest system of the hydrosphere) are also strongly interconnected, and both are affected by the rotation of the Earth (Bridge and Demicco, 2008), contributing to seasonal variability on the planet.

As the hydrosphere, atmosphere, biosphere, and lithosphere move relative to each other, they interact physically and chemically, exchanging materials that are stored for varying time spans within each domain. These chemical interactions are manifested in the production of chemogenic and biochemogenic particles that are precipitated out of the atmosphere and hydrosphere and accumulate as sediments at the Earth's surface. The atmosphere, hydrosphere, and biosphere are the main arteries of material exchange on the Earth, while the hydrosphere and lithosphere act as the main storage regions (Bridge and Demicco, 2008). Through these macro processes, the long-term evolutionary histories of the notional spheres are intimately interlinked as materials are interchanged among them. As noted by Bridge and Demicco (2008), changes in the storage of materials among the various spheres have led to changes in the composition of the atmosphere, hydrosphere, and lithosphere throughout Earth's entire history. These changes, natural or anthropological, will continue to influence the planet with little regard to any form of life that continues to inhabit its susceptible biosphere. 


\section{Understanding biogeochemistry}

The interconnectedness of the four major spheres can be physically demonstrated by the existence of elements of each sphere in a single location or in a piece of natural material found anywhere on the earth. A simple example is a lump of soil having materials from the lithosphere (minerals), elements of the hydrosphere (water) present as moisture, the biosphere (living organisms) represented as bacteria, fungi, insects, and plants, and the atmosphere (gasses) as pockets of air between the soil particles (Campbell et al., 2006). The material presence of the atmosphere, hydrosphere, and lithosphere contributes to the viability of the biosphere and hence is foundational to the maintenance of life on Earth.

Biogeochemistry is the study of chemical, biological and geological reactions on the Earth, in the way that nutrients such as water, carbon, oxygen, nitrogen, phosphorus, and sulfur are cycled from the abiotic components of the ecosystem through the biotic components of ecosystems (Schlesinger, 1997). The cycling of these materials is referred to as biogeochemical cycling to indicate the interrelated biological, geological, and chemical cyclical processes that are ongoing within the ecosystems (or interconnected biomes) of the biosphere.

A review of the biogeochemical processes and cycling of materials that occur in and through the terrestrial biosphere emphasizes the importance of the role of ecology. In its simplest definition, ecology is the study of the interrelationships among organisms and the physical and chemical environment impacting their existence. Bridge and Demicco (2008) describe an ecosystem to be a threedimensional block of hydrosphere, atmosphere, and lithosphere that contains specific living organisms engaging in an ongoing cycle of material distribution between them. Thus, disturbances within and between ecosystems will result in the redistribution and transport of elements between the biosphere, hydrosphere, lithosphere, and atmosphere.

\section{Life and biochemistry}

There is considerable philosophical, religious, and scientific debate surrounding the emergence of life on Earth, but wherever these patterns of thought intersect, there exists a great degree of controversy and argumentation on the subject. Personified by Charles Darwin, who published his major work in 1859, there developed perhaps the greatest human detractor from previous religious explanations for life's origins. Kirchner and Gerhart (2005), in their work "The Plausibility of Life" noted that according to Darwin's theory of origins, a single primordial cell gave rise to all life forms on Earth. The general acceptance of Darwin's hypothesis to a large degree forms the basis of conventional scientific agreement on the origins of life. This is expanded upon and articulated by John Gribbin (2012) in the following quote.

The first large structures associated with living things were mounds produced in shallow water by the growth of mats of algae, simple, single-celled 
organisms. Algae mats trap mud particles, another layer of algae forms on top of the mud, another layer of mud forms on top of the algae, and so on. The resulting mounds, which can be a meter or so high, are called stromatolites, and fossil stromatolites show that this kind of [primitive] life was flourishing in warm, shallow waters by around 3500 million years ago.

(Gribbin, 2012, p. 139)

Schlesinger (1997) reinforces the view that life arose in the sea by making the argument that biochemistry preferentially incorporated constituents that were abundant in seawater. The shallow-water emergence of life articulated in Gribbin's statement may have in all likelihood occurred on the edge of oceans, but what makes the premise interestingly relevant to the subject of biochemistry is the fact that there is a strong correlation between the elemental constituents of modern biota, and the solubility of elements in seawater. Further, there is evidence that those elements that are familiar poisons to living systems - elements such as lead, beryllium, arsenic, mercury and cadmium - are strikingly rare in seawater.

Fossil records indicate that around 2.5 billion years ago, more complex cells possessing a central nucleus evolved from stromatolites. Originally possessing primitive metabolic pathway processes, these primitive organisms produced methane by the splitting of simple organic molecules such as acetate that occurred in oceans from abiotic synthesis (Schlesinger, 1997). It is believed that some of these cells eventually evolved to develop the process of photosynthesis that began to release oxygen into the atmosphere. With time, oxygen is exposed to short-wave solar radiation and undergoes a disassociation of its atoms producing its allotrope ozone that eventually forms a layer over the surface of planet Earth. Ozone then began the important function of filtering out ultraviolet radiation that is damaging to DNA, a vital process that helped life to become more widely established on the evolving Earth (Gribbin, 2012). From these primitive processes, a series of mutually supporting connections between biotic and abiotic materials established the basis of the Earth's biogeochemical cycles.

\section{References}

Anderson, G.M. (2005). Thermodynamics of natural systems. New York, NY: Cambridge University Press.

Bridge, J.S., and Demicco, R.V. (2008). Earth surface processes, landform and sediment deposits. New York, NY: Cambridge University Press.

Campbell, N.A., Williamson, B., and Heyden, R.J. (2006). Biology: Exploring life. Boston, MA: Pearson Prentice Hall.

Clegg, B. (2009). Before the big bang. New York, NY: St. Martin's Griffin.

Gleick, P.H. (1996). Water resources. In Schneider, S.H. (Ed.). Encyclopedia of climate and weather (pp. 817-823). New York, NY: Oxford University Press.

Gribbin, J. (2012). Planet Earth: A beginner's guide. Oxford, England: Oneworld.

Kirchner, M.W., and Gerhart, J.C. (2005). The plausibility of life. New Haven, CT: Yale University Press. 
Prinn, R.G., and Fegley, B. (1987). The atmospheres of Venus, Earth, and Mars: A critical comparison. Annual review of Earth and planetary sciences. (Vol. 15, pp. 171-212). Palo Alto, CA: Annual Reviews, Inc. Retrieved May 27, 2012 from http://adsabs.harvard. edu/full/1987areps.15.171p

Schlesinger, W.H. (1997). Biogeochemistry: An analysis of global change. San Diego, CA: Academic Press. 


\section{A review of the biogeochemical cycling of the elements of life}

Biogeochemical cycles are the pathways that allow chemical elements and compounds to move through and between the biosphere, atmosphere, hydrosphere, and lithosphere. The passage of elements through these reservoirs is a recycling process, albeit in some cycles the element is accumulated or held for longer periods of time in one or more of the reservoirs through which it flows (Campbell et al., 2006). For life to be maintained in the biosphere, chemical compounds are repeatedly and essentially being transferred between organisms, and from one part of the biosphere to another, through the biogeochemical cycling within ecosystems.

Terrestrial ecosystems on Earth are identified mainly by the dominant types of plants that constitute the major composition of life within them, hence, the terms grasslands or forests denote the particular type of flora dominating the system. Even within the oceans, the dominant biomass is undoubtedly the largely unseen but highly productive planktonic algae that form the basis of the food web. Among the myriad of attributes and interactive processes inherent within the biomes, ecosystems possess the natural ability to exert macro-forces upon the surrounding environment, and in turn, are impacted in equal measure by the returns from those forces. Because ecosystems are natural systems, they are bounded by other parts of the world and exchange energy and matter through exchanges of liquids, solids, and gasses with the other parts of the world with which they are in contact (Anderson, 2005). Consequently, ecosystems are quintessential catalysts in the sustenance of biogeochemical cycles on Earth.

\section{Thermodynamics and life processes}

Within ecosystems, biota take in nutrients and get rid of waste products, and they do so in a state of constant flux where organic compounds proceed from one metastable state to another of lower energy, never really achieving thermodynamic equilibrium (at least in the conceivable short-term). So far as biota is concerned, six elements constitute the main organic compounds found in living tissue. These compounds are the building blocks of all the major biological macromolecules that include carbohydrates, proteins, lipids, and nucleic acids (Falkowski et al., 2008). Accounting for $95 \%$ of the biosphere, the six essential 
elements are carbon $(\mathrm{C})$, oxygen $(\mathrm{O})$, hydrogen $(\mathrm{H})$, nitrogen $(\mathrm{N})$, phosphorus $(\mathrm{P})$, and sulfur (S). Approximately 20 other elements in trace amounts are considered to be essential to life, but as research in the field of biochemistry continues, it is quite possible that other trace elements may also come to be considered as having important roles in the life process (Schlesinger, 1997).

How living organisms come to use these elements and cycle them from abiotic to biotic, organic to inorganic compound states, determine and are determined by the laws of thermodynamics as well as those mechanisms (such as enzyme flows) developed for overcoming the energy barriers separating products and reactants essential for maintaining the life of the organisms. Falkowski et al. (2008) explain that the production of macromolecules in biotic life requires an input of energy. Life depends on constant biological energy transduction mechanisms that can be simply explained as non-equilibrium redox chemistry reactions within living systems. Put in simpler terms, this is the action of organisms to convert energy from one form to another.

For an example, animals obtain energy by degradation of food components proteins, glucides, and lipids - that provide electrons to the respiratory chain within animal cells. Through a series of oxidization-reduction reactions (redox reactions), electrons are transferred across the cellular cytoplasmatic membranes and the energy thus released by the favorable electron transfer is transduced to the form of a transmembrane difference of electrochemical potential. What this means is that differences in the concentration of ions on opposite sides of a cellular membrane lead to a voltage difference allowing for energy transfer across the cell membrane. The dissipation of energy by the process of signal transduction, that is, the transmission of molecular signals from a cell's exterior to its interior, through the adenosine triphosphate (ATP) synthase thus enables the synthesis of ATP that is critical to intracellular energy transfer (Campbell et al., 2006). ATP is one of the end products of photophosphorylation and cellular respiration and is used by enzymes and structural proteins in many cellular processes, including biosynthetic reactions.

ATP's essential importance is that it transports chemical energy within cells for metabolism. Metabolic processes that use ATP as an energy source convert it back into its precursors. Comprised of the elements carbon, oxygen, nitrogen, hydrogen, and phosphorus, ATP is continuously recycled in organisms because ATP is essentially the product of redox reactions (Gajewski et al., 1986). Quoting,

[Since] all redox reactions are paired, the resulting network created in the metabolic processes is a linked system of elemental cycles, particularly those of carbon, hydrogen, oxygen, nitrogen, phosphorus. A forward reaction in one biogeochemical guild is complemented by a reverse reaction in another biogeochemical guild, illustrating the linked system of elemental cycles at the cellular level that are maintained by thermodynamic reactions and the impact of enzymes.

(Falkowski et al., 2008, p. 2705) 
These reactions are the basis upon which the biogeochemical cycles are established in living systems. The implication of this is that the biogeochemistry of the Earth is intricately connected to life processes, transcending to the basic cellular functions that support all life forms on the planet.

\section{Anthropogenic impacts on ecosystems}

The sum product of biogeochemical processes at the ecosystem scale gives rise to the global cycling of elements that maintains and perpetuates life on Earth. Many believe that this is a delicate albeit adaptable balance that has already been thrown out of salvageable states of flows and cycles by the actions of modern humans and their capitalist development machinery. One way in which this deterioration has happened is by the drawdowns on, and combustion of, the immense deposits of fossilized hydrocarbon compounds that were created over millions of years of biogeochemical activity, changes, reactions, and massive carbon sink especially during the Carboniferous period. These biogeochemical processes contributed to the stable states of atmospheric and environmental conditions which ushered in the Holocene epoch. The Holocene epoch is defined as the last 11,700 years of Earth's history that has been largely influenced by human societal development, population growth, movement, and global migration.

At certain scales, disturbances such as floods, landslides, volcanism, and windblown dust redistribute and mobilize elements in ratios that frequently differ from ecosystem stoichiometry. These imbalances influence biogeochemical interactions on large spatial and temporal scales, and create long-lasting biological and biogeochemical legacies (Hungate et al., 2003). Humans have, however, been making increasingly larger impacts on terrestrial ecosystems during the Holocene. In the quest to adapt the environment to suit human needs or desires, humans have taken actions that have progressively exerted negative forces upon the biogeochemical cycling of elements in significant and disturbing ways.

Some of the leading scientific minds writing about anthropogenic impacts on terrestrial ecosystems and on the biogeochemical cycles include Erle Ellis (2011), Steward Pickett et al. (2011), Vaclav Smil (2011), and William Schlesinger (1997). These researchers and scientific thinkers make their arguments based on historical research, modeling, and on data trends that can be organized along four major arguments.

- Human population density is a key factor in global patterns of anthrome emergence, largely because the human species has evolved to 'superdominate' the biosphere.

As argued by Smil (2011), the global 'anthropomass' (the sum of human biomass) in the first decade of the twenty-first century is greater than the mass of all wild terrestrial mammals. Consequently, human dependence on harvesting the products of photosynthesis for direct consumption, for feeding domestic food animals, for raw materials, and for energy, has increased to levels of substantial global 
impacts. Smil observes that during the past two millennia, human harvests from the environment, changes of land use due to the removal of primary forests, and conversions of grasslands and wetlands to grazing lands and agriculture have reduced the stock of global terrestrial plant mass by as much as $45 \%$. The estimate of the observed losses within the twentieth century alone accounts for as much as $15 \%$, representing an exponential spike in the rate of harvest during a relatively brief period of time on Earth.

Land use models conducted by Ellis (2011) suggest that as of the year 2000, a significant share of the terrestrial biosphere was already so impacted by human action that only an approximate landmass of $25-40 \%$ still existed as wildlands. Ellis (2011) cites Kaplan et al. (2011) and Goldewijk et al. (2010) both of whom conducted studies on global land use change during the past 12,000 years. These two researchers, operating independently, found that 8,000 years ago approximately $80 \%$ of the terrestrial biosphere existed as wildlands and $20 \%$ in seminatural anthromes. Since the Industrial Revolution, wildlands have been decreasing more rapidly with increases in human populations and related land use changes.

- Changes in net primary production (NPP) are a classic indicator of human alteration of ecosystem processes.

The total amount of new plant tissues created by photosynthesis is generally referred to as net primary productivity (NPP). The appropriation of plant biomass by humans through current annual harvests represents shares as high as $40 \%$, indicating that population growth and improved quality of life will continue to result in additional claims on the biosphere (Ellis, 2011; Schlesinger, 1997). Much of the expected upward trends lie in the predictability of human beings to identify, utilize, and manipulate ecosystems in relation to the different opportunities for use that selected ecosystems offer, and of equal importance, the potential economic productivity of the system.

Once coopted for human use, ecosystems often remain within human influence, due largely to the tendency for human systems to create what Ellis (2011) describes as 'novel anthropogenic patterns' in the way that settlements and other infrastructure are interconnected and expanded. The cooption of landmass for the establishment of cities on all of the Earth's continents has continued to be used for such habitation after hundreds of years, growing larger and more intensely inhabited. These environments invariably become jungles of concrete and glass, alienating forest ecosystems and wildlife habitats while turning peri-urban environments into monoculture crop farms and feedlots for domestic livestock. Combined, the appropriation of NPP and the creation of permanence in human systems continue to trend toward significant change being applied to terrestrial ecosystems on a global scale.

- One of the most general and irreversible anthropogenic changes observed across the terrestrial biosphere is 'altered patterns of biodiversity'. 


\section{How global environmental democracy died}

The negative impact on species biodiversity from human actions can be examined from several perspectives. Biodiversity affects the properties of ecosystems, so consequently the benefits that humans obtain from nature are dependent on the contributions of a diverse population of species (Ellis, 2011). Ironically, many of the activities critical for human subsistence has led to the loss of biodiversity, a situation that will likely continue in the future as human populations grow, and demands and drawdowns on nature increases (Díaz et al., 2006). Humans benefit from the diversity of organisms in ways that have contributed to the use of renewable resources. Biodiversity influences human well-being in the provision of access to water; to biomass production by plants, nutrient, and water cycling; soil formation and retention; production of fiber, shelter, clean air, and medicines; and the regulation of human health.

In tropical and subtropical environments, forest ecosystems are being removed and usurped by industrial crops and plantations, and as already noted, supplanting wide swaths of diverse ecologies with crop monocultures. Widely practiced since the beginning of the Industrial Age to provide vital products for human needs, monoculture agricultural plantations generally serve one major function - food production. Unfortunately, this single function often erases the myriad other essential functions previously available in the natural ecosystem replaced by monoculture operations. Díaz et al. (2006) report that in Argentina and Bolivia, the Chaco thorn forest is being felled at a rate considered among the highest in the world and being replaced with soybean cultivation. In Borneo, the species rich Dipterocarp forest is being replaced by oil palm plantations, a production system that is unable to support a minute fraction of the species previously existing in the forest environment. Díaz et al. (2006) make the argument that for all 'practical purposes' the changes observed in the Bornean forest are irreversible. Surveys and population counts conducted by Díaz et al. (2006) have shown that populations of animals and plants have been dramatically reduced by the changing land use patterns, down to such low numbers that many species could be considered functionally extinct.

In a study conducted by the University of Hawai'i at Manoa, researchers Camilo Mora and Peter Sale found that despite an increase in the amount of land being put aside globally as protected terrestrial and marine habitats (currently, individual parcels number in excess of 100,000 and cover 17 million square kilometers of land and 2 million square kilometers of oceans), global biodiversity is observed to be in steep decline (Mora and Sale, 2011). The authors noted that "expected scenarios of human population growth and consumption levels indicate that cumulative human demands will impose an unsustainable toll on Earth's ecological resources and services, accelerating the rate at which biodiversity is being lost" (p. 261).

Basing their projections upon previous research, Mora and Sale (2011) show that employing current scenarios of human consumption and population growth trends, the use of natural resources by humanity will amount to the productivity of up to 27 Earths by 2050. They warn that current and future human needs and requirements from nature will further exacerbate the challenge of implementing effective strategies for protecting conserved areas. Mora and Sale offer suggestions 
indicating that effective biodiversity conservation requires new interventions and approaches that address the underlying causes of biodiversity loss, with a major focus required to be placed on dealing with the growth of human populations and the associated rise in the consumption of resources.

- The evidence supports the hypothesis that the present state of the biosphere is predominantly anthropogenic, with observed changes in the ecological forms and processes unprecedented in the Holocene or earlier, heralding the emergence of the Anthropocene age.

Deriving his thesis from studies of changes to the terrestrial biosphere during several hundred years, Ellis (2011) believes that the terrestrial biosphere is currently anthropogenic and fundamentally distinct from the wild biosphere of the Holocene and before. He reasons that from a philosophical point of view, nature has become so impacted by human hands that it is now truly human nature. All ecosystems are in different states of human interaction, differing in the degree of humanness with no more wild nature to be found. This opinion is shared by Benjamin Halpern et al. (2008) who conducted studies on human impacts on marine ecosystems. Halpern and his research collaborators developed an ecosystem-specific, multi-scale spatial model to synthesize 17 global data sets of anthropogenic drivers of ecological change for 20 marine ecosystems. The analysis drawn from the assessment provides clear indication that human influence has affected almost all marine ecosystems, and a significant portion of approximately $41 \%$ of these habitats were affected by multiple forces acting simultaneously. Marine habitats unaffected by human influence do exist, but are located only at the north and south poles. Judging from the action of people over the last several decades and given that global warming has been opening up frozen polar waters, it is just a matter of time before anthropogenic forces begin to exert pressures on these last remaining marine habitats.

\section{Biosphere perturbations and influences on the biogeochemical cycles}

To develop a holistic understanding of changes and impacts within large systems, mathematical modeling is often used as a practical method of analysis. Physical experiments with the entire biosphere are impossible to conduct, thus, to analyze large-scale changes in the biosphere, mathematical modeling such as that used in studies conducted by Tarko (2003) provides a powerful tool to investigate changes in the biosphere. Using computer-generated models to simulate the dynamics of the atmosphere, the terrestrial and marine ecosystems around the globe, Tarko (2003) and others demonstrated that the quantity of greenhouse gasses $(\mathrm{GHG})$ in the atmosphere continues to increase. The increase in GHG directly affects weather and climate dynamics, causing global warming to accelerate. Correspondingly, ecosystems being disturbed, landscapes transforming, forests being reduced, and soil erosion on a global scale are all occurring 
simultaneously. All these changes have implications for the viability of the biogeochemical cycling of elements through interacting Earth systems that play important roles in the preservation of life by providing the ecological support necessary for maintaining biodiversity.

Biodiversity has always been an integral part of the human experience, and there are many moral reasons to preserve it for its own sake (Díaz et al., 2006). Moving from the mathematical to the philosophical, Tarko (2003) evokes a similar moral sentiment as Diaz. Humans need to revise modern intensities and adapt or rethink technological methods being used to harvest resources from the biosphere. Failure to make these adjustments renders catastrophic changes in the biosphere, so an important problem for humanity in the twenty-first century is to find educational, ecological, technological, and economic conditions acceptable to both mankind and the biosphere that will mitigate current difficulties, and avert the predicted crises already predicted or occurring.

Despite the achievement of what is considered to be epochal leaps in science and technology after the birth of the Industrial Revolution and especially since the start of the Green Revolution of Agriculture, humans still struggle to develop the scientific understanding of the balances required for feeding and powering humanity. The next frontier on Earth is therefore the need for the development and elevation of the science of global equilibrium, where scholars and practitioners will begin to calculate the laws of conservation into the equations of production, harvest, and consumption. By doing this, the science of doing things will begin to mimic the ethics of native peoples discussed in the first two chapters of this book, thereby arriving at the same behavioral outcomes from separate but equal understandings of how the Earth really functions.

\section{The cycling of carbon}

Carbon-based molecules are crucial for life, as without this element in one form or another, life on Earth would not exist. Carbon is the main component of biological compounds, and combined with other elements is also a major component of many minerals. Carbon exists in various forms in the atmosphere such as in combination with oxygen $\left(\right.$ as $\left.\mathrm{CO}_{2}\right)$, and hydrogen $\left(\mathrm{as} \mathrm{CH}_{4}\right)$. It is found in various combinations in the hydrosphere (carbonates and dissolved $\mathrm{CO}_{2}$ ); as various isotopes and hydrocarbon compounds buried in the deep layers of the Earth's lithosphere; and in all organic matter (such as living matter and soil) in the terrestrial biosphere (Falkowski et al., 2000). An estimated sum of 500 gigatons of carbon are stored aboveground in plants and other living organisms, while soil holds approximately 1,500 gigatons of carbon in the form of carbonates, minerals, and soil microorganisms (Lal, 2008).

The global carbon cycle is divided into the major reservoirs of carbon and interconnected by pathways of exchange between the atmosphere, the terrestrial biosphere, the oceans, and other aquatic biomes within the hydrosphere, the Earth's interior, and carbon from the Earth's crust and mantle. The carbon exchanges between reservoirs occur as the result of various chemical, physical, 
geological, and biological processes so that the atmospheric carbon levels of the Holocene epoch would be roughly stable without human influence (Schlesinger and Andrews, 2000).

The uptake of carbon in the terrestrial biosphere is dependent on biotic factors supported by thermodynamic laws that control the movement and fluxes of energy. Autotrophic organisms (such as plants and algae) extract carbon from the air in the form of carbon dioxide through the process of photosynthesis, converting the element into organic carbon compounds like carbohydrates, fats, and proteins. Heterotrophic organisms (such as animals and fungi) receive essential organic carbon by consuming other organisms. Carbon dioxide transfer through biological organisms into the soil carbon pool by the soil-making process of humification, and the resulting formation of secondary carbonates altogether provide numerous ancillary benefits by enhancing ecosystem services (Lal, 2008).

The carbon cycle has slow and fast components, thus carbon leaves the terrestrial biosphere in several ways and on different time scales. The combustion or respiration of organic carbon rapidly releases the element into the atmosphere, but it can be exported at a slower rate into the oceans through rivers, or remain sequestered in soils in the form of inert carbon. Carbon stored in soil can remain there for up to thousands of years before being washed into rivers by erosion or released into the atmosphere through respiration from soil. Schlesinger and Andrews (2000) state that the total global emission of $\mathrm{CO}_{2}$ from soil through respiration and other processes such as decomposition is recognized as one of the largest fluxes in the global carbon cycle.

Global carbon uptake follows a diurnal and seasonal cycle, being strongest in the northern hemisphere where there is more landmass than the southern hemisphere, thus having a greater capacity for northern hemisphere ecosystems to absorb carbon. However, the rate of release of $\mathrm{CO}_{2}$ in the temperate north is significantly less than that of tropical ecologies because the rate of soil respiration and decomposition of organic matter is higher in the tropics due largely to the more conducive warm temperatures and rainfall patterns ( $\mathrm{Lal}, 2008)$. The length of time carbon is sequestered in soil depends strongly on climatic conditions, so that changes in the course of climate have a direct impact on soil carbon releases to the atmosphere.

\section{Disequilibria in the modern carbon cycle}

Any change in the cycle that shifts carbon out of one reservoir puts more carbon in one or more of the other reservoirs, so changes in the flux of $\mathrm{CO}_{2}$ from human activities including the disruption of soils particularly in the highly productive tropical forests, play an enhanced role in the rise of atmospheric $\mathrm{CO}_{2}$ and the potential for accelerated global warming (Andreae et al., 2002). The large accumulations of soil organic matter in temperate forests arose largely because low temperatures restrict soil decomposers. Increased temperature warms up soils, and as a correlation, soil respiration increases with rising temperatures. As the planet warms, regions where low-temperature ranges have limited decomposition should decline, and soils increasingly will become a greater source of $\mathrm{CO}_{2}$ to the 
atmosphere, ending the process of net deposits of carbon laid down on temperate soils during the Holocene epoch.

Earth has evolved to the present by passing through several geological eras, periods, epochs, and ages of time. Modern humans have been borrowing significant amounts of required energy resources from stores laid down during the Carboniferous period ( 354 million to 290 million years ago). During the Carboniferous period, forests filled with huge trees flourished, ferns and other large leafy plants abounded, and aquatic environments were filled with algae. The death and fossilization of these massive quantities of plant life resulted in the stores of coal, oil, and natural gas that have been exploited sharply since the beginning of the Industrial Revolution (Gribbin, 2012).

The combustion, by humans, of these large stores of carbon energy sequestered and stored during a distant geological period indicates that a significant re-release of previously stored carbon is occurring in present times and is a direct result of human action. To borrow from the earlier discussion, just as changes in the carbon cycle shifts carbon out of one reservoir to put more carbon into one or more of the other reservoirs, comparatively, shifting carbon from one geologic time period to another through fossil energy combustion creates disequilibrium to the stable Holocene cycles, giving rise to current anthropogenic changes in the atmosphere, hydrosphere, and causing positive feedback effects on those ecological systems existing in the terrestrial biosphere.

As noted by Schlesinger (1997), the increase in atmospheric carbon dioxide observed in the modern era results from the ability of humans to change the fluxes of this gas to the atmosphere by an amount that is significant relative to the biogeochemical reactions that have buffered the system over long periods of geological time. Thus the reality of the carbon cycle is that since the middle of the $1700 \mathrm{~s}$ and the beginning of the Industrial Revolution, more than 350 gigatons (or 356 billion metric tons) of carbon has moved from stable stores into the atmosphere from the burning of fossil fuels (Climate Consent, 2017). The anthropogenic reality is that this disturbance is setting the Earth back more than 300 million years to the Carboniferous period when that much carbon dioxide last floated around in the atmospheric reservoir.

\section{The cycling of oxygen}

The oxygen and carbon cycles are inextricably linked through the action of photosynthetic organisms that capture sunlight energy in organic compounds to fuel the biosphere, giving rise to the presence of oxygen molecules in the atmosphere. Importantly, the presence of atmospheric oxygen in its allotropic form of ozone protects living organisms in the biosphere from ultraviolet light that damages DNA, and as well, oxygen sets the redox patterns responsible for organic metabolism (Schlesinger, 1997).

Largely because of the reactive nature of oxygen, its cycle is also linked to many other biogeochemical cycles, including that of nitrogen, hydrogen, sulfur, and a wide variety of metals resulting in the production of metal oxides. Similar to that 
Table 5.1 Annual fluxes of atmospheric oxygen (units of $10^{10} \mathrm{~kg} \mathrm{O}_{2}$ per year)

\begin{tabular}{lr}
\hline Photosynthesis (biosphere) & 30,100 \\
Photolysis of $\mathrm{H}_{2} \mathrm{O}$ & 0.03 \\
Photolysis of $\mathrm{N}_{2} \mathrm{O}$ & 1.30 \\
Total Gains & $\approx 30,000$ \\
Losses - Respiration and decay & \\
Aerobic Respiration & 23,000 \\
Microbial Oxidation & 5,100 \\
Combustion of Fossil Fuel (anthropogenic) & 1,200 \\
Photochemical Oxidation & 600 \\
Fixation of $\mathrm{N}_{2}$ by Lightning & 12 \\
Fixation of $\mathrm{N}_{2}$ by Industry (anthropogenic) & 10 \\
Oxidation of Volcanic Gasses & 5 \\
Losses - Weathering & 50 \\
Chemical Weathering & 12 \\
Surface Reaction of $\mathrm{O}_{3}$ & $\approx 30,000$ \\
Total Losses & \\
\hline
\end{tabular}

Source: Walker, 1980

of carbon, the oxygen cycle comprises of large annual fluxes superimposed on smaller, slower fluxes of the geologic cycle that keeps its composition close to a dynamic equilibrium between the production of free oxygen by photosynthesis, and its consumption by way of respiration. Walker (1980) summarizes these fluxes as gains from photosynthesis and photolysis, and losses from respiration, decay, and weathering. These relationships are shown in Table 5.1.

From the data provided in Table 5.1, it is clear that the combustion of fossil fuels represents a significant loss of oxygen. These anthropogenic factors combined with other human-caused actions such as deforestation, species decline, and loss of biodiversity demonstrate the cumulative effect that man-made actions play in the loss of oxygen largely due to the removal of photosynthetic biota from their contributing role in the production of oxygen.

\section{The cycling of hydrogen}

Hydrogen is an essential component of many biogeochemical cycles, including the carbon cycle, nitrogen cycle, and the sulfur cycle. Being a key component of the water molecule, hydrogen is also deeply linked to the water cycle. During photosynthesis plants recombine water and carbon dioxide from the soil and from the atmosphere, respectively, to form the carbohydrates and sugars they store in leaves, fruits, and roots. When the plant is consumed by herbivores, the hydrogen molecules in these compounds are transferred to the animal. When the animal (or plant) dies, the organic matter is stored in soils and the hydrogen molecules are released back into the atmosphere through the process of oxidation (Campbell et al., 2006). 
During anaerobic fermentation such as that occurring in wetland ecosystems, organic substances are processed into carbon dioxide and methane in a collaborative effort involving many different species of microorganisms, various processes, and biochemical reactions. An important process of these biochemical reactions is interspecies hydrogen transfer, a process that is integral to the symbiosis between certain methaneproducing bacteria (methanogens) and non-methanogenic anaerobes. In this anaerobic symbiosis, the non-methanogenic anaerobes degrade organic substances and produce molecular hydrogen $\left(\mathrm{H}_{2}\right)$. This hydrogen is then taken up by methanogens and converted to methane via the process of methanogenesis (Hook et al., 2010).

Anaerobic fermentation also occurs in the gut (reticulo-rumen) of ruminant animals. As a group (particularly cattle), ruminants have been growing in significant numbers as they are raised particularly in feedlots and other intensive production systems in industrialized countries for the production of meat, milk, and by-products. The process by which cattle and other ruminants process their foods mainly grain in industrial production systems - is through the biochemical action of anaerobes within the reticulo-rumen environment. Methanogens are autotrophic archebacteria that use anaerobic respiration for ATP synthesis. When nonmethanogenic anaerobes produce hydrogen, methanogens use this hydrogen for symbiosis, an important process that helps to maintain a lowered hydrogen partial pressure in the reticulo-rumen (Hook et al., 2010). This balance of production and usage of hydrogen in the reticulo-rumen ensures population equilibrium and as a key process demonstrates interspecies hydrogen transfer. Importantly, the methane produced by reduction of carbon dioxide is lost from the reticulo-rumen of ruminants by eructation. The rumen does not have methanotrophic bacteria, thus, the host ruminant cannot utilize methane and it is lost to the atmosphere in the manner described.

As a component of methane, hydrogen is lost to the atmosphere as a waste from ruminants. According to data from the EPA (2007), globally, ruminant livestock produce 80 million metric tons of methane annually, accounting for $28 \%$ of global methane emissions from human-related activities. A single adult cow emits 80-110 kilograms of methane, but with about 100 million cattle in the U.S. and 1.2 billion large ruminants in the world, ruminants are one of the largest sources of methane lost to the atmosphere. In the U.S., cattle emit about 5.5 million metric tons of methane per year into the atmosphere, accounting for $20 \%$ of U.S. methane emissions. Globally, mapping models have indicated that a strong relationship exists between excessive nitrogen and methane gas in the atmosphere and the location of intensive farm animal production areas. Calculations by the EPA show that mostly from pig and dairy cow manure, methane emissions increased by 50\% between 1990 and 2005 (Steinfeld et al., 2006).

Responding to global demand for meat, largely driven by improving economic conditions in the developing world, cattle ranching operations have grown so rapidly that it is now considered to be the greatest cause of deforestation in the Amazon region of South America. Approximately $80 \%$ of deforested areas in Brazil are currently used for pasture. Since the 1970s Brazil's cattle industry has been doubling on itself over incrementally shorter time periods, resulting in Brazil 
quickly owning the largest commercial cattle herd in the world. The result of this has been a steady climb to the top of the beef export market by Brazil, such that since 2003 the country has topped the world's export charts. The success of its cattle industry has since prompted the Brazilian government to implement policies aimed at doubling its share of the world market by 2018 (Steinfeld et al., 2006). This has indeed been the case with the acquisition of $51 \%$ of the U.S.based company National Beef by Brazil's Marfrig in April 2018 for a whopping $\$ 969$ million dollars. The acquisition makes Marfrig the second largest beef processer in the world at a slaughter capacity of 8.3 million animals per year.

The impact that the rapid herd increase is having on the Brazilian rainforest is significant. Greenpeace UK (2009) noted that between 1996 and 2006, an area the size of Portugal was carved out for cattle ranching in the Brazilian rainforest, with the FAO correctly predicting that by 2010 more than 1.2 million hectares of forest in Central America and 18 million hectares of forest in South America would disappear due in part to the clearing of land for cattle grazing. Recognizing these patterns and predictions, and focusing its attention primarily on the U.S. beef and dairy industries, in 2008 the Humane Society of the United States (HSUS) called for critical action from people by offering the following advice;

- Reduce the intake of meat: Every hour in the U.S., more than 1 million land animals are killed for human consumption. If each person cuts back on animal consumption by only 10\%, approximately 1 billion less animals would be slaughtered for consumption each year and the impacts of industrialized animal agriculture would be diminished.

- Refine practices, cultures, and diets: Not all foods are equal when it comes to animal welfare or their environmental footprint. Refining diets by avoiding conventional factory-farm products helps diminish animal suffering and protect the environment.

- Replace meats with vegetarian alternatives: The consequences of choosing vegetarian options are enormous, not only for farm animals, but for public health and environmental integrity.

There is no evidence to suggest that this advice has or will be taken seriously in the U.S. where residents have long become accustomed to a certain standard of living that has afforded the means to consume animal products. It means therefore that there will continue to be radical changes to the landscapes to accommodate intensive livestock production systems to meet growing demands, despite the knowledge that these systems in most instances are comparatively more expensive to sustain.

According to Wilson (2002), this particular pressure on agriculture is intensified in countries such as China, India, and in other major developing economies such as Brazil, by a dilemma shared in varying degrees by every developing country in the world. The dilemma first appears when per capita income rises as a direct consequence of the success of industrialization, and the population consumes more food, particularly western diets. With increasing wealth, people consume more meat and dairy products, thus migrating up the energy pyramid. Because 
fewer calories per kilogram of grain are obtained when first passed through poultry and livestock instead of being eaten directly, per capita grain consumption rises further, in all instances requiring greater investments in the co-opting of land for the production of crops for animal feeds (Wilson, 2002).

Human influences on the hydrogen cycle show a wider degree of interconnection with all other biogeochemical cycles in the patterns of feedbacks through the terrestrial ecosystems than will be possible to thoroughly examine here. However, in examining the correlations between methane release and cattle production, industrial development and increased food consumption, grain demands and expanding farmlands, this minimal analysis sheds light on the level to which humans are having an effect on ecosystems through livestock production, and how this effect in turn creates disturbing impacts on the natural cycling of hydrogen in its many forms.

\section{The cycling of nitrogen}

Nitrogen is one of the essential elements required for life to function, but it differs from carbon, oxygen, and hydrogen in that while plants get these elements from the air, nitrogen is made available to plant life from the soil, and for this main reason, it is considered a 'nutrient'. An essential component of the proteins that build cell material and plant tissue, nitrogen is necessary for the function of essential biochemical agents such as chlorophyll that makes photosynthesis possible. It is also a component of enzymes that help organisms carry out biochemical processes and assimilation of other plant nutrients. In addition, nitrogen is a key component of nucleic acids such as DNA and RNA that are important macromolecules necessary for reproduction and essential to life.

According to Canfield et al. (2010), the biogeochemistry of nitrogen depends almost entirely on reduction-oxidation (redox) reactions that are primarily mediated by certain microorganisms. Nitrogen fixation by lightning or by the action of free-living and symbiotic microbes accounted for all the nitrogen that is presently available to biota, but in the modern Earth, the various forms of biotic nitrogen fixation is greater than abiotic fixation by lightning as the fixed source of nitrogen on land. Nitrogen fixation by groups of microorganisms converts atmospheric nitrogen $\left(\mathrm{N}_{2}\right)$ to one of the forms of fixed nitrogen (nitrites and nitrates) that can be utilized by biotic life, while another group of denitrifying bacteria returns $\mathrm{N}_{2}$ (gas) back to the atmosphere, a reaction that lowers the overall stock of nitrogen available in the terrestrial biosphere (Schlesinger, 1997). The balance between these two processes (nitrification and denitrification) ensures that a steady state concentration of nitrogen is maintained in the atmosphere.

Among the important nutrients essential for healthy plants, nitrogen is one of the most important determinants of plant growth and crop yield - common symptoms of nitrogen deficiency being stunted growth and yellowish leaves. Consequently, plant growth and crop yield increases when nitrogen is added to soil, this despite the presence of nitrogen in soils but in forms that plants cannot access for assimilation. Johnson et al. (2005) explain that modern agriculture has come to rely heavily on the addition of plant nutrients to soils to increase crop productivity, and chemical fertilizers provide nitrogen in forms that plants can use 
immediately or after a brief conversion. The soil application of organic materials such as manure, bio-solids, and compost add some amount of readily available nitrogen, but most of the nutrient applied this way is contained in organic compounds that must decompose before plants can use the available nitrogen.

Schlesinger (1997) remarks that human perturbations of the global nitrogen cycle have been both widespread and dramatic, as largely through the increase in use of fertilizers in the urban ornamental industry (green lawns and urban landscapes) and in crop agriculture there has been a doubling of the rate that nitrogen enters the biogeochemical cycle on land. Figure 5.1 shows both the increase in

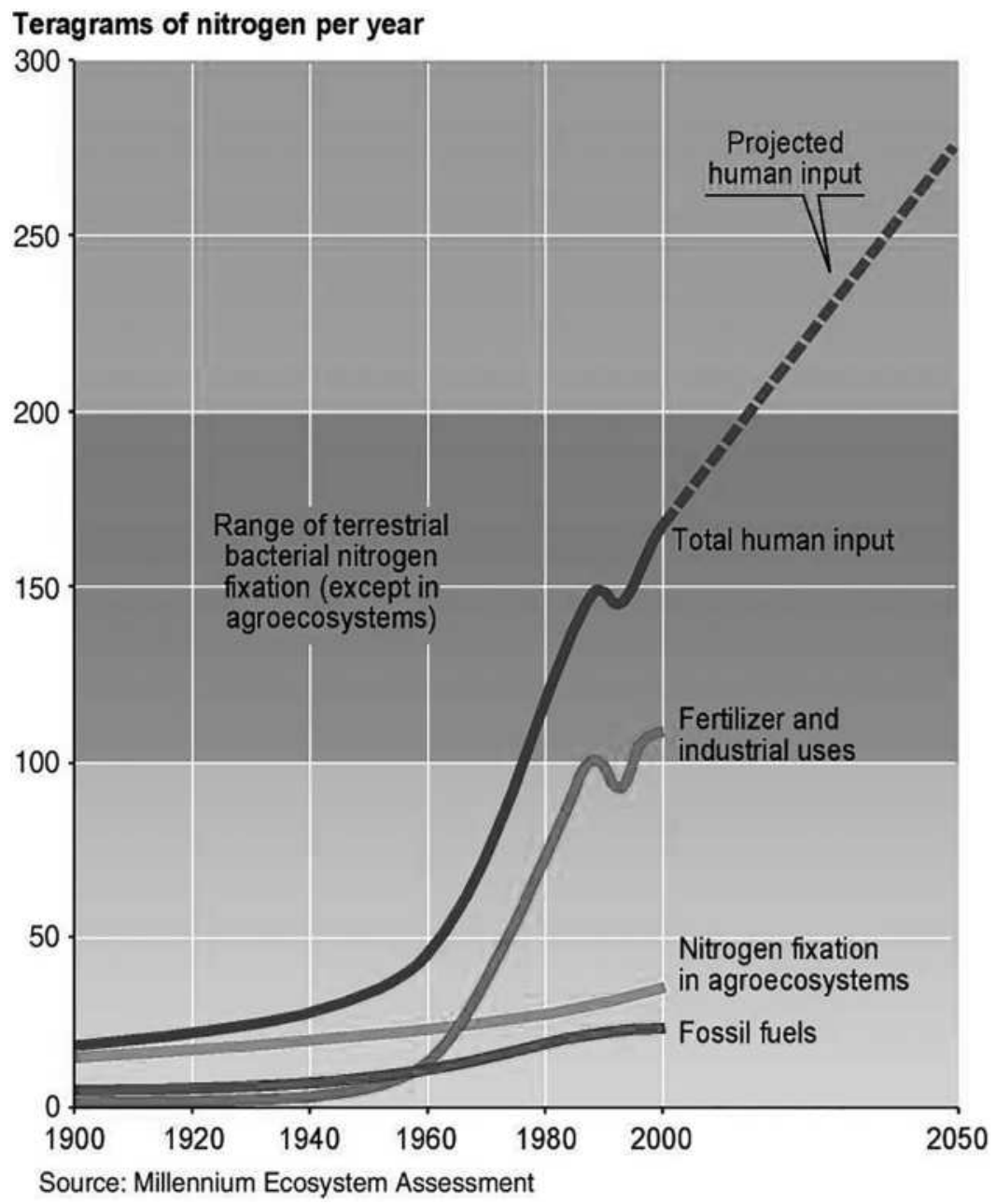

Figure 5.1 Reactive nitrogen on Earth by human activity

Source and permission: Philippe Rekacewicz, Emmanuelle Bournay, UNEP/GRID-Arendal. www. grida.no/resources/6073 
the use of reactive nitrogen since the beginning of the 1900s, and predictions for further use should use-trends remain as usual.

Because it's a plant nutrient, the massive increase in nitrogen runoff into wetlands, rivers, and lakes, and into other aquatic environments from land sources has led to massive blooms of algae, and the effects of this has been the local obliteration of species, this mishap resulting from the eutrophication of terrestrial and aquatic systems, causing global aquatic acidification among other ecological ills (Gruber and Galloway, 2008). It is quite unclear at the moment whether the process of denitrification will respond to this global increase in the availability of nitrogen. With full understanding of the increased availability of cheap foods since the beginning of the Agricultural Green Revolution, the issue of nutrient pollution is one that highlights the ill-fated direction in which anthropogenic nitrogen is driving global systems disturbances.

\section{The cycling of phosphorus}

The original stocks of phosphorus in the global phosphorus cycle came from the weathering of a related group of calcium phosphate minerals known as apatite. The historic quantities of these minerals were deposited with the passage of geologic time as ocean sediments that were later brought to the surface by uplift. Uplifted phosphate minerals were then weathered by physical processes such as rainfall, landslides, and the action of rivers that moves the element back toward the seas and oceans, thereby completing the geochemical cycle of the element (Falkowski and Godfrey, 2008).

Except with specialized and in rare circumstances, phosphorus does not exist in a gaseous form, thus it differs largely from the major biogeochemical elements previously discussed. No biological process (as that occurring in nitrogen fixation) exists that can produce dramatic increases in the amount of phosphorus available to plants in an environment where the element is deficient, so that within the terrestrial environment, according to Jahnke (1992), biota has to rely on the recycling of phosphorus in organic forms.

Most of the fundamental biochemicals that are connected to life processes contain phosphorus linked to organic molecules by phosphate ester bonds. These include impressive biochemical compounds such as the nucleic acids RNA and DNA (Falkowski and Godfrey, 2008). Phosphorus also plays an essential role in chemical energy control and transmission within cells, and of equal importance, provides structure at the cellular level as a component of a cell membrane. In animals, apatite forms structural body parts such as bones and teeth (Jahnke, 1992).

Due to the major role that phosphorus plays in the life processes of living organisms, it is therefore inseparable from the biological processes that occur in the biosphere (Jahnke, 1992). Over millennia, the existence of living organisms controlled the distribution and local cycling of phosphorus, this natural processing of the element only being surpassed during the Industrial Age when the vast mining of phosphate for application as a fertilizer nutrient to food crops and livestock forages began on an industrial scale. 
The most significant economic deposits of phosphate are found in sedimentary rocks of marine origin, which in some instances are harvested to the point of ecological and economic depletion. In a modern account eerily similar to the ecological demise of Easter Island, one of the richest sources of high grade phosphate rock ever found was discovered in 1900 on Nauru Island located in the Pacific Ocean. Changing hands between colonial powers between 1905 and the late 1960s, the phosphate on Nauru was aggressively mined and removed to support fertilizer production, industrial trade, and agricultural industries in Germany, Australia, and Great Britain. By the end of its sixth decade of phosphate mining, the people of Nauru had first observed its resources being shipped abroad, then enjoyed a brief period of high per capita income only to see this prosperity obliterated as ecological depletion led to economic ruin. Today, many of the indigenous plants and animals including economically important species on Nauru Island are extinct or endangered, and much of the island is depleted of plant life and unable to sustain habitation or cropping systems. Due largely to the significant vegetation loss, the micro-climate of Nauru has become hotter and drier, leading to a subsequent drop in the water table (Gowdy McDaniel, 1999).

While the story of Nauru illustrates a localized event that ended in ecological tragedy, the history of Nauru provides a forecast of global tragedies to come when limited materials such as phosphorus are over-harvested at the expense of environmental stability. Essentially, this example provides a metaphor for the harvest of limited resources such as coal, oil, and gas. On its own merit, however, the tragedy of Nauru sends a strong message about the irreplaceability of many of the elements and compounds upon which a burgeoning modern human population depends for daily survival. Phosphorus after all, is a limited resource like oil, and when it goes away there will be no replacement.

\section{The cycling of sulfur}

Sulfur was one of the gasses released by crustal outgassing during the accretion of the primordial Earth, but when Earth's oceans condensed, the atmosphere was cleared of sulfur gasses due to their high rate of solubility in water. According to Klotz et al. (2011), sulfur ranks as the 10th most abundant element in the solar system, and is the sixth most abundant element in Earth's microbial biomass. Based upon its chemical properties, in particular its wide range of stable redox states, the element plays key roles as a carbon carrier and as a structural element. When organisms assimilate sulfur compounds (such as $\mathrm{SO}_{4}$ ), it is reduced and converted into organic sulfur which is an important component of protein. Microbes use sulfur for the conservation and transformation of microbial energy, enabling the transformation of both organic and inorganic sulfur which have profound effects on the properties of the biosphere as a whole.

The ability of microorganisms to assimilate sulfur and transform it from inorganic to organic states makes it available to higher organisms in which it is 
utilized in the production of essential amino acids and vitamins that are consumed by animals when they eat plants. In this manner, microorganisms, plants, and animals play a key role in the cycling of sulfur within the biosphere and between the biosphere and atmosphere by absorbing sulfur in its different forms and releasing it for the next phase of the sulfur cycle. Stimola (2008) offers a simple picture of this process in explaining that when animals eat plants that contain sulfur compounds, the animals use the sulfur to carry out essential biochemical processes that would have been impossible without the prior transformation of sulfur into usable products that animals can assimilate. When that animal dies, bacteria break down the flesh into inorganic sulfides, sulfites, and then sulfates. Plants then absorb these inorganic sulfur compounds that are then transformed to organic compounds that animals once again can consume.

Schlesinger (1997) believes that direct emissions from human industrial activities have become the largest sources of sulfur gasses in the atmosphere. This is evidenced by readings taken from Greenland ice cores that show a sharp increase in the deposition of $\mathrm{SO}_{4}$ since the beginning of the Industrial Revolution. Since sulfur is a component in coal and other fossil fuels, when these are combusted for energy, sulfur gasses are released. The reactive nature of sulfur does not allow it to stay in the atmosphere for long, so it usually returns quickly to the biosphere and hydrosphere through rainfall, and to a lesser extent through the action of wind and other physical processes. Given natural circumstances, biogeochemical forces exert a major influence on the global sulfur cycle, but current human perturbation of the cycle is extreme, roughly doubling the annual mobilization of sulfur from the Earth's crustal zones (Klotz et al., 2011).

\section{The hydrologic cycle}

The elements that combine to form water - hydrogen and oxygen - have been discussed previously, but the major importance of water on the Earth warrants special mention of its cycle as a significant biogeochemical process that moderates, maintains, and accommodates life on the planet. The presence of water in the Earth's biosphere determines how and where biota is able to live. Although water is the most common substance on the surface of the Earth with the oceans covering more than $70 \%$ of the planet, there are ecological areas where the substance is either scarce (Chahine, 1992), or the salt content of available water too high to support biological processes.

A characteristic rarely occurring in other substances, water is found in three states gas (water vapor), liquid (water), and solid (ice). This makes it possible for the Earth to have a climate that is habitable for life forms since water acts as a climate ameliorator through the energy absorbed and released during transformation between the different states. On a global scale, water transfers energy around the planet, moving energy from the equatorial regions toward the poles, the transformation of water between the gas, liquid, and solid phases being vital for this transfer of energy (Davie, 2008). 
Water is also the universal solvent on planet Earth, allowing for the uptake of vital nutrients from the soil and into plants, and for the transfer of nutrients within a plant's structure. The ability of water to dissolve gasses such as oxygen allows animal and plant life to be sustained within bodies of water. For animal life existing within the terrestrial biosphere, their bodies are composed of $60 \%$ water, with the majority of this water within cells carrying dissolved chemicals vital for sustaining life. Davie (2008) notes that the human body can store up energy reserves that allow it to survive without food for several weeks, but survival is not possible for more than days without water.

The storage and movement of water between the biosphere, atmosphere, lithosphere, and the hydrosphere is conceptually defined as the hydrologic cycle. Water can be stored in any one of the following reservoirs - atmosphere, oceans, lakes, rivers, soils, glaciers, snowfields, and groundwater - moving between reservoirs by way of evaporation, condensation, precipitation, deposition, runoff, infiltration, sublimation, transpiration, melting, and groundwater flow. Most of the evaporated water found in the atmosphere is supplied from the oceans, where $91 \%$ is returned by way of precipitation. The remaining water is transported to areas throughout the terrestrial biosphere where climatological factors induce the formation of precipitation. Imbalances between rates of evaporation and precipitation over land and ocean is then corrected by runoff and groundwater flow to the oceans (Pidwirny and Jones, 2006).

The available water supply remains relatively static throughout the entire terrestrial biosphere, making water not just an invaluable natural resource but increasingly a commodity that is competed for between many different industrial sectors. While not often a subject that is discussed in open circles largely due to the controversy which it invites, water and water-use possess many levels of comparative advantage that has economic, ecologic, political, and social implications. Arguing form a purely economic perspective, Wilson (2002) suggests that in an open market, the agricultural use of water is outcompeted by industrial use. To offer an example, a thousand tons of fresh water yields a ton of wheat that is worth approximately $\$ 200$, but the same amount of water in industry yields $\$ 14,000$ of products. While this finding suggests that the economic value of water makes it more suited to industry than to agriculture, it often neglects the evidence that agricultural systems provide benefits for the sustenance of the hydrologic cycle at rates significantly more than that of industrial activities. In the majority of instances, the use of water for agriculture has never been valued, but rather treated as a renewable resource.

Pidwirny and Jones (2006) estimate that water is renewed in rivers once every 16 days on average, in the atmosphere once every eight days, with slower rates of replacement in large lakes, glaciers, ocean bodies, and groundwater taking from hundreds to thousands of years. Because of the accelerated rate of usage by humans of these slower renewed reservoirs, in particular groundwater, this source of water effectively is being made nonrenewable, a factor that will lead to the exploitation of ocean water to satisfy human needs in the future. 


\section{References}

Anderson, G.M. (2005). Thermodynamics of natural systems. New York, NY: Cambridge University Press.

Andreae, M.O., Artaxo, P., Brandao, C., Carswell, F.E., Ciccioli, P., da Costa, A.L., Culf, A.D., et al. (2002). Biogeochemical cycling of carbon, water, energy, trace gasses, and aerosols in Amazonia: The LBA-EUSTACH experiments. Journal of Geophysical Research. (Vol. 107). doi: 10.1029/2001JD000524. Retrieved May 6, 2012 from http:// lba.cptec.inpe.br/publications/LBA_JGR_Special_Issue_Oct_2002/LBA-EUSTACHOverview-Andi_Andreae_JGR\%202002.pdf

Campbell, N.A., Williamson, B., and Heyden, R.J. (2006). Biology: Exploring life. Boston, MA: Pearson Prentice Hall.

Canfield, D.E., Glazer, A.N., and Falkowski, P.G. (2010). The evolution and future of Earth's nitrogen cycle. Science. (Vol. 330, pp. 192-196). doi: 10.1126/science.1186120. Retrieved June 20, 2012 from http://faculty.uml.edu/david_ryan/84.653/Course\%20 Material/Canfield\%20etal\%20Science\%202010\%20N\%20review.pdf

Chahine, M.T. (1992). The hydrological cycle and its influence on climate. Nature. (Vol. 359, pp. 373-380). Retrieved July 4, 2012 from http://davidmlawrence.com/Woods_Hole/ References/Chahine_1992_HydrologicalCycle_Climate.pdf

Climate Consent. (2017). Target concentration for $\mathrm{CO}_{2}$ in the atmosphere. Retrieved from www.climateconsent.org/pages/carbonmaths.html

Davie, T. (2008). Fundamentals of hydrology. Second edition. New York, NY: Routledge.

Díaz, S., Fargione, J., Chapin, F.S., III, and Tilman, D. (2006). Biodiversity loss threatens human well-being. PLoS Biology. (Vol. 4, Issue 8, pp. 1300-1305). doi: 10.1371/journal. pbio.0040277. Retrieved from www.plosbiology.org/article/info\%3Adoi\%2F10.1371\%2 Fjournal.pbio.0040277

Ellis, E.C. (2011). Anthropogenic transformation of the terrestrial biosphere. Philosophical Transactions of the Royal Society A. (Vol. 369, pp. 1010-1035). doi: 1098/rsta.2010.0331. Retrieved June 10, 2012 from http://rsta.royalsocietypublishing.org/content/369/1938/ 1010.full.pdf + html

EPA. (2007). Ruminant livestock. March 21 Retrieved July 19, 2012 from www.epa.gov/rlep/ faq.html

Falkowski, P.G., Fenchel, T., and Delong, E.F. (2008). The microbial engines that drive Earth's biogeochemical cycles. Science. (Vol. 320, May 23, pp. 1034-1039). doi: 10.1126/ science. 1153213

Falkowski, P.G., and Godfrey, L.V. (2008). Electrons, life and the evolution of Earth's oxygen cycle. Philosophical Transactions of the Royal Society. doi: 10.1098/rstb.2008.0054. Retrieved July 4, 2012 from www.ncbi.nlm.nih.gov/pmc/articles/PMC2606772/pdf/ rstb20080054.pdf

Falkowski, P.G., Scholes, R.J., Boyle, E., Canadell, J., Canfield, D., Elser, J., Gruber, N., et al. (2000). The global carbon cycle: A test of our knowledge of Earth as a system. Science. (Vol. 290, pp. 291-296). doi: 10.1126/science.290.5490.291. Retrieved July 26, 2012 from www.esf.edu/efb/mitchell/Class\%20Readings/Sci.290.291.296.pdf

Gajewski, E., Steckler, D., and Goldberg, R. (1986). Thermodynamics of the hydrolysis of adenosine 5'-triphosphate to adenosine 5'-diphosphate. The Journal of Biological Chemistry. (Vol. 261, Issue 27). Retrieved July 20, 2012 from www.jbc.org/content/261/27/ 12733.full.pdf

Goldewijk, K., Beusen, A., van Drecht, G., and de Vos, M. (2010). The HYDE 3.1 spatially explicit database of human induced global land use change over the past 12,000 years. Global Ecology and Biogeography. doi: 10.1111/j.1466-8238.2010.00587.x 
Gowdy, J.M., and McDaniel, C.N. (1999). The physical destruction of Nauru: An example of weak sustainability. Land Economics. (Vol. 75, May, pp. 333-338). Retrieved from http://128.113.2.9/ gowdyj/mypapers/LandEcon1999.pdf

Greenpeace UK. (2009). How cattle ranches are chewing up the Amazon rainforest. January 31. Retrieved from www.greenpeace.org.uk/blog/forests/how-cattle-ranching-chewingamazon-rainforest-20090129

Gribbin, J. (2012). Planet Earth: A beginner's guide. Oxford, England: Oneworld.

Gruber, N., and Galloway, J.N. (2008). An Earth-system perspective of the global nitrogen cycle. Nature. (Vol. 451, January, pp. 293-296). doi: 10.1038/nature06592. Retrieved July 4, 2012 from www.cee.mtu.edu/ nurban/classes/ce5508/2011/Readings/Gruber08_ Nature_globalN.pdf

Halpern, B.S., Walbridge, S., Selkoe, K.A., Kappel1, C.V., Micheli, F., and D’Agrosa, C., et al. (2008). Global map of human impact on marine ecosystems. Science. (Vol. 319, Issue 5865, February 15, pp. 948-952). doi: 10.1126/science.1149345

Hook, S.E., Wright, A.G., and McBride, B.W. (2010). Methanogens: Methane producers of the rumen and mitigation strategies. doi:10.1155/2010/945785. Retrieved July 1, 2012 from www.hindawi.com/journals/arch/2010/945785/

Humane Society of the United States (HSUS). (2008). Animal agriculture and climate change. Author. Retrieved from www.humanesociety.org/assets/pdfs/farm/hsus-factsheet-on-climate-change-and-animal-agriculture.pdf

Hungate, B.A., Naiman, R.J., Apps, M., Cole, J.J., Moldan, B., Satake, K., Stewart, J.W.B., Victoria, R., and Vitousek, P.M. (2003). Interactions of the major biogeochemical cycles: Global change and human impacts. Retrieved May 27, 2012 from www.atmos.ucla. edu/ gruber/publication/pdf_files/gruber_ecol_04_pp.pdf

Jahnke, R.A. (1992). The phosphorus cycle. In Butcher, S.S., Charlson, R.J., Orians, G.H., and Wolfe, G.V. (Eds.). Global biogeochemical cycles (pp. 301-315). New York, NY: Academic Press.

Johnson, C., Albrecht, G., Ketterings, Q., Beckman, J., and Stockin, K. (2005). Nitrogen basics: The nitrogen cycle. Agronomy Fact Sheet Series. Fact Sheet 2. Cornell University Cooperative Extension. College of Agriculture and Life Sciences. Retrieved July 16, 2012 from http://nmsp.cals.cornell.edu/publications/factsheets/factsheet2.pdf

Kaplan, J.O., Krumhardt, K.M., Ellis, E.C., Ruddiman, W.F., Lemmen, C., and Klein Goldewijk, K. (2011). Holocene carbon emissions as a result of anthropogenic land cover change. The Holocene.(Vol.21 Issue 5, August,pp. 775-791). doi:10.1177/0959683610386983

Klotz, M.G., Bryant, D.A., and Hanson, T.E. (2011). The microbial sulfur cycle. Frontiers Research Topics, December. doi: 10.3389/fmicb.2011.00241

Lal, R. (2008). Sequestration of atmospheric CO2 in global carbon pools. Energy and Environmental Science (Vol. 1, pp. 86-100). doi: 10.1039/b809492f

Mora, I.C., and Sale, P.F. (2011). Ongoing global biodiversity loss and the need to move beyond protected areas: A review of the technical and practical shortcomings of protected areas on land and sea. Marine Ecology Progress Series. (Vol. 434, pp. 251-266). doi: 10.3354/meps09214. Retrieved from www.int-res.com/articles/theme/m434p251.pdf

Pickett, S.T.A., Cadenasso, M.L., Grove, J.M., Boone, C.G., Groffman, P.M., Irwin, E., et al. (2011). Urban ecological systems: Scientific foundations and a decade of progress. Journal of Environmental Management. (Vol. 92, pp. 331-362). Retrieved from www.nrs. fs.fed.us/pubs/jrnl/2011/nrs_2011_pickett_001.pdf

Pidwirny, M., and Jones, S. (2006). The hydrologic cycle. In Fundamentals of physical geography. Second edition. Retrieved June 26, 2012 from www.physicalgeography.net/ fundamentals/8b.html 


\section{How global environmental democracy died}

Schlesinger, W.H. (1997). Biogeochemistry: An analysis of global change. San Diego, CA: Academic Press.

Schlesinger, W.H., and Andrews, J.A. (2000). Soil respiration and the global carbon cycle. Biogeochemistry. (Vol. 48, Issue 1, January, pp. 7-20). Retrieved July 1, 2012 from www. sonoma.edu/users/C/Crocker/516-2011/soil\%20respiration.pdf

Smil, V. (2011). Harvesting the biosphere: The human impact. Population and Development Review. (Vol. 37, Issue 4, December, pp. 613-636). doi: 10.1111/j.1728-4457.2011. 00450.x

Steinfeld, H., Gerber, P., Wassenaar, T., Castel, V., Rosales, M., and De Haan, C. (2006). Livestock's long shadow: Environmental issues and options. Rome, Italy: Food and Agriculture Organization of the United Nations. Retrieved from ftp://ftp.fao.org/docrep/ fao/010/a0701e/a0701e00.pdf

Stimola, A. (2008). Understanding the elements of the periodic table: Sulfur. New York, NY: Rosen Publishing Group.

Tarko, A.M. (2003). Analysis of global and regional changes in biogeochemical carbon cycle: A spatially distributed model. International Institute for Applied Systems Analysis. Interim Report, IR-03-041. September. Retrieved August 12, 2012 from www.iiasa. ac.at/Admin/PUB/Documents/IR-03-041.pdf

Walker, J.C.G. (1980). The oxygen cycle in the natural environment and the biogeochemical cycles. Berlin, Federal Republic of Germany: Springer-Verlag.

Wilson, E.O. (2002). The future of life. New York, NY: Vintage Books. 


\section{Addressing the biogeochemical cycles with Transformative Anthropocentrism}

The climatic conditions on the Earth are determined by a number of complex interconnected physical, biological, and chemical processes happening in the atmosphere, the biosphere, and the hydrosphere. Specifically, the radiative properties of the atmosphere that act as a major controlling mechanism for the Earth's climate are established by the biophysical state or conditions on the surface of the planet, and also by the type and amount of trace constituents produced by biophysical processes and directed into the air. Interactions within and between the different components of the Earth system are generally expressed as variable rates of biogeochemical cycling that directly affect and are themselves affected by climate change, and may produce either negative or positive feedbacks upon the climate-regulating system (IPCC, 2007).

It has been well established that atmospheric carbon dioxide levels influence the Earth's temperature (Gribbin, 2012; Schlesinger and Andrews, 2000; Ellis, 2011). Climate models that include the dynamics of the carbon cycle suggest that the overall effect of increasing carbon-climate interactions is a positive feedback, hence future atmospheric carbon dioxide concentrations are predictably higher, and the global climate considerably warmer. Based on this revelatory bit of knowledge, the IPCC (2007) urges that models attempting to perform reliable projections of future climate changes should account explicitly for the feedbacks between climate and the physical, biological, and chemical processes (biogeochemical cycles) that determine the atmospheric concentrations of greenhouse gasses, reactive gasses, and aerosol particles.

Ellis (2011) contends that humans have already altered a significant amount of the Earth's natural systems, creating major anthropogenic changes in the hydrosphere and in the biosphere. Judging from the damage inflicted to the ozone layer decades ago, and with other incidences of human driven pollution of the air around us on every continent, the atmosphere has had its own share of anthropogenic changes. Significant in their impact and reach, these anthropogenic changes have collectively altered the normal chemistry of the atmosphere, and this in turn has inflicted permanently altering damage upon the planet's ecological systems. Ellis's contention is that during the last 300 years, with the expansion of human populations across the globe, and with more recent advances in the use of fossil energy since the beginning of the Industrial Revolution, there has been the "emergence of a suite of novel geologic processes in the Earth system comparable in scale 


\section{How global environmental democracy died}

with those used to justify the major divisions of geologic time" (p. 1011). The conclusion drawn here is that perturbations by humans on the biogeochemical cycling of elements and compounds essential to the stability of the Earth's climate have been significant enough to indicate the emergence of a new geological epoch - the Anthropocene.

In this discourse so far, our examination of the biogeochemical cycling of the major elements of life indicates that living organisms represented by multispecies diversity play an essential role in moderating environmental conditions within and between the interconnected spheres. Humans differ profoundly from all other species on Earth in the ways that people are able to drastically transform ecosystems through their large populations and their ever-increasing need to consume resources even beyond self-sustaining levels. The compelling differences between humans and other animal species stand out in their ability to alter the environment by super-physical means. In so doing they manipulate a wide array of powerful tools in their efforts (fire is a good example), and they apply well-developed social behaviors that confer the ability for social learning and action required for ecosystem engineering (Ellis, 2011). No other species on earth combines these three biome-altering characteristics, applying them on such a global scale.

Throughout the last two centuries, industrial human systems have introduced distinct and novel biospheric processes such as:

- The replacement of biomass fuel, human and animal labor, with the combustion of fossil fuels

- The industrial manufacture of reactive nitrogen to boost agricultural productivity

- Medicines and drugs that have improved the health, longevity, and population of humans, and the health, productivity, and population explosion of poultry, pork, and cattle

- The development and mass manufacture of synthetic organophosphates and other hydrocarbon compounds to control vector diseases and undesirable pest species.

Based on the ability to communicate in effective means across vast distances, humans have developed systems that are connected globally. Ellis (2011) believes that this has accelerated the pace of social change, propelled material exchange and tool refinement, the latter in turn increasing the ability for greater interaction with the biosphere at a rate that has been unprecedented in the evolutionary history of the Earth.

The rates of usage and change in the consumption of natural resources and the generation of wastes which tend to pool in reservoirs not deliberately intended, is consequently not restricted to small areas of concern, but instead are occurring on a growing global scale. The biogeochemical cycles maintained by the life processes of the biosphere provide irreplaceable ecosystems services on a global scale. The vast disturbances occurring within the ecosystems of Earth can therefore only result in corresponding negative disturbances in the cycling of essential 
life-sustaining processes that have shaped the chemical, physical, and biological environment of the current Holocene period. The status and nature of the Holocene is changing, and the change is beginning to get overwhelmingly pervasive.

\section{Defining Transformative Anthropocentrism}

In 2005, the United Nations-mandated 'Millennium Ecosystem Assessment' (MA) was published. The 2,500-page report took four years to compile and was drawn up by 1,300 researchers from 95 nations. Surveying the planet, the authors drew several conclusions or Key Messages that are summarized below:

- Everyone in the world depends on nature and ecosystem services to provide the conditions for a decent, healthy and secure life.

- Humans have made unprecedented changes to ecosystems in recent decades to meet growing demands for food, fresh water, fiber, and energy. These changes have helped to improve the lives of billions, but at the same time, they weakened nature's ability to deliver other key services such as purification of air and water, protection from disasters, and the provision of medicines.

- Among the outstanding problems identified are: the dire state of many of the world's fish stocks; the intense vulnerability of the 2 billion people living in dry regions; water supply constraints; and the growing threat to natural ecosystems from climate change and nutrient pollution.

- Human activities have taken the planet to the edge of a massive wave of species extinctions, further threatening its own well-being.

- The loss of services derived from ecosystems is a significant barrier to the achievement of the Millennium Development Goals to reduce poverty, hunger, and disease.

- The pressures on ecosystems will increase globally in coming decades, unless human attitudes and actions change.

- Measures to conserve natural resources are more likely to succeed if local communities are given ownership of them, share the benefits, and are involved in decisions.

- Today's technology and knowledge can considerably reduce the human impact on ecosystems, but they are unlikely to be deployed fully, however, until ecosystem services cease to be perceived as free and limitless, and their full value (intrinsic and extrinsic) is taken into account.

- Better protection of natural assets will require coordinated efforts across all sections of governments, businesses, and international institutions. The productivity of ecosystems depends on policy choices on investment, trade, subsidy, taxation, and regulation, among others.

(Millennium Ecosystem Assessment, 2005)

The findings of the Millennium Assessment Report make it clear that global ecosystems are in serious trouble. Since the logical assumption has always been that the symptoms expressed by the whole reflect the ailments of its parts, there is 
indication that there has been and will continue to be significant feedbacks on those biogeochemical cycles most at risk for triggering the greatest global imbalances.

The need therefore exists for better modeling of the processes that show the interconnections and correlations between climate change and global ecosystem decline, placing humans at the center of the troubled systems in such a way as to transform past actions into necessary future solutions. There is an explicit need for alarms to be sounded by various and collective means, and through an appropriate balance of scientific modeling, social messaging, and moral persuasions, so that the message for sociopolitical, scientific, and moral change may reach those best placed to apply incentives that evoke positive response.

One way these processes can be coalesced is through a novel reorientation of mindsets that will be referred to as Transformative Anthropocentrism. Transformative Anthropocentrism may be defined as the deliberate reaction to the violations of nature over time by human beings, with a concerted effort to re-engaging anew through collective action that brings people together in a shared effort, providing broad incentives to human actors whenever and wherever the environment benefits from their collective positive actions.

Owing to their innate desire for social development and upward mobility through economic and technological acquisition, in the western anthropocentric setting, humans have generally placed themselves at the center of existence in nature. In Transformative Anthropocentric thinking, humans could well continue thinking of themselves as being at the center of nature, but their thinking would seek to embrace a reordered reality that fully embraces the surrounding systems as inalienable components of human existence and development. Consequently, the demise of any part affects the whole, leading inevitably to destruction of human society. With such a transformed anthropocentric worldview, human beings would begin to make decisions that preserve the integrity of local systems through the promotion of behaviors that respect other species and peoples, all the while increasing their understanding of the importance of the biogeochemical cycles. This transformation in both thought and action establishes a new paradigm of inclusiveness that paradoxically saves humanity from its own fatalistic behaviors.

\section{References}

Ellis, E.C. (2011). Anthropogenic transformation of the terrestrial biosphere. Philosophical Transactions of the Royal Society A. (Vol. 369, pp. 1010-1035). doi: 1098/rsta.2010.0331. Retrieved June 10, 2012 from http://rsta.royalsocietypublishing.org/content/ 369/1938/1010.full.pdf+html

Gribbin, J. (2012). Planet Earth: A beginner's guide. Oxford, England: Oneworld.

IPCC. (2007). Fourth assessment report: Climate change 2007. Working Group I: The Physical Science Basis. Author. Retrieved June 3, 2012 from www.ipcc.ch/publications_and_ data/ar4/wg1/en/ch7s7-1.html

Millennium Ecosystem Assessment (MA). (2005). Living beyond our means: Natural assets and human well-being. Author. Retrieved from www.grida.no/resources/6073

Schlesinger, W.H., and Andrews, J.A. (2000). Soil respiration and the global carbon cycle. Biogeochemistry. (Vol. 48, Issue 1, January, pp. 7-20). Retrieved July 1, 2012 from www. sonoma.edu/users/C/Crocker/516-2011/soil\%20respiration.pdf 


\section{Part II}

\section{Applying practical solutions Reconnecting Earth and sky}

\section{Introduction}

There has been an exponential increase in the human population on earth from around 700 million to 6 billion people from the beginning of the industrial revolution to the start of the twenty-first century. This phenomenal accommodation of human expansion came about as a result of rapid advancements in agriculture, energy, manufacture, health, and longevity. In the area of agriculture, crop production has increased exponentially alongside scientific developments in crop varieties that have driven productivity levels upwards since the Green Revolution that began in the 1940s. An accompanying increase in demand for livestock products such as meat and milk stimulated a commensurately sharp rise in the numbers of livestock, and because success breeds (pun intended) more success, we have observed a further increase in human population to approximately 7 billion by the start of the new millennium.

The technological and scientific advancements in energy, food, and medicine, among other broad contributions of both the Industrial and Green Revolutions have however had consequential effects on the global ecology. For example, globally, around 3 billion tons of pesticides are used in agricultural crop protection, much of which have had non-target impacts especially given that less than $1 \%$ of insects are actually pests and the other $99 \%$ are beneficial. A report on agricultural fertilizer use from the EPA shows that between the years 1960 and 2007, the use of synthetic nitrogen fertilizer rose to a peak of $82.5 \mathrm{lbs} / \mathrm{acre} / \mathrm{yr}$ and phosphate and potash use measured between 25 and 36 lbs/acre/yr, respectively. This should be considered against the background that $11 \%$ (1.5 billion hectares or 3.7 billion acres) of the globe's total landmass is used for agriculture production, meaning that in the case of nitrogen for example, 305 billion lbs/acre/yr are applied and with a $20 \%$ loss through leaching, Much of the observed global aquatic eutrophication occurs directly as a result of industrial agriculture.

The explosion in urban migration and urban expansion were also shepherded in as the result of Industrial development. Access to jobs, education, medical care, and transportation have all been accommodated by developments in the energy sector and the relative ease with which urban infrastructural frameworks support the growth explosion of modern human societies. Beginning with the Industrial 


\section{Applying practical solutions}

Revolution, modern humans have increasingly harvested life-sustaining raw materials from their tangible stores on and within the earth in order to manufacture products that the world had never seen before. Many of these products end up with lengthy half-lives or degradability time spans of 10-1000 years, and with exponential usage and unwise disposal, the wastes pile up considerably. All of these manufactured luxuries have created need dependencies which are hard to break, but every modern human luxury comes at a price. The sum effect of their ready availability - from fossil fuel combustion to plastics, to methane and carbon dioxide emissions - has been global ecological imbalances in localized terrestrial environments, in wider regional ecosystems, and in the global atmospheric domain.

Earth's biogeochemical cycles have thus become indelibly broken by the mechanical successes of the Industrial Revolution and the scientific and technological progress that advanced the Green Revolution. If the Laws of Conservation are therefore still true, a strict adherence to remedial fixes will have to be implemented in order to redistribute matter lost from the biosphere and which is creating biogeochemical disequilibria in hydrospheric and atmospheric domains. Having entered the Anthropocene age by the cumulative errors of the Industrial age, the next century of human existence should necessarily become an age where human societies reengage with the earth through the application of higher moral standards of science, technology, and sustainable development. The chapters that follow showcase new ideas in low-carbon agriculture, in ecological restoration through biochar approaches, and in ethical reorientation, that offer solutions to the current global biogeochemical demise facing the world. 


\section{Feeding the future Farming in a post-carbon economy}

\section{The emergence and impact of modern agriculture}

Being strictly an invention by mankind, the practice of agriculture that emerged as a human occupation more than 10,000 years ago is not a natural process. Since the emergence of humans 250,000 years ago, much of their social, cultural, and communal activities centered around the habit of hunting and gathering for food and fiber, activities that resulted in a continuously migrant way of life for almost the entire quarter of a million years (Hamilton, 2009). Given the time-frame in which the tending of crops and animals began, compared to the entire existence of humanity on Earth, agriculture is a relatively recent invention, albeit an invention that has played a pivotal role in shaping the emergence of modern civilizations. Though often seen as a one-step transition from hunter-gatherer societies to sedentary farming communities, the agricultural revolution that occurred was much more complex, exhibiting varied patterns of animal and plant domestication in different parts of the world.

Humans therefore modernized in different ways, becoming dependent on, and acculturated to, different types of foods for basic survival or for value-added products such as wine from grapes (Smith, 1998). Systems of irrigation and land preparation differed around the world depending on proximity to rivers or other freshwater systems, and whether people farmed on flat land or hillsides. For example, the Egyptians used a type of water management technique known as basin irrigation to fully utilize the waters of the Nile River. Basin irrigation involved the development of a crisscross network of earthen walls formed in a field of crops that would be flooded by the river. When the fields were flooded, water would be trapped in the basins formed by the walls, the grid allowing water to be held longer than it would have naturally stayed, allowing the earth to become fully saturated for later planting. Once the soil in the flooded basin was fully watered, the floodwater would be drained to another basin that was in need of irrigation water (Postel, 1999). In the case of the pre-European Mayan civilization in Mexico, Guatemala and Belize, agriculture was not a uniform system of slash-and-burn with maize as the chief staple, but rather a range of adaptive systems suited to the varying site and ecological conditions, and involving techniques such as terracing and irrigation (Harrison and Turner II, 1978). 
In examining the record left by ancient civilizations around the world, archaeologists have now come to recognize that agriculture did not just emerge in one or two places, but was independently invented several times during the 10,000 years of human/agriculture co-evolution. The practice of agriculture has also not remained static. New plant species and varieties have been continually added to the human diet, with plants such as broccoli thought to be only 500 years old. New World crops such as maize, peanut, squash, tomato, and potato became staple foods or ascended to prominence in nearly every part of the world since their 'discovery' and transfer to Europe after Columbus's contact with the Americas in 1492 (Diamond, 1999).

While the archaeological evidence shows that innovations in plant breeding occurred in antiquity, modern agricultural practices benefited from the work of pioneer researchers including the Austrian monk Gregor Mendel. His longneglected research published in Proceedings of the Natural History Society of Brünn in 1865 (Fedoroff, 2010) demonstrated that plant traits were inherited and not acquired from the environment. Mendel's experiments on pea plants laid the foundations of plant hybridization, his experiments showing that crossing two plants with different characteristics could create a plant with potentially improved traits (Hamilton, 2009). The foundation laid by Mendel's work led to the discovery of hybrid vigor in 1908 by George Harrison Shull who, while working at the Carnegie Institution of Washington's Station for Experimental Evolution, developed a demonstration of Mendel's rules of inheritance and discovered the trait in corn plants (Fedoroff, 2010). Scientific discoveries such as these, among others which focused on synthetic fertilizers and insecticides, led to improved crop varieties, their eventual adoption into agricultural practices contributing to the launching of the Green Revolution in the 1940s.

Particularly in developed countries that receive intense private research funding, the application of improved genetics in agricultural science enabled yield increases in many crop varieties. In the last 50 years, significant yield increases occurred in crops such as corn, wheat, and soy, but productivity gains have been uneven across crops and regions of the world, as yields are languishing in cassava and other staple crops in the developing world where little or no research funding is available (Hamilton, 2009). The adoption of agricultural biotechnology has allowed plant breeders to introduce specific genes into crop cultivars from the same or different species, the specific outcomes being increased plant resistance to diseases and pests; reducing needs for pesticide applications; and the maintenance of production levels in poorer soils, or improvement in crop yields on the same unit area of production (FAO, 2004).

Matson et al. (1997) report that between the years 1700 and 1980, cultivated land areas across the world increased $466 \%$. Crop yields also increased dramatically, particularly because of selectively bred high-yielding varieties, fertilizers, pesticides, irrigation, and the invention of farm machinery. Much of the early years of the twentieth century experienced a worldwide demand for ammonia for use in fertilizers, most of this satisfied on a large-scale from deposits of guano in Chile. This source of fertilizer was recognized as a rapidly depleting resource when 
compared to worldwide demand, prompting much research into how ammonia could be produced from atmospheric nitrogen. In 1909, German scientist Fritz Haber developed a process to fix atmospheric nitrogen in his lab. The chemist Carl Bosch later expanded Haber's process to a factory scale and this process of fixing nitrogen became known as the Haber-Bosch process. Industrial fixation of nitrogen combines atmospheric nitrogen and hydrogen into ammonia, the basis for all synthetic nitrogen fertilizers. With abundant natural gas being the major source of the hydrogen and energy used in the process (Rich, 2006), the HaberBosch method for synthesizing ammonium nitrate made the traditional practice of recycling nutrients with crop rotation and animal manure less necessary, thus revolutionizing modern production agronomy (Thomas, 2008). Improvements in machinery since the beginning of the Industrial Revolution, and scientific and technological advancements leading to the Green Revolution, have sharply increased yields from cultivation and livestock breeding (Fedoroff, 2010).

During World War II, Germany and its allies while working on the development of organophosphates as nerve gasses discovered the insecticidal properties of these chemicals. After the war, development of other chlorinated hydrocarbons and organophosphates as pesticides ensued, albeit resulting in unintended consequences well beyond the boundaries of farm fields (Frazier, 1997). The necessities for agriculture's growth and expansion which include large-scale land appropriation and intensive production systems have resulted in displaced forests and grasslands, in greenhouse gas emissions from the overuse of fertilizers, in impacts emanating from diesel-fueled farm machinery, in soil degradation, and in dangerous algae blooms from excess nutrient runoff into surface water. The cumulative effects of these have been widespread ecological damage with associated human health impacts (EPA, 2012) as well as massive negative effects on global biodiversity.

The 1962 publication of Rachel Carson's 'Silent Spring' brought out a strong indictment against pesticides, DDT in particular, highlighting the negative impact of chemical bioaccumulation that the commonly used pesticide was having on birds (Carson, 1962). Linda Lear, in the introduction she wrote in the 2002 edition of 'Silent Spring', noted that when Rachel Carson died merely 18 months after the book's publication she had "set in motion a course of events that would result in a ban on the domestic production of DDT and the creation of a grassroots movement demanding protection of the environment through state and federal regulation" (Carson, 1962, p. x). Carson's work in the early 1960s was, however, the culmination of similar kinds of activism by several influential thinkers and environmentalists such as John Muir who was one of the founders of the Sierra Club (Fox, 1981). The fervor generated by Carson's book may have been the proverbial straw that broke the camel's back. When a follow-up study done by the National Institutes of Health found DDT or its by-products in all of the human tissues they examined, the pesticide along with many other organochlorine compounds was banned for use in the U.S. in the early 1970s (Deinlein, 1997). The sum result of these related environmental studies, research, and advocacy was renewed interest in a growing environmental movement which had begun with 
the efforts of persons including Aldo Leopold - a central figure in the history of conservation and environmental thought in the early 1900s (Meine, 2010).

In general, the growth in social and environmental concerns since the 1970s has heightened the need for alternative agricultural systems over the last four decades. Being one such alternative, organic farming substitutes cultural and biological inputs for synthetically made fertilizers and chemicals for crop nutrition and pest management (Zinati, 2002). While the modern organic movement is varied with different groups championing a wide array of organic approaches, there is a general challenge amongst them to decrease the use of synthetic fertilizers and pesticides, end the overuse of irrigation water, and reduce the agricultural industry's reliance on fossil fuels and other production inputs that contribute to negative impacts on the environment (FAO, 2004).

The organic movement identifies solutions in the precedence set by ancient cultures. The ancient Sumerians used sulfur compounds to kill insects, the Egyptians and Chinese used herbs and oils to control insect pests, and phenology practiced by the Chinese led to the timing of plantings to avoid pest attacks. The Chinese also used ants on citrus crops to reduce pest infestations, and soap as a pesticide against caterpillars. In the 1600s, tobacco infusions were used for insect pest control to great effect (Frazier, 1997), but this is not available as an acceptable replacement in the U.S. as current U.S. organic standards prohibit tobacco dust (nicotine sulfate) from being used on organically grown foods (NOP, 2012). The largest criticism, however, is that with the world population expected to reach 9 billion people by the year 2050 (PRB, 2012), there is an enormous challenge to continue to feed people through organic methods that, although making more efficient use of land and labor, may result in lower food yields.

Alternative methods of pest and disease control provide some opportunities for the change being sought by the organic food movement, but if transitions toward production systems exhibiting decreased dependence on modern farming practices are to be realized, there is a fundamental need to adopt a parallel science and technology trajectory similar to the advances which triggered the start of the Green Revolution. In a world faced with increasing populations and the simultaneous decrease in the availability of fossil fuel energy, alternative agricultural systems which seek to find a new paradigm based on low-carbon energy inputs must also as a matter of urgency embrace new sets of human ingenuity, innovation, global credibility, and acceptance if real solutions are to be found and universally adopted.

\section{Major factors reinforcing industrial farming practices}

Pre-Industrial Revolution agricultural systems relied primarily on energy input from the sun. Through the process of photosynthesis, plants supplied food for human needs as well as food for livestock. In turn, livestock provided manure fertilizer and the muscle power required for carrying out the various tasks of farming. With the emergence of industrialization and the consolidation of agriculture into fewer farms but larger economies of scale, 
food production tripled in the last century (Heinberg and Bomford, 2009) as agriculture became increasingly dependent on energy derived from fossil fuel sources (NNEC, 2012).

The enormous growth in food production was enabled by the development of chemical pesticides, herbicides, and fertilizers that accommodated the high performance of new hybrid crop varieties. The hydrogen and energy that is used in the production of nitrogen fertilizers comes from natural gas, and fossil fuels are the main sources from which most of the pesticides and herbicides are derived (Heinberg and Bomford, 2009). Fossil energy also enabled the application of irrigation in arid regions of the world where current scales of production would have previously been near impossible. The development of gas and oil-powered farm machinery has increased the capacity of farmers to clear land, till and plow, sow acres of seed, irrigate, broadcast herbicides, pesticides, and fertilizers. These modern advances have made the requirement for human and animal labor highly redundant in industrialized economies.

Heinberg and Bomford (2009) explain that the application of fossil fuels to the food system has supported the growth of human populations on earth from fewer than 2 billion at the turn of the twentieth century to nearly 7 billion at the beginning of the new millennium. Notwithstanding the ecological damage and greenhouse gas emissions associated with modern agriculture, agricultural technology has been largely responsible for the increased productivity observed from the industrial revolution onwards. According to Goklany (2001), had agricultural production been frozen at 1961 levels just before the publication of Rachel Carson's 'Silent Spring', producing as much food as being produced in 2018 would have required more than a doubling of land devoted to agriculture. Assuming that productivity in the added acreage would be as high as in areas already being farmed, the required agricultural land areas would have necessitated an increase from 12.2 billion acres to 26.3 billion acres, or an increase from $38 \%$ to $82 \%$ of global land area. The great paradox here is that while the marriage of agriculture to the fossil fuel industry has supported the growth of global human populations in part due to increased access to relatively cheap foods, it has done so with considerable efficiency and with decreased need for new agricultural land areas relative to modern population growth and demand, but sadly, with significant production and industrial harm.

Fossil fuels have accommodated the shipment of enormous amounts of food items worldwide, often from places of abundance to sites of scarcity, an arrangement that has reduced the reliance on local food production and enabled large cities to be built in extreme desert environments (Heinberg and Bomford, 2009). Supplying food items to areas of scarcity is not simply a matter of transportation, but also includes a number of inputs from the fossil fuel industry such as processing required for extending the quality of the items, and the plastics for packaging and bottling that have become an essential part of the modern food industry. For example, the processing and packaging of foods require inputs of energy that currently constitutes more than $75 \%$ of the price paid by the consumer for the food item (Gunther, 2000). 
As agriculture shifted from dependence on solar energy to a new dependence on fossil fuel energy and its related petroleum-based products, agricultural extensionists and other educators taught farmers to specialize and intensify their production methods. Lessons learned from a century of enormous success in food production and from significant advances in the agricultural sciences ensured that the modern educational system reinforces the academic structures in which agricultural scientists, producers, and farmers continue to be trained. Predictability of consistently high outcomes has therefore helped to perpetuate the modern educational paradigm, ensuring a continuation of the existing model.

With ensuing environmental problems such as those highlighted through Carson's work, educational methods and messages responded to scientific enlightenment and changed, with farmers receiving advice on integrated pest management, waste management, and animal husbandry skills (Lijmbach, 2002). In addition, regulatory agencies began to intervene, applying laws and rules that were meant to reduce impacts on non-target species. If change has occurred in the past, then certainly there is precedence for the future. As even more novel problems emerge in the twenty-first century, a thorough examination of status quo ecological challenges must be conducted with a view to shifting the educational paradigm toward one that reconditions scientists, extensionists, educators, and farmers toward a revolutionary approach to agricultural practice that considers ecological balance alongside crop productivity goals. This of course will require chipping away at both the structures and processes of modern agriculture.

\section{The post-modern agricultural network superstructure}

Modern agriculture has created an intricate network of connections ranging from researchers working on the development of pesticides, herbicides, and fertilizers, to the training of specialized mechanics needed to keep farm machinery operable. During the twentieth century, this post-modern network grew to include agricultural economists, food processors, food distributors, and a complex linkage of wholesale and retail distributors all playing important roles in some aspect of the food system before the commodity is finally delivered to the consumer. In order to create the farming efficiencies noted earlier, post-modern agriculture applied a capital-intensive strategy to which many farmers found difficult to adhere (Lijmbach, 2002). This resulted in fewer farmers surviving as modern practicing farmers, with the majority choosing to give up their farms and move away from the rural landscape as increasingly larger monocultural corporate structures supplanted and overtook traditional farming systems.

The net effect of these modern networks connecting the fossil fuel industry to the farm on the one hand, and those connecting the farm to the consumer on the other hand, is the creation of conditions where modern agriculture has emerged as a new superstructure powered by fossil energy. Increasing the complexity even further, modern agriculture now derives material resources from nature at irreplaceable rates; such is the case with the nutrient phosphorus. The inability to replace resources is one issue however. On the other end of the spectrum, the 
manufacture of petrochemicals and other materials such as plastics with low levels of recyclability creates huge amounts of wastes which end up in delicate parts of the environment. The modern farm is now an agricultural superstructure as far removed from the consumer as it is increasingly connected to and dependent upon machinery, chemicals, exorbitant amounts of water, and the complex distribution systems designed for taking products to markets.

Figure 7.1 illustrates this relationship between the modern farm - currently located somewhere between the sources from which it derives energy in the myriad of required agricultural inputs - and the distanced consumer upon which it ultimately depend for economic survival.

An important point illustrated in Figure 7.1 is that the post-modern farm does not consider the final consumer its true customer, rather, the products of the farm are directly targeted to the packaging and distribution agribusinesses networks that replace the farmer and the traditional farm gate, thereby creating an almost artificial association with the actual consumers of the products. The farmer to consumer divide explains the reason that it has become much easier for modern agribusinesses to forget who actually eats farm produce, and by natural consequence, harder for these non-human superstructures to hear the judgment calls of ethical consumers.

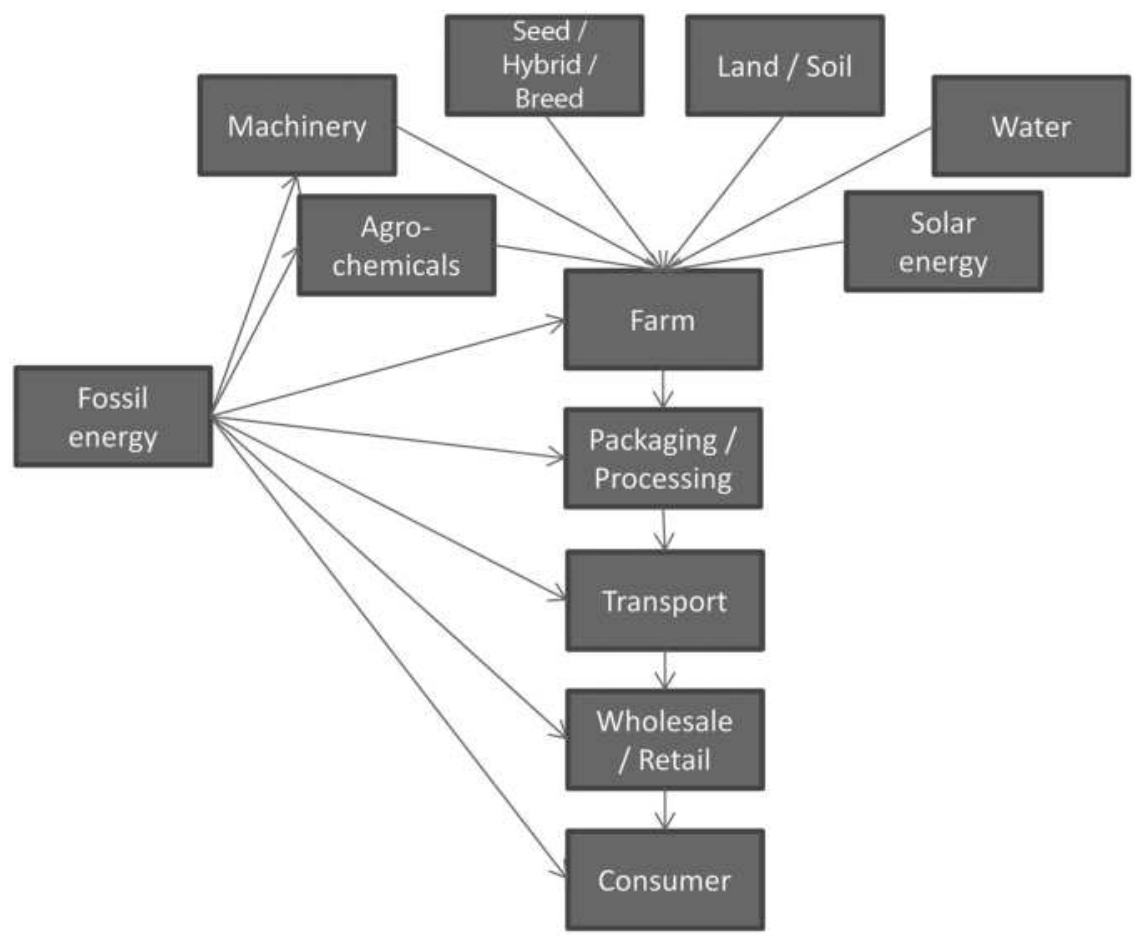

Figure 7.1 The modern farming superstructure: energy and economic networks 


\section{Applying practical solutions}

\section{Shifting to a low-carbon production model}

The giant agricultural superstructure as it exists today requires large amounts of fossil energy inputs and the production of tons of petroleum based products to remain commercially and structurally viable. The result of this has been a commensurately large amount of carbon dioxide emissions directly from petroleum use, and further emissions of nitrous oxide $\left(\mathrm{N}_{2} \mathrm{O}\right)$ and methane gasses from the land preparation exercises that go into the production of food, fiber, and forestderived products.

There is confirmation through research showing that conservation agricultural systems are among several available options for increasing the sequestration of carbon in soil, with agricultural croplands representing one of the most productive sources of sequestration (Graff-Zivin and Lipper, 2007). Soils contain more than twice as much carbon as the atmosphere, so increasing the amount of carbon in soils potentially reduces the amount of the element in the atmosphere through carbon dioxide emissions (FAO, 2004). With the release of carbon dioxide from industrial agricultural activities already relatively high, modern agricultural practices also account for the overwhelming share of nitrous oxide emissions with $84 \%$ of global nitrous oxide emissions coming from agricultural sources (The Stern Review, 2006). The significance of this is that nitrous oxide is 298 times more potent than carbon dioxide, making its release a very important issue confronted by the agriculture industry. The burden is placed squarely on the sector to implement changes and practices that will lower the release of nitrous oxide from agricultural soils.

Of equal significance is the release of methane from livestock activity. Responding to global demand for meat, largely driven by improving economic conditions in the developing world, cattle ranching operations have grown so rapidly that it is now considered to be the greatest cause of deforestation in the Amazon region of South America. Approximately 60\% of deforested areas in Brazil are currently used for pasture (Butler, 2012). Since the 1970s the Brazilian cattle industry has been doubling on itself in incrementally shorter time periods, resulting in Brazil quickly owning the largest commercial beef cattle herd in the world. The result has been a steady climb to the top of the beef export market by Brazil, so that since 2003 the country has topped the world's beef export charts. The success of its cattle industry has since prompted the Brazilian government to implement policies aimed at doubling its share of the world market by 2018 (Steinfeld et al., 2006).

According to data from the U.S. EPA (2007), globally, ruminant livestock produce 80 million metric tons of methane annually, accounting for $28 \%$ of global methane emissions from human-related activities. A single adult cow emits 80-110 kilograms of methane, but with about 100 million cattle in the U.S. and 1.2 billion large ruminants in the world, ruminants are one of the largest sources of methane lost to the atmosphere. In the U.S., cattle emit about 5.5 million metric tons of methane per year into the atmosphere, accounting for $20 \%$ of U.S. methane emissions (EPA, 2007). Globally, mapping models have indicated that 
a strong relationship exists between excessive nitrogen and methane gas in the atmosphere and the location of intensive farm animal production areas. Mostly from pig and dairy cow manure, methane emissions increased by $50 \%$ between 1990 and 2005 as determined by the U.S. EPA (Steinfeld et al., 2006).

In summarizing those structures contributing to the maintenance of modern industrial farming practices which reinforce the emission trends, the following factors must be considered important.

- Fossil fuel energy use

- Modern agricultural education and support systems

- Research and development perpetuating modern production practices and models

- Agricultural production systems modeled on the success of the Green Revolution

- Industrial fertilizers, pesticides, and herbicides

- Modern farm machinery suited to all phases of production and harvesting

- Processing, packaging, and transportation systems

- Social acceptance of relatively cheap food.

If the case is to be made for transition toward alternative systems of agriculture that are carbon-negative by the amount of potential of fossil fuels displaced, then these eight factors must be considered important parameters on which to focus change. A better understanding of the impacts of these parameters in the modern world should therefore help to generate serious discussions around the topic of changing the most negative structural norms of modern agriculture. The adoption of a worldview that proposes the diminution of the energy and economic super networks surrounding agriculture would be hard to fully realize unless it forecasts an economic output that is meaningful to corporate investors. Tackling the specific issues generated by these eight factors goes well beyond the scope of this chapter, but the proceeding discussion will examine the case for change on conventional farms, considering those aspects of the modern production system that can be manipulated by the adaptive farmer in order to:

- Decrease or eliminate dependence on fossil energy

- Increase or maintain crop productivity with little or no hydrocarbon/organophosphate herbicide or pesticide usage

- Significantly reduce the consumption of irrigation water

- Notwithstanding the notion of comparative advantage in crop production, work to reduce transportation and long-distance food distribution where it has become unnecessary to do so.

\section{Changing to an energy-sustainable agricultural system}

Steiner (2010) cites data from the research work of Gardner and Pimentel both published in 2009 which reveal that on an annual basis, the U.S. population alone consumes three times more fossil energy than the total solar energy captured 
by all harvested crops, forests, and grasses grown in the U.S. When the current rate of global population increase is considered alongside the decline in the continued availability of fossil fuels on which modern agricultural networks are dependent, there is little doubt that the existing relationship between agriculture and fossil energy must be dramatically altered. The Network for New Energy Choices (NNEC) suggests that among the ways to address this predicament is to improve the energy efficiency of food production and distribution by shifting from energy-intensive industrial agricultural techniques to less intensive methods. Examples of less energy-intensive agricultural techniques include pastureraised livestock, drip-irrigation, non-synthetic fertilizers such as those derived from plant sources, and no-till or conservation tillage crop management systems.

Conventional farms rely on farm machinery for brush cutting, weed elimination, irrigation, planting, and crop harvesting. Switching to the use of more efficient farm machinery and equipment would reduce the carbon footprint of the farm, but more dramatically, switching from fossil fuels to biofuels - especially biofuels produced on the farm - provides the means to becoming more energy independent. Establishing new and unique marketing techniques and designs aimed at reducing food processing and packaging, promoting decentralization of food production and improving the efficiency of food transportation are also achievable goals which the farmer can set as alternate means of reducing reliance on fossil energy (NNEC, 2012).

One of the ways that the constant and cheap supply of fossil fuels has changed the relationship between the farmer and the farm is the abandonment of recycling as a sustainable agricultural technique. Crop residues and biomass from various parts of the farm provide a constant supply of biomass energy that can be utilized for heat and electricity. As the cost of fossil energy rises amidst depleting availability, there has been increasing attention paid to, and research and development focused on biomass energy through pyrolysis processes such as combined heat and power (CHP) and combined heat and biochar (CHAB), the latter being focused on particularly for adoption into existing farming systems (Steiner, 2010).

In the farm environment, farm houses, barns, and other buildings such as milking sheds and packing houses can provide roof space for the installation of solar panels, but additional swaths of land are ideal sites for wind turbines. Other farmowned areas unsuitable for crop production or natural plant growth are useful sites for the construction of solar panel grids. Many of these sites are often still usable for certain types of livestock grazing even after the construction and operation of renewable energy projects. This provides added opportunity for farmers to lease parts of their property for wind power production and solar energy projects to earn an income between growing seasons, or while waiting for crops to mature (NNEC, 2012). These approaches essentially help the farmer to break the cycle of dependence on fossil fuels, and decrease or eliminate many of the challenges posed by the energy-intensive nature of agriculture. That said, it is important that the farmer understand that it is the prudent use of resources and judicious application of technology that will provide the capacity to improve the long-term 
sustainability of food production, and return the farm to the carbon neutral state of production that existed prior to the Industrial Revolution.

\section{The organic approach: improving productivity without chlorinated hydrocarbons, organophosphates, and industrial fertilizers}

Industrial farms rely heavily on huge quantities of synthetic fertilizers. The production of synthetic fertilizers such as nitrates requires significant energy inputs to be produced primarily from natural gas. Other fertilizing agents - notably potassium and phosphorus - are mined, the process of unearthing and transporting them consuming significant amounts of fossil fuel energy. All commercial potash deposits come from marine sources: ancient seas that are now buried and from saltwater brines. Potassium fertilizers are mined and produced in several places around the world from which they are shipped and supplied as essential farm inputs (IPNI, 2010). Similarly, phosphorus fertilizer is mined for commercial use, and with the exponential growth of global agriculture and crop production over the last century, phosphorus has become a depleted and limited resource. In the past, rock phosphate was used as the main source of phosphorus fertilizer, but rock phosphate has virtually disappeared from the market because of its very low water solubility and high transportation costs (Vitosh, 1990). In the last 20 years, rock phosphate has generally been processed before it is used as a nutrient fertilizer.

Modern farming systems also rely heavily on the use of pesticides to increase production efficiencies. Pimentel et al. (2005) reports, however, that the estimated environmental and healthcare costs associated with pesticide use in the U.S. are about $\$ 10$ billion per year. Herbicides are the most commonly used class of pesticides, with more than $90 \%$ of corn farmers in the U.S. relying on herbicides for weed control to the extent that Atrazine - one of the most widely used herbicides on corn - is among the most commonly found pesticides in streams and groundwater.

These realities are not blind to challenges of converting to organic practices. For many people, the concept of organic farming is merely the production of crops in the absence of synthetic pesticides, and often there is little contemplation of the components of fossil energy that accompanies organic activities. The reality is that in order to match the efficiencies and high levels of productivity that have been achieved through conventional farming systems, organic agriculture will require considerable knowledge and a transition period that is presented often with a great number of difficulties (Stockwell and Bitan, 2011). The main thrust of true organic approaches lies in avoiding the heavy reliance on fossil energy and on pesticides and herbicides. Efforts hinge on the use of crop rotation, composting, biological pest control, and an increase in the reliance on human labor.

Researchers Stockwell and Bitan (2011) identified that organic agriculture averages $60 \%$ less direct energy use compared to conventional production practices, and organic soils sequestered more carbon than conventional farms soils. 
With these factors in mind, Wright et al. (2006) offer several tips for transitioning from conventional to organic farming practices:

- Select fields that have had a history of light weed pressure, adequate fertility, and proper $\mathrm{pH}$ levels before beginning production

- Select fields with well-drained soils, adequate water-holding capacity, and that have been well rotated so that diseases and nematodes will not be a major concern

- Plant cover crops that will grow vigorously prior to the crop but can be killed by rolling with a roller or naturally by frost or maturity prior to planting the organically grown crop

- Choose crops carefully for planting during a season that is relatively free of pests or in a seasonal period when rainfall is adequate

- Apply composted chicken manure, mushroom compost, or other types of weed-free organic matter when available, to keep soil fertile and increase organic matter

- Use as little tillage as possible, since tillage destroys soil structure, causes erosion, reduces soil organic matter, and may result in lower yields.

- Use perennial grasses in the rotation if possible, since weeds, disease, and nematodes are reduced and organic matter is increased to a greater extent with grasses rather than legumes.

Despite the adoption of best practices and other common-sense approaches to organic farming, the main criticism has been that organic agriculture may have lower yields than conventional systems, therefore requiring more land to produce the same amount of food. The result, according to critics, will be more widespread deforestation and biodiversity loss that will undermine any environmental benefits gained by the adoption of organic practices (Halweil, 2012).

In an attempt to compare the yields of conventional versus organic farming systems, Seufert et al. (2012) conducted an assessment of the available data from 66 previous international studies. The assessment revealed that generally, organic yields are typically lower than conventional yields, but these yield differences are highly contextual, depending on system and site characteristics. The yield differences ranged from $5 \%$ lower organic yields in rain-fed legumes and perennials on weak-acidic to weak-alkaline soils, 13\% lower yields when best organic practices are used, to $34 \%$ lower yields when the conventional and organic systems are most comparable. Notwithstanding these results, Seufert et al. (2012) identified that when organic best management practices were applied to particular crop types and growing conditions, organic systems closely matched conventional yields, while under other conditions performance was weaker. The authors concluded that to establish organic agriculture as an important tool in sustainable food production, the factors limiting organic yields need to be more fully understood.

When the relative yield of organic agriculture is compared against that of conventional farming methods, there may be a rush to judgment by some to denounce organic agriculture as a failure. However when these yields are considered against the reality of $60 \%$ less direct energy usage in organic systems, avoided use of nitrogen fertilizers 
that dominate conventional inputs, the avoided use of herbicides and pesticides, and higher rates of human employment in organic systems, the results can be startling.

It should also be borne in mind that research and development on organic methods is sparse in comparison to efforts aimed at conventional practices, the educational system is biased toward those methods that have been practiced since the Green Revolution, and funding for crop varieties and non-synthetic pesticides is extremely scarce. It is against this backdrop that many proponents of organic agriculture have suggested that the time has come for the agro-business industry to start figuring out how to get high yields from crops without overreliance on synthetic fertilizers and pesticides (Chameides, 2012).

In many instances, age-old practices and measures often provide the most reliable and sustainable means of using certain types of natural resources. Even with the advent of phosphate fertilizer technology processes, organic phosphorus sources from animal manures, from composts, and from sewage sludge are still very important (NNEC, 2012). Although sewage sludge is currently not approved for use on organic farmland, the point here is that from a fertilizer and nutrient management perspective, the major differentiating factor is the availability of phosphorus. As global sources decline, or mining for phosphates becomes increasingly cost prohibitive, the tried-and-true old-fashioned methods will once again be embraced by conventional farming to the same degree that organic agriculture has found to be invaluable.

Increasingly, other materials and products of organic processes are being considered as important contributors to the organic farming system. Biochar production and utilization has been suggested by Steiner (2010) to be an effective tool if partnered with efficiency, conservation, and other renewable and sustainable approaches. Hunt et al. (2010) describes biochar as charcoal that has been produced under conditions that optimize certain characteristics deemed useful in agriculture, such as its high surface area per unit of volume and low amounts of residual resins.

Biochar as a soil amendment serves as a catalyst that enhances plant uptake of nutrients and water, and compared to other soil amendments, the high surface area and porosity of biochar enables it to adsorb or retain nutrients and water while providing habitat for beneficial microorganisms to flourish. Research conducted by Rondon et al. (2005) found that methane emissions were completely suppressed and nitrous oxide emissions reduced by $50 \%$ when biochar was applied to soil. In a similar study, Yanai et al. (2007) also determined that nitrous oxide emissions were suppressed when biochar was added to soil. The benefits of biochar to soil biodiversity, in carbon sequestration, for improving soil productivity, and in the generation of energy during its production process makes it a viable candidate to be studied for its benefits in farm-carbon dynamics.

\section{Optimizing the use of irrigation water}

Water-use issues have economic, ecologic, political, and social implications. Wilson (2002) suggests that in an open market, agricultural water usage offers lower returns than industrial use. For example, Wilson notes that a thousand tons of fresh water yields a ton of wheat worth approximately $\$ 200$, but the same amount of water in industry yields $\$ 14,000$ of product. This suggests that 
limited water resources are better allocated to industry than to agriculture. To be clear, however, organic agricultural systems provide many benefits in sustaining the hydrologic cycle at rates significantly above that of industrial agricultural approaches, making this service more competitive with commercial industrial use. Pidwirny and Jones (2006) state that water is renewed in rivers once every 16 days on average, in the atmosphere once every eight days, with slower rates of replacement in large lakes, glaciers, oceans, and groundwater, taking from hundreds to thousands of years. Because of the increasing use by humans of these slower renewed resources - in particular groundwater, which is effectively nonrenewable - we may have to exploit ocean water using energy-intensive desalinization technologies to satisfy human needs in the future.

As the demand for water outweighs supply, increased pressures and resource constraints will be placed upon farmers. At some point in the future, farmers involved in conventional farming systems will ultimately face the reality of water constraints, and must then begin to figure out how to grow crops and where to grow them in order to maximize the use of whatever water remains available. Bridgett McGrath (2008) reason that organic farmers have emerged as principal players in the implementation of water conservation practices, because they have gained levels of expertise in applying alternative approaches that will continue to grow in popularity as they face the challenge of managing scarce water. With increasing population growth and rising standards of living in places such as China and India, it is expected that the demand for food will only increase over time as will the demand to maintain water resources vital to agricultural production. Even where farming practices remain largely conventional, the key to a sustainable future will be rooted in the practices already in place within the organic movement (McGrath, 2008). There are various water-saving techniques already in place within the realm of organic practice, and in most cases they are specifically designed or adapted to the site where the technique is being applied.

The EPA Region 6 (2012) has compiled water-saving irrigation practices into three categories - Field Practices, Management Strategies, and System Modifications. These are explained as follows.

\section{Field practices}

Much like the ancient Egyptians did in ancient agriculture, field practices are techniques focused on impounding water in the field, improving its distribution, or achieving better soil moisture retention. These techniques are typically less expensive than conventional management strategies, and when they fall short of expectations and the management strategies and systems modifications discussed as follows are out of reach, the field practices of dryland farming and land retirement provide other avenues of exploration. Examples of field practices include:

The chiseling of extremely compacted soils: The use of soil borders, furrows, or ditches in order to allow gravity to distribute water across fields is the mainstay of this management system. 
Furrow diking to prevent runoff: Furrow diking involves the building of small temporary dikes across furrows to conserve water for crop production. The presence of the dikes also aids in preventing erosion.

Land leveling for more even water distribution: Laser leveling is a relatively modern technique that involves grading and precisely leveling the soil to eliminate any variation in the gradient and slope of the agricultural field. This type of precision agriculture helps control the flow of water and allows for more uniform soil saturation, and thus more efficient moisture retention.

Dry-land farming: These techniques takes into consideration the specific water needs of the plant species to be grown, thus it includes coordinating seeding to the ideal soil moisture content or choosing crops more suited for arid conditions.

Land retirement: The strategy of land retirement refers to an increasingly common policy of permanently or temporarily suspending farming activities on a particular acreage of agricultural land in exchange for financial incentives.

\section{Management strategies}

According to the EPA's definition, management strategies allow the irrigator to monitor soil and water conditions in order to ensure that water is delivered in the most efficient manner possible. The methods include: measuring rainfall, determining soil moisture, checking pumping plant efficiency, and scheduling irrigation. Most of these measures are self-explanatory.

\section{System modifications}

System modifications are often the most costly of the three categories, and require changing the existing irrigation system or replacing it with a new one. A typical modification to an existing system that allow for the most efficient delivery of water involves the addition of drip-irrigation tubes to a center pivot system, and retrofitting a water well with a smaller pump that can deliver similar or adequate amounts of water to the field. In some cases it may be more costeffective to install a replacement irrigation system. These include the installation of drip-irrigation, micro-sprinklers, constructing a tail-water recovery system, or solid set systems in which the pipelines can be removed from the field for cultural practices, eliminating the need for farming around sprinkler risers. This also allows for irrigation to be moved from location to location in order to improve overall uniformity because the pipes are not permanently fixed in the field (McGrath, 2008).

Despite all that has been said about the improvements in agricultural science and technology, gains observed in yields in the last century could not have been possible without the vast amounts of irrigation water that have been applied to agricultural fields. While conventional farming systems may not have 
appropriately responded to the ecological constraints caused by the overuse of water, the last three decades have observed a gradual shift to more conservative methods of irrigation that may lead to economic benefits that can be gained from this approach. The shift to more conservative irrigation systems has been pioneered by Israel, which developed a sustainable agriculture practice allowing its agricultural industry to extend limited water and satisfy both the growing demand for domestic use and the need for increased crop production.

Drip-irrigation and micro-sprinkler techniques have been used in Israel since the 1980s to expand crop output in semi-arid and arid regions of the country.

The irrigation systems are mostly computerized and depend on plant moisture sensors in the farm fields to operate the system automatically. Israeli agriculturalists have combined this technology with water-efficient crops and dry farming techniques to produce an irrigation efficiency of $90 \%$. For comparison, conventional furrow irrigation systems achieve an irrigation efficiency of $64 \%$. By combining irrigation technology with crop varieties that require less water and maximize uptake, Israel has seen its water requirements for crops fall from 2.85 acre-feet/acre in 1975 to 1.78 acre-feet/acre by 1998. Of equal significance, while water-use efficiency has increased and consumption continued to fall over the decades, Tal (2006) reports that agricultural output increased 12 -fold between 1980 and the year 2000.

The adoption rate of drip-irrigation and micro-jet sprinkler irrigation systems around the world has also been high, providing hope that the world may well be on its way toward more conservative and conscientious ways of consuming water for agricultural purposes. This is definitely a shift in the education paradigm of agriculturalists and researchers which should be both recognized and globalized as part of the new Green Revolution strategy.

\section{Reduce or improve transportation and food distribution channels}

Most farm products are processed, packaged, and transported after harvest, further increasing the energy footprint of the food item. The agribusinesses networks responsible for most of the foods produced in the industrialized world are consolidated and centralized, resulting in foods being transported over long distances and requiring additional inputs of energy beyond production (NNEC, 2012).

Modern agribusiness companies generally employ business strategies with the main aim of earning healthy profits on their goods and services, many of them controlling the entire production chain from growing the crops to food processing and packaging of the final products. These agribusinesses are therefore often criticized by worker advocacy and environmental groups who claim that they cause smaller farms to become uncompetitive and go out of business, and that they cause environmental damage through the practices employed.

In fact, the highly consolidated and centralized processing and packaging agribusinesses rely heavily upon a few extremely large farms that emerged in the second half of the last century as modern expensive equipment and capital-intensive inputs forced small farm operators away from agriculture, providing 
opportunities for large economies of scale to emerge (Henning, 2006). The small farms that remain in business, which often sell directly to consumers near the farm gate, rarely sell highly processed and heavily packaged products. Furthermore, because farming systems in developed countries are often regulated by extremely restrictive production and processing laws and rules, it is usually not possible for them to be located in proximity to urban areas. Consequently, this competitive advantage has accommodated the large processing and packaging agribusinesses that employ complicated shipping strategies to deliver foods to millions of urban dwellers.

From the previous statements it can be deduced that reducing the transportation miles of food from farm to consumer will involve a number of change strategies that include:

- Enacting laws and regulations that are friendly to small urban farms

- Accommodating the growth of urban farms and urban community gardening projects

- Promoting the growth of farmers markets in urban environments, especially in food-desert communities

- Shifting to an educational paradigm that promotes concepts in sustainable consumption

- Incentivizing the production and consumption of locally grown foods

- Improving urban transportation systems to enable food access by the poor and underserved.

It is a natural consequence that as farms are brought closer to people, there is increased probability of contact between consumer and farmer. When people visit farms and see where their foods are produced, they develop a greater appreciation for the farmer and the food item itself, but even more, they develop a keener understanding of the environment that helps sustain them. With proximity to consumers, there is less need for the over-processing of food items - this often translating into a significant decrease in the need for excessive packaging. Even where some amount of packaging is required, because of the closer proximity to consumers, there are many options available to reduce the need for plastics and for substituting alternatives that have far less impact on the environment. The simple act of reducing food distribution channels therefore provides opportunities for urban agriculture to sustain essential parts of the local biogeochemical cycles.

\section{Food and the future}

Human beings have lived on the earth for more than 250,000 years, but have farmed for only the last 10,000 years. There is a certain degree of uniqueness about agriculture that sets it apart from other kinds of economic activity. Beyond the production of food and fiber, agriculture also involves the management of natural resources and often requires a higher level of interaction with the ecological environment than most other types of industry. Additionally, agriculture impacts culture and people's 


\section{Applying practical solutions}

ways of life, and farmers are often considered to be the custodians of those cultures. When farmers are replaced by large economies of scale using huge quantities of energy, impacting sizable areas of landmass, and affecting the natural ecological balances in nature, what results is a disassociation from culture and environment by those who produce the foods that are essential to human life. In the years since the beginning of the Industrial Revolution, agriculture has emerged as a major user of fossil energy, increasingly dependent upon petroleum-based energy resources to power production, productivity, processing, packaging, and transportation.

The need for approaches that establish new relationships with the land, with water, and with air has emerged into movements that are interested in real change. Becoming carbon-negative in food production seems like an arduous and intractable task, but around the world there are many examples that this change has begun to occur. The hope is that in a timely manner it will take root on a global scale and continue to grow.

\section{References}

Butler, R. (2012). Cattle ranching's impact on the rainforest. Retrieved from http://rainforests. mongabay.com/0812.htm

Carson, R. (1962). Silent spring. New York, NY: Houghton Mifflin Company.

Chameides, B. (2012). Organic versus conventional farming. Duke. Nicholas School of the Environment. Retrieved from http://blogs.nicholas.duke.edu/thegreengrok/ conventional-vs-organic/

Deinlein, M. (1997). When it comes to pesticides, birds are sitting ducks. Smithsonian Migratory Bird Center. Fact sheet number 8. Retrieved from http://nationalzoo.si.edu/ scbi/migratorybirds/fact_sheets/fxsht8.pdf

Diamond, J. (1999). Guns, germs and steel: The fates of human societies. New York, NY: W. W. Norton \& Company.

EPA. (2007). Ruminant livestock. March 21. Retrieved from www.epa.gov/rlep/faq.html

EPA. (2012). Human health issues. Pesticides: Health and Safety. Retrieved from www.epa. gov/opp00001/health/human.htm

EPA Region 6. (2012). Be water wise! How to conserve water and use it effectively. August 20. Retrieved from www.epa.gov/region6/water/waterconserv/

FAO. (2004). Carbon sequestration in dryland soils. World Soil Resources Reports, 102. Retrieved from http://www.fao.org/agl/agll/docs/wsrr102.pdf

Fedoroff, N.V. (2010). The past, present and future of crop genetic modification. New Biotechnology. (Vol. 27, Issue 5, November, pp. 461-465). Retrieved from www.cemus. uu.se/dokument/UAG2011/sdarticle-14.pdf

Fox, S. (1981). The American conservation movement: John Muir and his legacy. Madison, WI: University of Wisconsin Press.

Frazier, M. (1997). A short history of pest management. Pennsylvania Integrated Pest Management. Retrieved from http://extension.psu.edu/ipm/schools/educators/curriculum/ contents/shorthistory

Goklany, I.M. (2001). The pros and cons of modern farming. PERC Reports. (Vol. 19, Issue 1, Spring, pp. 12-14). Retrieved from www.perc.org/pdf/mar01.pdf

Graff-Zivin, J., and Lipper, L. (2007). Poverty, risk and the adoption of soil carbon sequestration. Development Economic Analysis Division, Food and Agriculture Organization of the 
U.N. Retrieved from www.columbia.edu/ jz126/documents/graff-zivin_lipper_soil_ carbon_feb07.pdf

Gunther, F. (2000). Making Western agriculture more sustainable. FEASTA Review 1. June. Retrieved from www.feasta.org/documents/feastareview/guenther.pdf

Halweil, B. (2012). Can organic farming feed us all? WorldWatch Institute. Retrieved from www.worldwatch.org/node/4060

Hamilton, R. (2009). Agriculture's sustainable future: Breeding better crops. Scientific American, July 15. Retrieved from www.scientificamerican.com/article/agriculturessustainable-future/

Harrison, P.D., and Turner II, B.L. (Eds.). (1978). Pre-Hispanic Maya agriculture. Albuquerque: University of New Mexico Press.

Heinberg, R., and Bomford, M. (2009). The food and farming transition: Toward a post-carbon food system. Sebastopol, CA: Post Carbon Institute. Spring. Retrieved from www.post carbon.org/files/PCI-food-and-farming-transition.pdf

Henning, B. (2006). Why small farms matter: Economies of scale. BEEF. August 3. Retrieved from http://beefmagazine.com/americancowman/small-farm/economies_ scale

Hunt, J., DuPonte, M., Sato, D., and Kawabata, A. (2010). The basics of biochar: A natural soil amendment. College of Tropical Agriculture and Human Resources. University of Hawaii at Manoa. Soil and Crop Management. December. Retrieved from www.ctahr. hawaii.edu/oc/freepubs/pdf/SCM-30.pdf

International Plant Nutrition Institute (IPNI). (2010). Potassium fertilizer production and technology. Author. October. Ref. \#10121. Retrieved from www.ipni.net/ipniweb/portal. nsf/0/68907f5d1e5922f8062577ce006ad872/\$FILE/K\%20Fert\%20Prod\%20\&\%20 Tech\%2011\%2016\%2010.pdf

Lijmbach, S. (2002). A crisis of post-modern, agricultural education. Science as Culture. (Vol. 11, Issue 3, pp. 397-403). doi: 10.1080/0950543022000005122

Matson, P.A., Parton, W.J., Power, A.G., and Swift, M.J. (1997). Agricultural intensification and ecosystem properties. Science. (Vol. 277, Issue 5325, July 25, pp. 504-509). doi: 10.1126/science.277.5325.504

McGrath, B. (2008). Crisis or opportunity: Water conservation and organic farming. CCOF Certified Organic Magazine, Summer, pp. 7-11. Retrieved from www.ccof.org/ pdf/2008_summer_CertifiedOrganic.pdf

Meine, C. (2010). Aldo Leopold: His life and work. Second edition. Madison, WI: University of Wisconsin Press.

National Organic Program (NOP). (2012). National list of allowed and prohibited substances. USDA Agricultural Marketing Service. Retrieved from www.ams.usda.gov/ AMSv1.0/ams.fetchTemplateData.do?template=TemplateN\& navID=NationalOrganic Program\& page $=$ NOPNationalList $\&$ description $=$ National $\% 20$ List $\% 20$ of $\% 20$ Allowed\%20and\%20Prohibited\%20Substances\&acct=nopgeninfo

Network for New Energy Choices (NNEC). (2012). Energy and agriculture. Grace Communications Foundation. Retrieved from www.newenergychoices.org/index.php?page= EA_Intro\&sd=no

Pidwirny, M., and Jones, S. (2006). The hydrologic cycle: Fundamentals of physical geography. Second edition. Retrieved from www.physicalgeography.net/fundamentals/8b.html

Pimentel, D., Hepperly, P., Hanson, J., Seidel, R., and Douds, D. (2005). Organic and conventional farming systems: Environmental and economic issues. Report 05-1. College of Agriculture and Life Sciences, Cornell University. Retrieved from http://ecommons. cornell.edu/bitstream/1813/2101/1/pimentel_report_05-1.pdf 
Postel, S. (1999). Egypt's Nile valley basin irrigation. Retrieved from www.waterhistory.org/ histories/nile/nile.pdf

PRB. (2012). World population growth, 1950-2050. Population Reference Bureau (PRB). Retrieved from www.prb.org/Educators/TeachersGuides/HumanPopulation/Population Growth.aspx

Rich, D.K. (2006). The case against synthetic fertilizers/Industrial process opens door to many environmental risks. The Chronicle, January 14. Retrieved from www.sfgate.com/ homeandgarden/article/The-case-against-synthetic-fertilizers-2506802.php

Rondon, M., Ramirez, J., and Lehmann, J. (2005). Charcoal additions reduce net emissions of greenhouse gases to the atmosphere. Proceedings of the 3rd USDA Symposium on Greenhouse Gases and Carbon Sequestration. March 21-24, p. 208. Baltimore, MD.

Seufert, V., Ramankutty, N., and Foley, J.A. (2012). Comparing the yields of organic and conventional agriculture. Nature. (Issue 485, May 10, pp. 229-232). doi: 10.1038/ nature11069

Smith, B.D. (1998). The emergence of agriculture. New York, NY: Scientific American Library.

Steiner, C. (2010). Biochar from agricultural and forestry residues: A complimentary use of "waste" biomass. U.S. Focused Biochar Report: Assessments of Biochar's Benefits for the United States of America. Retrieved from www.biochar-us.org/pdf\%20files/biochar_ report_lowres.pdf

Steinfeld, H., Gerber, P., Wassenaar, T., Castel, V., Rosales, M., and De Haan, C. (2006). Livestock's long shadow: Environmental issues and options. Rome, Italy: Food and Agriculture Organization of the United Nations. Retrieved from ftp://ftp.fao.org/docrep/ fao/010/a0701e/a0701e00.pdf

Stern Review. (2006). Retrieved from http://webarchive.nationalarchives.gov.uk/+/www. hm-treasury.gov.uk/media/9/5/Chapter_25_Reversing_Emissions_from_Land_Use_ Change.pdf

Stockwell, R., and Bitan, E. (2011). Future friendly farming: Seven agricultural practices to sustain people and the environment. National Wildlife Federation. August. Retrieved from www.nwf.org/ /media/PDFs/Wildlife/FutureFriendlyFarmingReport.ashx

Tal, A. (2006). Seeking sustainability: Israel's evolving water management strategy. Science. (Vol. 313, Issue 5790, August, pp. 1081-1084). doi: 10.1126/science.1126011

Thomas, H. (2008). The alchemy of air. New York, NY: Harmony Books.

Vitosh, M.L. (1990). Phosphate fertilizers, N-P-K fertilizers. Extension Bulletin E-896. Michigan State University. October. Retrieved from http://fieldcrop.msu.edu/uploads/ documents/Phosphate\%20Fertilizers.pdf

Wilson, E.O. (2002). The future of life. New York, NY: Vintage Books.

Wright, D.L., Marois, J.J., and Katsvairo, T.W. (2006). Transitioning from conventional to organic farming using conservation tillage in Florida. SS-AGR-11: Electronic Data Information Source, UF/IFAS Extension. March. Retrieved from http://edis.ifas.ufl.edu/ pdffiles/AG/AG24600.pdf

Yanai, Y., Toyota, K., and Okazaki, M. (2007). Effects of charcoal addition on N2O emissions from soil resulting from rewetting air-dried soil in short-term incubation experiments. Soil Science and Plant Nutrition. (Vol. 53, pp. 181-188). doi: 10.1111/j.1747-0765. 2007.00123. $\mathrm{x}$

Zinati, G.M. (2002). Transition from conventional to organic farming systems: Challenges recommendations and guidance for pest management. Hort Technology. (Vol. 12, Issue 4, October-December, pp. 606-610). Retrieved from www.geography.siu.edu/pdfFiles/ Courses/429/429\%20Readings\%20S2011/1\%20Zinatti\%20transition.pdf 


\title{
8 Transitioning to low-carbon farming
}

\author{
An assessment of the process
}

Assessments carried out by the Food and Agriculture Organization of the United Nations showed that the world's agricultural sector is a major contributor of greenhouse gasses, particularly the super potent gasses methane and nitrous oxide. Most of the $\mathrm{CO}_{2}$ releases from agricultural activities occur as a result of fossil fuel combustion and practices that result in the degradation of soils. Twice as much carbon exists in soil as found in the atmosphere, but practices such as observed in agriculture over the last 60 years have shifted a considerable amount of soil carbon into atmospheric carbon dioxide. The sinking and storage of carbon back into the soil will logically restore the stable carbon ratios, making this goal essential to reducing greenhouse gas emissions to the atmosphere.

It has been hypothesized that if farmers transition to low-carbon techniques which also manage agricultural soils for the avoidance of methane and nitrous oxide emissions, the global agriculture sector could become a worldwide force in the mitigation of greenhouse gas emissions. It is however largely unclear what the basic incentives should be that will provide the stimulation for farmers to transition to low-carbon management practices. This chapter attempts to provide elucidation on some of the management techniques farmers may rely upon in order to begin the transition toward necessary change.

\section{Agriculture as a net greenhouse gas emitting sector}

All atmospheric gasses contribute to the greenhouse effect which is an important protective mechanism for the Earth. However, global warming is caused by increased emissions of gasses such as carbon dioxide, as well as others like nitrous oxide and methane that are more powerful than carbon dioxide due to their long duration in the atmosphere and strong absorption of long-wave radiation (Schlesinger, 1997). In evaluating the global greenhouse effect, carbon dioxide is used as the baseline greenhouse gas and has been assigned a value of 1 based on its warming potential. Methane has 21 times and nitrous oxide 298 times the global warming potential of carbon dioxide, so this means that a single ton of methane emissions has the global warming potential of 21 tons of carbon dioxide, and a single ton of nitrous oxide warms as much as 298 tons of carbon dioxide. 
Therefore, the values stated for nitrous oxide (298) and methane (21) are referred to as carbon equivalents (Miller et al., 2004).

Since soils have the capacity to hold twice as much carbon as the atmosphere, an increase in the amount of soil carbon could impact carbon emissions in the short-term, at least until low-carbon and other sustainable technologies can be fully developed, applied, and implemented globally. The FAO contends that an increase in the soil carbon content by 1.5 tons/hectare on 2 billion hectares of degraded lands could balance out predicted emission increases in carbon dioxide concentrations in the atmosphere (FAO, 2004). According to the FAO, agriculture accounts for approximately $14 \%$ of greenhouse gas emissions worldwide, this amount being equivalent to 6.8 gigatons of carbon equivalent, making agriculture the second largest industrial contributor to global greenhouse gasses emissions (UN News Centre, 2011).

The Stern Review (2006) - which conducted an assessment of the economics of global climate change - used data from the 1990s and early 2000s to suggest that the Earth is capable of absorbing 5 gigatons of $\mathrm{CO}_{2}$ equivalents $\left(5 \mathrm{GtCO}_{2} \mathrm{e}\right)$ per year. According to the Review, the global agricultural sector alone is responsible for producing $5.6 \mathrm{GtCO}_{2} \mathrm{e}$ annually. Given the current net global emissions rate, stabilization is likely to require complete de-carbonization of all agricultural activities, with significant attention placed on the emission of nitrous oxide for which the agricultural sector is accountable for $84 \%$ of global emissions (Stern Review, 2006).

Nitrous oxide is a potent greenhouse gas that contributes to global warming (CCC, 2012). In the natural course of biogeochemical cycling of elements, nitrous oxide is produced from a variety of sources in soil and water, particularly from processes involving microbial action in wet tropical forests (USEPA, 2010). The increase in demand for food stimulated the development of modern applications and technologies which along with increased use of synthetic fertilizers on agricultural soils provided the abundance of foods consumed today. Where large applications of fertilizer occur in soil conditions that are favorable to denitrification processes, significantly large amounts of nitrous oxide is produced and then emitted to the atmosphere. Similarly, even in environments where widespread use of animal waste as fertilizer is poorly controlled, it can lead to substantial emissions of nitrous oxide from agricultural soils (Kuikman et al., 2003). When the use of nitrogen-based fertilizers is excessive, large proportions of the added fertilizer provides no benefit to crop yield, but instead induces elevated nitrous oxide emissions. The widespread increase in nitrogen-based fertilizers, however, has been driven by the need for greater crop yields, and by the application of more intensive farming practices on a diminishing agricultural landscape as available farmland declines in industrialized and rapidly industrializing countries (Dave et al., 2012).

It is important that farmers become more generally educated about the way things work at the microscopic level. A better understanding of soil dynamics will help move this group of land stewards toward active participation in carbon management for biogeochemical stability. For example, it is consequential for farmers and their advisors to know that the carbon to nitrogen ratio of soil organic matter 
that results in stable organic matter typically falls within a range of about 10 parts of carbon $(\mathrm{C})$ to 1 part of nitrogen $(\mathrm{N})$. This is the normal C:N ratio of humus. The 10 to 1 carbon to nitrogen ratio required for stable organic matter means that for every 10 pounds of carbon sequestered in soil organic matter, 1 pound of nitrogen must accompany it. In the absence of sufficient amounts of nitrogen in the soil, stable formation of soil organic matter by way of soil microbial degradation of crop residues will not occur, and only minute amounts of carbon will be sequestered.

Importantly, at the 10:1 ratio, nitrogen is bound up in the microbial process and is generally unavailable for crop needs. Miller et al. (2004) explain that if a farmer adopted no-till that resulted in an increase of soil carbon of 0.45 ton/ac over 10 years, then $0.045 \mathrm{t} / \mathrm{ac}$ ( 90 pounds) of applied nitrogen would have been tied up in soil organic matter and not available to his crops. The implications here are that economic considerations of changing crop rotations should be considered carefully in carbon abatement programs. The amount of and ratio of nitrogen in soil is therefore essential for carbon sequestration, thus this knowledge becomes an important tool in the skillset that farmers engaged in carbon management programs require.

In 2010, the Congressional Research Service (CRS) in its report to the U.S. Congress compiled an estimate of greenhouse gas emissions and carbon sequestration of the U.S. forestry and agricultural activities over the years 2003-2007. The data was extracted from the EPA's "Inventory of U.S. Greenhouse Gas Emissions and Sinks - 1990-2007", and included an assessment of the greenhouse gasses carbon dioxide, methane, and nitrous oxide. The CRS report recognized that greenhouse gas emissions from agriculture, particularly methane emissions, are associated with livestock operations as the gas is released as part of the natural digestive process of animals and manure management. This methane gas release is in addition to nitrous oxide releases from crop production activities such as soil manipulation, the application of commercial fertilizers, manure application, and from the production of nitrogen-fixing crops (Johnson et al., 2010). These estimated emissions are expressed on the $\mathrm{CO}_{2}$-equivalent basis in Table 8.1. Negative net values (or the volume of greenhouse gasses even after sequestration) are shown in parentheses.

Table 8.1 Estimated GHG emissions and carbon sequestration: U.S. agricultural and forestry activities, 2003-2007 (million metric tons $\mathrm{CO}_{2}$ equivalent $-\mathrm{MMTCO}_{2} \mathrm{e}$ )

\begin{tabular}{lccc}
\hline Source & Emissions & Sequestration & Net \\
\hline Agricultural and forestry activities & 530 & 1,053 & 523 \\
Agriculture & 487 & 45 & $(442)$ \\
Land use change, forestry & 43 & 1,008 & 965 \\
U.S. total, all sources & 7,150 & 1,063 & $(6,087)$ \\
\hline
\end{tabular}

Source: Johnson et al. (2010) - CRS Report for Congress, 2010 


\section{Sequestration of GHG}

The FAO contends that despite what appears to be a dismal current trajectory, the agricultural sector has great potential to reduce its greenhouse gas emissions and sequester large amounts of carbon from the atmosphere (UN News Centre, 2011). Based on estimates from the Intergovernmental Panel on Climate Change (IPCC), the sequestration of carbon in soil through techniques such as improved cropland and grazing land management, as well as the restoration of degraded lands, provides the best potential in agriculture for climate change mitigation.

In the U.S., initiatives such as the Nebraska Environmental Trust Fund Project (NETFP) have examined the potential of carbon mitigation at the farm scale. The NETFP acknowledges that much research is being conducted in the U.S. to learn how carbon is sequestered in the soil and the techniques to keep it there, but policymakers disagree on whether soil carbon sequestration should be used to offset emissions, on who gets paid for it, and how much should be paid. Notably, the NETFP recognized that up to and in the year 2007 (and certainly all the way to 2018), "no one was looking at what it takes to get farmers and ranchers to adopt practices that enhance soil carbon" in the U.S., and in many other parts of the world (Kleinschmit, 2007, p. 1).

\section{Agricultural management for GHG reduction}

Agriculture can contribute to the reduction in emissions through the deliberate adoption of practices that capture $\mathrm{CO}_{2}$ emissions from the atmosphere and store it in the soil in the form of soil organic carbon (SOC) or elemental carbon. West and Post (2002) conducted analyses of carbon sequestration rates using a global database of 67 long-term agricultural experiments consisting of 276 paired treatments to show that changes in agricultural management can potentially increase the accumulation rate of SOC. Focusing on management techniques, Sampson and Scholes (2000) determined that changes in agricultural management can increase or decrease SOC. Their assessment revealed that the optimization of agricultural management for SOC accumulation helps in the sequestration of atmospheric $\mathrm{CO}_{2}$, and reduces the emission of methane $\left(\mathrm{CH}_{4}\right)$ and nitrous oxide $\left(\mathrm{N}_{2} \mathrm{O}\right)$. The consequence is the slowing down in atmospheric greenhouse gasses through agricultural management.

During the last years of the 1990s and into the early 2000s, interest in carbon sequestration as a method for greenhouse gas emissions mitigation increased, and carbon sequestration attracted attention from farming groups and policymakers who thought it would become a source of additional income to farmers. Progress has been made in countries such as Australia (DCCEE, 2012), but policy wrangling has created gridlock in both state and federal administrations in the U.S., and this is a major constraint on the use of policy instruments aimed at changing to net sequestration of carbon within the agricultural sector. 
Modern agriculture is facing increasing demands upon which the core fundamentals of farming are increasingly under review by consumers, environmentalists, policymakers, and the farming community itself (Starritt, 2010). The good news is that studies have been conducted in many parts of the world showing the value of integrating the science of soil carbon sequestration with the economic and policy issues surrounding it. The benefit of this is that it will provide agricultural scientists, environmentalists, farmers, and policymakers with innovative and environmentally friendly practices for improving land management and crop production. It is this integrative, interdisciplinary approach that merges agricultural management practices, economics, and policies for carbon sequestration in soil, which will help to steer the agricultural sector toward widespread adoption of low-carbon management practices. These approaches will, it is hoped, continue the enhancement of land productivity, increase the soil carbon pool, and benefit the overall environment (Lal and Follett, 2009).

\section{Case study analyses - what's involved in making the transition?}

Many farms in the U.S. and in other parts of the world have operated for generations, utilizing Green Revolution agricultural practices which have been criticized for contributing to water quality problems, environmental pollution, and greenhouse gas emissions. For many of these farm operations it is difficult to change behavior to practices that contribute less to environmental problems. Reasons for the difficulty include a myriad of production applications which are perceived as backward or obsolete despite their cleaner outcomes. Moreover, the relative ease with which modern technologies are readily accessible makes their practices very hard to break away from.

Many farmers who consider less conventional approaches to farming have chosen to transition to organic agriculture, and they do this for many different reasons. These reasons include seeking a better price for their crops, a desire to lessen reliance on agricultural chemicals, or an ideology driven by the need to abandon commercialism or participation in the industrial agricultural system. Some farmers are also attracted to organic production methods which use natural tools and the strengths of a farm's own ecosystem to build a sustainable farming operation (MOSES, 2012).

Firestone (1993) notes that case studies are pertinent when research addresses a descriptive question such as "what is happening or has caused something to happen". The three proceeding case studies are provided to serve as a prelude for further investigation of those factors that cause farmers to transition from modern conventional agricultural practices toward carbon abatement techniques and practices. The case studies are primarily taken from reports published by various research groups, and as well, are drawn from different parts of the U.S., as well as from other parts of the world. 


\section{Case study \# 1}

Name of project: Nebraska Environmental Trust Fund Project

Number of participants: $>20$ farmers of diverse background (Nebraska)

Hypothesis: Adopting carbon sequestration practices is a win-win situation for present and future farmers.

Project focus: To show the benefits of improved soil carbon and how to incorporate practices to improve soil carbon levels.

Project life: 3 years

Lessons learned: Based on interviews and observations, it was learnt that farmers and ranchers make decisions based on four main factors: (1) economics, (2) environment, (3) social pressure, and (4) control needs.

Decision-making factors: The study elicited the following factors as important in the transition process.

- Background information is important.

- Financial incentives must be present

- Group learning reinforces positive peer pressure

- Publications are required and necessary

- Learning from others makes it believable

- Change is slow

- Observations are important

- Success cannot always be measured.

Outcome: Project planners and participants believe the outcome was positive. Carbon values (units) were selected by project staff and farmers as representative numbers to show a comparison between crops and practices rather than real pounds or tons of carbon. On the 5,000 acres managed by farmers in the project, a total of 107,083 units of carbon were stored annually during the base-line years. This value increased by 49,119 (46\%) because of planned practices in the years after the project. Carbon increases were due to a reduction in tillage, conversion to grass or permanent forage, extending the growing season by adding additional forage or cover crops, and increasing the use of grazing animals to harvest forage and grain crops.

(Kleinschmit, 2007)

\section{Case study \# 2}

Name of project: Agricultural and land management carbon offsets opportunities

Number of participants: 1 rice farmer (Mississippi) 
Objective: Intermittent flooding of rice reduces water and energy use while lowering methane and carbon dioxide emissions

Project focus: To show the benefits of intermittent flooding (as opposed to permanent inundation) to reduce greenhouse gas emissions.

Lessons learned: By using less irrigation water and diesel fuel to run the water pumps, the farmer saved $\$ 15$ per acre. Pesticide run-off from fields was reduced by $60 \%$. The main driver for transition was economics. Avoided emissions are an economic benefit to the farmer.

Decision-making factors: The study elicited the following factors as important in the transition process.

- Educational support was received from State University Extension Agronomist

- Economic returns

- Saving water for future farming by the farmer's children.

Outcome: Reduction in chemical runoff improved habitat conditions for local populations of fish and amphibians. The farmer reduced his water use by $30 \%$. Greenhouse gas emissions reduced were by 0.92 metric tons of carbon dioxide equivalent per acre, coming from reductions in carbon dioxide emissions due to reduced diesel use and from reductions in methane emissions caused by saturated ground conditions. Preliminary measurements found methane reductions of $30 \%$ over conventional rice flooding. The reduction in methane emissions was equivalent to 0.83 metric tons of carbon dioxide equivalent.

(Massey, 2011)

\section{Case study \# 3}

Name of project: A new approach for sustainable agricultural land management (SALM) practices

Number of participants: 60,000 smallholders (Kenya)

Objective: To encourage smallholder farmers to adopt improved farming techniques, boost productivity, increase resilience to climate change, and earn carbon credits.

Project focus: To combat erosion and enrich degraded soil by increasing soil carbon and organic matter through mulching, cover crops, manure, and plant waste management.

Lessons learned: Carbon management techniques helped to improve soil water infiltration, water holding capacity, as well as nutrient supply and soil biodiversity. The resulting soils were better, helping 
to raise farm yields and incomes, improving food security. In a scenario where smallholders in western Kenya experience the effects of climate change first-hand every year through the impact of drought and the decline of soil fertility, new techniques are making agriculture more resilient to climate change. Additionally, an important lesson learned was that carbon solutions needed to be easily scalable, which requires broadly applicable methodologies and robust finance mechanisms.

Decision-making factors: The study elicited the following factors as important in the transition or pre-adoption process.

- Support from the World Bank's Bio-Carbon Fund

- Carbon finance helped make the project financially sustainable

- Increased farm yields and incomes were observed by smallholders before adoption.

Outcome: Cost-effective monitoring of soil productivity improvements were achieved despite the difficulties entailed in accessing remote farms in developing countries such as Kenya. Soil carbon is of fundamental importance not only to soil fertility, sustainable agriculture, and the development of rural populations, but it is also strategic for climate change mitigation.

(World Bank, 2012)

\section{Analytic generalizations}

In discussing the issue of generalizations from case studies, Firestone (1993) observes that the most desired convergence occurs when three or more independent sources all point to the same set of events, facts, or interpretations. Based on this observation, the following list of decision-making features provides some suggestions on factors necessary for farmers to transition to on-farm carbon abatement programs. These are;

- The provision of background information on carbon abatement is a matter of priority

- Financial incentives are important for making change

- Group learning is essential especially in farming communities

- Educational publications are valuable

- Learning from others makes it believable

- Change is slow

- Observations are important

- Success cannot always be measured - some people place a high value on extrinsic values 
- Educational support is a catalyst for decision making

- Economic returns is a major reason farmers change to carbon abatement/ emissions avoidance programs

- Saving water for future farming by children is important to older farmers

- Support from development agencies is vital especially in developing countries

- Carbon finance is helpful and makes projects financially sustainable

- The observance of increased farm yields and incomes by smallholders is important for adoption to occur.

There is a fair degree of commonality in the findings from these three case studies. Although not relying on an elaborate set of data, it is not very difficult to triangulate or establish converging lines of support for what farmers and other case study participants believe are important for the process of transition. Table 8.2 organizes the 14 decision-making factors from the case studies into four categories Economics, Education, Social Pressure, and Environment. These four factors must be understood, populated, and applied in projects focusing on agricultural transition to low-carbon farming.

Table 8.2 Decision-making factors for transition to low-carbon farm economy

\begin{tabular}{|c|c|c|c|}
\hline Economics & Education & Social pressure & Environment \\
\hline Financial incentives & $\begin{array}{l}\text { Background } \\
\text { information }\end{array}$ & Group learning & Change is slow \\
\hline Economic returns & $\begin{array}{l}\text { Educational } \\
\text { publications }\end{array}$ & $\begin{array}{l}\text { Learning from } \\
\text { others including first } \\
\text { adopters }\end{array}$ & $\begin{array}{l}\text { Success is not always } \\
\text { measurable }\end{array}$ \\
\hline $\begin{array}{l}\text { Support from funding } \\
\text { sources }\end{array}$ & $\begin{array}{l}\text { Observations are } \\
\text { important }\end{array}$ & - & $\begin{array}{l}\text { Extrinsic values are } \\
\text { important }\end{array}$ \\
\hline Carbon finance & Educational support & - & - \\
\hline $\begin{array}{l}\text { Farm yields and } \\
\text { incomes }\end{array}$ & - & - & - \\
\hline
\end{tabular}

\section{Changing to net sequestration of greenhouse gasses as a farming goal}

Large farming operations in the U.S. and elsewhere around the world spend a considerable amount of financial inputs on energy, pesticides, and synthetic fertilizers. Where regulatory agencies place checks and balances on nonpoint and point source pollution, farmers are placed in difficult situations where spending costs increase as measures to prevent nutrient pollution are put in place (Moyer, 2011). Many farmers are cognizant of the impacts their operations have upon the ecosystem and have adopted management practices that curbed nutrient runoff while increasing farm productivity at the same time. 
Since the 1930s when Jerome Irving Rodale popularized the term 'organic' to mean grown without pesticides, the organic food production movement has grown and become popular as an increasing number of consumers place greater demands on farmers to produce food crops without chemical pesticides (Rodale Institute, 2011). Organic farm production developed as a direct response to consumer demands, with many organic farmers admitting that their transition was predominantly driven more by economic incentives and less so by ideological motivation.

The last several decades going back to the 1970s have witnessed an increasing awareness of global climate change caused by greenhouse gas emissions. Since agriculture is increasingly recognized as a major emitter of some of the most potent greenhouse gasses, there has been an emerging movement challenging the sector to not only lowering its emissions, but reversing and eventually sequestering carbon into plants and in soil (FAO, 2004). The low-carbon movement has been gathering momentum around the world, with leading organizations such as the 'Fair Climate Network' emerging in India (FCN, 2012), the 'Soil Association' in Europe, and the 'Post Carbon Institute' in the U.S. What these organizations all have in common is that they recognize organic farming as a management strategy that avoids synthetic fertilizers and chemical pesticides. The low-carbon organizations see their main objective being a search for even lower carbon farming applications achieved by the application of organic methods. The aim is not only to reduce hydrocarbon usage but to avoid greenhouse gas emissions while sequestering carbon. The collective strategies of low-carbon farming being promoted by these organizations recognize the following techniques as important progressive steps during the transition to a low-carbon agricultural management model.

- Calculate the carbon footprint of the farming operation

- Adopt organic practices as well as additional low-carbon farming practices that reduce and/or avoid greenhouse gas emissions of carbon dioxide, methane, and nitrous oxide

- Make the switch to renewable energy applications on-farm. This includes wind, solar, geothermal, biogas, and bio-crops where applicable, available, or appropriate

- Develop and apply practices that sequester carbon in farm soils. Biochar applications offer one such approach.

(Soil Association, 2011; FCN, 2012)

In many ways, farming is just like any other job. Most farmers farm their land because of tradition, and large farms in particular are profit-seeking ventures that must be kept financially afloat in order to stay in business. The factors that motivate farmers are varied, but for the majority of farmers the economics of staying in business and making a profit is more important than almost any other reason. The cost of switching to organic production systems is relatively high, the market considerably smaller, making this proposition financially risky for most - including even those who have ideological leanings toward sustainable farm practices. 
The low-carbon techniques described in this chapter require strong management input and offer reasonable returns on investments, improved ecological habitats, and resurgence of biodiversity. These benefits are embraced by the farmer if $\mathrm{s} / \mathrm{he}$ is able to access financial support, educational and technical assistance, and see others adopting the practices. If farmers in both developed and developing countries are expected to fully participate in the efforts to reverse the trends of global warming, then development organizations and policy making agencies involved in climate change mitigation efforts must ensure that these essential prerequisites are readily provided. Only then will the world begin to see the beginnings of true reform in the agricultural industry that may form the basis for a paradigm shift away from the gravest ecological underachievement of the Green Revolution.

\section{References}

CCC. (2012). CO2 equivalents. Climate Change Connection (Author). Retrieved from www.climatechangeconnection.org/emissions/CO2_equivalents.htm

Dave, S.R., Davidson, E.A., Smith, K.A., Smith, P., Melillo, J.M., Dentener, F., and Crutzen, P.J. (2012). Global agriculture and nitrous oxide emissions. Nature Climate Change (Vol. 2, pp. 410-416). doi: 10.1038/nclimate1458. Retrieved from www.nature.com/ nclimate/journal/v2/n6/box/nclimate1458_BX1.html

DCCEE. (2012). The carbon farming initiative handbook. Department of Climate Change and Energy Efficiency. Government of Australia. Retrieved from www.climatechange. gov.au/en/government/initiatives/carbon-farming-initiative/ /media/government/ initiatives/cfi/handbook/CFI-Handbook-20120403-PDF.pdf

FAO. (2004). Carbon sequestration in dryland soils. World Soil Resources Reports, 102. Retrieved from http://www.fao.org/agl/agll/docs/wsrr102.pdf

FCN. (2012). Low carbon farming. Fair Climate Network (Author). Retrieved from www. fairclimate.com/tech/farming.aspx

Firestone, W.A. (1993). Alternative arguments for generalizing from data as applied to qualitative research. Educational Researcher. doi: 10.3102/0013189X022004016. Retrieved from http://edr.sagepub.com/content/22/4/16.abstract

Johnson, R., Ramseur, J.L., and Gorte, R.W. (2010). Estimates of carbon mitigation potential from agricultural and forestry activities. Congressional Resource Service (CRS) Report for Congress. January 26. Retrieved from www.nationalaglawcenter.org/assets/crs/R40236. pdf

Kleinschmit, M. (2007). Breaking new ground: Carbon management at the farm scale. Final Report: Nebraska Environmental Trust Fund Project. March 26, 2007. Center for Rural Affairs. Retrieved from www.cfra.org/files/carbon_report_final.pdf

Kuikman, P.J., Velthof, G.L., and Oenema, O. (2003). Controlling nitrous oxide emissions from agriculture: Experience in the Netherlands. Retrieved from www.coalinfo.net.cn/ coalbed/meeting/2203/papers/agriculture/AG069.pdf

Lal, R., and Follett, R.F. (2009). Soil carbon sequestration and the greenhouse effect. Madison, WI: Soil Science Society of America, Inc.

Massey, J.H. (2011). Intermittent flooding of rice reduces water and energy use while lowering methane and carbon dioxide emissions. In Stockwell, R., and Bitan, E. (Eds.). 
Future friendly farming: Seven agricultural practices to sustain people and the environment. Retrieved from www.ncwf.org/Docs/FutureFriendlyFarming.pdf

Miller, P., Engel, R., and Bricklemyer, R. (2004). Soil carbon sequestration in agriculture: Farm management practices can affect greenhouse gas emissions. Montana State University Extension Service. Montguide. Retrieved from http://msuextension.org/publications/ AgandNaturalResources/MT200404AG.pdf

MOSES. (2012). Transitioning to organic crop production. Midwest Organic and Sustainable Education Service. Organic Factsheet. Retrieved from www.mosesorganic.org/attachments/ MOSES\%20fact\%20sheet/24transCrop.pdf

Moyer, J. (2011). Making the transition to organic farming: It may be easier than you think. Rodale Institute. Retrieved from www.rodaleinstitute.org/transition_fact_sheet

Rodale Institute. (2011). The history of Rodale Institute. Retrieved from www.rodaleinstitute. org/about_us

Sampson, R.N., and Scholes, R.J. (2000). Additional human induced activities. In Watson, R.T., et al. (Eds.). Land-use, land-use change, and forestry: A special report of the intergovernmental panel on climate change. New York, NY: Cambridge University Press.

Schlesinger, W.H. (1997). Biogeochemistry: An analysis of global change. San Diego, CA: Academic Press.

Soil Association. (2011). Technical information. Soil Association 2011 (Author). Retrieved from www.soilassociation.org/innovativefarming/lowcarbonfarming/Technical information

Starritt, A. (2010). Carbon sequestration in farming systems: A direction for enhancing carbon sequestration and soil health in broad acre agriculture. Nuffield Australia Project No 1003. Retrieved from www.nuffieldinternational.org/rep_pdf/1302686961Alastair_ Starritt_final_report.pdf

Stern Review. (2006). Retrieved from http://webarchive.nationalarchives.gov.uk/+/www. hm-treasury.gov.uk/media/9/5/Chapter_25_Reversing_Emissions_from_Land_Use_ Change.pdf

UN News Centre. (2011). UN agency creates tool to mitigate agriculture's contribution to global warming. February 15. Retrieved from www.un.org/apps/news/story.asp?NewsID=37536\& $\mathrm{Cr}=$ global+warming $\& \mathrm{Cr} 1=$

USEPA. (2010). Methane and nitrous oxide emissions from natural sources. United States Environmental Protection Agency. April. Retrieved from www.epa.gov/nitrousoxide/pdfs/ Methane-and-Nitrous-Oxide-Emissions-From-Natural-Sources.pdf

West, T.O., and Post, W.M. (2002). Soil organic carbon sequestration rates by tillage and crop rotation: A global analysis. Soil Society of America. (Vol. 66, pp. 1930-1946). Retrieved from http:/cdiac.ornl.gov/programs/CSEQ/terrestrial/westpost2002/westpost 2002.pdf

World Bank. (2012). World Bank and partners help smallholder farmers increase productivity and revenue. Press Release No:2012/252/SDN. January 30. Retrieved from http:// web.worldbank.org/WBSITE/EXTERNAL/NEWS/0, contentMDK:23100745 pagePK: 64257043 piPK:437376 theSitePK:4607,00.html 


\section{The kinetic role of biochar in climate change mitigation}

With the increasing problem associated with carbon dioxide in the atmosphere, it is an opportune time to begin a global focus on redirecting the net flow and storage of carbon back into the soil, where the sustainable storage capacity is twice that of the atmosphere. Soils are fundamental to the productive capacity of terrestrial ecosystems. Soil organic matter (SOM) is composed primarily of carbon, and SOM makes up approximately $57 \%$ of soil by weight (Sundermeier et al., 2005). Organic compounds are produced by plants when they utilize sunlight energy and combine this with carbon dioxide from the atmosphere and nutrient-enriched water from the soil. SOM is created by the cycling of these organic compounds in plants, animals, and microorganisms in the soil.

When organic matter is decomposed it forms humus - a dark brown, porous, spongy material that provides a carbon and energy source for soil microbes. Humus is a principal component of soil carbon and has an average lifespan of hundreds to thousands of years. SOM determines much of the soil's quality, being an important substrate of cationic exchange that is the warehouse of most of the nitrogen, phosphorus, and sulfur potentially available to plants. SOM is also the main source of energy of microorganisms, and is a key determinant of the structure of the soil (Bates, 2010). Soils with high organic matter are more productive than soils where much of the organic matter has been depleted through tillage and poor management practices and transported away by surface runoff and erosion (Sundermeier et al., 2005).

SOM is a complex mixture that includes decomposing plant and animal tissue, microbes such as protozoa, nematodes, fungi, and bacteria. Carbon and its compounds can remain stored in soils for millennia, or it can be quickly released back into the atmosphere through certain processes of disturbance. Factors which determine how long carbon remains in the soil include climatic conditions, soil texture, natural vegetation, and drainage. In agricultural systems, the amount and length of time carbon is stored in soil is determined predominantly by how the soil resources are managed. According to the Ecological Society of America (2000), over the past 150 years and especially since the inception of modern agricultural mechanics, the amount of carbon in the atmosphere has increased by $30 \%$. Correlational assessments and other studies conducted around the world have resulted in the overwhelming number of scientists believing that there is a 
direct relationship between increased levels of carbon dioxide in the atmosphere and rising global temperatures since the beginning of the Industrial Revolution.

Since scientists and practitioners recognized that modern agricultural practices can have deleterious impacts on soils, a variety of prescriptive agricultural practices have been proposed and put into practice to mitigate the possible consequences. One proposed method to reduce atmospheric carbon dioxide is to increase the global storage of carbon in soils. An added benefit to this proposed solution is the potential for simultaneous enhancement of agricultural production through management techniques which have been proven successful in creating a net carbon sink in soils. As discussed in the previous chapter, these techniques include conservation tillage that minimizes or eliminates the need for manipulation of the soil for crop production, and also applies the practice of leaving crop residues on the soil surface. Other techniques such as cover cropping, the addition of nitrogen fertilizers in ratios that support optimal carbon sequestration, the growing of non-food plants or bioenergy crops on semi-arid lands, as well as crop rotation, have all been employed as methods to sink carbon into the soil (Ecological Society of America, 2000).

Recent agronomic determinations have shown that nearly all agricultural soils have the capacity to store more carbon, with potential for even a modest increase in carbon stocks across the large land areas used for agriculture resulting in a greater degree of greenhouse gas mitigation. However, there is much uncertainty and debate as to the total potential of soils to store additional carbon, the rate at which soils can store carbon, the permanence of this carbon sink, and how best to monitor changes in soil carbon stocks (Sanderman et al., 2010). More applied research is needed to find the answers to these questions, and the answers must be factored into the strategy for reconnecting soil carbon and atmospheric carbon cycles.

\section{What is biochar?}

When plants are left to rot, the carbon and oxygen contained within their structures combine in a relatively short period of time to release carbon dioxide back into the air. If plants are heated in the absence of oxygen through the process of pyrolysis, charcoal is formed. Charcoal, largely carbon, can be burned, and when this happens the carbon is lost to the atmosphere. However, if charcoal is buried and not burned, the two elements carbon and oxygen take a long time to recombine into carbon dioxide. What this means is that with carbon burial, some of the most abundant greenhouse gasses can be taken out of the atmosphere and locked into the ground for an extended time.

Bruges (2009) suggests that charcoal is one of, if not the oldest industrial technologies known to humans. Hunt et al. (2010) describes biochar as charcoal that has been produced under conditions that optimize certain characteristics deemed useful in agriculture, such as its surface area per unit of volume and the low amounts of residual resins it contains. The type of heat treatment applied to organic biomass used to produce biochar contributes to its large surface area and 
its characteristic ability to persist in soils with minimal biological decay. Hunt et al. (2010) defines the technical terms for the processes that create biochar as 'pyrolysis' and 'gasification'. These processes heat biomass to the point of carbonization, but in the absence of oxygen. Because the heating process occurs without oxygen, the biomass is not completely turned to ash. Instead, what happens is that the biomass is disassembled and converted into water vapor, synthesis gasses (syngas), liquids, oils, and biochar. Pyrolysis and gasification can be done on an industrial scale, but they are also useful to small-scale gardeners as well as to both small and large farm operators. Regardless of scale, modern pyrolysis uses closed containers in order to control the pyrolysis process. These closed containers restrict airflow and convert biomass to biochar or pure carbon (Major et al., 2010).

For the reasons stated, during the last decade there has been a growing wave of excitement engulfing biochar products, largely due to scientists advocating that humanity might be saved from the worst effects of global warming if large quantities of biochar is buried in soil (Hunt et al., 2010). The benefits of biochar, however, are not limited to carbon sequestration. With the associated processes of carbon sink and soil organic matter symbiosis, it is possible that degraded lands can be restored, and better harvests of crops can be achieved by mixing finegrained biochar into soil.

The debate as to the total potential of soils for storing additional carbon has therefore focused on biochar. Biochar as a soil amendment serves as a stable soil component that improves the uptake of nutrients and water by plants. When applied as an amendment to soil, raw organic materials supply nutrients to plants and to soil microorganisms. Compared to other soil amendments, the high surface area and porosity of biochar enables it to adsorb or retain nutrients and water while providing structural habitat for beneficial microorganisms to flourish. Research conducted on the Amazon Basin's human-made Terra Preta soils, and on naturally occurring biochar from forest and grassland fires, suggests that biochar can persist for millennia with very little decay. Using the latest technology, laboratory studies estimate that biochar has a mean residence time in soils on the order of 1300-4000 years, findings that dispel previous doubts about the capacity of biochar to sequester carbon and remain unchanged in most agricultural soils for very long periods of time. Studies conducted by Hunt et al. (2010) and by Domingues et al. (2017) suggest that the benefits of biochar to soil biodiversity, carbon sequestration, carbon sink, soil productivity, and to the generation of energy during its production process makes it a viable candidate to be studied further for its benefits to carbon dynamics in an anthropogenic world.

\section{A short history of char}

Interest in biochar came with the rediscovery of deep dark areas of Terra Preta do Indio or Indian black earth in the Amazon rainforest in the late 1870s. These dark soils were found in areas where the natural soil is generally thin, red, infertile, and acidic in nature. In contrast, the dark areas of Terra Preta soils are alkaline with high carbon content, containing potshards that indicated it was 


\section{Applying practical solutions}

man-made and not naturally occurring. It was revealed that this Terra Preta is a pre-Columbian civilization creation by indigenous peoples who learned that amending soil with charcoal provided benefits such as the sharp improvements in crop productivity observed by early European 'discoverers' (Bruges, 2009). What has been surprisingly demonstrated is that Terra Preta can maintain crop yields for centuries, something that even chemical fertilizers are incapable of doing for more than a comparatively abysmal three growing seasons. As observed in the Amazon rainforest, crops planted on Terra Preta produce yields of up to four times greater than the same types of crops planted on soil from similar parent material (Wayne, 2012).

The conclusion that has emerged is that biochar is an ancient practice that converts agricultural waste into a soil enhancer that can hold carbon, boost food security, and discourage deforestation. The process of making it creates a finegrained, highly porous charcoal that helps soils retain nutrients and water. In many places around the world, biochar is found in soils as a result of vegetation fires and historic soil management practices commonly used by indigenous peoples. What these indigenous groups learned was that biochar could be an important tool for improving food security and crop diversity on croplands with depleted or degraded soils, low SOM, and inadequate water resources (Jackson, 2010).

A point to note, however, is that a large number of pottery shards was mixed in with the biochar found in the stores of Terra Preta soils in the Amazon rainforest. These pottery shards, in addition to plant residues, animal feces, fish and animal bones, and other organic material, contributed nutrients such as nitrogen, phosphorus, calcium, zinc, and magnesium essential to maintaining high microorganism activity in the soil. This mulch mixture of organic waste and charcoal permeated the black soils with essential microorganisms crucial to soil productivity. This method of managing the soil was much different from simple slash and burn practices employed in India and Africa. While slash and burn improves soil fertility for brief periods, the addition of char and organic waste material ensures a longer-term effect on soil fertility, providing benefits for centuries (Bruges, 2009).

What the native people of the Amazon had discovered and applied was a method of enriching the poor Amazonian soils with easily made charcoal, thereby enabling a source of food for a large population of people. While highly speculative and difficult to support scientifically, it is possible that the discovery of biochar technology may have saved the Amazon rain forests from earlier loss of tree cover, as people sought the means to produce food to support their growing civilizations. That biochar may have played a significant role in environmental management in the past is not farfetched, however, as there is evidence to support the occurrence of deforestation in other parts of the world by indigenous groups living in Africa, the Americas, India, and Europe. It is obvious that pre-Columbian Indians identified, developed, and practiced a simple but effective method of soil conservation that has proven more advanced than any agricultural production methodology discovered before the Green Revolution. A concerted effort to merge Biochar Revolution techniques with certain Green Revolution 
applications may therefore prove to be a more valuable prospect than ever before considered.

\section{Net Primary Production (NPP) and carbon sequestration}

In order to produce biochar, biomass is required. From a human-centric perspective, there are two basic ways to produce biomass; one likely scenario would be biomass-derived from existing agricultural crop residues, the second being biomass sourced from dedicated biomass production systems such as fast-growing forests trees or woody shrubs. The International Biochar Initiative contends that biochar and bioenergy production from urban, agricultural, and forestry biomass residues can help combat global climate change through a number of different pathways. These include the (1) direct sequestration capacity of biochar and the creation of stable soil carbon pools, (2) displacement of carbon-positive fossil fuel energy, (3) increased global Net Primary Production from increased soil fertility, and (4) reduction of methane and nitrous oxide emissions. Regardless of the approach, the assumption must be that no new land clearance will be used to provide short-term biomass feedstock, nor would there be any conversion of agricultural land from food to biomass-crop production as a source of biochar feedstock because of the negative perception for food security.

Introduced and discussed briefly in Chapter 5, Net Primary Production (NPP) is defined by Huston and Wolverton (2009) as the net flux of carbon from the atmosphere into green plants per unit time. NPP directly refers to a rate process quantifying the amount of vegetable matter produced on a daily, weekly, or yearly basis in a given area of landspace. Whether measuring the rate at which photosynthesis occurs or the rate at which the individual plant increases in biomass, the general concern is with primary production (Townsend et al., 2008). The central idea is that new plant tissues are produced, and over time, primary production results in the addition of new plant biomass to the entire system.

Put simply, Primary Production is the fixation of energy by autotrophs (photosynthesizers) in an ecosystem. In order to distinguish usable energy created, ecologists distinguish between gross and net primary production. Gross Primary Production is the total amount of energy fixed by all the autotrophs in the ecosystem, whereas Net Primary Production is the amount of energy left over after autotrophs have met their own energetic needs. Net Primary Production is more clearly defined as Gross Primary Production minus respiration by primary producers, thus it is the total amount of energy available to the consumers in an ecosystem (Running et al., 2000). This makes NPP a fundamental ecological variable, not only because it measures the energy input to the biosphere and the terrestrial carbon dioxide assimilation by plants, but also because of its significance in indicating the condition of the land surface area and status of a wide range of interconnected ecological processes.

Anthropogenic activities which have given rise to changing terrestrial biological productivity has been considered by many scientists as the single most fundamental measure of global change. Biological productivity on earth is the source 


\section{Applying practical solutions}

of food for all humanity, beginning with the process of photosynthesis which is the means by which plants remove carbon dioxide from the atmosphere and use it to produce carbohydrates and sugars which are the basic compounds used for food and energy assimilation. Biological productivity provides fiber, as well as the means by which humans and all animal species survive, thus defining a fundamental variable contributing to the habitability of Earth.

Running et al. (2000) note that the spatial variability of net primary production over the Earth ranges from extremely high for Evergreen rain forests, to very low for desert habitats. In terms of NPP per unit area, ecological areas that are warm and wet generally are more productive, the most productive systems being estuaries followed by swamps and marshes, tropical rain forests, and temperate rain forests. These are followed by Northern coniferous forests, savannas, agricultural lands, woodlands, and shrub habitats (Townsend et al., 2008). Knowledge of NPP therefore offers a set of valuable data that, in a given ecological area, suggests the type of habitat best able to contribute to the highest rates of biomass production and may indicate the types of biomass from which biochar may be best produced. Table 9.1 provides a simple ranking of these ecological habitat types in terms of their relative net primary productivity potential.

With few exceptions, many of the ecological areas listed in Table 9.1 have been under threat from habitat loss over the last century. Tropical rain forests, however, with an abundance of biomass being harvested to satisfy demands for food, fiber, building materials, and depleted for various environmental services for Human needs, have faced a significant loss of land area in recent decades. The first Report of the World Commission on Forests (Krishnaswamy and Hanson, 1999) found that the Earth's forests are vanishing at 150,000 square kilometers $(93,205$ square miles) per year, with tropical rain forests suffering the loss of 140,000 square kilometers of this total per annum. Data derived from NASA images indicate that $55 \%$ of global deforestation is caused by slash-and-burn agriculture, $20 \%$ from

Table 9.1 Net primary productivity by ecological area

\begin{tabular}{ll}
\hline Ranking & Ecological Area \\
\hline 1 st & Estuaries \\
2nd & Swamps \\
3rd & Marshes \\
4th & Tropical rain forests \\
5 th & Temperate rain forests \\
6th & Northern conifer forests \\
7th & Savannas \\
8th & Woodlands \\
9th & Shrub habitats \\
\hline
\end{tabular}

Source: Townsend et al. (2008) 
logging, 15\% associated with roads and infrastructural construction, and 10\% attributed to cattle ranching operations.

Clark et al. (2001) believe that information on net primary production in tropical forests is needed for the development of realistic global carbon budgets. This is necessary for projecting how these ecosystems will be affected by climatic and atmospheric changes. Tropical forests, mostly patronized by the poorest residents of society, are disproportionately important in the world carbon budget, representing an estimated 59\% of the global carbon pool in forests. If biochar must play a significant role in carbon sequestration and sink, its feedstock sources and the environments from which these are sourced should become well understood and factored into the carbon dynamics equation. This is how poor countries could contribute significantly to global carbon sequestration even while enhancing their own opportunities for increased food and energy production.

The strong contemporary relationship between food and energy even outside the realm of fossil fuels must be revalued, and these associations must be considered within the context of the biogeochemical cycling of elements between the terrestrial biosphere and the atmosphere. Biochar programs must therefore be instituted in environments that are suitable, sustainable, and manageable, not simply in terms of the amount of biochar products that can be harvested and processed, but also in terms of the quality of the biochar products, the ecological habitat conditions in which it is considered for application, its contribution to NPP, and consequently its role in food and forests biomass generation.

\section{Biomass pyrolysis and biochar production}

A current dilemma in which humanity finds itself is that it has to meet necessary energy consumption needs while being ethically obligated to managing the levels of greenhouse gasses being emitted into the atmosphere at the same time. With this problem in mind, McLaughlin (2010) reasons that biomass is the renewable resource that has the best potential to affect energy-related greenhouse gas emissions, with multiple scenarios available by which biomass could influence the current energy consumption options. The natural ability of biomass to convert carbon dioxide into usable compounds as carbohydrates and sugars enables plants to sequester carbon into its tissues, release it to herbivores as food, or back into the soil when the plants or herbivores die. Biochar offers an improvement upon the natural ability of plants to sequester carbon, representing a product that arrives at its permanent state through the process of biomass pyrolysis, during which process there is the release of usable syngas and oils as one set of byproducts, the other being biochar itself.

Several variations of pyrolysis technology currently exist and have been emerging in recent years. These provide a range of conversion technologies from slow pyrolysis, fast pyrolysis, to gasification biomass conversion technologies, among other applications (McLaughlin, 2010). Essentially, the process of pyrolysis releases heat which can be used for electricity. This electricity can be used to replace existing power generating systems that currently use fossil fuels as the main source of 


\section{Applying practical solutions}

energy. What makes this particular approach unique is that a life cycle pattern emerges that shows a progression from biomass sequestration of carbon dioxide, through the pyrolysis of biomass that produces energy in several forms, and progressing through the production of biochar that when used as a soil amendment, performs the invaluable tasks of permanently sinking carbon into the soil. Consequently, a resilient systems cycle is generated, which provides a reasonable solution to the modern predicament of runaway greenhouse gas emissions, especially significant in places where fossil energy usage for development can be avoided.

It has been clearly observed and demonstrated that fossil fuel sources are finite and contribute significantly to greenhouse gas emissions. One way to diversify from the use of fossil fuel energy is to produce bioenergy from renewable biomass. Gaunt and Lehman (2008) espouse two scenarios for feedstock production through life cycle approaches involving (1) the use of crop wastes as feedstocks, and (2) through purpose-grown bioenergy crops. Kullander (2009) suggests that the most promising means of extracting energy from biomass is to focus on using the residues from forestry and agricultural operations. Certainly, the right sources

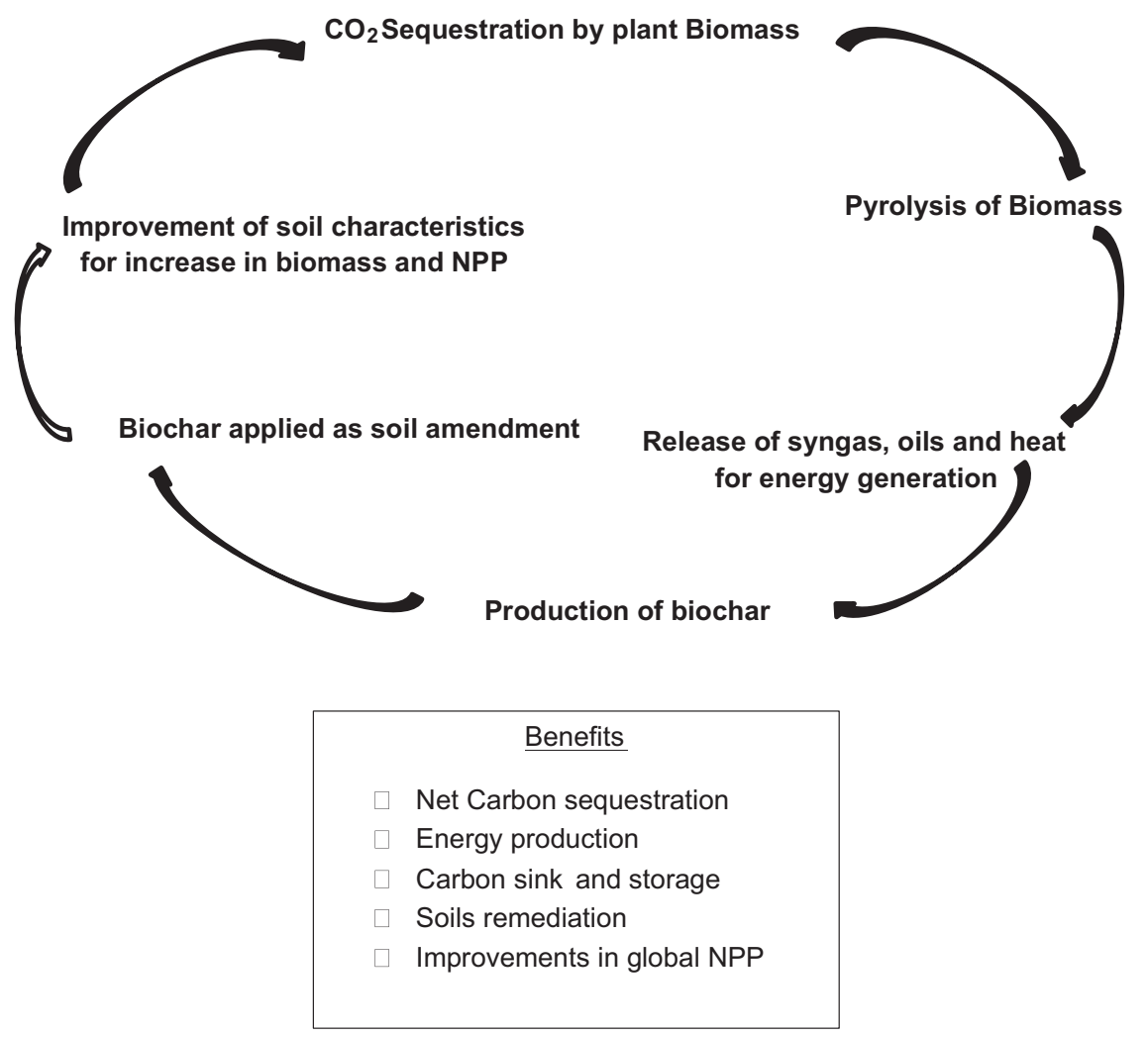

Figure 9.1 The resilient systems carbon cycle 
of biomass will have to be found, and improvements in the understanding of what types and species of plant biomass produce the best biochar under different ecological habitat and soil conditions will also have to be determined. Kullander (2009) believes that if this is done well, the current annual global bioenergy output may double from its present value of 13,000 Terawatt hours (TWh) in the next few decades.

\section{Re-inventing 'fire': a new look at energy from biomass}

Energy products can be derived from biomass through direct combustion as well as from a number of alternative routes that can be broadly divided into microbial fermentation (ethanol), extraction of oils (biodiesel), pyrolysis (heat), and gasification (electricity). Since biomass feedstocks can be processed for energy through any of these methods, the challenge presented to researchers as well as producers is to identify not only the most suitable feedstock available for energy, but the most efficient method by which energy can be extracted and utilized.

For example, when switchgrass is burned for energy, it produces 14.6 times more energy than the input of energy required to produce it. However, converting switchgrass to ethanol is calculated to consume $45 \%$ more energy than it costs to produce it (Pimentel and Patzek, 2005). In addition, switchgrass tends to become invasive in many places in which it is introduced, thereby posing significant risks to environmental habitats. Furthermore, many alternative bioenergy production systems such as corn ethanol and soy biodiesel have come under increasing scrutiny and criticism because they are seen to compete for land and other resources with food production systems, leading to higher food costs that has resulted in social conflicts in various parts of the world. From a purely economic perspective, the energy gains of corn ethanol and soy biodiesel are relatively low in comparison to the energy investment in fertilizers, tillage, and transportation (Lehman and Joseph, 2009), making these crops very expensive sources for alternative energy.

In many developing countries, particularly those with amenable soil and climate conditions for palm oil production, pressure for productive tillable land has led to increasing deforestation, often at the expense of indigenous groups and subsistence farmers who are driven off land they farmed for generations. In the case of Indonesia, although the Indonesian Constitution is meant to protect indigenous peoples' rights, a series of other policies and laws often allow these rights to be ignored in the national interest. Even where negotiations with local communities took place, native indigenous people were never given the chance to say no to the takeover of lands, and were never informed that their rights were being extinguished in the process of plantation development. A study conducted in 2006 by Colchester et al. reported that oil plantations covered more than 6 million hectares in Indonesia, most of this land being the ancestral lands of indigenous peoples. The report further stated that regional land use plans envisaged the clearance of a further 20 million hectares for expanding estates of palm oil. Clearly, bioenergy projects can be bad if they do not consider social factors at parity to economic and political factors. 
Despite criticisms as to whether the energetics derived from biomass energy are favorable when all inputs and processes are taken into account, research has provided strong evidence pointing to favorable energy outcomes of biomass energy projects. One such study is reported by Gaunt and Lehmann (2008), showing that low-temperature slow pyrolysis offers an energetically efficient strategy for bioenergy production, and the land application of biochar reduces greenhouse emissions by suppressing the release of both nitrous oxide and methane gasses from the soil. Rondon et al. (2005) found that methane emissions were completely suppressed and nitrous oxide emissions were reduced by $50 \%$ when biochar was applied to soil, and in a similar study, Yanai et al. (2007) also determined that nitrous oxide emissions were suppressed when biochar was added to soil.

Further benefits have been documented showing that the reduction in nitrous oxide emissions is consistent with the more widespread observation that fertilizers are used more efficiently by crops in situations where biochar is applied to soil. Equally compelling, Park et al. (2011) showed that biochar application was effective in metal immobilization by reducing the bioavailability and phytotoxicity of heavy metals from soils on which certain vegetables crops are grown. The energy dynamics of biomass is therefore quite pervasive and should be viewed not solely for those energy-generating processes that compete with fossil fuels, but also the manner in which energy and thermodynamic laws dictate conditions in soils amended with biochar, and the resulting biomass eco-systems that sprout up to sequester carbon dioxide from the atmosphere.

\section{The role of biochar in the development of carbon-negative energy systems}

Lehman and Joseph (2009) describe the creation of bioenergy through pyrolysis in combination with biochar sequestration of greenhouse gasses as the beginning of a biochar revolution. They believe that this is an approach that holds promise for obtaining energy while simultaneously improving the environment. According to the authors, for every unit of energy produced or possibly even consumed by this method, greenhouse gasses are removed from the atmosphere in correlating units. And not only does biochar improve microbial symbiosis in the soil for net primary productivity, it also immobilizes trace elements such as metals that are potentially deleterious to human and animal health.

During pyrolysis, thermal decomposition occurs where biomass starts to break down at a molecular level and volatile gasses called wood gas are released. Wood gas can be condensed to produce a liquid called pyrolysis oil. Both wood gas and pyrolysis oil can be used to make fuels that are cleaner and more efficient than the solid biomass, and at cost-effective production rates.

Pyrolysis has three advantages which make it less problematic than other proposed bioenergy systems (Gaunt and Lehman, 2008);

- Unlike first generation biofuels such as corn ethanol, pyrolysis has a relatively high net energy ratio (energy returned on energy invested - EROEI), suggesting it is energetically efficient. 
- Pyrolysis is capable of utilizing a wide variety of feedstock materials including waste streams and perennial bioenergy crops grown on marginal lands, thereby diminishing competition with land for food crops or the need for monoculture plantations.

- Nutrients and carbon can be cycled back into the ecosystems (including in marginal soils) through the application of biochar.

In the process of biomass pyrolysis, approximately half of the carbon is released as carbon dioxide, while the other half is trapped within the biochar co-product (McLaughlin, 2010). Even if all the carbon was released during this process, it would still be considered carbon neutral because plants originally removed the carbon from the atmosphere through photosynthesis. When the biochar feedstock material is sourced in a sustainable manner, a greater portion of carbon is trapped than is released during the full-life cycle production of biochar. McLaughlin (2010) offers further clarity in noting that biochar applications would be carbonnegative in the soil by the amount of elemental carbon in the biochar that is calculated and predicted to be stable in the soil, converted to the carbon dioxide equivalent (CO2e). The assertion is that if the biochar were used to substitute for a fossil fuel such as coal, it would be additionally carbon-negative by the amount of carbon dioxide emissions avoided by not using that fossil fuel.

What emerges from these arguments is that biomass to bioenergy conversion and biochar production are potentially superior to fossil fuels on the basis of being carbon-negative, having impacts through avoided emissions from fossil fuels, as well as by providing a stable sink for carbon dioxide in the soil. Because of the possibility of sequestering more carbon than is produced, biochar has been labeled a 'carbon-negative' energy source. Gaunt and Lehman (2008) declare that the chief benefit of biochar over many other bioenergy technologies is the wide variety of feedstocks from which it can be made, as well as the fact that it can produce a variety of energy outputs from these feedstocks. As listed earlier, these energy outputs include syngas, electricity, bio-oil, hydrogen, nitrogenous fertilizer, heat, and, of course, biochar. This flexibility in both input and output provides biochar production with a strong advantage over many other bioenergy systems.

Carbonization, the traditional method for making charcoal, emits greenhouse gasses such as methane and sooty black particles in the smoke that is considered undesirable in modern energy generation. Carbonization as a method of making charcoal is practiced in many developing countries, and was quite likely the process used in making the biochar rich Amazon soils now referred to as Terra Preta. Biochar can be made by several different methods including slow pyrolysis, fast pyrolysis, gasification, and carbonization. Each of these has costs and benefits, but slow pyrolysis is considered to be slightly more technologically advanced and able to optimize for biochar production with approximately $40 \%$ of the biomass transformed into biochar (Lehman and Joseph, 2009).

On the other hand, fast pyrolysis is generally used to maximize the production of bio-oils, but the process also generates a significant amount of biochar as a co-product. The gasification of biomass for energy production aims at producing 
wood gas, and results in minimal biochar production which occurs as a by-product (McLaughlin, 2010). The variety of methods available for producing biochar therefore can be optimized for different circumstances and product output, adding flexibility and adaptability to techniques that can be used virtually anywhere in the world. What differentiates modern methods of biochar production from the less efficient traditional charcoal-making approach is that in modern pyrolysis (such as cookstoves and kilns) or in combined heat and power bioenergy power stations, dangerous wood gasses are re-combusted in order to reduce or eliminate hazardous emissions.

A series of studies conducted between 2009 and 2014 show that key chemical and physical properties of biochar are greatly affected both by choice of feedstock and process conditions such as temperature and time. These chemical and physical properties affect the interactions biochar has within the environment of its application as well as its fate in the soil once it has been applied. Currently, there is no foolproof screening technique that provides the means for biochar products to be compared or matched to a particular site. The development of such a technique would provide a tremendous boost to the field of biochar development and production.

\section{Distributed energy from biomass pyrolysis}

Primarily driven by environmental concerns, there is growing pressure for the generation of more electricity from renewables. Improving energy efficiency has promoted the application of distributed energy resources (DER) from varied, multiple, smaller energy generating units into existing electricity systems. Conventionally, power plants have been large centralized units, but there is an emerging trend toward distributed energy generation in which energy conversion units are situated close to energy consumers, and large units are substituted by a network of smaller ones (Alanne and Saari, 2006). A distributed energy system is considered by many to be an efficient, reliable, environmentally friendly alternative to the traditional energy system. Others point to a distributed energy system as being important to national security, because the distributed nature of the energy supply is harder to target for damage or destruction.

Reinholde (2012) provides the following reasons why biochar from combined heat and biochar $(\mathrm{CHAB})$ energy generating processes play an important role in distributed energy approaches.

- Small distributed facilities limit the need to transport fuel over great distances, both reducing costs and improving the environmental performance of justifying biomass usage

- Biochar is a highly valuable product when adequately produced and utilized

- Combined electricity, heat and biochar production becomes an attractive alternative to combined heat and power (CHP) in places with limited lowtemperature heat energy demand. 
Among the proponents of combined heat and biochar, the organizers of CHAB Camp (Paul Anderson, Thomas Reed, and Hugh McLaughlin) point out that society has hundreds of reasonably priced devices that use wood and other biomass as fuel, deliver usable heat, and generate ash. In the promotional material for the inaugural CHAB Camp in 2010, they indicated that

a similar selection of devices could be developed to consume biomass, provide usable heat, and create a solid residue that would perform as an acceptable biochar. Distributed biochar production by CHAB devices in affluent and impoverished societies worldwide can make an important contribution to the diverse biochar objectives.

(CHAB Camp, 2010, p. 2)

These efforts are notable and are not isolated incidences of recent progress. Gaunt and Lehman (2008) acknowledge that while many systems are currently being researched, piloted, and deployed, there remains significant work to be done on creating economically viable biochar production systems. With increasing recognition of biochar systems as a viable bioenergy with associated benefits for soil productivity, the existing market void for effective production systems is likely to be quickly filled by a host of competing technologies with unique production scales and strategies. Gaunt and Lehman (2008) think it will take some time during which these technologies will have to be tested in the real world before the most effective technologies can be identified, and the most efficient means for biochar production are determined for various operators and bioregions.

From all appearances, simple biochar technologies have indeed begun to run the gambit of real-world applications. Anderson (2012) reports that the use of dry biomass for heat generation ranging from small cookstoves up to giant installations are increasingly being made and used in various places around the world. Accordingly, the use of biomass gasification units of the 'mini sizes' are being better understood both in terms of the applied technology and the economic context in which they are used. Where labor is inexpensive, machines are available in sizes that can be manually operated, whereas where labor is expensive, they are large enough in thermal output to justify capital investments as heating equipment, as well as for charging modern batteries.

Judging from what has already been achieved in countries such as Kenya, Malaysia, India, Australia, and the U.S., Anderson's prediction is that their uses for heating moderate buildings and for institutional-size cooking will become increasingly common in the next few years, and as well, the production of biochar in devices the size of standard 55-gallon (200 liter) barrels is also likely to become widespread. With more than 3 billion people in the world living at or below the poverty line - and most of them living in developing countries where Green Revolution technologies are yet to affect their livelihoods - taking a combined approach through low-carbon faming technologies along with biochar approaches to reducing energy and food poverty will have a two-fold impact. In one instance the soil environment will benefit tremendously, and second, the global emission 


\section{Applying practical solutions}

of greenhouse gasses will be halted. The prospect of the poorest citizens of the Earth making an impact on the Earth's most pressing problem is indeed food for thought, and certainly an undertaking to ponder. The price of fixing the anthropogenic world may therefore be paid to the developing world, perhaps with contemplation of the compensation being reparations for past atrocities against both people and land. After all, it is they that have borne the full cost of the damage done so far.

\section{References}

Alanne, K., and Saari, A. (2006). Distributed energy generation and sustainable development. Renewable and Sustainable Energy Reviews. (Vol. 10, Issue 6, pp. 539-558).

Anderson, P.S. (2012). Barrel-size micro-gasification for combined heat and biochar (CHAB) in "Mini" industries. ETHOS Conference of 2012, January 29. Seattle-Kirkland, WA. Retrieved from www.vrac.iastate.edu/ethos/files/ethos2012/SunAM/Anderson Microgasification \%20for\%20 combined\%20heat\%20and\%20biochar\%20in\%20 Mini\%20Industries.pdf

Bates, A. (2010). The biochar solution: Carbon farming and climate change. Gabriola Island, British Columbia: New Society Publishers.

Bruges, J. (2009). The biochar debate: Charcoal's potential to reverse climate change and build soil fertility. White River Junction, VT: Chelsea Green Publishing.

CHAB Camp. (2010). Hands-on development of "combined heat and biochar" devices. Paul Anderson, Thomas Reed, and Hugh McLaughlin. New England Small Farm Institute (NESFI), Belchertown, MA. Retrieved from http://terrapreta.bioenergylists.org/files/ CHAB\%20Camp\%20info\%20from\%20abstract\%20for\%20IBI.pdf

Clark, D.A., Brown, S., Kicklighter, D.W., Chambers, J.Q., Tomlinson, J.R., Ni, J., and Holland, E.A. (2001). Net primary production in tropical forests: An evaluation and the synthesis of existence the data. Ecological Applications. (Vol. 11, Issue 2, pp. 371-384). Retrieved from ftp://ftp.forest.sr.unh.edu/pub/MLSmith/John\%20R/Backup/ NPP,carbon\%20pub/i1051-0761-011-02-0371.pdf

Colchester, C., Andiko, J.N., Sirait, M., Firdaus, A.Y., Surambo, A., and Pane, H. (2006). Promised land: Palm oil and land acquisition in Indonesia: Implications for local communities indigenous peoples. Moreton-in-Marsh, England: Forest Peoples' Program (FPP).

Domingues, R., Trugilho, P.F., Silva, C.A., de Melo, I., Melo, L., Magriotis, Z., and Sánchez-Monedero, M. (2017). Properties of biochar derived from wood and high-nutrient biomasses with the aim of agronomic and environmental benefits. PLoS ONE. (Vol. 12, Issue 5, p. e0176884). doi: 10.1371/journal.pone.0176884

Ecological Society of America. (2000). Carbon sequestration selects. Author. Retrieved from www.esa.org/education_diversity/pdDocs/carbonsequestrationinsoils.pdf

Gaunt, J.L., and Lehman, J. (2008). Energy balance and emissions associated with biochar sequestration and pyrolysis bioenergy production. (Vol. 42, Issue 11, pp. 4152-4158). doi: $10.1021 / \mathrm{es} 071361 \mathrm{i}$

Hunt, J., DuPonte, M., Sato, D., and Kawabata, A. (2010). The basics of biochar: A natural soil amendment. College of Tropical Agriculture and Human Resources. University of Hawaii at Manoa. Soil and Crop Management. December. Retrieved from www.ctahr. hawaii.edu/oc/freepubs/pdf/SCM-30.pdf

Huston, M.A., and Wolverton, S. (2009). The global distribution of net primary production: Resolving the paradox. Ecological Monographs. (Vol. 79, pp. 343-377). Retrieved from http://dx.doi.org/10.1890/08-0588.1 
Jackson, J. (2010). Biochar: Wisdom of ancient Amazonians may hold secrets of carbon capture. Environment and Technology. Retrieved from www.earthtimes.org/articles/ news/353300,biochar-wisdom-of-ancient-amazonians-may-hold-secrets-of.html

Krishnaswamy, A., and Hanson, A. (Eds.). (1999). Our forests, our future. World Commission on Forests and Sustainable Development. Retrieved from http://www.iisd.org/sites/ default/files/publications/wcfsdsummary.pdf

Kullander, S. (2009). Energy from biomass. The European Physical Journal: Special Topics. (Vol. 176, Issue 1, pp. 115-125). doi: 10.1140/epjst/e2009-01152-1

Lehman, J., and Joseph, S. (Eds.). (2009). Biochar for environmental management: Science and Technology. Sterling, VA: Earthscan.

Major, J., McLaughlin, H., Hepperly, P., Knight, E., Yarrow, D., and Mitchell, S. (2010). Biochar: A field guide for gardeners and farmers. Smashwords edition. EcoTechnologies. Retrieved from https://www.kobo.com/us/en/ebook/biochar-a-field-guide-for-gardeners-and-farmers

McLaughlin, H. (2010). Biochar and energy linkages in: Biochar and energy co-products. Assessments of Biochar's Benefits for the United States of America. Retrieved from www. biochar-us.org/pdf\%20files/biochar_report_lowres.pdf

Park, J.H., Choppala, G.K., Bolan, N.S., Chung, J.W., and Chuasavathi, T. (2011). Biochar reduces the bioavailability and phytotoxicity of heavy metals. Plant and Soil. (Vol. 348, Issue 1-2, pp. 439-451). doi: 10.1007/s11104-011-0948-y

Pimentel, D., and Patzek, T.W. (2005). Ethanol production using corn, switchgrass, and wood: Biodiesel production using soybean and sunflower. Natural Resources Research. (Vol. 14, Issue 1, pp. 65-76). doi: 10.1007/s11053-005-4679-8. Retrieved from www. c4aqe.org/Economics_of_Ethanol/ethanol.2005.pdf

Reinholde, E. (2012). Cost competitive biomass gasification for power, heat, and biochar production. Presented at Biomass 2012: Confronting Challenges Creating Opportunities: Sustaining Commitment to Bioenergy. July 10. Retrieved from www1.eere.energy.gov/ biomass/pdfs/b12_reinholde_1-c.pdf

Rondon, M., Ramirez, J., and Lehmann, J. (2005). Charcoal additions reduce net emissions of greenhouse gases to the atmosphere. Proceedings of the 3rd USDA Symposium on Greenhouse Gases and Carbon Sequestration, March 21-24, p. 208. Baltimore, MD.

Running, S.W., Thornton, P.E., Nemani, R., and Glassy, J.M. (2000). Global terrestrial gross and net primary productivity from the earth observing system. InSala, O.E., Jackson, R.B., Mooney, H.A., and Howarth, R.W. (Eds.). Methods in ecosystem science. New York, NY: Springer-Verlag.

Sanderman, J., Farquharson, R., and Baldock, J. (2010). Soil carbon sequestration potential: A review for Australian agriculture. CSIRO Land and Water, Australian Government, Department of Climate Change and Energy Efficiency. Retrieved from www.csiro.au/en/ Portals/Publications/Research - Reports/Soil-Carbon-Sequestration-Potential-Report.aspx

Sundermeier, A., Reeder, R., and Lal, R. (2005). Soil carbon sequestration: Fundamentals. Extension Factsheet. Ohio State University Extension. AEX-510-05. Retrieved from http://ohioline.osu.edu/aex-fact/pdf/0510.pdf

Townsend, C.R., Harper, J.L., and Begon, M. (2008). Essentials of ecology. Malden, MA: John Wiley \& Sons.

Wayne, E. (2012). Conquistadors, cannibals and climate change: A brief history of biochar. Oxford University, Pro-Natura International. June. Retrieved from www.pronatura. org/wp-content/uploads/2012/07/History-of-biochar.pdf

Yanai, Y., Toyota, K., and Okazaki, M. (2007). Effects of charcoal addition on N2O emissions from soil resulting from rewetting air-dried soil in short-term incubation experiments. Soil Science and Plant Nutrition. (Vol. 53, pp. 181-188). doi: 10.1111/j.1747-0765. 2007.00123.x 


\section{Biochar in the age of renewable energy policy}

\section{Cogeneration in the U.S. - a look at energy policies and incentives}

Yale University's office of sustainability (2012) defines cogeneration to be the production of both heat and electricity from a single fuel source. Also known as combined heat and power or CHP, cogeneration is considered to be a highly efficient system, capturing heat lost during the production of electricity and converting it into useful heat energy. The thermal energy captured during the generation of electricity is usually made available in the form of steam or hot water. The efficiency of traditional power plants that generate electricity is estimated at $32 \%$. For comparison, cogeneration systems are typically $60-80 \%$ efficient, effectively more than doubling the efficiency rate of traditional electrical power plants. These efficiency gains result not only in cost savings but in reduced air pollution and lower or negative greenhouse gas emissions. Added benefits include increased power reliability and quality, reduced grid congestion, and avoided distribution losses which are problems often besetting contemporary energy generating systems.

According to a report from the EPA in 2012, the average efficiency of power generation in the U.S. has remained at 34\% since the 1960 s, with the annual energy lost in wasted heat from power generation being greater than the total energy use of the entire country of Japan. CHP has been in use in the U.S. in some form or another for more than 100 years, but remains an underutilized resource for various reasons. Representing approximately $8 \%$ of U.S. generating capacity compared to over $30 \%$ in countries such as Denmark, Finland, and the Netherlands, there is an obvious need to tackle and remove the constraining factors which include a host of market and non-market barriers.

Recognizing the benefits of CHP and its current underutilization as an energy resource in the U.S., the EPA announced that the Obama Administration would begin in 2012 to support a new challenge to achieve 40 gigawatts (GW) of new, cost-effective CHP by 2020. The objectives outlined for achieving this goal would:

- Increase total CHP capacity in the U.S. by 50\% in less than a decade

- Save energy users $\$ 10$ billion a year compared to pre-2012 energy use 
- Save 1 quadrillion Btu's of energy - the equivalent of $1 \%$ of all energy use in the U.S.

- Reduce emissions by 150 million metric tons of $\mathrm{CO}_{2}$ annually - equivalent to the emissions from over 25 million cars

- Result in $\$ 40-\$ 80$ billion in new capital investment in manufacturing and other U.S. facilities over the decade between 2012 and 2022.

As far back as 2001, the EPA established the combined heat and power (CHP) partnerships to encourage cost-effective CHP projects in the U.S. The CHP Partnership was intended to foster cooperative relationships with the CHP industry, state and local governments, and other relevant stakeholders including facilities in the industrial, commercial, district energy and institutional sectors; project developers; equipment suppliers; state, local, and tribal energy; environmental and economic development agencies, as well as CHP end users. The goals outlined by the EPA can only be achieved through the promotion of these utility partnerships with the CHP industry to reduce risk to potential users, the encouragement of effective and innovative CHP policies and financing, as well as encouraging highly efficient CHP to be used in areas where new generation capacity is needed (EPA, 2012).

The proposed partnerships and initiatives were also intended to provide opportunities for biochar operators to increase their visibility with agencies like the EPA. While biochar technology is playing catch-up in the U.S. with other more established CHP technologies using various fuel sources, it is important to note that combined with the recognized virtues of $\mathrm{CHP}$, biomass pyrolysis provides a compelling means for removing carbon dioxide from the atmosphere as well as stemming the release of other important greenhouse gasses. Once fully recognized as an important means of sequestering, sinking, and storing carbon dioxide, it should not be long before combined heat and biochar (CHAB) receives increased investments that improve the technology and make it an acceptable method of cogeneration in the U.S. Environmental benefits such as reduced emissions that are generated by combined heat and power systems including biochar are also quantifiable and thus easily monetized.

Up until the end of Obama's presidency in 2016, many states offered financial incentives or revenue streams for emissions reductions and other environmental attributes that were designed to reward highly efficient or renewably fueled generation projects like CHP. It stood to reason that biochar projects would benefit not only from federal agencies, but also from incentive programs offered by state and local governments as these entities continued to create regulatory incentives to recognize and reward technologies using biomass, mainly because of the positive environmental attributes they possess. Some of these revenue streams for biomass CHP projects included emissions cap-and-trade allowances, new source emission offsets, carbon dioxide offsets, energy portfolio standard certificates, and voluntary market renewable energy certificates. Various forms of these revenue streams from biomass have been adopted by State legislatures and practiced in California, Colorado, and Minnesota (Dettmann et al., 2011). The programs 


\section{Applying practical solutions}

provided financial incentives for the promotion of new environmentally beneficial sources of energy generation, and although there is a great degree of variability in the structure and value of the different programs, in general they provided either capital-cost offsets or production-based funding mechanisms. With the end of the Obama administration, however, the EPA has taken on a different ideological outlook, so while the information on combined heat and power partnerships remains on the agency's website (as of November 2017), it is unclear what direction the partnerships will take during the Donald Trump presidency.

\section{Pro biochar policies and initiatives: limitations and constraints}

Several countries have established targeted initiatives that promise to include biochar from biomass within the framework of their renewable energy policies. In Australia, the Carbon Farming Initiative (CFI) has been introduced to allow landholders to generate offset credits from activities that reduce emissions or sequester carbon, especially including biochar applications to farm soils (Cowie, 2012). In the U.S., the International Biochar Initiative reports that the American Power Act - a plan to secure America's energy future, contains several important provisions to support deployment of biochar as a climate mitigation and adaptation tool. The bill, drafted by Senators Kerry and Lieberman in 2010 was touted by Kerry to be supported by a wide and deep coalition of business leaders, environmentalists, political leaders, and others (American Power Act, 2010), but has not achieved the necessary consensus for its passage to date.

External to the issue of policy, certain challenges exist which have been dampening efforts to establish combined heat and biochar initiatives. Writing in the Spring 2012 issue of Silviculture Magazine, Scholefield (2012) states that as awareness of biochar and $\mathrm{CHAB}$ furnaces build, there are several challenges to overcome, the first being barriers to investment. What currently exist are welldeveloped distribution networks for fossil fuels and relatively low investment requirements for traditional furnaces and boilers, together suppressing incentives to adopt CHAB systems. It will therefore be critical for proponents to secure a biomass feedstock supply to provide sustainably reliable sources of biomass feedstock for the CHAB system, and transportation and service logistics must be thoroughly evaluated before committing to the technology purchase.

Factors relating to research and development are also paramount. Many $\mathrm{CHAB}$ reactors are presently in research and development phases with new products coming on line, but investments in these initiatives also require funding which has not been easily forthcoming. Proponents are confident, however, that as the demand for $\mathrm{CHAB}$ systems increase, advances in technology and the availability of feedstock and systems to support these ventures will be advanced. The most successful projects are characterized by joint ventures, partnerships, and collaboration such as found in the EPA's partnership program, so the hope is that the biochar community will rally together to address the constraints (Scholefield, 2012). 
Several issues act as constraints on the full recognition and support of biochar production techniques on the same level as combined heat and power (CHP) technologies. Attempting to engender a better understanding of the specific limitations, Brick (2010) explains that biochar production and utilization systems (BPUS) entail three components - feedstock acquisition and preparation, feedstock conversion, and biochar handling, transport, and application. Much of the data and information on biochar and $\mathrm{CHAB}$ devices has been gathered from small units which have been mostly tested in the laboratory environment. While the data has been useful for extrapolation, there is little expectation at this point that it will generate enough investment interest before these systems are tested on a commercial scale. There are a few large pilot-sized facilities that produce greater amounts of char and that are more useful for understanding potential economic and environmental issues associated with conversion. These systems, however, do not provide full insight into feedstock acquisition and preparation or biochar handling, transport, or application - these being critical aspects of the system from both an economic and an environmental standpoint.

Brick (2010) determines that the projects that have produced most of the biochar used in actual field trials were pilot projects. It is the argument here that because biochar characteristics are variable, depending on the feedstock and the processing methods used, the data from a pilot project is limited to source, process, place, and purpose. Stated another way, biochar's agronomic impact will depend on the kind of biomass, the pyrolysis method used, the soil type on which the biochar will be added, and the type of crop to be grown. Each feedstock conversion application combination therefore presents a unique situation, but fortunately, work has begun on a biochar classification scheme that may ultimately yield a useful predictive system. However, at the present time, chemical analysis of individual chars combined with field trials is the only tool available for evaluating biochar impacts, thereby placing pressure on researchers and producers to find more compelling means of assessment.

\section{Biochar's role in sustainable agriculture and forestry}

The second law of thermodynamics is inserted into the context of sustainable agriculture by Bates (2010), who argues that entropy is tirelessly at work to disperse energy and matter, and for this reason, concentrations of virtually anything have been a source of wealth since the dawn of history. Historically, forests, spices, fish, and game animals, as well as fertile soils have conferred wealth on people and on communities, just as in contemporary times the concentrations of materials such as minerals and hydrocarbons have afforded the acquisition of wealth. There may not be current conversation about biochar had there not been the discovery of Terra Preta in the Amazon. Bates (2010) notes that the genius of the makers of Terra Preta was that they concentrated nutrient flows sourced from rivers, lakes, estuaries, fuels, and forests into the places where they prepared food, lived, and tilled the soil. This was indeed genius behavior, for instead of dispersing those nutrients away by simply burning their wastes in the open air, the 
indigenous peoples used pyrolysis to conserve the elements that were needed to confer soil fertility to their farms. Essentially, this behavior makes biochar applications an investment in a wealth-generating mechanism. This may be as true today as it was for the Indian tribes who made the first Terra Preta soils.

In stark contrast to the conservation approaches practiced by the indigenous peoples of the Amazon, modern agriculture utilizes an approach where soil elements are quickly dispersed from their points of origin. Modern commerce is a principal export mechanism and it has become the conduit through which wealth is imparted to a few at the top of the wealth pyramid, but at the same time it gradually depletes the stores of natural resources originally available in a particular place. Commerce, therefore, is a very efficient method of accumulating wealth to a few at the distant top, but it only does so by depleting and dispersing natural resources from various source points to specific commercial destinations.

Bates (2010) explains that carbon can only be stored in one of four reservoirs soil, atmosphere, oceans/seas, and life. In order for planet Earth to remain relatively 'cool', there is a need to store carbon mostly within the terrestrial biosphere, a reservoir that provides the largest and safest repository for carbon. The practice of agriculture has come to depend directly on fossil energy in order for work to be carried out, and there is also indirect dependency upon petroleum through the application of hydrocarbons in the form of plastics, lubricants, herbicides, and pesticides. This dependency triggered the overuse and degradation of soil resources that in turn has caused the global economy to shift carbon from the terrestrial biosphere into one or more of the other three reservoirs. As a result of this shift, the atmosphere is now overflowing with carbon as carbon dioxide, and Earth is responding to this pressure by overheating from its greenhouse effect.

As world population increases, there is a corresponding increase in the demand for land resources to grow crops and rear animals for human consumption. In most developing countries where populations are increasing the fastest, sizable acreages are being converted to crop and grazing lands, and primary forests are being felled at alarming rates in order to satisfy burgeoning demands (Figure 10.1). The Global Forest Resources Assessment 2010 (FRA, 2010) examined the trends for about 90 variables covering the extent, condition, uses, and values of forests and other wooded land, with the aim of assessing all benefits from forest resources.

The report showed that the annual net conversion from forest land use to other land uses averaged 4.9 million hectares per year over the 15-year period from 1990 to 2005.

The need to reduce and halt greenhouse gas emissions to the atmosphere has been recognized for several decades. Scientist recognize that we are very close to the tipping point from which cumulative greenhouse gas emissions may result in irreversible global changes to planet Earth. Besides the proposal for extravagant designs that will enable the capture and storage of carbon deep beneath the ocean, the terrestrial biosphere offers a reasonable and relatively easy approach to sequestering carbon dioxide through the process of photosynthesis by green plants. Bates (2010) suggests that only by way of the 'life' reservoir can we stuff carbon into the deeper earth reservoir in a cost-effective way. The way to do this is by investing 
Very degraded soil

Degraded soil

Stable soil

Without vegetation

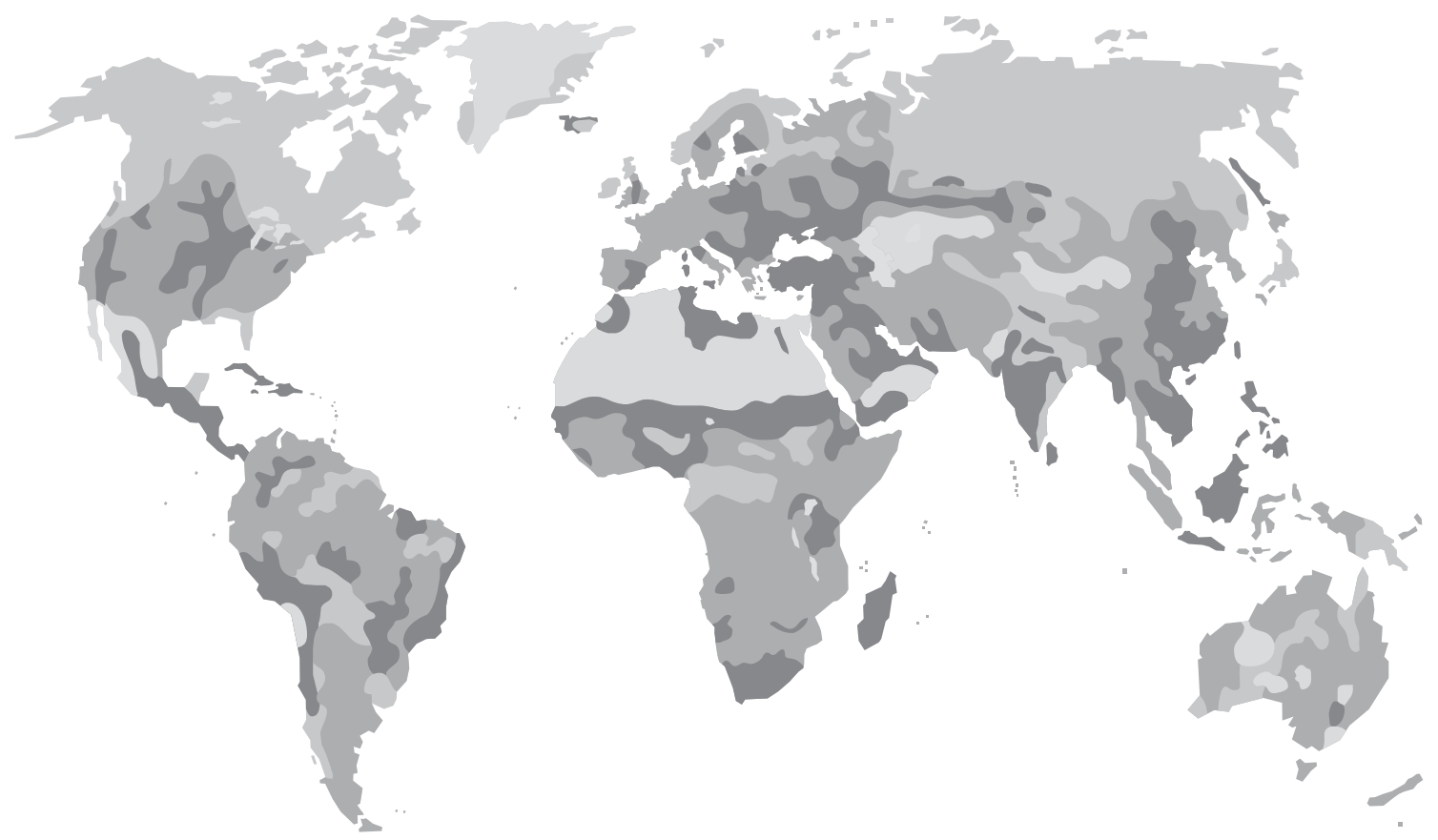

Figure 10.1 Degraded soils - world

Source: Living Planet Report, 2016, p. 53 
more carbon into growing plants by the process of NPP, and to grow these plants over more of the surface of the planet than is currently being done (Bates, 2010).

One of the important challenges of modern agriculture is the need to meet the growing demand for safe and nutritious food and renewable materials, and finding the means to do this in a manner that conserves natural resources and biodiversity for future generations. Amidst specific constraints such as those intertwined in the productivity gains that are essential for satisfying the demand for food, agricultural, and forestry products, there are other related problems impacting agriculture. Problems such as adverse weather conditions, depleted soils, pests and diseases overload, and scarcity of water are modern challenges never seen before. In many parts of the world, soil erosion causes the loss of millions of hectares of farmland, forcing farmers to find new land for farming, often at the expense of delicate natural habitats (Shikwati, 2011). Productivity is determined by the availability of rain and fresh water to irrigate crops, and while the often inappropriate use and overuse of agrochemicals pollutes waterways, agriculture relies heavily on the availability of fresh water, a resource that is becoming increasingly scarce and harder to access.

Faced with the challenge to keep pace with increasing food demands, farmers in industrialized countries are met with the simultaneous demands of managing plant nutrients in order to maintain high crop productivity, while minimizing environmental impact and maintaining soil quality. Many have changed the way they farm, opting for sustainable approaches that offer the means of managing nutrients while minimizing environmental impact. Hunt et al. (2010) report that several studies in both tropical and temperate climates have demonstrated biochar's ability to increase plant growth, reduce leaching of nutrients, increase water retention, and increase microbial activity.

Studies conducted on Colombian Oxisol (a soil type common in Hawai'i) showed a total aboveground plant biomass increase of $189 \%$ when biochar was applied at a rate of 23.2 tons per hectare. Biochar research also indicates that both biological nitrogen fixation and beneficial mycorrhizal relationships in common beans were enhanced by biochar applications, while the occurrence of native plant species increased by $63 \%$ in areas where biochar was applied on soils in studies conducted in Brazil. Hunt et al. (2010) also cite Cheng et al. (2006, 2008); and Major et al. (2010), who conducted several studies showing that the characteristics of biochar most important to plant growth can improve over time well after its initial incorporation into soil.

What these studies show, as demonstrated by the performance of Terra Preta soils in the Amazon region, is that biochar possesses special characteristics that improve crop productivity, sinks and stores stable carbon in terrestrial soils, reverses soil acidification, and changes the thermodynamic relationships between soil nutrients, soil microbes and plant root systems. In slowing the process of entropy that has been a major harbinger of the collateral damage of modern agricultural systems, biochar application approaches which are hinged on carbon storage in the soil may hold the key to future agricultural productivity comparable to Green Revolution gains. 


\section{Impacts on the global poor}

Tejerina (2010) makes an important point in noting that land degradation results from disturbances which are often linked to climate change. Positive feedback loops mean that land degradation compounds and worsens climate change, in turn increasing the tendency for ecological disturbances which lead to dangerous disruptions in the Earth's biogeochemical cycles. Climate change and land degradation mutually reinforce each other and can be represented by a vicious cycle that creates and perpetuates poverty in those parts of the world susceptible to the most significant climatic disturbances. As Tejerina (2010) notes, poverty itself is not a major cause of land degradation and climate change, but it is affected by both in a mutually reinforcing cycle, thus completing a downward spiral.

Despite the common perception that capitalism as an economic model has created conditions for upward mobility out of poverty, there is only a relatively small group of countries that have propelled their economies since the Industrial Revolution, typically with the use of fossil fuels. The result, however, has been changes in climate with adverse impacts that continue to affect poor nations disproportionally, largely due to their geographical and climatic conditions, relatively higher dependence on natural resources, and their limited capacity to adapt to change (Hunt et al., 2010).

Since the beginning of the Industrial Revolution, there has been steady global population growth that has placed increasing pressure on land for food production, often leading to increased rates of land degradation, especially in places where financial resources are scarce, thus restricting the ability to adapt to the challenges being confronted. The consequence of this has been sharp increases in food prices that have given rise to major concerns over the food security of the world's most vulnerable peoples. With close to $50 \%$ of the world's population lacking access to modern energy, emerging economies containing a proportionately large number of poor people will continue to be affected by fragile environmental balances, serious crop failures, and rampant food shortages.

Consensus exists that bioenergy plays an important role in achieving economic growth through carbon-negative approaches such as biomass energy and biochar production (Muradov and Veziroglu, 2008). Biomass is one of the most plentiful and well-utilized sources of renewable energy in the world, with much of the biomass-derived fuels currently in use coming from wood products, dried vegetation, crop residues, and aquatic plants. Over the past 20 years, the use of biomass as a source of renewable energy has increased relative to hydropower in the generation of electricity, and it recently surpassed hydropower in becoming the most commonly used renewable energy source (Mohan et al., 2005). Biomass is a widely utilized source of energy due to its low cost and indigenous nature, accounting for almost $15 \%$ of the world's total energy supply and as much as $35 \%$ in developing countries where it is mostly used for cooking and heating (Yamamoto et al., 2001). In many developing countries, particularly those in Africa, biomass fuels are vital to basic welfare and economic activity, contributing approximately $90 \%$ of household energy needs. 


\section{Applying practical solutions}

The tragedy of biomass, however, is that in developing countries, it is generally used in open hearths or simple stoves that are inefficient and polluting, causing negative impacts on human health. The combustion of biomass fuels also emits pollutants that cause 1.6 million deaths globally each year, most victims being women and children who spend considerably more time around smoke-filled open woodstoves and firesides (Kammen, 2006).

Wood harvested from trees has been the most common biomass used for energy almost everywhere on earth. Humans have used wood for heating and cooking for a very long time, and woody biomass has been converted by pyrolysis to charcoal for thousands of years. As far back as the Iron Age, the pyrolysis process of making charcoal has been used for forging metals and for light industry (Bates, 2010). In the 1600s, England experienced an energy crisis due to a shortage of wood. During this period, much of northern England, Scotland, and Ireland were deforested to produce the charcoal and wood products that formed part of the backbone of the early Industrial Revolution. It was this crisis that triggered the move toward the mining of coal for energy, and coal was eventually substituted for wood and charcoal as the main fuel source for domestic purposes, the use of these fuels eventually spreading to America (Smil, 1999).

In the last 30 years, new technological innovations in bioenergy have opened the door to a revolution in commercial bioenergy production. These innovations have seen improvements in the development of renewable energy such as ethanol, methanol, and biodiesel production and in the gasification of biofuels. Countries such as Brazil have exemplified these advances in its significant success with using sugarcane for ethanol. What this has done is to dramatically reduce the need for imported oil and gas into Brazil, making this country unique in its ability to supply a sizeable amount of its fuel energy from domestic biomass sources. In the years since Brazil invested in ethanol bioenergy, the country has seen an almost 50\% decline in gasoline use, a situation that induced significant cutback on expenditure for fossil energy. A major economic value derived from this investment in renewable energy has been the creation of jobs and related business investment opportunities in the sector, which has been a major part of the economic improvement in Brazil's economy in the last 25 years (Kammen, 2006).

In various developing countries, crop residues form an important potential biomass energy source, especially in densely populated regions where much of the land is used for food production. Kammen (2006) reports that as far back as 1996 China generated crop residues in the field from maize stover, rice straw, and wheat straw, in addition to agricultural processing of residues such as rice husks, maize cobs, and bagasse. This totaled approximately 790 million metric tons by weight, with a corresponding energy content of about 11 exajoules (EJ). One exajoule is equivalent to 1015 British thermal units (Btu's). Kammen (2006) notes that if this biomass was used for generating electricity at an efficiency of $25 \%$, the resulting electricity generation would equal the total amount of electricity generated from coal in China in the entire year of 1996.

Developing countries may be particularly interested in this nexus because of biofuels' significant employment benefits compared with fossil fuel energy systems that 
often benefit external corporations and distant oil-supplying countries. Because of the familiarity of smallholders and the poor with charcoal, it may not be particularly difficult to engender enthusiasm for the production of biochar systems even where the concept is not well-known. The availability of crop residues often in large amounts provides ready opportunities for biochar applications to be made available to the poor. In many parts of the developing world, this is already the case.

According to the environmental news website Mongabay.com (2009), the scientific committee of the Congo Basin Forest Fund (CBFF) awarded Belgium's Biochar Fund and its Congolese partner ADAPEL the sum of $€ 300,000$ in 2009 to implement its biochar concept in ten villages in the Equateur Province of the Democratic Republic of Congo. Funding was given on the basis of the CBFF scoring high on the committee's selection criteria that focuses on:

- Reducing the rate of deforestation in the Congo Basin

- Alleviating poverty and improving livelihoods of the poorest forest communities

- Strengthening the capacity of local partners

- Improving knowledge of the forest ecosystem and the factors leading to its alteration

- The presentation of a highly innovative and creative conservation concept.

Similar projects have been implemented in India, China, Africa, South and Central America, as well as the Caribbean. While large-scale biochar production and utilization systems (BPUS) have not yet become commonplace in the developed world, a large number of small-scale biochar applications have been built, tested, and implemented in the regions named above.

In a presentation delivered to the ETHOS Conference of 2012 in Seattle/ Kirkland on January 29, 2012, Dr. Paul Anderson described a number of barrel-size units used for micro-gasification for combined heat and biochar (CHAB) in 'Mini' industries being operated in Florida, England, Kenya, Mongolia, New England, Uganda, and Costa Rica (Anderson, 2012). The International Biochar Initiative (IBI) has been at the forefront of biochar applications, leading the charge to enable the adoption of biochar technologies in developing countries. A major objective of the IBI is to collaborate with other organizations to empower villagers by providing opportunities for development that are environmentally sustainable, particularly those efforts focusing on reducing deforestation while improving soils for local farmers through the use of biochar.

In Africa, IBI's collaboration with groups such as the African Christians Organization Network (ACON) has focused on the production of improved cookstoves that reduce or remove problems associated with smoke inhalation commonly associated with traditional fireplaces and practices that use charcoal. ACON has teamed with experts to design projects that work alongside local villagers to promote energy conservation and reduce deforestation through the use of improved cooking stoves. They do so by designing biochar-producing stoves, training local farmers on application and utilization of biochar, and making fuel 


\section{Applying practical solutions}

briquettes from aquatic weeds such as water hyacinth and other non-forest biomass materials (Miles, 2009).

Judging from these examples, there is a gradual but discernable movement toward renewable energy alternatives in developing nations as resource-poor people - particularly farmers - recognize the benefits of biochar. The specific benefits of biochar systems as they affect the global poor can be listed as follows;

- Avoidance of Land Degradation: Biochar reduces land degradation caused by loss of organic carbon by adding stable carbon to soil and thereby improving soil fertility. Biochar also retains nutrients in soil, prevents leaching and erosion, and requires less production inputs for cultivation. The high waterholding capacity of biochar is another important attribute that prevents land degradation by erosion, and its application to soil promotes biological activity by providing suitable habitats for microbial colonization which has a positive effect on soil biota.

(Tejerina, 2010)

- Alleviation of poverty: The use of biochar as a soil amendment represents an opportunity to enhance sustainable agricultural practices that contribute to climate change mitigation. Biochar utilization promotes poverty reduction because it results in increased soil fertility and productivity, and reduces the need for production inputs, which translate into more income for its users.

(Bates, 2010)

- Clean Energy Option: The production of biochar from non-forest resources such as agricultural crop wastes reduces dependence on forests resources and can translate into more forest environments being saved from destruction. The global poor are often deprived of amenities such as electricity that is often taken for granted in the developed world. Simple, affordable gasification units point the way toward the adoption of efficient and applied technologies that can improve livelihoods through increased work efficiency, provision of jobs, as well as to reduce the reliance on charcoal and wood for heat and energy. Likewise, clean cookstoves such as that promoted by ACON offers a cleaner alternative to the open fireplaces used by many of the global poor. Reduction in smoke inhalation by women and children in the Sub-Saharan Africa alone could reduce related deaths by about 400,000 persons per year.

(Kammen, 2006)

\section{Farms, forests, food, and energy}

There is overwhelming evidence that the earth is warming, and that the contributing factors have been the release of greenhouse gasses from the burning of fossil fuels, from deforestation, and from overused and degraded soils. While there 
have been many attempts to tackle the challenges presented by global climate change, important fora such as the Kyoto, Copenhagen, and Paris conventions have not resulted in the kind of progress for which most climate change advocates would have hoped. As humanity continues to release greenhouse gasses into the atmosphere which is now creeping beyond 400 ppm of carbon, many have warned that we are close to the tipping point from which there may not be a point of return (McKibben, 2010).

The supply of fossil energy has been reliable, cheap, and accessible throughout the last 100 years or more, but increasingly, oil and gas reserves have been running low, and new sources have become increasingly difficult to find. It appears that once again, similar to those problems encountered by England in the 1600s when the country faced a real energy crisis as a result of deforestation, humanity currently faces the reality of the end of peak energy. The problem of oil depletion is not simply a matter of energy shortage. There are major industries tied to fossil fuels, ranging from lubricants, plastics, and hydrocarbons that are essential to maintaining modern agricultural productivity (Alanne and Saari, 2006). This poses grave consequences, as much of the world depends upon these supporting industries to remain economically and agriculturally viable.

Agriculture as an industry has become so dependent upon fossil fuel that the demise of the latter will place significant limitations and constraints on crop productivity and food production. Peak oil it appears, is directly co-related to peak food, and as fossil energy falls into recession, it should be expected that agricultural productivity will commensurately decline, sending food prices sharply upwards. The crash of the fossil fuel industry will dramatically see the domino crash of all dependent industries, not dissimilar to the economic phenomenon of Dutch Disease. To stave off this eventuality, the overarching need is to find and apply the best options that will serve multiple purposes using very simple approaches. These must include such options as;

- Replacing fossil energy with biomass/biochar alternatives, as well as using solar energy where applicable and feasible

- Stemming carbon emissions by sinking and storing carbon in soil

- Reducing and stopping methane and nitrous oxide emissions through biochar use in production agriculture

- Sequestering more carbon dioxide from the atmosphere by increasing NPP

- Supporting sustainable agricultural practices through polyculture and implementing low-carbon education as a part of modern agricultural training

- Rejuvenating degraded soils by adopting habitat-specific cultural best management practices that include biochar applications

- Reversing global deforestation by incentivizing sequestration initiatives.

There will be the need to apply a wide range of supporting renewable alternatives in order to achieve and exceed each individual alternative listed. The good news is that there are a number of organizations taking the charge for alternative energy strategies in a world that is advancing beyond the Anthropogenic age 


\section{Applying practical solutions}

(Ellis, 2011). Among them is the International Biochar Initiative that must continue to support the global poor through its laser focus on small-scale biochar applications, bearing in mind the tremendous potential for the poor as a group to positively affect the growing problem of global warming. It is imperative that these organizations begin to see themselves as agencies for change and development, and in doing so should pay attention to international environmental policy. This must occur in order to provide a framework in which governmental institutions, researchers, and producers altogether envisage and achieve the best place for biochar and other biomass applications among the existing options in renewable alternatives. When pro-poor organizations take part in conversations on international environmental policy, it will ensure that the global poor have a rational voice at the table, and their potential will be unveiled as part of the workable strategy for undoing the effects of the broken global biogeochemical cycles.

\section{References}

Alanne, K., and Saari, A. (2006). Distributed energy generation and sustainable development. Renewable and Sustainable Energy Reviews. (Vol. 10, Issue 6, pp. 539-558).

American Power Act. (2010). Website, John Kerry, US Sen, MA. Retrieved from www. kerry.senate.gov/work/issues/issue/?id=7f6b4d4a-da4a-409e-a5e7-15567cc9e95c

Anderson, P.S. (2012). The future of micro-gassifier stoves: Meeting the goals of the global alliance for clean cookstoves. Keynote Presentation to the 2012 ETHOS Conference, SeattleKirkland, WA. 28 January, 2012. Retrieved from http://www.drtlud.com/wp-content/ uploads/2012/10/ETHOS-2012-PSA-Keynote.pdf

Bates, A. (2010). The biochar solution: Carbon farming and climate change. Gabriola Island, British Columbia: New Society Publishers.

Brick, S. (2010). Biochar: Assessing the promise and risks to guide U.S. policy. NRDC Issue Paper. November. Retrieved from www.nrdc.org/energy/files/biochar_paper.pdf

Cheng, C.-H., Lehmann, J., and Engelhard, M. (2008). Natural oxidation of black carbon in soils: Changes in molecular form and surface charge along a climosequence. Geochimica et Cosmochimica Acta. (Vol. 72, pp. 1598-1610).

Cheng, C.-H., Lehmann, J., Thies, J.E., Burton, S.D., and Engelhard, M.H. (2006). Oxidation of black carbon by biotic and abiotic processes. Organic Geochemistry. (Vol. 37, pp. 1477-1488).

Cowie, A. (2012). Bright prospects for biochar offsets in Australia. International Biochar Initiative. Retrieved from www.biochar-international.org/biochar_offsets_Australia

Dettmann, J., Ritten, A., and Snavely, A. (2011). Renewable energy certificates and renewable portfolio standards. Biomass Magazine, April 30. Retrieved from http:// biomassmagazine.com/articles/5491/renewable-energy-certificates-and-renewableportfolio-standards

Ellis, E.C. (2011). Anthropogenic transformation of the terrestrial biosphere. Philosophical Transactions of the Royal Society A. (Vol. 369, pp. 1010-1035). doi: 1098/rsta.2010.0331. Retrieved June 10, 2012 from http://rsta.royalsocietypublishing.org/content/369/ 1938/1010.full.pdf + html

EPA. (2012). Combined heat and power partnership. Retrieved from www.epa.gov/chp

The Global Forest Resources Assessment 2010 (FRA). (2010). The Food and Agriculture Organization (FAO). Retrieved from www.fao.org/forestry/fra/fra2010/en/ 
Hunt, J., DuPonte, M., Sato, D., and Kawabata, A. (2010). The basics of biochar: A natural soil amendment. College of Tropical Agriculture and Human Resources. University of Hawaii at Manoa. Soil and Crop Management. December. Retrieved from www.ctahr. hawaii.edu/oc/freepubs/pdf/SCM-30.pdf

Kammen, D.A. (2006). Bioenergy in developing countries: Experiences and prospects. International Food Policy Research Institute. Bioenergy and Agriculture: Promises and Challenges. 14. Brief 10 of 12. December. Retrieved from www.ifpri.org/sites/default/files/ publications/focus14_10.pdf

Major, J., McLaughlin, H., Hepperly, P., Knight, E., Yarrow, D., and Mitchell, S. (2010). Biochar: A field guide for gardeners and farmers. Smashwords Edition. EcoTechnologies. Retrieved from https://www.kobo.com/us/en/ebook/biochar-a-field-guide-for-gardenersand-farmers

McKibben, B. (2010). Eaarth: Making a life on a tough new planet. New York, NY: St. Martin's Griffin.

Miles, T. (2009). Kenya: Western gasifier stove project. African Christians Organization Network. May 10. Retrieved from www.stoves.bioenergylists.org/taxonomy/term/1442

Mohan, D., Pittman, C.U., Jr., and Steele, P.H. (2005). Pyrolysis of wood/biomass for biooil: A critical review. Energy Eु Fuels. (Vol. 20, 2006, pp. 848-889). Retrieved from www.che.ncsu.edu/ILEET/CHE596web_Fall2011/resources/biomass-biofuels/Pyrolysisof-Wood.pdf

Mongabay.com. (2009). Congo biochar initiative will reduce poverty, protect forests, slow climate change. May 19. Retrieved from http://news.mongabay.com/2009/0519-biochar. html

Muradov, N., and Veziroglu, T. (2008). Green path from fossil-based to hydrogen economy: An overview of carbon: Neutral technologies. International Journal of Hydrogen Energy. (Vol. 33, pp. 6804-6839).

Office of Sustainability. (2012). What is cogeneration? Yale University Press, 2010-2012. Retrieved from http://sustainability.yale.edu/co-generation

Scholefield, S. (2012). Combined heat and biochar: A revolution for greenhouse bioenergy. Silviculture. (Spring, pp. 16-18). Retrieved from www.silviculturemagazine.com/ sites/silviculturemagazine.com/files/issues/2012041406/Spring\%202012\%20med\%20 res_blue\%20beam_2.pdf

Shikwati, J. (2011). (Blog) Challenges of modern agriculture. Retrieved from www.steward shipcommunity.com/stewardship-in-practice/challenges-of-modern-agriculture.html

Smil, V. (1999). Energies: An illustrated guide to the biosphere and civilization. Cambridge, MA: MIT Press.

Tejerina, M.R. (2010). Biochar as a strategy for sustainable land management, poverty reduction and climate change mitigation/adaptation? Thermolysis of lignin for value-added products. Thesis Dissertation, University of Amsterdam. June.

Yamamoto, F., Fujino, J., and Yamaji, K. (2001). Evaluation of bioenergy potential with a multi-regional global-land-use-and-energy model. Biomass and Bioenergy. (Vol. 21, pp. 185-203). 


\section{How alleviating energy-poverty will also improve the climate}

\section{An analysis of food production and population growth}

There has been rising population growth and often sharp declines in food production in developing countries during the last five decades, particularly countries in South Asia, Sub-Saharan Africa, and occasionally in areas of Latin America and the Caribbean (Haub, 2012; FAO, 2009). The Food and Agriculture Organization (FAO) predicts that by the year 2050 the world will still be far from stemming the ongoing problem of worldwide economic deprivation and malnutrition being experienced by significant parts of the rising population in developing nations. The main contention is that the U.S. $\$ 1.25$ per day poverty line is an unrealistic measure of poverty, and using this as the level above which people are not considered poor will perpetuate conditions of deprivation and undernutrition throughout the world (FAO, 2009).

An examination of the sharp rise in food production in developed nations especially since the Green Revolution (early 1940s to late 1970s) indicates an inalienable congruence between the modern food production system and the use of fossil fuels to both power the engines of the farm and to derive the organophosphate pesticides and fertilizers necessary for both crop and animal production (Boyard, 2012; Karekezi et al., 2012). Animal production - especially poultry, pork, and ruminants - depends almost exclusively on the production of cereal grain crops, which in turn relies upon large inputs of energy, herbicides, and pesticides for the achievement of high yields of food calories to sustain their numbers (Pimentel and Pimentel, 2003).

Between the years 1960 and 2000, global food production increased by more than $250 \%$ (FAO, 2009). This impressive growth in global food production happened as a result of agricultural intensification and the direct consequence of significant investments in irrigation and in research and development. These investments resulted in improved crop cultivars and enhanced performance of animal breeds. Naylor (2008) notes that during this period of time, cereal output grew almost three-fold, and poultry, pork, and ruminant production rose by $100 \%$, $60 \%$, and $40 \%$, respectively. Notably, these trends have occurred overwhelmingly within the agricultural sector of wealthy western nations that possess the financial resources to afford and expend large amounts of money on fossil energy (Pimentel 
and Pimentel, 2003). The positive result has been an increased production of food and fiber which markedly reduced or eliminated hunger in western capitalist economies (Skorup, 2010) and in the former Soviet Union.

In developing countries such as China and India where Green Revolution technologies were adopted later, modern varieties have contributed to large increases in crop production although gains in productivity have been reported as being uneven across crops and regions. Evenson and Gollin (2003) report that for the most part, consumers in India and China have generally benefited from declines in food prices, but farmers, particularly the majority smallholders, have only benefited where input cost reductions have exceeded price reductions to consumers. Remarkably, although the application of Green Revolution technologies initially increased rice yields in Asia, Tilman et al. (2002) reveal that further yield increases have not occurred in the past 20 years, markedly so in those rice-producing regions of Japan, Korea, and China where farmers were early adopters.

The problem of decreasing food production, particularly that which exists outside the influence of Green Revolution applications, is also of paramount importance in developing countries. Garcia and Rosenberg (2010) argue that while there is little scope for increased production of marine food sources, the risk of further declines in catches exists if overfishing continues. While the capacity of global fishing fleets to catch fish has increased six-fold during the last four decades, the actual harvests of catch have remained static, indicating that productivity has declined significantly. With approximately $20 \%$ of global aquatic food being produced in inland fishing systems, there is widespread recognition of its significance to the economy and food security in low-income nations. Increasingly however, changes to these inland aquatic systems have occurred as a result of ecosystems disturbances from deforestation, land use changes, and runoff related to the overuse of fertilizers and hydrocarbon pollutants promulgated by Green Revolution strategies (Tilman et al., 2002).

Notwithstanding the overwhelming achievement of success, Cesere et al. (2006) explain that the last 50 years of Green Revolution 'style of agriculture' has led to some devastating environmental impacts as a result of the incorporation of industry into agriculture. Cesere et al. (2006) lament that farming as an important human activity has now become a race to keep food production ahead of population growth, leading to an unfortunate situation requiring the acquisition of more natural resources from the earth, much of which is nonrenewable and cannot be replenished.

Two nonrenewable yet invaluable agricultural inputs are potash and phosphorus. Because high-quality, economically mineable deposits are geographically concentrated, potash is produced in only 12 countries of the world with Canada, Russia, and Belarus accounting for approximately $70 \%$ of global capacity and $90 \%$ of estimated reserves (PotashCorp, 2011). As it pertains to phosphorus, the most significant economic deposits of phosphate are found in sedimentary rocks of marine origin which in some instances are harvested to the point of ecological and economic depletion (Gowdy and McDaniel, 1999). 
Currently, one in seven people still do not have access to sufficient food and are undernourished (mostly in developing countries), while an equal number are over-fed (mostly in developed countries). This dichotomy highlights both the strengths and weakness of the Green Revolution, and elucidates the need to take advantage of the strengths while applying adequate safeguards to avoid the weaknesses including those that cause ecological degradation. The FAO (2009) forecasts an ability to identify known threats to the food system by highlighting certain emerging factors that will increase the risks of a rise in hunger. The agency argues that population and consumption growth will cause an increase in demand for food during the next century, leading to increasing competition for land, water, and other resources that threaten the supply of food.

When contemplated alongside the increasingly grave prospects of anthropogenic global climate change, the developing world needs to become cognizant of ways to make its food system more resilient to shocks that cannot be predicted in advance. To address the projected growth in population and satisfy related rise in food demand, food production in developing countries need to almost double by 2050, this achievement only being plausible if investments in production inputs are made, and the neglect of investments in agricultural research and development efforts is immediately and permanently reversed (OECD/FAO, 2012; FAO, 2009).

Clancy et al. (2002) explain that global food production has outstripped population growth since the Green Revolution years, and many countries that were once practically synonymous with famine have achieved self-sufficiency in staple foods. Why then do poverty and food insecurity continue to plague the developing world, keeping one in seven persons in perpetual states of helplessness, thereby exerting major constraints on development? The FAO answers this question by arguing that hunger is a problem of localized poverty, not global food scarcity, and because the essential tools for wealth creation are inaccessible to the poor, their ability to become food secure is consequently limited (FAO, 2009).

There has been full recognition that technical change is the source of most productivity growth in the long run, and scientific revolution in agriculture has made the process of technical innovation much more knowledge and capital-intensive. Most agricultural crop research is conducted by publicly funded agricultural research centers and by a handful of large agribusiness concerns which are involved primarily in the development of hybrid seed technology, chemical technology including herbicides and insecticides, and agricultural machinery. Small-scale agriculture as practiced in most developing nations is faced with limited financial and educational resources, rendering it difficult and often impossible for important agricultural research to be conducted by farmers (Poole and Buckley, 2006).

As a result of these specific challenges, the diffusion of new technologies becomes a matter of policy concern in developing economies, and the emergence of credit programs designed to improve especially the access of small farmers to modern inputs are an essential component of the input programs which should be implemented (Timmer et al., 1983). Also, the emulation of certain strategies that contributed to the success of the Green Revolution is an urgent and pivotal need 
which should be applied in the context of the developing world. While simple solutions do not exist which will solve all the food insecurity problems being encountered across widely variable regions, agricultural productivity should be contemplated with the realization that the absence of affordable sources of energy and lack of access to available sources will stifle any attempt aimed at increasing both food production and food access.

Since energy, as a necessary input, sits as an important catalyst in the gains made by the Green Revolution, it should become a focal need within any plan for changing the level of production among small-scale, poor, technologically challenged and rural producers. The FAO (2009), which has examined these issues in nearly all regions of the world for several decades, believes that the advent of biofuels has the potential of altering these prospects in developing countries.

\section{Are food and energy production systems integrally divergent?}

In the face of major global socio-economic challenges (rising hunger and poverty) and severe ecological deterioration on a worldwide scale (climate change, deforestation, and degrading agricultural soils), those who live in economically disadvantaged regions of the world, particularly the global south, will continue to face an increasingly bleak future (World Bank, 2009a). In this regard, if the Earth's natural resources are to be safeguarded amidst enhanced efforts to feed 9 billion or more people by the year 2050, there will be the requirement to apply levels of efficient food production that have never been achieved before (Simmons, 2011). Since food production at all levels requires the input of energy, and because the application of energy is required for improving production efficiencies (FAO, 2012), there can be no productivity gains in the absence of a framework that considers both food and energy as a coupled production strategy (Barnes et al., 2010). This has been the hallmark achievement of the Green Revolution and is a lesson that should now be applied in the developing world context.

As Green Revolution advances have also demonstrated, the realization of efficiencies in food production is not possible without the input of appropriate applied technology. During the years of highest productivity gains, food shortages across the world were not only addressed through improvements in plant breeding, but by a linear integration process involving tripling the application of inorganic fertilizers, expanding the land areas under irrigation, and increasing the use of fossil fuels for farm mechanization, food processing, packaging, and transportation (Evenson and Gollin, 2003). While the amount of calories produced per acre of agriculture was significantly increased, the unfortunate side effects constituted negative anthropogenic impacts on the world's resources which now require a simpler set of appropriate production technologies for reform. These technologies should be such that they will enable farmers to grow food crops with equal or greater efficiency, providing more food, and more access to it, to those in need, while relying on fewer nonrenewable natural resources and generating less waste with even less harmful effects than is currently the case (Robertson and Swinton, 2005). 


\section{Applying practical solutions}

In 2011 the FAO commissioned a study which examined the linkages between energy and agricultural food systems and their implications for food security and climate. A major aim of the study was an examination of energy uses along the entire agricultural food production chain, including the potential of agricultural food systems to also produce energy (FAO, 2012). The study confirmed the already well-known observation that modern agricultural systems use a significant share of the global energy supply, relying heavily on fossil fuels to meet production targets. The important conclusion drawn by the study was that in order to meet both the energy and food challenges of the future, including the problems associated with anthropogenic change, agricultural food systems need to become 'energy-smart'. The recommendations of the FAO study therefore included the establishment of a "long-term multi-partner food systems program" encompassing food, energy, and technology, and based on the three major pillars;

- Technology: improving energy efficiency in food production systems

- Alternative energy: increasing the use of renewable energy in food systems

- Integration and access: improving access to modern energy services through integrated food and energy production systems.

Further modernizing of the existing food and agriculture systems by increased use of fossil fuels is no longer an affordable or sustainable option, especially in developing countries where the ability to afford fossil energy continues to wane. At this juncture in the continuing evolution of agriculture, there is an increased need to rethink the role of energy when considering the options for improving food systems. Bearing in mind that with almost 3 billion people having limited access to modern energy services for heating and cooking, agricultural food production systems that impact the poor and in particular the energy-poor communities of the world, have an essentially unique role to play in alleviating the problem of global energy-poverty (FAO, 2012).

According to the United Nations Development Program (UNDP) report on the role of energy in reducing poverty, communities exhibit significantly reduced ability to achieve food security and no opportunities for achieving productive livelihoods that can lift them out of poverty without their having access to electricity and sustainable sources of energy. In reality there is no account on record in which a country in the post-industrial revolution era has substantially reduced poverty without a massive increase in its use of commercial energy, or by shifting to more efficient energy sources that provide energy services of higher quality (UNDP, 2005). As demonstrated by Brazil since the 1970s, the harnessing of advances in science enabled the country to switch to alternative sources of energy from which it gained income from food exports as well as provided more affordable and healthy foods to its population. Simmons (2011) refers to Brazil's success as the transformation of a nation's struggles into an economic and humanitarian triumph which should be replicated in many other places. 


\section{Understanding the concept of Integrated Food-Energy Systems (IFES)}

An integrated food-energy system (IFES) can be broadly defined as a 'systems approach' to development in which there is the application of a resilience strategy encompassing food, technology, and energy in a synergistic relationship with biophysical and social interdependencies, as well as sociopolitical dynamics at various scales. Applied in the manner defined, an IFES integrates, intensifies, and consequently aims to increase the production of both food and energy by transforming the by-products of one domain into the feedstocks for the other. Sachs and Silk (1990) argue that the valuing of agricultural by-products in this manner is important in the design of IFES for specific agro-climatic regions since these designs should follow the paradigm of natural ecosystems. IFES are modern, ecologically sound systems that are characterized by closed loops of resources flows, incorporating many of the rational traditions of peasant farming operations but at a completely different level of scientific and technical knowledge.

IFES in no way implies a departure from the proven successes of Green Revolution technologies, but rather searches for those aspects of the modern scientific approach that can be applied at the level of the poor farmer, while abandoning those aspects which are clearly flawed and destructive to the natural ecological cycles. Simultaneously, the nature of an 'integrated' approach purports that knowledge will also be sought and applied from other sources, thus indigenous knowledge - which has for too long been relegated to levels of insignificance by western educational worldviews - will be reassessed and given appropriate levels of credence. Sahai (1996) makes a rather illuminative point in noting that indigenous knowledge reasserts its importance with the realization that there is no rice, wheat, or cotton plants lying around in the forests and wildlands of Asia, Europe, Africa, or the Americas. Instead, forest and wildlands only carry wild, low producing, or unrecognizable ancestors of modern plants out of which indigenous communities of men and women over generations bred hundreds of races of food and cash crops. These plant communities formed the basis of the world's agriculture, providing the foundation material of modern plant breeding and global food security for which modern science often takes sole credit.

An integrated approach to food and energy implies three interdependent factors. These are inputs of renewable energy, multi-task devices, and time sharing of devices such as engines and other technologies (Sachs and Silk, 1990). To create an early impact on poverty and livelihoods in developing agricultural economies, the application of IFES strategies involves the utilization of ideas and techniques of different vintages with the implicit aim of accommodating heterogeneity rather than the imposition of homogeneity across the board resulting in displacement of labor. The shift to modern integrated systems therefore will require a new educational paradigm that affects all levels of cultural, social, and educational institutions including governments, with the aim of supplanting transmissive educational models with more transformative and experiential 
elements of learning that are more suited to developing nation societies, their cultures, their needs, and their ways of knowing and doing (Wals et al., 2013).

\section{Existing policy and economic frameworks in developing countries}

Agriculture is the major source of employment, livelihoods, and income for between $50 \%$ and $90 \%$ of the total population in developing countries, and of these percentages, small farmers constitute $70 \%$ to $95 \%$ of the farming population (Kwa, 2001). Making up such a significant proportion of the total population in developing nations, small farmers have traditionally survived on subsistence production, but many have experimented with export crops sometimes with occasional initial success, and often with ruinous failures. According to Kwa (2001), the industrialization and export orientation of modern agricultural approaches has not been beneficial to small farmers in developing economies, as they have been largely marginalized by policies that have caused a continuation of the vicious cycle of poverty. This cycle of poverty has led to the inability of many developing countries to attain satisfactory levels of overall development.

With acknowledgment to the success of Green Revolution technologies by the late 1960s, global institutions such as the World Bank began to actively promote the adoption of industrial agricultural methods that offered high crop productivity. Because these advanced technology applications were expected to benefit all farmers including the poor, incomes were expected to increase, therefore situations of poverty and livelihoods were expected to be improved as well (Kwa, 2001).

Since agriculture is the major economic force in the majority of developing states, it is of interest to briefly examine the global economic policies advocated by the World Bank and similar institutions in light of continuing stifled development in these nation states. Notably, the heavy dependence on imported agricultural inputs including fossil fuels and their derivatives could not be sustained economically by developing countries, and economic crises and financial failures led to the proliferation of loan packages from the international financial institutions. Structural adjustment policies were then introduced as a condition for borrowed loans - specifically policies to enforce economic liberalization - often involving the conversion of domestic agricultural production to export-oriented crops (Shah, 2013).

As a consequence of these policies, many small farmers were pressured to switch from diverse traditional polycultures to monocultures targeted to overseas markets. The switch to monoculture crops was more pronounced in world regions and in countries where farmers were confronted with steep reductions in the prices of staples and traditional crops as cheap subsidized imports from industrialized countries flooded the local markets. At the same time, the cost of agricultural inputs increased considerably, with the price of fertilizers increasing by more than $400 \%$ as was the case in Tanzania between 1989 and 1992, and Jamaica after 1983 (Bagachwa and Cromwell, 1995; Robinson, 1992). In almost every developing 
country scenario examined, the importation of over-competitive cheaper products occurred as a result of economic and trade liberalization policies strongly advocated by international financial institutions (Moïsé et al., 2013).

Kwa (2001) notes that although food surpluses are generally increasing on the world market, instead of abating food scarcity for those most in need, hunger and food insecurity remain more of a problem than they had been before the periods of structural adjustment. Industrial agricultural methods of production promulgated on the Green Revolution with its narrow focus on yield increases is clearly not the answer to eradicating poverty according to Kwa (2001), and the emerging 'Gene Revolution' methods being integrated into modern industrial agriculture although promising many scientific benefits - may not offer much relief to the already serious problems of hunger and poverty faced by many developing countries.

A factor that seems to go hand in hand with energy-poverty and lack of access to resources is that poor people often live in the most ecologically sensitive and marginal environments of the world, making their situation especially vulnerable to environmental degradation and the adverse effects of climate change (UNDP, 2005). There is consequently a clear and urgent need to apply remedial development strategies in developing countries that avoid the previous pitfalls encountered by inappropriately applied technologies and maligned structural adjustment policies.

Applying IFES in developing countries therefore implies the adoption of a holistic approach to planning, implementation, and management, with broad objectives established to address issues in policy (economic, environment, social), education, support systems, and sustainability at all levels. Toward these aims, Sachs and Silk (1990) believe that the design of IFES in developing countries requires a simultaneous consideration of the following inputs:

- The biophysical components of resource management

- The social and ecological impacts of the technologies used

- The institutional settings involved.

IFES are systems-oriented, thus the methods of application and complexity of the design are flexible and adaptable with respects to the site-specific configuration of climatic and environmental conditions, ecological sustainability, prevailing economic conditions, existing forms of social organization, community participation, social and cultural desirability, and the level of technical sophistication available (UNDP, 2005; Sachs and Silk, 1990). The concept of whole system thinking involves the preferences for looking at systems in a holistic manner in order to solve problems, because when the 'whole' system is examined rather than individual parts, and when an integrated approach is used to examine that 'whole', the overall effectiveness of the process, business, or organization improves dramatically (Center for Sustainability, 2011).

Essentially, because system thinking is involved with understanding how things influence each other, both naturally and socially, there has been the observation 
that the incorporation of this philosophy into a business operation increases its effectiveness, resulting in a decrease in costs and in strong competitive advantage (Gharajedaghi, 2007). This makes system thinking a valuable component in the conceptualization of natural and social system projects such as IFES which offers a sharp departure from neo-classical economic approaches and unsuitable policy interventions.

\section{Applying smart IFES in sustainable development projects}

In 1986 the Financiadora de Estudos e Projetos (FINEP) or Funding Authority for Studies and Projects - an organization of the Brazilian federal government in collaboration with UNESCO, held an international conference in the field of food-energy integration in Brasilia. This was followed by a second conference in New Delhi, India in 1988 organized with the cooperation of UNESCO as well as Brazilian and Indian authorities, research organizations, and universities. The conferences provided a valuable forum to review ongoing work on IFES, compare IFES in ecologically diverse regions, and to discuss future research priorities in the field. Sachs and Silk (1990) suggest that the conferences were instrumental in showing that by the end of the 1980s the concept of IFES had attracted considerable attention in many developing countries, leading to both research and practical implementation in many of them.

Sachs and Silk (1990) state that IFES can operate at various scales, ranging from the industrial-sized operations in Brazil that were designed to primarily produce ethanol and fertilizer for use in towns, cities, and on large farming operations, to small biogas systems developed in parts of rural India to effect change at the household level. Both these approaches utilized the production of a food crop from which an energy source is derived where waste would otherwise have resulted. In the case of Brazil, sugarcane was the food crop, with ethanol and bagasse utilized for energy and fertilizer, respectively. In the case of India, animals such as poultry and swine were raised for food and their waste processed into biogas and used as energy and fertilizer for crop production by small farmers.

In Brazil, India, and China, all of whom have invested in research and education for IFES, there is evidence that traditional and indigenous smallholder farming systems have blended desirable aspects of modern agricultural science to implement IFES projects. Although assessments have determined that IFES based on agro-ecological farming practices at different scales can contribute to climatesmart agriculture and food security, Bogdanski (2012) reports that evidence is still sparse and successful practices are often not upgraded due to the complexity of implementing IFES. In most cases, developing country farmers prefer simple farming systems over the more complex and integrated alternatives offered by developed nation practitioners of IFES, because these western top-down technologies increased the workload and knowledge intensity required to manage intricate feedback loops.

Many experts are convinced that efforts to modify current trends in IFES require clear policy incentives if more diverse and integrated systems are to be 
up-scaled considerably. According to Bogdanski's recommendations, the following policy interventions are crucial to IFES:

- The provision of rewards to those systems that reduce externality costs and generate non-monetary benefits to the society as a whole - such as climate benefits, clean water, and increased biodiversity

- Incentivizing the quicker uptake of IFES by making them easier to afford in the first place, especially those designs that involve energy technologies such as biogas digesters, biochar approaches, or improved cooking stoves

- Addressing the knowledge intensity of IFES by providing adequate education, research, knowledge dissemination, and technical support among rural communities.

The World Economic Forum (2012) cautions that with land, water, and energy emerging as major constraints to future economic growth and social progress, government, business, and civil society need to address population dynamics as an important variable in their efforts to promote sustainable development. Integrally, the failure to promote sustainable patterns of consumption and production increases pressures on all natural resources, exposing severe vulnerabilities which are very pronounced in the world's least developed countries. These countries currently face significant water, energy, food, and infrastructure shortages, and have the highest human population growth rates, the weakest governance capacities, the lowest levels of production, and the highest levels of poverty in the world.

Efforts to anticipate these glaring symptoms of poverty and underdevelopment must be complemented by increasing investment and productivity in the agricultural sector of developing countries. This will happen by ensuring smart applications of IFES. Investment strategies must therefore encourage the sustainable use of land, water, and energy, ensure that people have equitable access to essential resources, and must provide special support to smallholders and to others with weak bargaining power in society. In the vast majority of cases, those with the weakest bargaining power are women and indigenous groups, therefore special attention must be paid to them (World Economic Forum, 2012; Soma, 2005).

The case being made for sustainable initiatives such as smart IFES is that they offer a much wider range of investment opportunities in the farming sector. Appropriately applied and culturally relevant IFES stimulates the creation and sustenance of new local businesses. Additionally, the inherent integrative feedback loops and cycles that are essential for project maintenance ensure that agriculturalists and technologists remain in local communities rather than migrate to urban centers. While many challenges exist, there are vast socio-economic opportunities available through IFES that should not be overlooked. As FAO-directed research has revealed, sustainable agricultural development - employing integrative approaches to food and energy production - is essential for improving food security and reducing the effects of poverty, and consequently is an important driver of overall development wherever the system is applied (Bogdanski, 2012). The fullscale attention to the development of IFES in developing economies points the 
way to a wider inclusion of the world's poor in the process of change, and extends the conversation beyond policy to the level of implementation, which should be the next phase in the ecologic empowerment of the poor while they become more involved in the processes that will help to mitigate global climate change.

\section{Energy-poverty in the developing world - Asia and Africa perspectives}

According to the United Nations Development Program (UNDP, 2010), 'energy poverty' as a concept in economic development arose from the definition of poverty itself. Poverty is defined as the lack of what is necessary for material well-being, including the lack of access to resources leading to physical deprivation. Poverty as a condition transcends the problem of inadequate income, poor health and nutrition, low education and skill levels, inadequate livelihoods, bad housing conditions, and social exclusion, having stark implications for human and social development (UNDP, 2010). The United Nations Educational, Scientific, and Cultural Organization (UNESCO), defines poverty in either relative or absolute terms. Absolute poverty measures poverty in relation to the amount of money required to meet a person's basic needs such as food, clothing, and shelter. Relative poverty is a metric most often used in developed countries or in urban centers. Relative poverty defines the condition of poverty in relation to the economic status of other members of the society, determining that people are poor if they fall below prevailing standards of living in a given societal context. UNESCO (2012b) emphasizes that an important criticism of the concepts of absolute and relative poverty is that they are both largely concerned with income and consumption.

The World Bank has been conducting poverty assessments (PA's) of the poor in developing country regions of the world since 1993. The assessments of the poor, based on their own voices and expressions about their various states of being poor, has led the World Bank to conclude that poverty is a complex and multidimensional phenomenon entailing a gendered, dynamic, complex, institutionally embedded set of circumstances that in most instances is also location specific (UNDP, 2010). Drawn from its assessment of conditions in South Asia and SubSaharan countries, the World Bank has determined that there has been a slowdown in agricultural growth during the last several decades which has slowed the pace of poverty reduction among agriculture-dependent households. This slowdown in agricultural production has been occurring at the same time that Green Revolution technologies have been ushering in periods of growth and proliferation in agriculture in other parts of the world (Narayan, 2011).

Noticeably, the poverty rate among households engaged in agriculture in SubSaharan Africa and South Asia is significantly higher than for non-agricultural households, and the poorest rural households tend to be more dependent on agriculture for a source of income. In the majority of South Asian and Sub-Saharan countries studied by the World Bank, agricultural growth is constrained by the lack of or inadequate investments in the agricultural sector, unclear land tenure 
rights, the absence of or lack of access to applied technology, and inappropriate technical assistance support and delivery systems (Narayan, 2011; Barry and Gacitua-Mario, 2006).

An important question that emerges is why, after decades of global overproduction of food alongside increasing efficiencies in oil exploration, extraction, and consumption, is $40 \%$ of the world population (Karekezi et al., 2012) still left behind in a stagnated state of progress that has stifled the ability to improve their living conditions? Part of the answer lies in the lack of access to energy and its critical impact on food production, health, education, and income, that cumulatively continues to be significant causes for the chronic poverty observed among the world's poorest peoples (UNDP, 2011). Since poverty inhibits access to modern energy services, there is a commensurate absence of technology which often relies on more modern energy sources in order to enable increased food production and land productivity. This then causes a vicious cycle to develop, which perpetuates the underdevelopment observed in world regions such as Sub-Saharan Africa and South Asia.

Karekezi et al. (2012) assert that the relationship between poverty and energy is validated by the fact that poor people in developing countries make up the largest percentage of an estimated 2.7 billion people or $40 \%$ of the world's population. This group relies on traditional sources of biomass energy such as wood, charcoal, and animal waste for cooking and heating. They also comprise the majority of the 1.4 billion human beings living in the modern world without access to grid electricity. Africa and South Asia contain the majority of inhabitants still reliant on traditional biomass energy sources. The impending tragedy of this dependence on traditional biomass is that by 2030, as estimated by the UNDP (2011), household air pollution from biomass use in inefficient stoves will result in more than 1.5 million deaths a year with the majority of the victims to be women and children.

\section{Ending the food versus fuel argument}

The reduction of 'energy-poverty' is being increasingly recognized as an integrally absent development goal upon which the attention of developmental and governmental agencies must focus. Opportunities for achieving food security and the attainment of productive livelihoods will elude more than 1.6 billion people if they continue to subsist without access to basic amenities such as electricity and sustainable sources of energy. Moreover, communities have little chance to provide basic services such as education and healthcare which can help lift them out of poverty, unless the naïve argument of 'food versus fuel' recedes into the rightful place of irrelevance, and is replaced by the demonstrably more intelligent argument promoting the integration of 'food and energy'. The argument about food versus fuel is one that reasons against the cultivation of energy crops which are believed to compete directly with food crops for food and other inputs resources. The fact of the matter is that the food-energy integration argument is already rationalized by the status quo paradigm upon which the highly successful modern food production system exists. The inalienable congruence between agriculture and fossil fuel energy and 
the success it has brought, should help to erase the argument against any future congruence between biofuels and agriculture in the developing country context.

Integrated food-energy systems (IFES) can be applied in many different ways, and they utilize various technology applications in achieving objectives. In addition to improving food and energy security through alternative energy approaches, IFES provides farmers with the capability to use their resources more efficiently. An added advantage of IFES approaches over modern industrial agricultural systems is their focus on soil conservation and improvements in biodiversity, in order to reduce the impacts of agriculture and energy applications on climate change.

However, judging by the slow progress made over the last three decades toward more climate-smart and poverty-reducing production systems, it has become very apparent that in the absence of the necessary institutional and policy adjustments first, the task of IFES implementation will be arduous to accomplish. Development organizations and others who have focused their attention on the improvement of people's livelihoods - particularly those in the global south - hold the belief that in order to accelerate this process, there is a need for the integration of modern science and traditional knowledge in order to inform and engage all stakeholders alike. Fundamental to this is the requirement for a robust, practical, and holistic assessment of successful integrated farming systems and their institutional and policy requirements deliberately based on systems-oriented thinking. Shifting focus from the parts to the whole implies shifting from analytical thinking to contextual thinking. Modern industrial agriculture has advanced the kind of production that has applied analytical thinking very successfully, but unfortunately has not impacted many of people who still live in dire poverty today. IFES advances contextual thinking that promises to bridge that development gap.

While agricultural productivity is declining in the rural sectors of many developing countries, improved energy services are observably in critically short supply also. One explanation can be found in the lack of understanding of processes in rural areas and a commensurate failure to appreciate the positive contribution that energy services can make to improving livelihoods (Clancy et al., 2002). Another explanation of the problem can be found in the fact that biomass does not fall in the realm of energy ministries, being more likely the concern of ministries of forestry and agriculture whose main mission and objectives most often do not include energy (Clancy et al., 2002). The frequent lack of cross ministry cooperation further compounds the issue, contributing to a deeper alienation of agriculture from energy initiatives. In developing countries, therefore, a structural reformation in governmental management within ministries and departments must precede even the idea of policy reform.

In the treatise on 'Energy poverty in Africa', Iwayemi (2010) notes the strong correlation between expanded access to increasingly cheaper sources of energy, and the large gains in productivity, rapid economic growth, and significant reduction in poverty witnessed in the world economy within the last century. This understanding led Iwayemi (2010) to denote that increased use of modern energy services per capita is a primary stimulus for higher and sustained economic growth and improvement in the living standards of the poor in low-income developing countries. 
Having developed a theoretical understanding of the poverty/energy relationship, the UNDP conducted a review of 17 energy access projects across South Asia (UNDP, 2010) to determine workable and non-workable strategies required for breaking the vicious energy-poverty cycle. Results of the study indicate that most energy projects targeting the poor adopt a minimalist approach that focuses greatest attention on the basic energy needs of the poor for lighting homes, for cooking, and heating. As the UNDP (2010) determined, the minimalist approach has little impact on poverty reduction because they do not provide opportunities to poor households to increase their incomes.

Improving upon the minimalist approach means that since poor people work mainly in agriculture, energy must also be addressed toward their agricultural production systems in order to raise productivity and provide opportunities for wage earning. Development agencies attempting to reduce energy-poverty among target groups are faced with challenges often inherent in the felt needs of intended beneficiaries. Chineyemba (2010) reports that when rural people were asked to express their need for improved energy services, highest priority was given to 'electric lighting'. While this is a significant desire of people who have existed in the relative darkness provided only by candles or kerosene lamps all their lives, there has been a greater recognition that as an unfelt need, the most financially sustainable energy supply options are those that will provide power to productive enterprises that can obtain profitable returns to rural peoples. While poor people may think all they need is electric lighting, development organizations must know that the real path to economic development goes well beyond lighting to energy products that can power engines and pump water.

Chineyemba (2010) notes that an important aspect of the energy-poverty nexus is that rural wealth will not increase unless goods and services can be sold outside the village, implying that roads, transportation, and improved technologies are necessary complementary inputs to poverty alleviation. Based on these factors, Chineyemba (2010) draws the conclusion that the cycle of energy-poverty experienced by rural peoples particularly those in developing countries will only be broken by a combination of improved energy services with end uses that generate cash incomes. These end uses are most likely to be those that target improvements in the production activities of the poor, either by increasing productivity, extending the range of outputs, or improving the quality of output in measurable degrees. Chineyemba's arguments are supported by the findings of the UNDP (2010), which show that minimalist approaches to solving the problem of energypoverty have failed to effect improvements in the livelihoods of the poor, and that the kind of investment that is required needs to address income creation.

\section{Energy-poverty as a parameter of economic underdevelopment}

Clancy et al. (2002) argue that despite existing awareness that almost 2 billion people still use traditional biomass fuels, and that these are among the poorest people in the world, little attempt has been made to critically analyze the energy-poverty nexus in depth. Decades of apathy toward the energy-poverty 


\section{Applying practical solutions}

relationship can perhaps be explained by the fact that the biomass in rural areas is collected at zero monetary cost by women and children, thus the activity is invisible and falls outside national energy accounts. While there is growing interest in renewable energies by national governments and development agencies worldwide, the focus has been placed on electricity generation which mainly benefits urban users, leaving out rural people who constitute the majority of the poor in developing countries.

The continued existence of energy-poverty, therefore, makes it reasonable to draw the conclusion that the present structures and processes within the traditional energy sector do not function in a manner that provides many benefits to the poor. An investment in energy is paramount, but energy in the context of the developing world, and certainly energy that is both available and accessible. If the identification of that energy source is such that it empowers the poor with direct ownership, provides them access to food and technology, and makes investments in soil carbon banking, then the cumulative impact of 3 billion poor people will be recognized for what it is - a driving force for global reform of energy and ecological restitution, to which the world will have to suddenly pay attention.

\section{The economic and environmental importance of bioenergy crops on rural and developing countries' economies}

The form of energy generated from wood, biomass, organic wastes and residues, and energy crops, is generally referred to as bioenergy (FAO, 2005). The vast majority of developing countries around the world utilize traditional bioenergy sources that include fuelwood, charcoal, cattle dung, and other organic residues. When biomass is converted to higher value products and to more efficient and convenient energy carriers including wood pellets, biogas, biodiesel, and bioethanol, the resulting energy is referred to as biofuels. According to FAO (2012), bioenergy contributes to the mitigation of climate change and to the diversification of energy options, therefore playing an important role in the establishment of energy-smart food systems. An energy-smart food system requires a transformation along the food chain that involves three interrelated processes. These are:

- Developing a deeper reliance on more low-carbon energy systems and using energy more efficiently

- Strengthening the role of renewable energy within food systems

- Providing greater access to modern energy services for development, while simultaneously supporting the achievement of national food security and sustainable development goals.

With increasing cognizance of the problems caused by energy-poverty, the incorporation of bioenergy production into existing agricultural systems is seen as a means to enhance energy security, promote rural development, in addition to reducing greenhouse gas emissions. When bioenergy is contemplated in this 
manner, there is tremendous potential to increase agricultural productivity in developing countries, particularly those that suffer the most from both food shortages and energy-poverty. The Food and Agricultural Organization supports the idea that liquid biofuels could be a driver for realizing the potential for addressing poverty in developing nations, noting that the new investments that liquid biofuel production could bring to agriculture should be used to improve productivity throughout the entire agricultural sector, increasing both food and energy production. However, development agencies and governments should ensure that liquid biofuels development contributes to food security by including smallholder farmers in its cultivation and production (FAO, 2011).

Inserting an important caveat, however, FAO (2012) notes that the agricultural yields of smallholders under subsistence production systems are often lower than those of large plantations, so that in many instances subsistence producers will require more land to produce the same units of liquid biofuels. The explanation is that lower productivity may be partly due to the lack of access and quality of energy available to smallholders compared to large economies of scale. Other concerns raised by FAO (2011) include the impact of bioenergy production on land use, biodiversity, land rights, and food production, but bioenergy encompasses such a wide range of feedstock types, systems of production and fuels, that its impacts cannot be generalized. The magnitude and impacts of bioenergy production will depend on several factors that are related to the type of feedstock under production, available bioenergy technology, the way production is managed, and the environmental, socio-economic, and policy context in which development takes place (Ashworth et al., 2013).

Larsen and Petersen (2010) explain that the development of the bioenergy sector has been encouraged by technological advances in biomass conversion that occurred during the last decade. More careful agronomic approaches to the development of productive varieties and improved cultivars have also occurred during the last five years, but only after the initial rush in the 1990s to develop bioenergy alternatives to fossil fuels. Those initiatives took place in the absence of a proper agronomic understanding of feedstocks, especially appropriate assessments of the full costs and benefits within a particular ecological environment. New research and development approaches are noted in the recommendations of the Biomass Research and Development Board (BRDB) to the federal government of the U.S. The recommendations suggest that harnessing of the potential of biomass resources for energy in a sustainable manner depends on successfully addressing major challenges including;

- Increasing the yield, reliability, and sustainability of feedstock supply

- Improving land and resource use efficiency

- Reducing feedstock production costs

- Continuing to deliver needed levels of goods, services, and values now and into the future, while minimizing impacts to the environment.

Bearing in mind the recommendations of the BRDP, the successful establishment and expansion of bioenergy production in developing countries needs to 


\section{Applying practical solutions}

be based on sound technical, environmental, and economic information that will allow stakeholders to identify the sustainable bioenergy production options best suited to their particular context. In taking steps to connect food production increases with energy availability, the process of building an energy-smart food system should address concerns about land suitability, water availability, economic competitiveness, as well as the myriad of socio-economic costs and benefits related to food security, economic growth, and poverty reduction (FAO, 2012). Therefore, in addition to ongoing efforts to improve the agronomic performance of bioenergy crops, there is the requirement for an integrated approach to addressing the multiple concerns raised by bioenergy and biofuels production in developing countries. An integrated model requires full understanding of the current bioenergy situation and related opportunities and risks, and knowledge of synergies and trade-offs. Integrally, there needs to be the presence of government support providing an enabling policy framework and institutional environment, with effective means for policy implementation. Both Kuchler (2010) and FAO (2012) further advocate for the kinds of policy instruments that enforce good practices by investors and producers in order to reduce risks and seize opportunities, as well as proper impact monitoring and evaluation and policy response mechanisms.

Although the constraints noted by the FAO are noteworthy, there are examples of developing countries that have used biofuels efficiently. According to South Centre (2008), exploiting the advantages of an energy-smart food production system provides opportunities to address the energy needs of the poor, contribute to climate change mitigation, address environmental challenges, support rural development, and reduce poverty. The development of canebased ethanol in Brazil, for example, has emerged over the past 30 years with initial injections of subsidies to promote research, development, and for marketing and promotion of the product. Together these policy instruments and incentives enabled the development of the Brazilian cane ethanol industry while at the same time resulting in steep declines in production costs. The current state of the Brazilian biofuel industry is one that is highly competitive and profitable, with multiple studies indicating that with Brazil's use of improved technologies, biofuel production is having a positive impact on its food security. Moreover, assessments indicate that the production of biofuel from sugarcane has not disturbed sensitive land areas in the country, nor has there been any depletion of traditional pastureland as a direct result (South Centre, 2008; Jank, 2006). As noted by Hofstrand (2009), over the last 30 plus years Brazil has made significant advances in running its economy on renewable energy, the sector now representing $46 \%$ of its total annual energy supply. By comparison, with a stronger reliance on fossil fuels, renewable energy accounts for only $7 \%$ of the U.S. annual supply. The Brazil case study indicates that a deliberate and focused investment in bioenergy is both possible and plausible, and that developing countries could adopt an integrated system that not only addresses domestic energy-poverty, but creates less dependence on fossil fuels while improving food resources. 


\section{The economic and environmental importance of biomass crops}

In the developed economies of the world there is a wide array of emerging opportunities for energy security from biomass crops, and according to the IIED (2010), there is accelerated pace at which these are being developed. In contrast, many developing countries often view biomass energy as being backward, inefficient, noncommercial, a health hazard, a poverty trap, and a major cause of deforestation. As a result of one or more of these factors, the collection of biomass products is often legislated to be illegal in many cases, placing even greater burdens on those whose livelihoods depend upon these forms of energy. Biomass energy systems, however, have significant impacts on ecosystem services, and as a major component of land use, also carry great potential for impacting the problem of poverty.

Biomass energy currently makes up a significant share of the world's renewable energy, and with increases in its use expected in both developed and developing nations, it is predicted that the share of biomass energy will triple from $10 \%$ to $30 \%$ of the global total by the year 2050 (IIED, 2010). Developing countries consume disproportionately larger amounts of biomass energy, with $26 \%$ of their energy needs obtained from these sources. Macqueen and Korhaliller (2011) suggest that in order to capitalize on the expected growth in global biomass energy use, developing nations should act now to legalize sustainable biomass value chains where such legal constraints exists, and create a platform for more advanced biomass energy options in the future. Previous concerns that the demand for fuelwood and charcoal was outpacing sustainable supply on a scale that makes it a major cause of deforestation are not supported by the available evidence, and Macqueen and Korhaliller (2011) note the renewed interest in the use of fuelwood, charcoal, and biochar - used alongside sustainable harvesting practices - as a sustainable energy source for many rural communities.

As a starting point, in order for increasing biomass energy use to have positive impacts on both poverty reduction and ecosystem services, there is a requirement for the applicators of innovative interdisciplinary research to outline transition pathways that optimize these impacts (IIED, 2010). Advantages exist in the fact that poor households spend one-fifth of their monthly income on wood and charcoal, representing a huge economic resource. Additionally, per unit of energy, biomass production is more labor intensive than other energy sources, thus having the potential to boost rural employment and reduce poverty. In many parts of Sub-Saharan Africa and South Asia, efforts have commenced to focus on combating real inefficiencies in wood use and health hazards in the home. An area which has received significant attention is the use of energy efficient stoves to replace the traditional three-stone system that has caused harmful smoke inhalation resulting in the deaths of hundreds of mainly women and children. Energy efficient stoves like the clean cookstoves previously discussed, use half the fuelwood that traditional stoves require, and they are very cost efficient with a payback time of only a month in some regions of Africa (GNESD, 2011). 
Macqueen and Korhaliller (2011) showed that when biomass is managed sustainably through all phases from cultivation to energy production, there is significant advantage over other forms of energy. Advantages encompass local accessibility, energy security, lower carbon emissions, carbon sequestration, and the flexibility to be converted into heat, electricity, liquid, or gas at a range of commercial scales from small to large-scale applications. The success of programs aimed at addressing energy-poverty over the next two decades will be determined by how well these advantages of biomass are implemented and managed right now. Furthermore, a global focus on energy-poverty reduction will mean that a major instrument of underdevelopment will also likely become a tool for addressing the major causation factors of climate change. However one looks at the matter, addressing energy-poverty is a win-win for not just the energy-poor, but also for the food-poor. It also presents a major win for the global environment that has suffered the most from fossil energy hegemony.

\section{Land tenure, bioenergy crops, and rural development as instruments of change}

Repeated assessments conducted by the FAO reveal that in the majority of cases biofuel policies have been designed within a national framework without consideration for unintended consequences at the national and international levels (FAO, 2008). When these unintended consequences are examined, there are often implications for high food prices partly resulting from increased competition from biofuels for scarce agricultural input and resources. The immediate impact is observed on two fundamental indicators of development - poverty and food security. The main reason governments establish laws and policies designed to address energy in general and bioenergy alternatives in particular, is the recognition that energy access is critical to development and central to the everyday lives of people. In order to make the process effective, efforts to expand energy access to the needy should be grounded in a robust information-base that elucidates all the issues impacting their existence (Nussbaumer et al., 2011).

The United Nations Development Program warns that current actions to eradicate energy-poverty are both slow in pace and low in scale. This is partly because international development agencies are yet to focus on the recognition of the collective global power of the billions of people whose exit from the realm of energy-poverty will have a profound impact on global biogeochemical cycles. Should the lack of focus continue, more people will be without modern energy access in 2030 than those who currently have access today (UNDP, 2010). Equally, when proposed solutions are possibly a poor fit - such as the proposed wide-scale use of LPG in Haiti where a majority of the population live below the poverty line - then modern fuels are of very limited impact since potential users often do not have the financial means to pay for the fuel or to invest in the appliances that deliver the desired service (Nussbaumer et al., 2011). It has been observed, however, that increasing global demand for biofuels offers economic opportunities to farmers and rural communities in developing countries, and this can lead to 
opportunities for rural development. The rule to be considered is that the capacity for farmers and rural communities to take full advantage of available opportunities depends on the existence of an enabling environment that considers all aspects of their livelihoods (FAO, 2008).

The context in which bioenergy for development must be contemplated should incorporate a planning strategy based on the best information available, development of a thorough livelihoods analysis, consultation with target groups, and avoidance of top-down approaches when delivering development services (FAO, 2008; UNDP, 2010). For example, a bottom-up approach would adopt an intervention strategy that takes into consideration the most basic energy needs of the energy-poor. Since cooking is amongst the very basic needs, the best available source of energy in the form of heat that will afford convenience to women is often prioritized (Nussbaumer et al., 2011). Women and men, however, exist in social communities, so that the fixes applied must consider the interactions between sexes and genders that enable their livelihoods without the alienation of any subgroup. The identification of sustainable bioenergy crops suited to the environment and the skill levels of local people that convey this type of convenience will begin to usher in a greater sense of well-being and empowerment among the poor. In Africa, Asia, parts of Latin America, and the less developed countries of the Caribbean, the establishment of a bioenergy chain (patterned on the Haitian charcoal chain) through the stages from crop production, processing, to affordable appliances aimed at the reduction of indoor pollution, is a bottom-up approach that is well warranted.

The twin problems of food security and energy-poverty are often compounded by the lack of access to land, this being a critical issue if vulnerable households are to enjoy sustainable rural development. The FAO (2002) advocates that access to land is important for rural households to experience sustainable development, and this can be obtained through formal, informal, customary, or other arrangements. For the most part, government policies aimed at rural development through the establishment of alternative energy projects must confront land tenure problems with appropriate project design specific to simultaneously improving both food insecurity and energy-poverty situations. This requires recognizing and tackling land tenure related problems in the earliest stages of rural development, agricultural development, or bioenergy development projects. There also ought to be the recognition that the matter of land tenure is not restricted solely to land access, but applies to other critical natural resources such as water, trees, grazing areas, all of which are essential for sustaining people's livelihoods.

When individuals and families gain increased access to land and natural resource assets, they are better able to be food secure, and this enables them to increase their access to material resources, as well as access to markets and other economic opportunities. As the FAO (2002) determined from multiple studies conducted worldwide, the denial of land resources to large segments of rural society imposes unanticipated costs that contribute to extreme poverty, dependence, social instability, and unsustainable migration to urban areas. This pattern eventually contributes to localized land degradation, environmental pollution, and 
broken biogeochemical cycles that impact the climate. Notably, when more equitable access to land and other assets are available, there is recognizable stimulation of faster and broader-based economic growth that affects not only those in rural areas, but entire countries. Land tenure is therefore the basis upon which the world's poorest people begins the process of economic transformation that ripples through to the ecological transformation of which the world is in a crucial need.

\section{Changing maligned infrastructures}

Having established their country's political, economic, and rudimentary manufacturing framework on patterns copied from oil and coal-rich developed nations, most developing country governments are ill prepared to tackle the problem of energy-poverty which continues to impede development objectives. This has created a permanent yet displaced energy infrastructure mostly unsuited to the development pathways of energy-poor countries. This infrastructure comprises large centralized oil- and coal-powered stations, complex electricity grids, and oversized agricultural machinery created in industrialized countries to take advantage of once cheap fossil fuels. The reality of life in many developing countries is that the constant disruptions in electricity makes productivity almost impossible and causes repeated damage to machinery which are expensive to fix or replace. The oil bill in many of these countries is often equal to, or less than the value of its total exports, making it almost futile to develop an export sector without moving to more viable energy alternatives. However, much of the hindrance faced by research that will lead to breakthroughs in alternative energy exists within the constraints of an ideological legacy reinforced by the existence of the pervasive fossil fuel infrastructure. There is the obvious need to seek a new or adapted design more suited to energy alternatives that promise less economic complexity.

Research conducted in the U.S. has provided strong evidence pointing to favorable energy outcomes of biomass energy projects. They show that low-temperature slow pyrolysis offers an energetically efficient strategy for bioenergy production, and the added benefit is that land application of the resulting biochar reduces greenhouse emissions by suppressing the release of nitrous oxide and methane gasses from the soil (Gaunt and Lehmann, 2008). Improvements in energy efficiency have also helped to promote the application of distributed energy resources (DER) from varied, multiple, small energy generating units, into existing electricity systems. Alanne and Saari (2006) point to an emerging trend toward distributed energy generation in which energy conversion units are situated close to consumers and large units are substituted by a network of smaller ones. A distributed energy system is considered by many to be an efficient, reliable, environmentally friendly alternative to the traditional energy delivery system, while others point to a distributed energy system as being important to national security.

With improvements in land tenure arrangements and focused efforts at developing agronomic improvements in food and bioenergy crops grown by local farmers, distributed energy applications are well suited to developing country conditions. National institutions and educational curricula therefore must ensure 
that this becomes an area of research for agricultural engineering. To support this recommendation, Anderson (2012) reports that the use of dry biomass for heat generation ranging from small cookstoves up to large installations is increasingly being made and used in various places around the world. Accordingly, the use of biomass gasification units in 'mini' sizes is being better understood both in terms of the applied technology and the economic context in which they are used. Where labor is inexpensive and plentiful, the machines are available in sizes that can be manually operated, and where labor is scarce or expensive, they are large enough in thermal output to justify capital investments for electrical output.

Judging from what has already been achieved in Kenya, Malaysia, India, Australia, and the U.S., Anderson (2012) predicts that the use of biomass pyrolysis for heating buildings, for farming operations and processing, and for institutional-size cooking will become increasingly common. Because of the familiarity of smallholders and the poor with charcoal, it may not be particularly difficult to engender enthusiasm for the production of energy from oil crops and biomass. It is left up to the practitioners of development to envisage, understand, collaborate, consult, and apply the measures that will achieve the singular objective of change.

\section{Three hypothetical arguments for addressing energy-poverty and agricultural underdevelopment}

Agricultural development does not exist in a vacuum, the strong correlation between food security and access to energy demonstrating this very clearly. Energy is a critical enabler, and economies that have achieved growth and development have utilized energy security to establish development and prosperity. Developed countries have used energy security to improve their economic growth, and the Green Revolution advancements in crop performance and land productivity which eliminated hunger in their economies was achieved due to wide-scale access to cheap energy.

The achievements made during the years of the Green Revolution did not affect the global south in meaningful ways, and the current existence of large pockets of food insecurity in these nations is the result of too little investment in research and development for staple food crops, at the expense of larger investments in crops such as coffee, sugarcane, and bananas produced exclusively for export to developed country markets.

Even more, where value-added opportunities existed for certain crops, much of the manufacture or processing of these commodities has occurred in developed nations, this behavior largely mimicking the arrangements established during the colonial period. An example of this is that cacao and sugar are produced in developing countries and exported at low prices to richer countries, yet when milk is added to these products, the resulting 'milk chocolate' is sold at relatively high prices in markets largely inaccessible to the cacao- and sugar-producing countries. This loss of economic gain - partly due to productive incapacity - translates into income losses, so that national incomes in developing country states never equate or surpass payments for the importation of goods of necessity, such as oil. This has 
led to significant payouts from national income that have resulted in severe balance of payments problems in these developing countries.

Hypothesis \# 1: Research institutions and agricultural curricula must reflect the need to address hybrid vigor and value-added products, and work to improve crop varieties and develop higher yielding nutrient-rich crop cultivars in order to achieve higher productivity in staple food crops in developing countries.

When there is access to affordable energy services, societies experience a whole range of benefits including increased productivity, enhanced competitiveness, economic growth, and improved health and well-being. Fossil fuels have not affected the lives of the current poor largely because they mostly exist outside its infrastructure, and national budgets tend to be directed toward satisfying the needs of urban centers at the cost of funding and services for rural areas where the poor mostly live. Research and development objectives must therefore create the capability of bioenergy crops to provide mechanical power in order to benefit agriculture, food processing, textiles production, and other manufacturing.

The urgency with which there is a need to find reliable alternative energy sources in developing countries is clearly noted by the fact that global poverty itself is a major contributor to global warming, mainly because poor people use traditional biomass as their only energy source (Yergin, 2012). As populations increase in the global south, more biomass is required and more forests are removed for energy consumption, and for farming. In many cases the farming is not just for the production of domestic produce, but for the production of export crops and livestock. With increased removal of primary and secondary forests, net primary production (NPP) falls and greenhouse gasses are released into the atmosphere, further compounding the global warming problem.

There is evidence, however, that if global poverty is appropriately addressed, an integral area of need will be access to modern energy supply including the associated technologies required to improve agricultural productivity in marginalized societies. This complexity of issues connects alternative energy development to poverty alleviation, making the issue of sustainable development one that is not only concerned with the environment but with the economic status of the poor. As noted by Karekezi et al. (2012), the essential prerequisite for overcoming poverty is economic growth, and its achievement has never occurred in any country without improvements in access to cleaner and more modern forms of energy and the services they provide.

Hypothesis \# 2: The modernization of biomass and bioenergy into sustainable systems suited to the conditions of the rural poor can directly reduce poverty by raising productivity and extending the quality and range of products they are capable of making. This should become an area for investment that must take higher priority over fossil energy approaches, and should therefore accommodate an investment in bioenergy infrastructural development as a policy goal. 
Biofuels remain a significant storyline as the world works toward a new energy future without fossil oil. The patterns of development in countries such as Brazil, Costa Rica, and Mali must be emulated and adopted in every case where this is possible, but ideas should also be drawn, albeit counter-intuitively, from countries such as Haiti that has developed a well-structured but informal business model in the 'charcoal chain' which employs more than 150,000 people throughout the country. Part of Haiti's charcoal chain illustrates a destructive ecological component in the removal of secondary forest trees and even tree roots for charcoal production, but its business components - from the manufacture of charcoal stoves, to production of bagged charcoal for local markets - are sound economic entities worthy of celebration. The non-viable aspect of the charcoal chain, however, can be salvaged and remedied. A new 'biomass energy chain' based on modern improvements in technology and co-cropping production systems involving reforestation through energy farming efforts, or smallholder cultivation for distributed energy should be considered as a sustainable alternative. The best part of Haiti's charcoal chain can thus be preserved, with the worst part remodeled as a foodenergy poverty reducing strategy.

Considering the centrality of climate change as a major global issue, the ability to identify a secure, safe, and reliable source of energy to power world economic growth is one of the great challenges of this century (Harvard University, 2013). The effects of climate change is always local, however. As repeatedly demonstrated in Haiti, the natural disasters brought about by localized environmental conditions disproportionately affect poorer countries, and the poorest within them will experience the worst devastation to their lives (OECD, 2003). Significantly, it has been recognized that if the use of fossil oil can be avoided and replaced with more affordable and practical alternatives, there would be an almost immediate impact on balance of payments and national incomes in developing countries.

Hypothesis \# 3: The mindset that bioenergy must become an immediately perfect replacement for fossil fuels in developing economies should be abandoned, and development of crops, technologies, and a new infrastructure appropriate to relieving energy-poverty must be developed on their own merits over time.

Having examined the scenarios, the United Nations Development Program (UNDP, 2010) advocates for four major practices considered essential for the mainstreaming of energy access within the national development strategies of poor countries.

- The development of a well-articulated long term national renewable energy access policy that is situated within the general policy framework of development and poverty reduction

- Identify and develop the capacity of key stakeholders involved in project implementation, technology development and supply, education and 
curriculum development, provision of services, financing, civil society organization, as well as the capacity of final consumers including women

- Engaging with stakeholders at all planning and implementation levels to ensure a broad base for information dissemination and project support, for the achievement of national consensus on the importance of energy access

- Establish and strengthen lead energy institutions and public universities to ensure that good practices and lessons learned in individual projects are translated into sector-wide strategies and policies.

As the most progressive economies in the developing world have shown, there is a need for national institutions to themselves adopt more practical sets of objectives including an ideology that ushers in new thinking on bioenergy alternatives. Universities and higher education institutions in developing countries need to increase their pace of adaptation to fit the urgency of the prevailing circumstances. Wherever appropriate reforms are adopted and results are positive, developing nations will benefit from international cooperation within an environment where their voices, intentions, and future objectives are expressed and heard as equal partners, not merely as dependencies or seekers of development loans.

\section{References}

Alanne, K., and Saari, A. (2006). Distributed energy generation and sustainable development. Renewable and Sustainable Energy Reviews. (Vol. 10, Issue 6, pp. 539-558). http:// dx.doi.org/10.1016/j.rser.2004.11.004.

Anderson, P.S. (2012). Barrel-size micro-gasification for combined heat and biochar (CHAB) in "Mini" industries. ETHOS Conference of 2012, January 29. Seattle-Kirkland, WA. Retrieved from www.vrac.iastate.edu/ethos/files/ethos2012/SunAM/Anderson_Micro gasification $\% 20$ for $\% 20$ combined $\% 20$ heat $\% 20$ and $\% 20$ biochar $\% 20$ in $\% 20$ Mini $\% 20$ Industries.pdf

Ashworth, K., Wild, O., and Hewitt, C.N. (2013). Impacts of biofuel cultivation on mortality and crop yields. Nature Climate Change. (Vol. 3, pp. 492-496).

Bagachwa, M.S.D., and Cromwell, E. (1995). Structural adjustment and sustainable development in Tanzania. Dar es Salaam, Tanzania: Dar es Salaam University Press.

Barnes, D.F., Singh, B., and Shi, X. (2010). Modernizing energy services for the poor. World Bank Investment Review: Fiscal 2000-2008. December. Commissioned by the Energy Sector Management Assistance Program (ESMAP). Retrieved from http://siteresources. worldbank.org/EXTENERGY2/Resources/EnergyForThePoor.pdf

Barry, B., and Gacitua-Mario, E. (2006). Transition from post conflict to long-term development: Policy considerations for reducing poverty. Guinea-Bissau Integrated Poverty and Social Assessment (IPSA). Report No. 34553-GW. May 26. World Bank's Africa Region. Retrieved from www-wds.worldbank.org/external/default/WDSContentServer/ WDSP/IB/2006/08/28/000160016_20060828093508/Rendered/PDF/3455310vol.01. pdf

Bogdanski, A. (2012). Integrated food: Energy systems for climate-smart agriculture. Agriculture and Food Security. (Vol. 1, Issue 9). doi: 10.1186/2048-7010-1-9. Retrieved from www.agricultureandfoodsecurity.com/content/1/1/9 
Boyard, A. (2012). On the need for action in sub-Saharan Africa. Groupe Energies Renouvelables, Environnement et Solidarités (GERES), Press Release. May 9. Retrieved from www.geres.eu/en/press-realeses/247-energie-durable-solutions-zones-rurales

Center for Sustainability. (2011). Whole system thinking. Retrieved from www.centerfor sustainability.org/resources.php?category $=195 \&$ root $=176$

Cesere, A., Aizenman, A., and Heisler, M.K. (2006). The effects of the Green Revolution. University of Michigan. Retrieved from http://sitemaker.umich.edu/section7group1/ home

Chineyemba, P.U. (2010). Energy access in rural areas. In Energy poverty in Africa. Proceedings of a Workshop held by OFID in Abuja, Nigeria, June 8-10, 2008. OFID Pamphlet Series 39. Vienna, Austria. October. Retrieved from www.ofid.org/LinkClick. aspx?fileticket $=x N K y \_X e Y w 7 g \% 3 D \&$ tabid=109

Clancy, J.S., Skutsch, M., and Batchelor, S. (2002). The gender: Energy-poverty nexus: Finding the energy to address gender concerns in development. DFID Project CNTR998521. Technology and Development Group University of Twente and Simon Batchelor, Gamos Ltd, UK. Retrieved from www.esmap.org/sites/esmap.org/files/The\%20 Gender\%20Energy\%20Poverty\%20Nexus.pdf

Evenson, R.E., and Gollin, D. (2003). Assessing the impact of the Green Revolution, 1960 to 2000. Department of Economics, Yale University and Department of Economics, Williams College. Retrieved from www.sciencemag.org/content/300/5620/758.abstract

FAO. (2002). Land tenure and rural development. FAO Land Tenure Studies, 3. Rural Development Division. Retrieved from ftp://ftp.fao.org/docrep/fao/005/y4307e/y4307e00.pdf

FAO. (2005). Bioenergy, key to the fight against hunger: Two billion people lack access to sustainable energy services. FAO Newsroom. April 14. Retrieved from www.fao.org/newsroom/ en/news/2005/101397/index.html

FAO. (2008). The state of food and agriculture 2008: BIOFUELS: Prospects, risks and opportunities. Economic and Social Development Department, Rome, Italy. Retrieved from www.fao.org/docrep/011/i0100e/i0100e00.htm

FAO. (2009). Global agriculture towards 2050. High-level Expert Forum, Rome. October 12-13. Retrieved from www.fao.org/fileadmin/templates/wsfs/docs/Issues_papers/ HLEF2050_Global_Agriculture.pdf

FAO. (2011). Energy-smart food for people and climate. Issue Paper. Food and agriculture organization of the United Nations. Retrieved from www.fao.org/docrep/014/i2454e/ i2454e00.pdf

FAO. (2012). Energy-smart food at FAO: An overview. Environment and Natural Resources Management Working Paper, Number 53. FAO. Retrieved from www.fao.org/ docrep/015/an913e/an913e.pdf

Garcia, S.M., and Rosenberg, A.A. (2010). Food security and marine capture fisheries: Characteristics, trends, drivers, and future perspectives. Philosophical Transactions of the Royal Society, Biological Sciences. (Vol. 365, pp. 2869-2880). doi: 10.1098/rstb.2010.0171

Gaunt, J.L., and Lehmann, J. (2008). Energy balance and emissions associated with biochar sequestration and pyrolysis bioenergy production. Environmental Science and Technology. (Vol. 42, Issue 11, pp. 4152-4158). doi: 10.1021/es071361i

Gharajedaghi, J. (2007). Systems thinking: A case for second-order-learning. The Learning Organization. (Vol. 14, Issue 6, pp. 473-479). doi: 10.1108/09696470710825088

GNESD. (2011). Bioenergy: The potential for rural development and poverty alleviation. Global Network on Energy for Sustainable Development (GNESD). Summary for policy-makers. GNESD-SPM-BET-11/2011. Retrieved from www.uneprisoe.org/upload/unep\%20 ris\%C3\%B8/pdf\%20files/bioenergy_potentialfordevelopment_spm.pdf 


\section{Applying practical solutions}

Gowdy, J.M., and McDaniel, C.N. (1999). The physical destruction of Nauru: An example of weak sustainability. Land Economics. (Vol. 75, May, pp. 333-338). Retrieved from http://128.113.2.9/ gowdyj/mypapers/LandEcon1999.pdf

Harvard University. (2013). The future of energy. Center for the environment. Retrieved from http://environment.harvard.edu/events/future/video

Haub, C. (2012). Factsheet: World population trends 2012. World population datasheet 2012. Population Reference Bureau. July. Retrieved from www.prb.org/Publications/ Datasheets/2012/world-population-data-sheet/fact-sheet-world-population.aspx

Hofstrand, D. (2009). Brazil's ethanol industry: Part two. Iowa State University, extension and outreach. Department of economics, University Extension. Retrieved from www. extension.iastate.edu/agdm/articles/hof/HofFeb09.html

IIED. (2010). Biomass energy: Optimizing its contribution to poverty reduction and ecosystem services. Report of an International Workshop. October 19-21. Parliament House Hotel, Edinburgh, IIED, London, UK. Retrieved from http://pubs.iied.org/pdfs/G03004.pdf

Iwayemi, A. (2010). Introduction and overview. In Energy poverty in Africa. Proceedings of a Workshop held by OFID in Abuja, Nigeria. June 8-10, 2008. OFID Pamphlet Series 39. Vienna, Austria. October. Retrieved from www.ofid.org/LinkClick.aspx?fileticket= xNKy_XeYw7g\%3D\&tabid=109

Jank, M. (2006). The agro-energy revolution: Brazil's head start. ICONE. Retrieved from www.iconebrasil.org.br/en/?actA =7\&areaID=8\& secaoID=64?=artigoID=1202.

Karekezi, S., McDade, S., Boardman, B., and Kimani, J. (2012). Energy, poverty, and development. In Global energy assessment: Toward a sustainable future (Chapter 2, pp. 151190). Cambridge: UK: Cambridge University Press. Retrieved from www.iiasa.ac.at/ web/home/research/researchPrograms/Energy/GEA_Chapter2_development_hires.pdf

Kuchler, M. (2010). Unravelling the argument for bioenergy production in developing countries: A world-economy perspective. Ecological Economics. (Vol. 69, Issue 6, pp. 1336-1343). http://dx.doi.org/10.1016/j.ecolecon.2010.01.011

Kwa, A. (2001). Agriculture in developing countries: Which way forward? Trade-Related Agenda, Development and Equity (T.R.A.D.E.) Occasional Papers 4. South Centre. June. Retrieved from http://focusweb.org/publications/2001/agriculture_which_way_ forward.html

Larsen, H., and Petersen, L.S. (2010). Non-fossil energy technologies in 2050 and beyond. Ris $\varnothing$ Energy Report 9. Ris $\varnothing-R-1729(E N)$. November. Retrieved from http://130.226.56.153/ rispubl/reports/ris-r-1729_uk_summ.pdf

Macqueen, D., and Korhaliller, S. (2011). Bundles of energy: The case for renewable biomass energy. Natural Resource Issues No. 24. London: IIED. Retrieved from http://pubs.iied. org/pdfs/13556IIED.pdf

Moïsé, E., Delpeuch, C., Sorescu, S., Bottini, N., and Foch, A. (2013). Estimating the constraints to agricultural trade of developing countries. OECD Trade Policy Papers, No. 142, OECD Publishing. http://dx.doi.org/10.1787/5k4c9kwfdx8r-en

Narayan, S. (2011). Nourish South Asia: Growing a better future for food justice. Oxford, UK: OXFAM.

Naylor, R.L. (2008). Managing food production systems for resilience. In Chapin, F.S., Kofinas, G.P., and Folke, C. (Eds.). Principles of natural resource stewardship: Resiliencebased management in a changing world. New York, NY: Springer.

Nussbaumer, P., Bazilian, M., Modi, V., and Yumkella, K.K. (2011). Measuring energy poverty: Focusing on what matters. OPHI Working Paper No. 42. University of Oxford. Retrieved from www.unido.org/fileadmin/user_media/Services/Energy_and_Climate_ Change/EPP/Publications/nussbaumer\%20et\%20al\%202011\%20measuring\%20 energy $\% 20$ poverty $\% 20$ focusing $\% 20$ on $\% 20$ what $\% 20$ matters.pdf 
OECD. (2003). Poverty and climate change: Reducing the vulnerability of the poor through adaptation. Organization for Economic Cooperation and Development (OECD). Retrieved from www.oecd.org/env/cc/2502872.pdf

OECD/FAO. (2012). OECD-FAO agricultural outlook 2012-2021. OECD Publishing and FAO. Retrieved from www.fao.org/fileadmin/templates/est/COMM_MARKETS_ MONITORING/Oilcrops/Documents/OECD_Reports/Ch5StatAnnex.pdf

Pimentel, D., and Pimentel, M. (2003). Sustainability of meat-based and plant-based diets and the environment. The American Journal of Clinical Nutrition. (Vol. 78, Issue 3, September, pp. 660-663). Retrieved from http://ajcn.nutrition.org/content/78/3/660S.long

Poole, N., and Buckley, C.P. (2006). Innovation challenges, constraints and opportunities for the rural poor. Background Paper, International Fund for Agricultural Development (IFAD). January. Retrieved from www.ifad.org/events/gc/29/panel/e/poole.pdf

PotashCorp. (2011). Nutrients: Potash. Online Review. Retrieved from www.potashcorp. com/industry_overview/2011/nutrients/4/

Robertson, G.P., and Swinton, S.M. (2005). Reconciling agricultural productivity and environmental integrity: A grand challenge for agriculture. Frontiers in Ecology and the Environment. (Vol. 3, pp. 38-46). Retrieved from www.esajournals.org/doi/pdf/ 10.1890/1540-9295\%282005\%29003\%5B0038\%3ARAPAEI\%5D2.0.CO\%3B2

Robinson, J.W. (1992). Lessons from the structural adjustment process in Jamaica. Prepared for the 24th Annual Conference, Regional Program of Monetary Studies, Bank of Jamaica. October. Retrieved from www.ccmf-uwi.org/files/publications/conference/437.pdf

Sachs, I., and Silk, D. (1990). Food and energy: Strategies for sustainable development. Hong Kong, China: United Nations University Press.

Sahai, S. (1996). Importance of indigenous knowledge in IPR system. Economic and Political Weekly. (Vol. 31, Issue 47, November 23, pp. 3043-3045).

Shah, A. (2013). Structural adjustment: A major cause of poverty. Global Issues. Social, Political Economic and Environmental Issues That Affects Us All. March 24. Retrieved from www.globalissues.org/article/3/structural-adjustment-a-major-cause-of-poverty

Simmons, J. (2011). Technology's role in the 21st century: Making safe, affordable and abundant food a global reality. Elanco Animal Health. Retrieved from http://plentytothink about.org/wp-content/uploads/2011/03/Three-Rights-White-Paper-Revised.pdf

Skorup, J. (2010). Norman Borlaug: An American hero. Michigan Science, No. 12. March 4. Retrieved from www.michiganscience.org/12262

Soma, D. (2005). Energy as a key variable in eradicating extreme poverty and hunger: A gender and energy perspective on empirical evidence on MDG \#1. DFID/ENERGIA project on Gender as a Key Variable in Energy Interventions. December. Retrieved from http://94.126.106.9/r4d/PDF/Outputs/Energy/R8346_mdg_goal1.pdf

South Centre. (2008). Food and energy crisis: Time to rethink development policy. Reflections from the high level north-south dialogue on food and energy security. Geneva, South Centre. June. Retrieved from www.southcentre.org/index2.php?gid=1062\&option=com_ docman\&task=doc_view

Tilman, D., Cassman, K.G., Matson, P.A., Naylor, R., and Polasky, S. (2002). Agricultural sustainability and intensive production practices. Nature. (Vol. 418, August 8, pp. 671677). doi: 10.1038/nature01014. Retrieved from www.nature.com/nature/journal/v418/ n6898/full/nature01014.html

Timmer, C.P., Falcon, W.P., and Pearson, S.R. (1983). Food policy analysis. World Bank. Baltimore and London: Johns Hopkins University Press. Retrieved from www.stanford. edu/group/FRI/indonesia/documents/foodpolicy/fronttoc.fm.html

UNDP. (2005). Energizing the millennium development goals: A guide to energy's role in reducing poverty. August. Retrieved from www.undp.org.cu/eventos/biomasa/Energizing\%20 


\section{Applying practical solutions}

the\%20Millennium\%20Development\%20Goals\%20-\%20A\%20Guide\%20to\%20En. pdf

UNDP. (2010). Human development report: The real wealth of nations: Pathways to human development. New York, NY: United Nations Development Program. Retrieved from http://hdr.undp.org/en/

UNDP. (2011). Towards an "energy plus" approach for the poor: A review of good practices and lessons learned from Asia and the Pacific. Environment and Energy Series. New York, NY: United Nations Development Program. Retrieved from http://web.undp.org/asia/ pdf/EnergyPlus.pdf

UNESCO. (2012a). Biocultural diversity: Education for sustainable development: Preserving linguistic and cultural diversity. Retrieved April 12, 2012 from www.unesco.org/new/en/ education/themes/

UNESCO. (2012b). Poverty. Social and human sciences webpage. United Nations educational scientific and cultural organization (author). Retrieved January 15, 2013 from www.unesco.org/new/en/social-and-human-sciences/themes/international-migration/ glossary/poverty/

Wals, A., Mulder, M., and Eernstmann, N. (2013). How to educate in a changing world? Towards competence-based tertiary agricultural education. Education \& Competence Studies, Wageningen University, Wageningen, Netherlands. Retrieved from http:// knowledge.cta.int/Dossiers/S-T-Policy/Reshaping-tertiary-agricultural-education/ Feature-articles/How-to-educate-in-a-changing-world-Towards-competence-based-tertiaryagricultural-education

World Bank. (2009a). Africa's development in a changing climate. Key policy advice from World Development Report 2010 and Making Development Climate Resilient: A World Bank Strategy for Sub-Saharan Africa. Retrieved from http://siteresources.worldbank.org/INTWDR2010/Resources/5287678-1252586925350/Africa-WDR2010-booklet.pdf

World Bank. (2009b). Bioenergy development: Issues and impacts for poverty and natural resource management. Agriculture and Rural Development Notes. (Issue 49, August). Retrieved from http://siteresources.worldbank.org/EXTARD/Resources/3366811231508336979/49Bioenergy.pdf

World Economic Forum. (2012). The missing link in sustainable development: A call to integrate population in the water, food, energy nexus. Global Agenda. Retrieved from www3. weforum.org/docs/WEF_GAC_MissingLinkSustainableDevelopment_GlobalAgenda_ Overview_2012.pdf

Yergin, D. (2012). The quest: Energy, security, and the remaking of the modern world. New York, NY: Penguin Books. 


\section{Envisioning a transformative age}

\section{Reverting to the Carboniferous period: does the past predict the future?}

Between 359 and 299 million years ago, the Earth lay in a period of sweltering heat amidst an abundance of atmospheric greenhouse gas. This was the Carboniferous period, a geologic time famous for the vastness of tropical swamps and supersized vegetation made so by an abundance of sunshine and a thick carbon dioxide soup in the atmosphere. Global greenhouse conditions cradled the Earth's globe, enabling ferns to grow into monster shrubs and hardwood trees to grow to gigantic expanses of height. The rate of photosynthesis was incredibly high during the Carboniferous, with the abundant plant life sucking up much of the carbon dioxide soup, fixing carbon into plant tissue, and subsequently cycling net volumes of oxygen back into the atmosphere. The respiration cycle, indelibly connected to the process of photosynthesis, eventually ushered in the equilibrium states of carbon and oxygen that created the major biogeochemical cycles of carbon, oxygen, and the hydrologic cycle that would accommodate higher animal life including that of the human species.

By far, the Carboniferous period seemed to have been responsible for the most significant sink of carbon in the history of the planet, exerting the single greatest influence on modern human development. The biogeochemical workings and carbon-sinking mechanisms of the period produced massive subterranean stores of hydrocarbons from those gigantic forests that fossilized beneath the surface of the earth over millions of years, and which would usher in the age of human industrial technology by providing the carbon-based energy now powering the planet. However, the vagaries of the Industrial Age have led inevitably to the Anthropocene age. In a little more than two centuries of human activity, driven mainly by fossil fuel combustion, vast collateral damage has accrued to the Earth's ecological balance. Presently, the Earth is poised to erupt into a neo-Carboniferous era if trends in greenhouse gas releases continue, the inevitable result being the final destruction of those stable biogeochemical cycles which began to emerge 300 million years ago.

In the burning of fossil fuel in thousands of industrial villages around the globe; in the consumption of millions of barrels of fuel to power the homes of 3 billion 
human beings in industrialized nations; in the fossil energy being guzzled up by 1.2 billion cars every single day, year round, the collective action of people in the Anthropocene age is grinding rapidly toward the undoing of the Carboniferous period, pumping 60 million years of previously stored carbon dioxide back into the atmosphere. Those who stand in denial of the actions of humanity that contribute to global scale warming should consider this bit of knowledge. Among those who possess the power of wisdom to act, they must without hesitation engender a new set of moral actions to unwind what humanity has already done to throw the world into the global climatological tailspin that has already begun to unravel.

\section{Engendering a new ethos}

Aspects of the 'key messages' of the UN's Millennium Assessment Report of 2005 provides both predictive and prescriptive sets of applications necessary for changing the current trajectory. The clear and central message of the report enunciates the need for changes in the attitudes and actions of humans and their institutions. It calls for an integrative approach toward solving the resource needs of today's users through various social, moral, legal, economic, and ethical means. To stimulate the change that is necessary, there is a fundamental requirement to apply an array of stimuli to the human psyche, addressing education, morality, social justice, economic prosperity, and ethical sensibilities.

Authors Lautensach et al. (2008) suggest that environmental ethics comprises human notions about right and wrong behavior toward the natural environment along with the justifications for those notions. They explain that every individual harbors a personal environmental ethic that informs decision-making and personal judgments. However, there is a wide variety of ethical notions about the environment that includes various forms of anthropocentrism (where humans are placed at the center of the moral universe), transformative anthropocentrism (humans are centrally positioned but the species ability to thrive is only guaranteed when everything else is equally valued), biocentrism (where all forms of life have moral standing), and ecocentrism (where the ecosystem itself is accorded the highest moral standing). Whichever of these ethical persuasions, or combinations of them, emerge to influence global action in the face of anthropocentric behavioral demise, it will have to engender a sweeping inclusivity of humans from all regions and economic backgrounds than ever contemplated before. Thus, the term humans must come to mean not just western people, but humanity of every creed and status.

The central argument of today's writers on environment, ecology, and ethics, is that the moral ethos that dominates capitalist pursuits since the beginning of the Industrial Revolution adheres to an anthropocentric view of the world. This viewpoint has shaped the current environmental problems and is in dire need of change. What prevents a change is the great skepticism and reluctance among western societies to broadly embrace or adopt any ethical concept that seems to relegate humans below the standing of other living organisms, or even the very ecological system in which space they live, breathe, consume, and occupy. However, some 
particular environmental ethics as Deep Ecology and Conservationism have enjoyed relative publicity, while others such as Ecofeminism and Existentialism which have found following by niche groups - have achieved results in certain targeted projects.

As discussed in the early chapters of this book, many indigenous belief systems adhere to an ethical notion that treats the Earth as being 'alive', and by consequence, the harvesting and use of the resources found within natural systems must be done with care, avoiding overexploitation at all costs. For example, the Navajo interpretation of nature attributes geological change, equilibrium states, and the sustainability of life in the surface environment to dynamic processes of renewal driven by interactions between Earth environment and sky environment (Semken and Morgan, 1997). This belief system is eerily parallel to the concepts in biogeochemical equilibrium that the thesis of this book advances. Some of these indigenous belief systems have been built into the curriculum of universities and colleges around the world, as is the case of the Navajo interpretation that has been included in the Earth System Sciences coursework at Navajo Community/Technical College in New Mexico.

It is clear that the present-day ethics of neo-economics will not help in the shaping of a future compatible with reversing the effects of global warming and climate change. Those who are more closely connected to the natural environment, regardless of their leading environmental ethic and despite their relative states of marginalization, will have to take the lead. In so doing, their grassroots leadership may begin the birthing of a new revolution that reshapes their continued existence in the absence of neo-classical economic thinking on the matter of ecological preservation and restitution.

So far as the avoidance of a neo-Carboniferous age is concerned, it is getting increasingly likely that a grassroots movement by the earth's most marginalized people must begin the biomass revolution that will sink and store carbon as a way out of poverty while reversing the patterns of climate change. It will be by their example in applying a new worldview to understanding the cyclical processes of nature that the conscience of mega-corporations will be stimulated, and maybe, the opportunity for profiting from biogeochemical reform will lure them into an acceptance of 'a new way of doings things'.

The Gaia theory is one such ethical notion that has been put forward as a scientific argument for the management of the Earth as an ecological whole system. It warrants further debate and needs adherence to its logic by political and scientific thought leaders, but it nonetheless offers hope that people might be brought together from across the divide on the single urgent matter of global action on climate management.

\section{Gaian ethics in the age of climate change}

Articulated along the lines of Earth Systems Science, the Gaian paradigm of Earth as a living system was conceived by James Lovelock and Lynn Margulis in the 1970s. This purview has inspired many researchers working across disciplines 
to study the Earth from the intellectual perspective that the planet's biophysical processes are inseparably linked together to form a self-regulating system in which life is an integral sustaining factor of the system as a whole. Arguing from his strength as an atmospheric chemist, James Lovelock took renewed notice of Earth's atmosphere with its delicately balanced composition of oxygen, nitrogen, hydrogen, methane, and traces of other elements, and hypothesized that the Earth's biosphere contains most or all of the essential characteristics of a living organism.

This idea has come to be known as the Gaian hypothesis, its core principle representing that the modern earth is sustained by the life contained in its biosphere, which in turn is sustained by those stable processes that support life itself. The Gaia model perceives the planet Earth as a living superorganism, implying that not only do living organisms impact their nonliving environment though variously modifying it, but that they both evolve together as a unified entity. Lautensach et al. (2008) believe that although the Gaia model's empirical base is positioned within the reductionist models of planetary science, the theory is holistic in the sense that it first acknowledges the systemic properties and then explains the synergism between the components of the Earth's biosphere.

The Gaia theory has been criticized considerably, and James Lovelock has responded with a largely adaptive and evolving set of viewpoints that has been slowly re-establishing the value of the theory as a strong platform calling for the ethical treatment of the Earth. This is also borne out in the understanding of commentators such as Schneider and Boston (1992), who note that Earth System Science is not necessarily parallel to the Gaia Hypothesis, although both concepts take an interdisciplinary approach to studying systems operations on a planetary-scale. They explain that Earth System Science seeks an understanding of the mass and energy transfers among interacting components of the Earth's notional systems (biosphere, hydrosphere, lithosphere, and atmosphere), which is not entirely synonymous to the Gaia principle that postulates the usefulness of considering the Earth as if it were a single living organism, indivisible from its notional spheres. The strong implication here is that Gaia theory has evolved into an ethical appeal that may well be finding its voice in an age when humankind is being implored to change the way Earth's global ecosystems are being treated.

People are beginning to use the Gaia model to extend their pre-existing body of personal values into new dimensions, and to refocus them with new priorities in ecological management concepts. Notably, the Gaia concept has provided a point of convergence between anthropocentrists and ecocentrists from where they can mutually explore the middle ground that the human species, like all other species, fulfills the role of a vital, although conscious organ in the physiology and biogeochemistry of the planet. Therefore, as a vital component of Gaia (Earth), humanity can claim that its efforts to ensure its continued existence will also have a benefit for the Earth, thereby establishing a new ethical relationship with the environments and resources with which its shares the biosphere (Lautensach et al., 2008). 
It is the arrival at this point of understanding - according to Crist and Rinker's (2010) understanding of Lovelock's hypothesis - that with the help of Gaian ethics, the motivation of humans will advance from pure egotism to an elevated state of enlightened self-interest. Purely from its emerging position as an ethical viewpoint, Gaian ethics have the potential of bringing enlightened self-interest to anthropocentrists and ecocentrists alike, so that both groups can claim mutual goals and achievements, even though they do not share the same sets of ethical values.

Lautensach et al. (2008) suggest that perhaps the main criticism is that Gaian ethics offer little help with the task of weighing the rights of future generations against the basic human rights of present-day individuals. There is no ignoring the fact, however, that the value systems advanced by this ethical viewpoint contributed to the popular sentiments that drove the world's politicians toward Kyoto in 1997, Copenhagen in 2009, and to the more recent global climate conference held in Paris in 2015. Perhaps too, the highly visible signs of global climate change in recent years will contribute further to the credibility of the theory and need for adopting Gaian ethics. Judging from the need to change behaviors and attitudes to preserve the important biogeochemical processes necessary for life on earth, any ethical persuasion or combination of them, that achieves this objective will certainly be welcomed.

\section{Undoing the tragedy of the global commons: roles of corporations, citizens, and governments}

The Global Commons are simply the un-owned and expansive natural space resources of the Earth that span continents and encompass ocean systems beyond the boundaries of individual country states. The global commons include vast biogeochemical reservoirs such as the atmosphere, oceans, the polar zones, and river systems shared by multiple countries. While not generally perceived in the same way, the global commons have been increasingly subjected to the tragedy of the commons as conceptualized by Garett Hardin in the 1960s. The tragedy of the global commons, however, has been demonstrated in the overexploitation of resources by global corporations, institutions, and governments, many of whom lack the moral responsibility to allocate resources sustainably or the motivation to control emissions, reduce wastes, and prevent the pollution that impacts the lives and environments of non-beneficiaries.

Largely because proprietary rights to resources in the realm of the global commons do not generally exist, especially where no treaties or use-agreements have been agreed upon, polluting entities do not bear the full cost of the negative impacts exerted within this realm (Snape and Gunasekera, 1997). In fact, there have been few laws or usage rules agreed upon by most countries, particularly the ones responsible for the highest proportion of global pollutant discharges, and in some cases, powerful countries even use political hegemony to shelter polluting corporations from their gravest actions. As a result, perturbations to the biogeochemical cycles continue to occur when overexploitation and drawdowns in 
regions and territories vulnerable to the disadvantages of exploitation go undeterred. The impacts are then borne out through prohibitively expensive problems including saltwater intrusion into aquifer systems, nutrient overload and runoff into surface water, and climate-changing atmospheric pollution from the release of greenhouse gasses. When these problems occur alongside crippling balance of payments and trade deficiencies in overlabored economies, their economies become overburdened and lead to socio-economic and political crises including refuge seeking, mass starvation, and even terrorism.

A vibrant global commons is essential to ensuring the sustainability of the Earth's resources, but the much-needed vibrancy can only be necessitated through interconnections of actions and responses between individuals, institutions, and private and public sector organizations both local and global in reach. With the increasing impairment of natural resources, potable water, and clean air, the viability of plant and animal species remains threatened. The necessary ethic therefore calls for a rebalancing of those human affairs that intersect with the life-sustaining forces on the Earth. Within the framework of this emerging ethic, any intent or action to destabilize this essential symbiosis should be considered a major grievance and dealt with as such.

There is a growing school of thought suggesting that through focused educational reform that addresses ecological knowledge as a civic matter, humanity will become more deeply sensitive to the interrelatedness between people and planet, and their understanding will engender a greater spirit of mutualistic symbiosis with nature and the global commons. This school of thought adheres with Garrett Hardin's (1968) recommendation that in order to solve the destructive behavior of mankind, there is a requirement for a shift in personal morality.

This shift in morality espoused by Hardin would be on par with that moral conscience within nations which recognized degenerate behaviors such as the genocide of native peoples, the chattel slavery of Africans, the Jewish holocaust, and the Rwandan genocide as intolerable treatment of human beings which should never be allowed to happen again. It is quite possible that the collective evolution of the human brain has not fully progressed to the point where it perceives the atrocities upon the global commons as exacting the same deleterious consequences upon humans as the aforementioned vices did, that the tragedy of the global commons is in action and fact a social injustice issue and therefore must be abruptly addressed. The development of this particular set of human ethics, after all, belies the arrival at a higher level of consciousness than ever attained before, but sadly, humanity as a whole may just not be there yet.

The obstacles are evident, however. To address the tragedy of the global commons, humanity requires an effectively functioning private sector to bring the advantages of innovation, trade, and entrepreneurial spirit to addressing resiliency implementation. Equally, human society requires a transparent and responsive public sector to facilitate the fulfillment of human aspirations which should not be neglected in the conversation on ecological resiliency. The stark truth is that sustainable solutions for ecological redevelopment require global institutional conditions that shape incentives for collective action, and development 
cooperation often promotes the creation of favorable institutions that help to support paradigm shifts.

Action, however, is a quintessential tool in the arsenal of change. When it comes to the issue of global warming, for example, many individuals, as well as corporate institutions, often feel morally compelled to act, but on the whole most have not done so. Even more, others question the effect of their minute role amidst the global burden of inaction, their inertia contributing to even higher levels of inaction. For those among us who have been advocating for action, it appears that warnings, urgings, and vociferous cries have fallen on very deaf ears. Seemingly, only an obvious fire in the skies indicating a burning climate will spur us all into action like the fire on the Cuyahoga did in the summer of 1969.

Without the fire, however, other stimuli will be required to nudge humanity into the action needed to halt climate change. According to Modney (2010), there are two main drivers for action on sustainable issues. The first of them is moral obligation, and the second is a self-serving reasoning often posited by the common man. This is framed through the question, "What's in it for me?" Modney (2010) cites a series of Towers Watson studies that examined the factors driving employee engagement on sustainability initiatives in the workplace and beyond. It turns out that one of the 'best practices' that has been shown effective is to complement education with personal incentives to involve people in varying levels of engagement and social consciousness.

Questions of education, morality, and the development of social movements through collective action are unquestionably important in the quest to change the manner that humans are impacting the global commons, how they have radically changed global ecosystems and the biogeochemical processes cycling between them. What remains is a clear indication that education and incentivization alongside collectivism often motivate and shape moral change, and moral factors play an important role in the processes that lead to tangible behavior change. The conditions for change, however, should be forged between all sectors of society, across social and moral divides and ethical value systems, but must involve an investment in common human beings, in their actions, habits, norms, and cultures, their indigenous knowledge, and their level of technology. And this must happen without prejudice, regardless of where people live.

\section{Have we entered the neo-Carboniferous period? From burning rivers to melting polar ice}

On February 27, 2018, on what should have normally been a blisteringly cold winter morning, with the sun not predicted to rise at the North Pole for almost another month, climate scientists discovered that a rather extraordinary warm thaw was eating away on centuries of frozen ice at one of the coldest places on planet Earth. Over the prior weekend, a gigantic storm had sent an intense pulse of heat through the Greenland Sea, causing polar temperatures to soar to as high as 35 degrees Fahrenheit which is a whopping 50 degrees above normal and a disastrous 3 degrees above melting point. According to Reuters News, the warm 


\section{Applying practical solutions}

pulse of air penetrated right through the heart of the Central Arctic, spiking the temperatures for the entire region north of 80 degrees latitude to the highest level ever recorded. Data assessments maintained by the Danish Meteorological Institute since 1958 revealed that no other warm intrusions came close to these temperatures, and even though warm surges had happened in the past, they had occurred with a fair degree of rarity. Between 1980 and 2010, warm Arctic spells occurred in four of the 30 years, but became more frequent, longer-lasting and more intense in four out of the five winters between 2013 and 2018. The North Pole was getting noticeably warmer.

The scientists from the Danish Meteorological Institute and from the University of Colorado who were interviewed by Reuters News believed that the warming events were directly related to the decline of winter sea ice in the Arctic. A notable observation was that the January 2018 ice extent was the lowest ever recorded. As told by the scientists to the news organizations, the simplest scientific explanation about what was actually happening is that as sea ice melts it becomes more vulnerable to winter storms which causes it to drift at a faster pace and disintegrate into smaller bits of ice. Winds coming in from the south then push the smaller pieces of ice further north into the Central Arctic, exposing the open water and releasing heat to the atmosphere from the open ocean. Scientists have consequently discovered wide open water north of Greenland, which is an area normally covered by old, thick sheets of ice.

Another theory for the February 2018 Artic warming spell is the sudden warming of the stratosphere that occurred between the last weeks of 2017 and early 2018. The stratosphere is the atmospheric layer about 30,000 feet high, and warming in this zone tends to rearrange warm and cold air masses. Being dry, the polar air has very little of the overwhelmingly important greenhouse gas - water vapor, but when old, thick, stable ice melts, this water vapor is released to the atmosphere. When the atmosphere in the polar region warms, more evaporation occurs, and thus a positive feedback is created from the greenhouse effect of increasing water vapor.

A third plausible theory is that actual temperature increases in latitudes in the Northern Hemisphere is reflecting the effect of the band of urban-industrial civilization between $25^{\circ} \mathrm{N}$ and $70^{\circ} \mathrm{N}$, which would indicate the hand of humanity on the destruction of stable ice in the Artic Pole. Whether just a blip on the bell curve of time or indicative of a new normal at the North Pole, climate scientists have uniformly expressed disbelief and common concern at both the February 2018 Arctic temperatures and the state of the once stable sea ice.

Humanity's state of response inertia - our Noah's Flood Inertia Syndrome must wake up from its slumber. The smell of distant rain is not indicative of lifegiving water, but instead signals a spell of lightning storms and tumultuous weather that spells our certain doom. Or perhaps it only spells the doom of those among us who are too poor and marginalized to adequately respond to the changing state of the Goldilocks planet we endearingly call Mother Earth. 


\section{References}

Crist, E., and Rinker, B.H. (Eds.). (2010). Gaia in turmoil: Climate change, bio-depletion, and Earth ethics in an age of crisis. Cambridge, MA: MIT Press.

Hardin, G. (1968). The tragedy of the commons. Science. (Vol. 162, Issue 3859, pp. 1243 1248). doi: $10.1126 /$ science.162.3859.1243

Lautensach, A., Sarkar, S., and Kalof, L. (2008). Environmental ethics and the Gaia theory. In Cleveland, C.J. (Ed.). Encyclopedia of Earth. September 10. Retrieved July 13, 2012 from www.eoearth.org/article/Environmental_ethics_and_the_Gaia_theory

Modney, M. (2010). Sustainability: What's in it for me? Creating a cycle of employee engagement with incentives. The Green Economy Post. Retrieved August 20, 2012 from http:/greeneconomypost.com/sustainability-creating-employee-engagement-incentives11178.htm

Schneider, S.H., and Boston, P.J. (Eds.). (1992). Scientists on Gaia. Cambridge, MA: MIT Press.

Semken, S.C., and Morgan, F. (1997). Navajo pedagogy and earth systems. Journal of Geoscience Education. (Vol. 45, p. 109). Retrieved May 18, 2012 from http://semken.asu.edu/ pubs/semken97_npes.pdf

Snape, R., and Gunasekera, D. (1997). Countdown to Kyoto: The consequences of the mandatory global carbon dioxide emissions reductions. Australian APEC Study Centre, Canberra. Retrieved August 19-21, 1997 from www.apec.org.au/docs/snape.pdf 


\section{Index}

aborigines 11

Abulafia, David 6

adenosine triphosphate (ATP) 51

African Christians Organization Network (ACON) 133

agricultural and land management carbon

offsets opportunities case study 102-103

agriculture: challenges of modern 130;

emergence and impact of modern

77-80; existing policy and economic frameworks in developing countries 144-146; factors reinforcing industrial farming practices 80-82; hypothetical arguments for addressing energy-poverty and 159-162; low-carbon agricultural production model 84-93; as net greenhouse gas emitting sector 97-99; post-modern agricultural network superstructure 82-83; role of biochar in sustainable 127-130; use of fossil fuels 135; see also food production; integrated food-energy system (IFES)

American Indians 10

American Power Act 126

Anthropocene problem complex 26-27, 32,168

anthropocentrism 168

atmosphere 43-44, 170

Australia 11

Aymaran people 13

Bali 11

Berry, Thomas 22

biocentrism 168

biochar: in age of renewable energy policy 124-136; agronomic impact
127; background 110-111; biomass pyrolysis and 115-117; energy dynamics of biomass 117-118; energy policies/ incentives 124-126; impacts on global poor 131-134; pro policies and initiatives 126-127; role in climate change mitigation 109-122; role in development of carbon-negative energy systems 118-120; role in sustainable agriculture and forestry 127-130; short history of char 111-113

biochar production and utilization systems (BPUS) 133

biochemistry 47-48

biodiversity 54

biogeochemical cycles: addressing with Transformative Anthropocentrism 71-74; anthropogenic impacts on ecosystems 52-55; background 41-42; biochemistry 47-48; biosphere perturbations and influences on 55-56; carbon cycle 56-58, 71; disruptions of 20-21; in era of anthropogenic climate change 41-48; hydrogen cycle 59-62; hydrologic cycle 66-67; nitrogen cycle 62-64; oxygen cycle 58-59; phosphorus cycle 64-65; review of 50-67; sulfur cycle 65-66; thermodynamics and life processes 50-52; use of system theory 36 ; zonal spheres 43-46

biomass energy: economic and environmental importance of biomass crops 155-156; as instrument of change $156-158$; use by global poor 149 ; use in energy-sustainable agricultural system 86 ; use in food production 131-134 
biomass pyrolysis: biochar production and 115-117; distributed energy from 120-122; use by indigenous people 128

biomimicry 35

biosphere 46, 170

Bitan, Eliav 87

Bolivia 12-13

Bomford, Michael 81

Boston, Penelope 170

Brazil 20, 142

Brazilian rainforest 61,84

Brundtland Commission 31, 32

Canfield, Donald E. 62

'carbon capture and storage' (CCS) 38

carbon cycle 56-58, 71, 128

Carbon Farming Initiative (CFI) 126

Carboniferous period 167

carbon-negative energy systems 118-120

carbon sequestration 100, 105-107, 113-115, 156

Carson, Rachel 1-3, 79, 81-82

case studies: agricultural and land management carbon offsets opportunities 102-103; Nebraska Environmental Trust Fund Project 102; sustainable agricultural land management practices 103-104

Chineyemba, P.U. 151

chlorofluorocarbon gasses (CFCs) 2

Clancy, Joy S. 151

Clark, Deborah A. 114

Clean Water Act (CWA). 1-2

climate change 21, 26, 30, 131, 169-171

Cloud Institute for Sustainability

Education 31

cogeneration 124-126

collective action 32

Columbus, Christopher 6-7, 78

combined heat and biochar (CHAB) 86, 125-127

combined heat and power (CHP) 86, 124-125

commons 28, 171-173

Congo Basin Forest Fund (CBFF) 133

Crist, Eileen 171

Crutzen, Paul J. 34

Cuyahoga River Fires 1, 3, 173
Daly, Herman 29

Darwin, Charles 47

deforestation 61, 84, 132

dichlorodiphenyltrichloroethane (DDT) 79

Eaarth (McKibben) 26

Earth 42-43, 46, 169-172

Easter Island 'ecocide' 8, 65

Eberhart, Mark 36

ecocentrism 168

ecological succession 10

ecology: understanding 18; understanding systems ecology 18-19

economics 38-39

economy 28

eco-psychology 22-23

ecosystems: anthropogenic impacts on 52-55; forest 54, 61; intrinsic rights of 24-25; use of system theory 36 education: Education for Sustainability

31-33; functions of 28-29; transforming 31-32

Education for Sustainability 31-33

Ellis, Eric. C. 53, 55

energy 36-38

energy policies/incentives 124-126

energy poverty: in developing world

148-149; hypothetical arguments

for addressing agricultural

underdevelopment and 159-162;

infrastructure 158-159; as parameter of

economic underdevelopment 151

energy production systems 141-142

environmental literacy 23-24

Environmental Protection Agency (EPA)

124-126

ethics 11-12

Evenson, Robert E. 139

exclusive tribal property rights (ETRs) 9

'extreme instrumentalism' 29

Federal Water Pollution Control Act of 19481

'Feeding the Fire' (Eberhart) 36

fertilizers $80,87,88-89$

fire 10

Firestone, William A. 101

Food and Agriculture Organization 97-98, 140,142 
food distribution channels 92-93

food production: economic and environmental importance of bioenergy crops on rural and developing countries' economies 152-154; economic and environmental importance of biomass crops 155-156; energy production systems and 141-142; integrated food-energy system 143-148, 150; population growth and 27, 81, 90, 130-131, 138-141; see also agriculture; integrated food-energy system (IFES)

food versus fuel argument 149-151

fossil fuels 37-38, 66, 81-82, 86, 135, 142, 167-168

Free Capitalist Market system 28

Gaian ethics 169-171

Garcia, Serge M. 139

Gaunt, John L. 116, 118, 119, 121

genocide 12

Gerhart, John C. 47

global commons 171-173

global poor 3, 131-134, 136

global warming 3-4, 26, 38, 55, 57, 97-98, 107, 111, 136, 160, 169, 173

Goldewijk, Kees Klein 53

Gollin, D. 139

greenhouse gas emissions: agricultural management for reduction 100-101; climate change and 26; role of agriculture 97-99; sequestration of 100, 105-107

Green Revolution 80, 89, 101, 138-141, 144-145, 158-159

Gribbin, John 47-48

growth 29-30

Gulf of Mexico oil spill 30

habitat fragmentation 19-20

Haida 11-12

Halpern, Benjamin 55

Hardin, Garett 171-172

Hardin, Garrett 31

Hatuey (Taíno cacique) 6

Hawkin, Paul 34-35

Heinberg, Richard 81

holistic operational wisdom (HOW) 8-9
Humane Society of the United States (HSUS) 61

hydrologic cycle 66-67

hydrosphere 45

indigenous people: aboriginal way of predicting nature 11; American Indian knowledge of fire as restorer of life 10; Haida ethics and values 11-12; Inuit knowledge of muskox 10; natural capitalism 33; positive user traits with nature 8-12; potlatching in NWC indigenous culture 9; resiliency trait of Subaks 11; rights of nature and 12-14; traditional ecological knowledge 8-9, 21-22, 24

industrial farming practices $80-82$

Industrial Revolution 17-18, 29, 35, 131, 168

infrastructure 158-159

integrated food-energy system (IFES): application in food production 150; applying in developing countries 145-146; applying in sustainable development projects 146-148; concept of 143-144

Intergovernmental Panel on Climate Change (IPCC) 100

International Biochar Initiative 136

Inuit 10

irrigation systems: basin irrigation 77; dripirrigation 91-92; field practices 90-91; management strategies 91 ; microsprinkler techniques 92; optimizing use of 89-92; system modifications 91-92

Iwayemi, Akin 150

Johnson, C. 62

Jones, Scott 90

Kaplan, Jed O. 53

Kirschner, Marc W. 47

Klotz, Martin G. 65

Korhaliller, Sibel 155-156

Kwa, Aileen 145

land degradation 131, 134

land tenure 156-158

language 27 
Las Casas, Bartolme 6

Lautensach, Alexander 168, 171

Law of Mother Earth (Bolivian law) 12-13

Lehman, Johannes 116, 118, 119, 121

Leopold, Aldo 80

life 47-48

life processes $50-52$

lithosphere 45

Lovelock, James 169-171

low-carbon agricultural production model: case studies 101-105; changing to energy-sustainable agricultural system 85-87; management practices 106-107; optimizing use of irrigation water 89-92; organic approach 87-89; reduce/improve transportation and food distribution channels 92-93; transitioning to $97-107$

Macqueen, Duncan 155-156

Margulis, Lynn 169

markets 27-28

Mars 42-43

Martinez, Dennis 10

McGrath, Bridgett 90

McKibben, Bill 26

methane 84-85, 97-98, 170

Millennium Assessment Report 73-74, 168

Miorelli, Cathy 24

modern agriculture 77-80

modern scientific knowledge (MSK) 8

Modney, Mary 173

monoculture agriculture $10,12,53-54$, 119,144

Montreal Protocol 2

Mora, Camilo 54

Morales, Evo 13

muskox 10

Native Americans 33

natural capitalism 33-36

'Natural Law' (Mark) 24

Natural/Traditional Market system 28

nature: positive user traits of indigenous people $8-12$; rights of $12-14$

'The nature of design' (Orr) 29

Nebraska Environmental Trust Fund

Project (NETFP) 100, 102

neo-Carboniferous period 173-174 neo-pollution issues 2-3

net primary productivity (NPP) 53, 113-115

Network for New Energy Choices

(NNEC) 86

nitrogen cycle 62-64

nitrous oxide 97-98, 118

Noah's Flood Inertia Syndrome 3-4, 174

Northwest Coast (NWC) 9

'Ode of the Lost Indian Nation' 13-14

organic agriculture $80,87-89$

organophosphates 79

origins of life 47-48

Orr, David 29

Oxisol 130

oxygen cycle 58-59

ozone hole 2-3

Park, J. H. 118

pesticides 79-80, 81, 87, 89

phenology 11

phosphorus cycle 64-65

Piclett, Steward 51

Pidwirny, Michael 90

Pimentel, David 85, 87

The Plausibility of Life (Kirschner and

Gerhart) 47

population growth: food production and

$27,81,90,130-131,138-141$; impacts

on ecosystems $52-54$

post-modern agricultural network

superstructure 82-83

Post, Wilfred M. 100

potlatch 9

poverty 148-149

Raynal, Guillaume Thomas 6

Reinholde, E. 121

Rinker, Bruce 171

road building 20

Rodale, Jerome Irving 106

Rondon, Marco 118

Rosenberg, Andrew 139

Roszak, Theodore 24

Running, Steven W. 114

rural development 156-158

Sahai, Suman 143

Sale, Peter 54 
salmon 9

Sampson, R. N. 100

Santone, Susan 34

Schlesinger, William H. 48, 51, 63, 66

Schneider, Stephen 170

Scholes, R. J. 100

seasonal knowledge 11

Seufert, Verena 88

Shiva, Vandana 27, 29

Shull, George Harrison 78

'Silent Spring' (Carson) 1, 79, 81

slavery 12, 16-17

Smil, Vaclav 51-512

soil organic carbon (SOC) 100

soil organic matter (SOM) 109-110, 112

solar system 42-43

Squire, John 13

Steiner, Christoph 85

Sterling, Stephen 29

Stern Review 98

Stockwell, Ryan 87

stratosphere 174

Subaks 11

sulfur cycle 65-66

Sumerians 80

sustainability economics 38-39

sustainable agricultural land management

(SALM) practices 103-104 sustainable development 32-33

sustainable development projects

146-148

systems ecology 18-19

system theory 36

Terra Preta 127-128, 130

'There was an Indian' (Squire) 13

thermodynamics 50-52

traditional ecological knowledge (TEK) 8-9, 21-22, 24

'The Tragedy of the Commons' (Hardin) 31

Transformative Anthropocentrism 71-74

transformative anthropocentrism 168

values $11-12$

Venus 42-43

'Viable Human' (Berry) 22

water 66-67

West, Tristram O. 100

wholeness 36

Wilson, Edward O. 61

Wright, David 88

Yanai, Yosuke 118

zonal spheres 43-46 